\title{
Who do we think they are? \\ Transformations in feminist knowledge production regarding men who have used violence in their heterosexual relationships in Canada
}

\author{
by \\ Deborah E. Conners
}

A thesis submitted to the Faculty of Graduate and Postdoctoral Affairs in partial fulfillment of the requirements for the degree of

Doctor of Philosophy

In

Sociology

Carleton University

Ottawa, Ontario

(C) 2016, Deborah E. Conners 


\begin{abstract}
This qualitative study explores how the development of increasingly nuanced and diverse knowledges relevant to the reduction and prevention of intimate partner violence (IPV) is affecting theory, service provision and activism in feminist anti-violence movements in English Canada. I posit that, in response to the development of these knowledges, shifts in feminist violence against women (VAW) doxa have been following a slow and painful trajectory that is part of, and reflects, struggles within a broader feminist and non-feminist social science scholarship and practice in Anglo North America. Primary research for the project was done in Ontario, Canada, and included interviews with 32 research participants (who work in feminist VAW services, partner abuse response programs, or as counsellors), participant observation, a focus group and an early findings feedback workshop. Using the conceptual framework of sociologist Pierre Bourdieu, I bring the interview data and the literature addressing IPV into conversation, identifying and analyzing three sociologically significant encounters which have been important in influencing how feminist VAW theory and practice have unfolded over time. The first encounter encompasses feminist intragroup struggles for recognition related to intersections of the female victim/survivor and male perpetrator conceptual foundation of VAW scholarship and practice with feminist work on racialization, colonialism and postmodern approaches to knowledge production as well as an increasing interest in women's agency. The second encounter is the development of a debate between feminist VAW scholarship and gender parity scholarship (wherein women and men are claimed to equally engage in violence). The final encounter explored relates to new understandings of the therapeutic possibilities for healing from trauma; knowledges generated in this area are only recently gaining attention in feminist VAW work in relation to its ramifications for male perpetrators of IPV. While the encounters documented here have been experienced by many as polarizing, as conundrums, or even as an impasse, there are also efforts underway to engage with this unfolding. I document the interrelated and intertwined engagements of those involved in the field of work to reduce and prevent intimate partner violence, explicating how and why this transformative period is so difficult for all concerned.
\end{abstract}




\section{Acknowledgements}

I would like to thank my committee: co-supervisors Jacqueline Kennelly and Diana Majury whose patience and willingness made this project possible; and Janet Siltanen and Holly Johnson who rounded out a fabulous committee. Your challenges and support will be forever appreciated. I would also like to thank my life partner Kate Kechnie and friends who put up with me throughout. 


\section{Who do we think they are? Transformations in feminist knowledge production regarding men who have used violence in their partner relationships in Canada}

\section{Table of Contents}

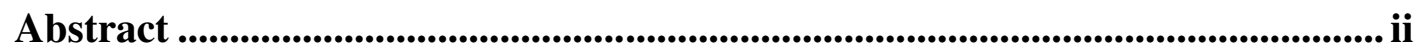

Acknowledgements ................................................................................................ iii

Table of Contents........................................................................................................ iv

List of Figures ....................................................................................................... vi

List of Appendices .............................................................................................................. vii

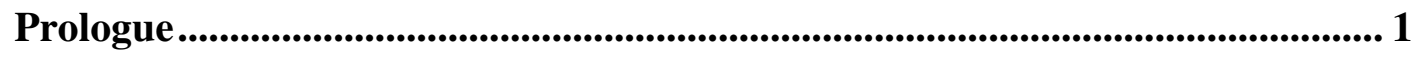

Chapter 1: Introduction ........................................................................... 3

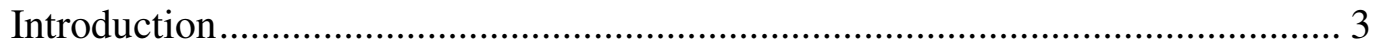

The Substantive Problematic ...................................................................... 4

Theoretical and Methodological Considerations ............................................ 8

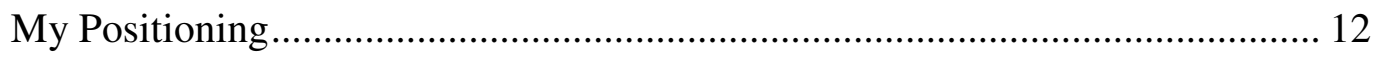

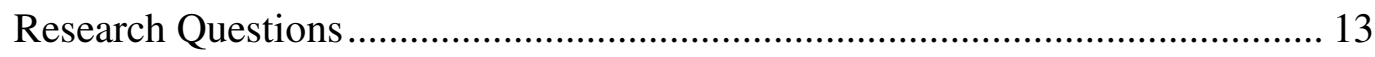

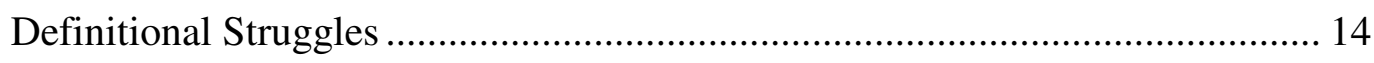

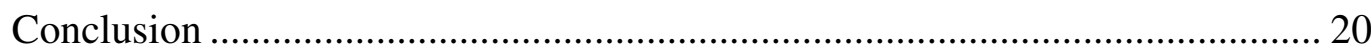

Chapter 2: Theorizing Work on IPV with Bourdieu .......................................... 24

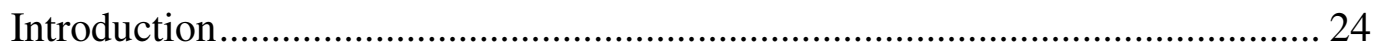

Structure, Agency and Bourdieu.............................................................. 26

Situating Bourdieu in the Sociological Literature ........................................... 32

Feminist Uses of Bourdieusian Concepts ........................................................ 41

Theorizing Feminist VAW Knowledge Production With Bourdieu................... 46

The Theoretical Framework For My Research................................................ 52

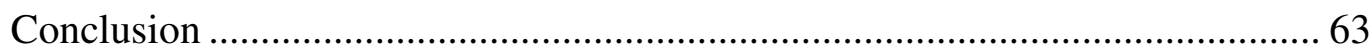

Chapter 3: Methodology ..........................................................................65

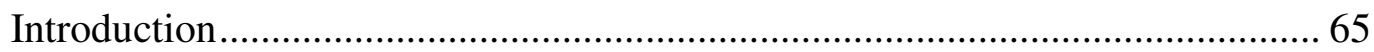

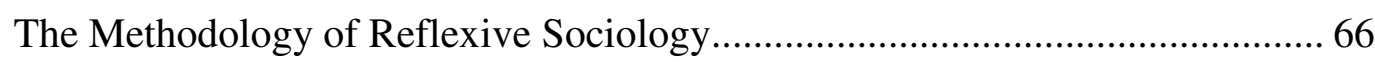

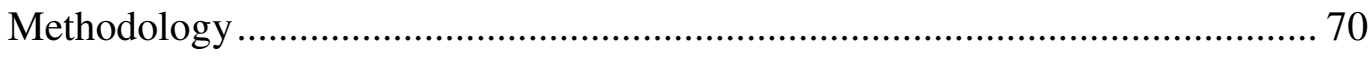

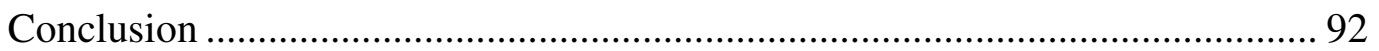




\section{Chapter 4: The Social Construction of Feminist VAW Doxa}

Regarding Intimate Partner Violence................................................................... 94

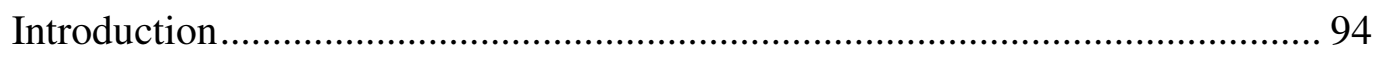

Patriarchy as the source of wife abuse ............................................................. 95

The social construction of male perpetrators ................................................ 102

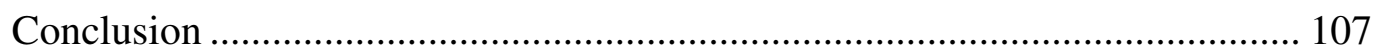

Chapter 5: Encounters of Feminist VAW Doxa ................................................ 109

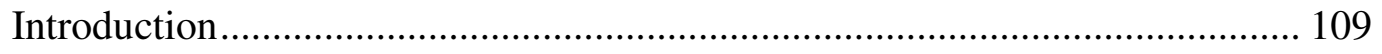

The First Encounter: Feminist Engagement ................................................ 110

The Second Encounter: Gender Parity.......................................................... 130

The Third Encounter: Trauma-Informed Theory and Practice ......................... 148

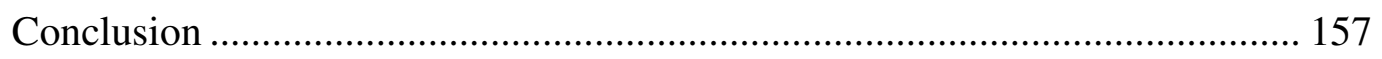

Chapter 6: Feminist VAW understandings of perpetrators........................... 158

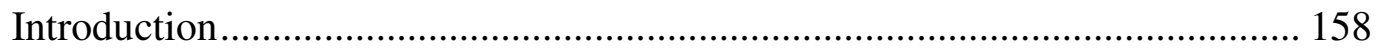

Exploration of VAW Doxa in the Naming and Meaning of IPV .................... 161

The Foundations of Patriarchal and VAW Doxa as Seen in the Interviews ...... 170

A Changing Perspective on Heterosexual Male Perpetrators ........................... 175

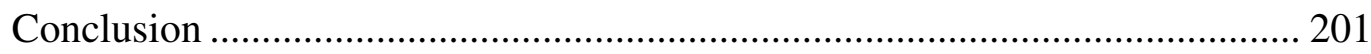

Chapter 7: The Problem is the Problem............................................................... 206

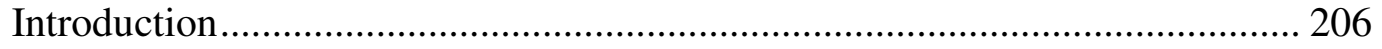

Partner Abuse Response (PAR) Workers ..................................................... 208

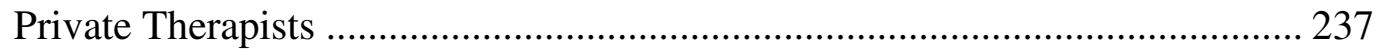

Interviewees Working With Men Who Have Been Victimized ....................... 250

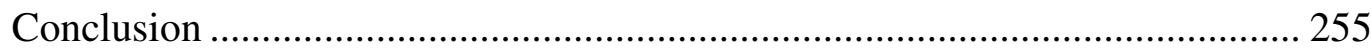

Chapter 8: The Struggle for Recognition in the Field:

Why is it so difficult?........................................................................................................ 257

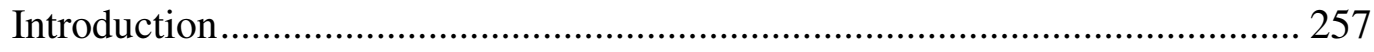

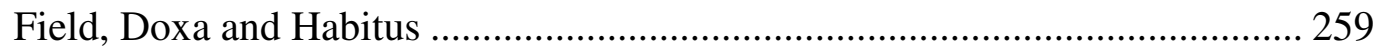

Examining the development of the field .................................................... 265

The Opportunities Revealed in This Research.............................................. 273

Personal Reflection on the Process ............................................................. 277

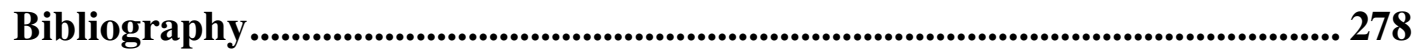

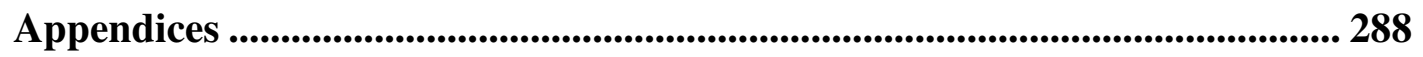




\section{List of Figures}

Figure 1: A feminist view through a sociological lens of feminist VAW

conceptualizations of men who have used violence in their partner relationships

with women 


\section{List of Appendices}

Appendix A: The Study Participants

Appendix B: The Interviewees

Appendix C: Interview Data Collection Tools

Appendix D: Focus Group Data Collection Tools

Appendix E: Early Findings Feedback Workshop Data Collection Tools 


\section{Prologue}

An understanding of what is at stake in the research one undertakes can be difficult to gain when in the midst of the dissertation project. Thus, in this prologue I wish, from the post-writing perspective, to articulate the positioning of my dissertation within the discipline of sociology as well as the sub-discipline of feminist sociology.

bell hooks (2000) argues that feminism is for everybody, a position I endorse and exemplify in this dissertation. Doing research that is "for" people outside the academy moves my project away from what some consider the mainstream of sociology (Sprague, 2008) and toward the sociology "engaged in conversation with publics" (Burawoy, 2005, p. 7) put forward by Burawoy in his Presidential Address to the American Sociological Association. Burawoy's proposal, outlining what has become a well-known model of four streams of sociology (professional, policy, critical and public) and asserting the need for the development of public sociology against the hegemony of professional sociology, has generated a maelstrom of debate within the discipline. More recently Burawoy (2014) has articulated some of the difficulties of undertaking public sociology including the uncomfortable and sometimes perilous task of acting at the intersection of the two fields (in the Bourdieusian sense): the academic and political.

In contrast, Sprague (2008) argues that a plea for a sociology focused on and for the public represents a re-ignition of an ongoing theme rather than a new project for the discipline. In a special issue of the Canadian Sociological Journal focused on Burawoy's proposal, Creese, McLaren and Pulkingham (2009) add to this critique, asserting that Burawoy's argument for the development of a more public face for sociology and his 
proposals for how to achieve this neglect the Canadian context in which many Canadian intellectuals actively engage, to a much greater degree than within American sociology, as public intellectuals.

Certainly, the PhD training within the Department of Sociology and Anthropology at Carleton University includes an emphasis on the opportunities for and responsibility toward public engagement on the part of sociologists (and particularly feminist sociologists), an emphasis I take up in the design of my dissertation project. Grounding the research in the reflexive sociology of Pierre Bourdieu allows me to explore "how... socio-political praxis [could] work without either depending on consensus or devolving into new forms of authoritarianism" (Powell, 2012, .p. 98), a question Powell (2012) claims as significant to public sociologists who seek to work with multiple, overlapping and contradictory epistemic systems.

The production of knowledge that goes beyond a claim to legitimacy through an appeal to the authority of the scientific method, and is able to support both translation between knowledge systems and movement toward the transcendence (Powell, 2012) of apparently irreconcilable positions and positioning to the degree necessary for a social system to function, is an urgent need in our conflict-ridden world. My $\mathrm{PhD}$ dissertation is an attempt to contribute to understandings of how this need might be met within feminist sociological contexts. 


\section{Chapter 1}

\section{Introduction}

\section{INTRODUCTION}

Each society, at each moment, elaborates a body of social problems taken to be legitimate, worthy of being debated, of being made public and sometimes officialised and, in a sense, guaranteed by the state (Bourdieu \& Wacquant, 1992, p. 236, emphasis in original).

Before second-wave feminists named violence against women as a social problem, wife abuse was seen as an aberration from the legitimate (patriarchal) right of the husband to use his authority to discipline his wife. Men who crossed the line of 'appropriate' discipline into abuse were often seen as 'hen picked' and needing to reclaim their rightful role of head of household (Dobash \& Dobash, 1979). This argument followed the line of reasoning that the husband was, in response to a wife who was not submissive enough, losing self-control and lashing out. The solution to the problem was two-fold: one part was for her to be more submissive; the other part was for him to regain control of himself and his household. In contrast, feminist theorists and activists named these abused women as the victims and their male partners as the perpetrators of criminal behaviour within the context of a patriarchal culture which supports male dominance. Thus the concept of the 'female victim (and later the victim/survivor) and male perpetrator' was a foundational concept in the development of feminist violence against women (VAW) theory, activism and practice. This framing was powerful in generating a wave of public, social and state support for ending violence against women and continues to provide a foundational concept for feminist work in this area today. It also provided 
my own touchstone for learning about intimate partner violence in the 1980s in Ontario and late 1980s and early 1990s in Prince Edward Island. Challenges to this initial framing of VAW theory have, in recent decades, been gaining force and my experience of these contestations has led me to the current project. I posit that, in response to these challenges, shifts in feminist VAW characterizations of male perpetrators of intimate partner violence have been following a slow and painful trajectory that is part of, and reflects, struggles regarding how IPV is represented within a broader feminist and nonfeminist social science scholarship and practice.

\section{THE SUBSTANTIVE PROBLEMATIC}

'Violence against women' and the 'female victim/survivor and the male perpetrator' are key concepts that I investigate in this dissertation in relation to the historical trajectory of the problematization of intimate partner violence (IPV) in Anglo North America and specifically in Ontario, Canada. Feminists have most often used a violence against women lens to address intimate partner violence. This approach has generated significant social change in relation to the issue. In this dissertation I use a feminist sociological lens to look at feminist VAW lenses rather than looking through a VAW lens.

Figure 1 illustrates my approach. I focus on the social construction of feminist VAW understandings of male perpetrators of violence in heterosexual relationships from the 1950 s to the present time. I use Bourdieu's reflexive sociology to theorize the development of these understandings as 'doxa;' the doxa of a group develops in oppositional and relational engagements with other groups engaged in responding to a social issue. I examine feminist violence against women doxa and intra-feminist critiques 
of that doxa (as shown by the solid arrows indicating the internal-to-feminism nature of this engagement) in the context of two other established and competing lenses for addressing IPV: patriarchal and gender parity doxa (as shown by the dotted arrows indicating external engagement). Finally, I explore emerging impacts relating to the development of trauma theories (indicated by dotted arrows). I brought this scholarship into conversation with social practices through interviews with VAW service providers, partner abuse response program facilitators, psychotherapists in private practice and men working with male survivors of childhood or adult abuse.

\section{Figure 1: A feminist view through a sociological lens of feminist VAW conceptualizations of men who have used violence in their partner relationships with women}

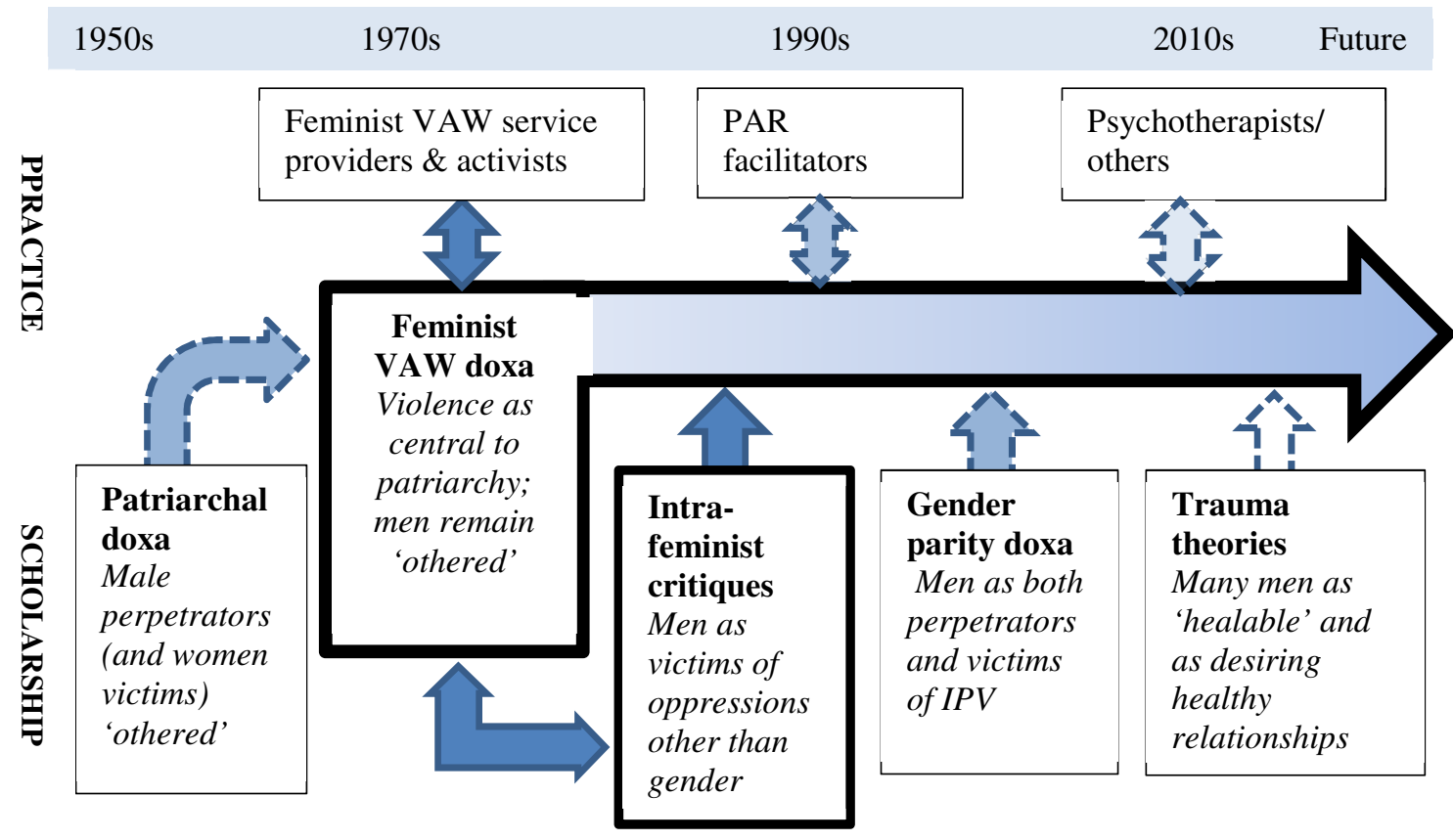

Examining approaches to addressing intimate partner violence leads to a sociohistorical analysis. We see that the feminist VAW conceptual framework was developed in the 1960s and 1970s in response to, and against, existing mainstream patriarchal 
interpretations of wife abuse as an aberration; in patriarchal doxa, male perpetrators and women victims were seen as 'other.' By the 1980s, feminist VAW understandings which identified violence as endemic to patriarchal societies and reclaimed women experiencing abuse as victims rather than as responsible for the violence they experienced - were experiencing uptake across Canadian society, energizing a broad societal shift in how intimate partner violence was seen and addressed that resonated with other changes in gender relations at that time. Intra-feminist critiques of the white middle-class hegemonic positioning of much feminist theory and activism, present from the early years, gained force and nuanced feminist VAW articulations of IPV and violence against women more generally over time. For example, women of colour articulated the effects of racism (Crenshaw, 1991; 2012), Indigenous women the ongoing effects of colonialism (McGillivray \& Comaskey, 1999), lesbian women explored violence in same-sex relationships (Ristock, 1994) and transgender rights were asserted (Mathen, 2004). The gender parity framing, in which both men and women are conceived to be responsible for partner violence, has gained strength more recently and occupies an oppositional relationship to feminist VAW framings (Dutton, 2007). Further changes relate to the explosion of research in neuroscience over the past three decades and the resulting impacts on understandings of therapeutic possibilities for healing from trauma. Knowledges generated in trauma theoretical propositions are being imported into feminist VAW theory and practice regarding female victims (as well as being generated by feminist research and practice) but are only just gaining attention in feminist VAW work in relation to their ramifications for male perpetrators of IPV (Randall, 2013). 
There are several layers of social structure and human agency that need to be addressed in my study. There is the layer of the social interaction of individuals engaged in intimate relationships. The second layer is that of the interaction of those working on the issue from various positions who have a common (although often unrecognized as such) interest in working toward the reduction and prevention of intimate partner violence. A third layer lies in the interaction between social practice and scholarship on social practice, as theory has a generative capacity as well as the capacity to reveal. It is in the second and third layers that I have the most interest and it is in these layers that sociologist Pierre Bourdieu's (Bourdieu \& Wacquant, 1992) insistence on the reflexive aspects of social science research has particular relevance. I wish, in my work, to tell the story of intertwined social relations from which, Bourdieu claims, changes in knowledge production and social practice necessarily emerge (Bourdieu \& Wacquant, 1992).

My project is about the gap between a theoretical model and the phenomenal world. I am engaging in a reflexive examination of the construction of a conceptual framework (VAW) and the work that the concept of the female victim/survivor and the male perpetrator has done and is doing. I am drawing out the nuances between seeing a regularity and applying that pattern as a lens which explicates 'truth' (Bourdieu, 1990). A new lens can powerfully shift society's understanding of a social issue but can also lead to different erasures than those that previously existed and/or leave some areas of understanding neglected. I am addressing the changes that develop on the ground as researchers, practitioners, workers, victim/survivors, perpetrators and others all engage with, and react to, the foundational concepts as well as the new conceptual tools that are generated with and against those foundational concepts. Finally I am exploring the 
transformational period which I claim is occurring in feminist VAW perspectives on intimate partner violence and specifically regarding men who use violence in their relationships at the current time, explicating how and why this transformative work is so difficult for all concerned.

\section{THEORETICAL AND METHODOLOGICAL CONSIDERATIONS}

In order to undertake this research project I needed an approach to the topic that would allow me to think, what was to me, unthinkable. Sociologist Pierre Bourdieu (1990) notes that the unthinkable is "at any given time, ... not only everything that cannot be thought for lack of the ethical or political dispositions ... but also everything that cannot be thought for lack of instruments of thought such as problematics, concepts, methods and techniques" (p. 5) which, he adds, "explains why good intentions so often make bad sociology" (p. 5). In order to commit 'good' sociology I needed a theoretical approach that would extend my ability to see different perspectives on the topic I was committed to exploring. Bourdieu's reflexive sociology has provided this lens and language to think the unthinkable.

As a feminist scholar, I held a reflexive insider stance in my approach to this study of feminist knowledge production. ${ }^{1}$ As a scholar undertaking a sociological study of feminist theory and practice, I engaged an outsider position to the degree that I brought the reflexive sociology of Pierre Bourdieu to bear on feminist theories and practices. Taking an unusual theoretical approach to the analysis of a social problem is helpful for

\footnotetext{
${ }^{1}$ I discuss my insider status further in the next section and in the "My Process" section of the
} methodology chapter. 
the generation of new insights. In this case, using Bourdieu's reflexive sociology allowed for the examination of the female victim/survivor and male perpetrator concept through a lens which had not previously been used. Feminist scholars have not been reticent in pushing the boundaries for understanding of the reflexive aspects of knowledge production and how the production of knowledge has ramifications for social practice and social hegemonies. My dissertation research both relied upon and adds to feminist epistemological literature in this area.

Bourdieu is adamant that theory and methodology must be inextricably linked. In his approach, the theoretical and methodological framings of a sociological inquiry are constructed in an iterative process to create a research project with the qualities necessary to reveal a social reality that is not common sense to the researcher. Using Bourdieu's theoretical tools, I conceived of my research object as the social construction of feminist anti-violence work relating to intimate partner violence and more specifically to male perpetrators of violence within heterosexual relationships. I investigated the research object as being part of a Bourdieusian 'field' of influences. I defined this field as including feminist and non-feminist approaches to addressing IPV from the 1950s to the present time, and as comprised of interventions at the level of research and scholarship, service provision, and activism. ${ }^{2}$ In this field there are complex, overlapping and conflicting perspectives regarding what constitutes IPV and what approaches should be taken to reduce and prevent it. In Bourdieu's language, each of these perspectives characterizes a position in the field called a 'habitus;' each position represents an

\footnotetext{
${ }^{2}$ Policing and justice are two further areas of intervention in IPV that could have been part of this investigation. In the interests of appropriate scoping these two areas are not focuses of this project.
} 
internally coherent (or coherent enough) understanding of the issue of intimate partner violence and what is truth about it. These truths are, in Bourdieusian terms, the 'doxa' of the various groups in this field. In other words, my investigation explored what constitutes the socially real for each of these groups in their interactions with each other.

The Bourdieusian field supports the development of a complex analysis of this situation. Bourdieu proposes that his concept of the field,

... promotes a mode of construction that has to be rethought anew every time [we use it]. It forces us to raise questions: about the limits of the universe under investigation, how it is "articulated," to what and to what degree, etc. it offers a coherent system of recurrent questions that saves us from the theoretical vacuum of positivist empiricism and from the empirical void of theoreticist discourse (Bourdieu \& Wacquant, 1992, p. 110).

The boundaries of the Bourdieusian 'field of work to reduce and prevent intimate partner violence' that I drew for this study are not those usually articulated. I named and defined this field as a way to scope my project but also as a way to focus on work that intersects although the people involved do not necessarily relate to each other as doing the same work. This definition allowed me to include and give (brief) attention to the patriarchal work in this area that the second-wave feminist interventions of the 1960s and 1970s were constructed to address. It was also a helpful delineation because I wanted to give both feminist and non-feminist current efforts the same serious consideration. If I had begun with a framing of my project as addressing violence against women, I would not have been able to undertake this examination with an attitude of accepting, or even engaging all positions in the field. As Bourdieu (1999) asks, in the introduction to The Weight of the World,

... how can we offer readers the means of understanding - which means taking people as they are - except by providing the theoretical instruments that let us see those lives as necessary through a systematic search for the causes and reasons they have for being what they are? (Accardo \& Bourdieu, p. 1). 
The term Bourdieu uses for this process of consideration is objectivation. I wanted to be able to 'objectify' all the positions in the field - those that appear more in alignment with my concerns and interests and those that appear less so. Not taking violence against women as a starting point gave me this license. While 'violence against women' resides in the core of my feminist identity, I also came to this study with some awareness of how this theoretical orientation has - as well as producing powerful insights - generated gaps in understanding (as does any theoretical framing). One way that gaps are generated is by the elision of a theoretical concept with reality. Feminists tend to think of violence against women as an element of the phenomenal world. We forget that violence against women is actually a social construct. (This is not to say that women are not victimized; but rather that VAW is a conceptual framework within which those experiences and the social context of those experiences have been conceptualized.) It was an important stake in the ground to identify work to reduce and prevent intimate partner violence as the Bourdieusian field with which I was concerned and violence against women as a social construct within that field.

However, this field I named is also a construction. It includes and excludes. By taking this starting point I lost the context provided by a view of violence against women as happening across other dimensions such as stranger rape, rape culture, institutional or systemic violence or violence against disabled women. This was pointed out to me by several of my interviewees who use the term violence against women when discussing intimate partner violence. Without this context, they argued, my study would lose a vital connection to the reality of violence women face in societies across the globe. While I found that this starting point did sometimes disrupt my feminist understanding of VAW it 
also provided opportunities for clarifying these understandings as I will explore in chapter three.

\section{MY POSITIONING}

During my sojourn as a coordinator of a women's centre in the mid-1990s, young feminists in the organization were initiating conversations in which they positioned men as allies. These conversations made me sensitive to earlier second-wave constructions of men as 'other;' when I began this project I had come to a place of believing that the feminist VAW approaches needed to change in relation to how men are conceptualized. But I was not hearing of change happening in my, at that point in time, limited contact with feminist practice on the issue of intimate partner violence. I was hearing of resistance to new knowledges but not of ongoing adaptation within VAW work. And I was hearing many competing articulations of what intimate partner violence was about. I came to this study asking, "What is really going on in intimate partner violence?" I felt a responsibility to find the answer to this question and to understand if my identity group which included feminist VAW activists and practitioners - was taking an approach I could still believe in and work toward. I also began to see that, while I could not discover an objective answer to the question of what is going on with intimate partner violence, I could begin to understand the social context of my question. I could develop my understanding of the social processes involved in the negotiation of change regarding such a complex and significant social issue.

As I developed my project I became aware of the importance of the commitments held by those involved in work to reduce and prevent IPV in influencing how they approach the issues. It seemed that while the female victim/survivor and male perpetrator 
was a foundational concept in the field of work to reduce and prevent IPV, there were exceptions and challenges to this thinking that were creating tensions. I began to frame my project as exploring the tensions between the commitments and the conundrums being experienced. I also began to see the situation as one of impasse as I gained understanding of how the commitment to the female victim/survivor and the male perpetrator was under direct challenge from within feminist communities and externally (see Figure 1).

I pictured VAW as an elastic band being stretched wider and wider to account for more complexity and nuance. We could see the complexity but were still contained and constrained by the foundational concepts. I did find both commitments to these foundational concepts and unresolved conundrums among my interviewees. But I also began to suspect that this concept of the female victim/survivor and male perpetrator had a life of its own that required further explanation. It was in doing the analysis and writing that I one day found myself writing that we were in a transformational period regarding feminist VAW thinking on intimate partner violence. This insight broke open my sense that 'we' were stuck; I became instead aware of the overall sense of something new emerging. When I looked back over my draft dissertation chapters with this new awareness I found that it was already embedded in what I had written to date.

\section{RESEARCH QUESTIONS}

My new awareness of the transformational processes underway supported a stronger understanding of my overarching research question, which became: How can we understand the historical trajectory of the problematization of male violence in heterosexual intimate relationships in the English North American literature and among 
practitioners? The exploration of this question was supported by sub-questions which individually inquired into the theory to be applied and the insights to be generated: (i) How can Bourdieu's reflexive sociology help us understand the positions and positioning of those working to reduce and prevent intimate partner violence over time? (ii) What sociological insights can be generated about the field of work on the reduction and prevention of IPV through the application and extension of nuanced understandings of the intertwining of structure and agency available in the sociological and feminist literature? (iii) How is the development of increasingly nuanced and diverse knowledges relevant to the reduction and prevention of intimate partner violence affecting activism and service provision in feminist anti-violence movements? Seeing a transformative period regarding feminist VAW understandings of male perpetrators of IPV raised two further questions: (i) How can we understand the desire of many VAW workers to have a conversation about the need for healing work on the part of male perpetrators of intimate partner violence in conjunction with the perception by these same workers of the lack of feminist space for this conversation to happen? And, (ii) Why is the shift that is occurring so difficult? Addressing these questions leads to an articulation of the trajectory of work to reduce and prevent intimate partner violence.

\section{DEFINITIONAL STRUGGLES}

Telling the story of work to reduce and prevent IPV first requires the definition of several terms. The Bourdieusian field is a place of power struggle. One clear struggle that has been enacted within the field over time is the power to name what is happening. Is it wife abuse? Is it woman abuse (which can include past spouses, common law couples and dating partners)? Is it violence against women (which can include many kinds of violence 
beyond the intimate relationship)? Is it violence against Women of Colour (to reflect the need to address intersections of personal and state violence)? Is it domestic violence (which is nominally gender neutral)? Is it intimate violence (which can include caregivers of disabled women)? Is it partner assault (focused on physical/legal crime)? Is it intimate partner violence (to include those not living together, past relationships and same-sex or trans relationships)? Is it coercive control (which emphasizes psychological and emotional abuse)? The naming and definition of intimate partner violence has been an integral part of the ongoing transformation in understandings of intimate partner violence examined in this dissertation. Below I set this definitional struggle within the context of the history of feminist efforts to end violence against women.

The early terms 'wife battering' and 'wife abuse' existed within a social context in which men were assumed to have such a degree of power over women that the idea of women being abusers in heterosexual relationships was not considered, or if considered, was discounted as being of such minor incidence as to not constitute a social issue (Russell 1982, Walker 1979). It is important to note that this was the case in both patriarchal and feminist approaches to the issue. In focusing on violence against women, feminists were not confronting a mainstream conceptual framing that posited women and men as equally violent (as is the case today). The point early second-wave feminists were making was that violence against wives by their husbands was $a$ social issue rather than a private trouble as it was seen in patriarchal articulations. An increasing awareness of the complexity and variety of relationships (e.g. common law, divorce, same-sex, dating) involved in intimate partner violence led to the general abandonment of the term wife abuse. The term wife abuse was replaced by woman abuse and still later by domestic 
violence, a nominally gender neutral term which, as noted by my interviewees, still carries the connotation of male to female violence. The development of the term intimate partner violence was identified by several of my interviewees as emerging from state initiatives to develop gender neutral terminology. This creation has been resisted by many feminists as it makes invisible the structural forces that make women vulnerable to violence by their male partners. However, over time such terminology has gained dominance in the field, particularly within governmental and legal settings.

The struggle regarding definitions and the naming of IPV has been reflected in the naming of the groups doing work in the field. In this dissertation, I refer to feminists working to reduce and prevent intimate partner violence using a VAW theoretical framework as feminist VAW scholars and practitioners. While feminist anti-violence work emerged from the efforts of women who were struggling against and to change mainstream interpretations of intimate partner violence, the successes of feminist VAW efforts in changing societal understandings of IPV (to however (un)stable a degree and however mixed the results in terms of outcomes for women who experience abusive relationships) have led to the institutionalization of VAW approaches in state-supported efforts to reduce and prevent IPV. In their work to address intersectional causes of violence against women, Women of Colour and Indigenous women have identified feminist VAW efforts as 'mainstream' in that this engagement of the state neglects the state as a source of violence and oppression inflicted on marginalized women and men (Arvin, Tuck \& Morrill, 2013; INCITE!, 2007; Sokoloff, 2005). In light of this identification, I use the terminology of 'mainstream feminist VAW approaches' in this dissertation. 
Mainstream feminist VAW scholars and practitioners positioned violence against women within the context of unequal power relations between women and men, power relations that are operationalized at the individual, family, community and broader institutional and social levels, a context referred to as patriarchy. Diana Russell (1982) draws on the Webster Dictionary in defining patriarchy as "“a form of social organization in which the father is recognized as the head of the family"' (p. 3). She continues: "Outside of the family it also refers to 'government by men'” (p. 3). Rebecca Dobash and Russell Dobash (1979) identify two elements of patriarchy: structure and ideology. The structural elements of patriarchy reside in social arrangements which exhibit an unequal access to power between women and men. The ideological aspects are found in social beliefs that confirm a need for hierarchical social strata and reinforce the current order. These two aspects of patriarchy were identified by second-wave feminists as providing the context and justification for ongoing and systemic male violence toward women, and specifically, intimate partner violence.

In the 1960s through to the early 1980s, mainstream feminist VAW theorists made this routinized violence visible as the social foundation upon which wife abuse rests, as can be seen in Susan Schechter's (1982) definition of wife or woman abuse as: "an historical expression of male domination manifested within the family and currently reinforced by the institutions, economic arrangements, and sexist division of labor within capitalist society" (p. 209). These feminist VAW theorists emphasized the uni-directional nature of domestic violence from husbands toward wives - an aspect of intimate violence previously taken for granted - as something requiring explanation. They also foregrounded the control aspect of IPV. Dobash and Dobash (1979) argue that violence in 
the family "should be understood primarily as coercive control" (p. 5), terminology that has since become common within feminist VAW articulations of IPV (Stark, 2007).

In further contrast to patriarchal articulations, feminist VAW scholars defined abuse within intimate relationships broadly to capture actions that have violent effects in the physical, emotional, intellectual, sexual, social, economic, or spiritual realms. In 1982, Russell points out that domestic violence was often examined separately from sexual violence, and that the rape of wives by husbands was an issue neglected by both mainstream and feminist scholars and activists. She builds a convincing case that these two issues should be considered together showing, in a study of 930 women, that $10 \%$ had experienced both wife rape and beating. Catharine MacKinnon (1987) also supports an integrated approach to the examination of IPV and rape in intimate relationships. She argues that sexuality forms the core of men's oppression of women and sees battering as an inherently sexual act encompassing the eroticization of violence. MacKinnon contends that when we argue that rape is violence rather than sex, we collude with a dichotomy of violence and sex which leaves us unable to critique where the line is between normal heterosexual sex and rape. The naming of sexual assault as an aspect of intimate partner violence that must be accounted for in theoretical explanations of IPV was a key contribution of feminist analyses. However, there were also problems identified with this naming. For example, Smart (1989) argues that, while MacKinnon emphasizes the ways that male sexuality distorts female sexuality, she presents,

...male sexuality in a state of nature. Male sexuality then is not cultural, it is natural and transhistorical. Moreover, it can remain undistorted whilst distorting female sexuality. Yet it is problematic to posit that culture, history, language, ethnicity can construct female sexuality, whilst proposing that men are outside culture, merely being its makers (p. 77). 
Smart argues for expanding feminist doxa regarding male agency in partner violence to include the social structuring of men. This contestation regarding how to address male perpetrators is a key thread I follow in this dissertation.

By the early 1990s, the work of feminist scholars, service providers and activists involved in efforts to end violence by men against their female partners, led to violence against women being recognized internationally. The definition of VAW in the United Nations Declaration on the Elimination of Violence Against Women is "any act that results in, or is likely to result in, physical, sexual, psychological harm or suffering to women, including threats of such acts, coercion or arbitrary deprivation of liberty, whether occurring in public or private life" (UN General Assembly, 1993).

Feminist understandings of IPV have been further developed in response to gender parity framings of women and men as equally violent. Feminists insist that the meaning, frequency, severity and impacts of violence must be considered in order to effectively address it (Johnson \& Dawson, 2011). Use of these indicators substantiates feminist claims that violence by men against women in heterosexual relationships is a singularly serious social issue (Dobash et al., 1992; Kimmel, 2002; Stark, 2007). Thus, in Violence against Women in Canada: Research and Policy Perspectives (2011), Holly Johnson and Myrna Dawson define intimate partner violence as "physical and non-physical abuse experienced by women at the hands of male current or former partners" (p. 65). In doing so, Johnson and Dawson are able to maintain a focus on male violence against women in heterosexual relationships, which they maintain is the social issue requiring attention.

It can be seen in the above review that violence and intimate partner violence have varying boundaries in the feminist literature and among the research participants in this 
study. These boundaries have been, and remain, a site of contention. In my dissertation, I use the term intimate partner violence to identify physical, emotional, intellectual, sexual, social, economic, or spiritual violence between current or past intimate partners, who may or may not currently cohabitate or have cohabitated in the past. In this framing I include violence by men, women and transgender people toward their intimate partners in heterosexual and queer relationships. Through this inclusion I seek to include the definitional boundaries found in the field both within feminist VAW framings and beyond these framings.

\section{CONCLUSION}

This qualitative study explores how the development of increasingly nuanced and diverse knowledges relevant to the reduction and prevention of IPV is affecting theory, service provision and activism in feminist anti-violence movements in an area of Englishspeaking Canada, arguing that a transformational period in how male perpetrators of IPV are viewed within VAW approaches is underway. In this introduction I have outlined the scope of the project, defined the topic to be addressed and outlined the central arguments.

Chapter two presents the reflexive sociology of Pierre Bourdieu which forms the theoretical frame of the project. Bourdieu (1992) argues that a significant pitfall awaiting sociological research is the inadvertent replication of social problems. The identification of a research object which challenges (even critical) common sense thinking requires a rupture with one's beliefs regarding what constitutes a legitimate social problem. As I wished to understand feminist conceptualizations of male perpetrators of IPV, the use of Bourdieu's reflexive sociology led me to look for a point of rupture in my feminist understanding of these men. This was accomplished through an examination of the social 
construction of violence against women relating to IPV and specifically to male perpetrators. The designation of the field as including both feminist VAW and nonfeminist approaches to addressing IPV allows an examination of the relational development of feminist VAW understandings.

In chapter three, I outline the qualitative research methodology that emerged with and from the theoretical framework of the project. The primary data collection methods for my study included interviews, participant observation, a focus group and an early findings feedback workshop. My methodological goal was to accomplish what Bourdieu (1992) calls participant objectivation, in which the views and positionings of the various participants in the field are brought into focus through an examination of the nexus of the institutional positions which they occupy. Over the course of my research my understanding of the field shifted from seeing a range of oppositional positions and conundrums among those in the field to seeing an evolving set of knowledges being negotiated by evolving sets of people. This shift was incremental, culminating in an insight that the foundational feminist VAW understanding of male perpetrators is in a transformational period.

The foundations and early development of mainstream feminist VAW doxa are visible in scholarly work and practice in the field, as is explored in chapter four. In this chapter, I document the establishment of the feminist VAW doxa, habitus and subfield. Feminist VAW efforts succeeded in shifting wife abuse from a private trouble to a social problem. In doing so, new doxa in relation to wife abuse were established. This doxa responded to an insight that formed against patriarchal doxa, insisting that women were not responsible for male violence against women, men were. 
In chapter five I investigate the current transformative period through the literature, identifying and analyzing three sociologically significant encounters which have been fundamental in influencing how feminist VAW theory and practice have unfolded over time. The first encounter encompasses intra-group struggles for recognition within feminist VAW movements; the second critiques from the gender parity camp; the third, the impact of trauma theories (see Figure 1).

Chapters six and seven analyze the primary data of the project in relation to several positions in the field. Chapter six presents the analysis of the interviews with women working with women victim/survivors in VAW framings and chapter seven the interviews with men working with male perpetrators in Partner Abuse Response (PAR) programs, private therapists and men who work with male victims. The interview excerpts analyzed demonstrate that the current transformation in feminist VAW doxa relating to male perpetrators of IPV is being met among those in the field with mixed responses - including resistance, uncertainty, fear, misrecognition, and hope. I argue that tracing the development of the field using a Bourdieusian lens, as I do in this dissertation, allows us to see the unfolding of a current transformative movement in feminist VAW understandings of men who use violence in heterosexual relationships in Canada.

I bring the analysis of the interviews with VAW workers, PAR workers, private therapists and men who work with male victims, together in chapter eight to address the question of why the current transformative period is so difficult for those involved. The increasingly varied positions and positioning among those working to reduce and prevent IPV can be seen through a Bourdieusian lens as providing the impetus for changes to habitus and doxa that inevitably lead to changes in the field. While the encounters 
documented in this dissertation have been experienced by many as polarizing, as conundrums, or even as an impasse, there are also efforts underway to engage with this unfolding. In this final chapter I document the interrelated and intertwined engagements of those involved in the field of work to reduce and prevent intimate partner violence, explicating how this transformative movement is being experienced by those in the field and illuminating opportunities and responsibilities for the feminist VAW subfield in this time of transition. 


\section{Chapter 2 \\ Theorizing Work on IPV with Bourdieu}

\section{INTRODUCTION}

One of the most powerful instruments of rupture lies in the social history of problems, objects, and instruments of thought, that is, with the history of the work of social construction of reality... you must retrace the history of the emergence of these problems, of their progressive constitution, i.e. of the collective work, oftentimes accomplished through competition and struggle, that proved necessary to make such and such issues to be known and recognized as legitimate problems, problems that are avowable, publishable, public, official. (Bourdieu \& Wacquant, 1992, p. 238).

How does a critical sociologist think what is to her unthinkable? Bourdieu argues

that we must create a rupture with what we think we know. We must experience what he calls radical doubt. For Bourdieu, the most powerful sociological explanations emerge when critical theorists are able to reflexively engage with the concepts that they themselves have developed in order to understand social problems. 'Violence against women' is such a concept in my feminist identity group, having been developed by feminists in response to patriarchal articulations of wife abuse. Following Bourdieu, I made the examination of this concept central to the creation of my theoretical and methodological framework. Taking this approach positioned my work as an inquiry into knowledge production. Especially in the early stages of this research I continually needed to come back to this insight. My project was not about violence against women; it was about the generation of feminist knowledge regarding violence against women.

Bourdieu's reflexive sociology emerged through his efforts to transcend an ongoing dilemma in sociological theory, that of the polarization of social structure and human agency as explanations for sociological phenomena. Bourdieusian and feminist 
scholars have extended the concepts of habitus, field and doxa, and developed the capacity to further nuance our understandings of the interactions of structure and agency, particularly in terms of gender. I have found both the Bourdieusian conceptual framework and the structure/agency literature to be a rich source of material in developing the theoretical approach to my research.

In the last two decades, Bourdieusian feminists have identified, in the use of Bourdieusian concepts, an opportunity for extending our understandings of the interaction of social structures and (specifically) women's agency. The investigation of structure and agency is integral to my research topic as scholarly and practical work on intimate partner violence exemplifies the theoretical divide between structure and agency in a number of different ways. I have engaged with the work of Bourdieusian feminists as an anchor for my exploration of the intertwining of structure and agency.

In this chapter I develop my theoretical frame. I first present Bourdieu's conceptual framework and explore how sociologists who are seeking to transcend the perceived dichotomy between structure and agency are working with the Bourdieusian concept of habitus to do so. From there, I explore how feminists have engaged with Bourdieusian concepts when explaining structure and agency with reference to gender and outline how these understandings are implicated in my research. I also examine Bourdieu's explication of the logic of practice and relate that work to knowledge production regarding intimate partner violence. I draw this material together in outlining my framework for exploring how we can understand the relational positions and positioning of the people working in the field of work to reduce and prevent intimate partner violence. The work of Bourdieusian feminist Beverly Skeggs is then presented as 
providing a way of understanding the development and 'stickiness' (Ahmed, 2004) of this positioning.

\section{STRUCTURE, AGENCY AND BOURDIEU}

The need to account for the impact of both social structures and individual agency when theorizing social issues has been of ongoing significance to sociologists and other social scientists. However, transcending the historical polarization of these concepts has proven to be difficult. Sociologists who have tried to address the structure-agency theoretical divide have generally been perceived as having erred on one side or the other. Pierre Bourdieu is one of these sociologists. Bourdieu's conceptual framework of reflexive sociology is sometimes critiqued as having left little room for agency. However he himself claims to have elaborated a "constructivist structuralism or... structuralist constructivism" (Bourdieu, 1989, p. 14, emphasis in original), designed to take both social structures and human agency into account in social research.

Pierre Bourdieu (1930-2002) developed the concepts of habitus and field in part as an effort to transcend the structure-agency binary and to avoid either a mechanistic understanding of agency in which social structures determine action, or a subjective understanding in which the agent is free to consciously and rationally choose her or his own goals. His own life provided him with a puzzle to work on in this regard. Bourdieu used his own agency to dramatically change his expected life course - moving from a relatively obscure rural childhood to become one of the preeminent sociologists of the late $20^{\text {th }}$ century. However, his fractured experience of belonging within his new social class (or his old one) reflected the workings of structure. In Homo Academicus (1988) he reported on a study in which he compared the social origins of specific academics to the 
positions that they held in the academy. He found a statistical correspondence between social origins and academic positioning although the system claimed to be based on merit and, in his experience as an agent within the system, merit was rewarded. Through his conceptual framework of reflexive sociology, he worked on this puzzle, explicitly seeking to move beyond the structure-agency dichotomy that he saw as one of a number of "false antinomies of social science" (Bourdieu \& Wacquant, 1992, p. 178 n. 133).

\section{Habitus and field, doxa, cultural capital and symbolic violence}

What the Bourdieusian concepts of habitus and field bring to the structure-agency debate is an understanding of human agency constrained by the social and historical experiences of the agent. This constraint is expressed in the concept of habitus: everything internalized that has brought the individual to this point in time and place. The habitus exists within a field (a number of intersecting fields actually, which becomes relevant when using the concepts but for the sake of clarity while explaining them will be downplayed). The field is that which, external to the individual, has formed the habitus. Each field has a doxa, a set of common sense assumptions associated with it that provide the sense of fit between the habitus and the field for the agent. Bourdieu emphasizes that the habitus is a matter of practical knowledge, embodied by an agent. When explaining habitus he often used the metaphor of the "feel for the game" that allows an expert player to participate in a way that cannot be explained simply by an intellectual understanding of the rules. Regarding the field he says,

\footnotetext{
We may think of the field as a space within which an effect of field is exercised, so that what happens to any object that transverses a space cannot be explained solely by the intrinsic properties of the object in question. The limits of the field are situated at the point where the effects of the field cease (Bourdieu \& Wacquant, 1992, p. 100).
} 
The field and habitus reinforce each other through the existence of the doxa associated with the field.

This relationship of reinforcement between the field and habitus explains the reproduction of social stability. However, there are also a number of opportunities for human agency. The first, emphasized by Bourdieu himself, occurs when an individual experiences a misalignment between the doxa of the field and their habitus. While the habitus originally develops as a reflection of the field, temporal and material change (whether perceived as good or bad) can lead to the perception of choices earlier invisible and then to novel uses of agency, which can in turn create changes in, the field (Bourdieu \& Wacquant 1992). Chodos and Curtis (2002), in their critique of Bourdieu's Masculine Domination (2001), explicate two resulting opportunities for political agency specifically in terms of gender. The first of these is to make the naturalized experience of the field visible through a process of deconstruction. The example provided by Chodos and Curtis is the success of feminist work in distinguishing biological sex and socially constructed gender. In making visible gendered expectations of women and men as socially constructed, rather than as a feature of biological imperative, doxa that had been internalized as 'how women and men are' became open for discussion on how women and men could be. The second approach involves making specific changes to social practices in order to "attack directly, or produce consequences that undermine indirectly, the binary divisions of domination" (Chodos \& Curtis, 2002, p. 402). An example of this would be the creation of laws making marital rape illegal. This shift in the field brings a challenge to the internalized belief of both women and men that it is a husband's right to have sex with his wife whenever he wants. Both of these strategies produce changes in 
the relationship between the habitus and the field, the first through making the limits of the habitus visible (and therefore a question of choice rather than unconscious adherence), and the second through making changes in the field (which then requires a corresponding adjustment in doxa and habitus).

Bourdieu argues that the kind of 'game' exhibited by a 'player' in the field can be predicted by the kinds of cultural capital that they hold. According to Terry Lovell (2000), Bourdieu presents three forms of cultural capital. The first is held within the individual "in the form of long-lasting dispositions" (Lovell 2000, p. 22). The second takes the form of cultural values and goods and the third is of an institutionalized form such as educational qualifications. Individuals act to maximize the effectiveness of their cultural capital. They can also act to try to influence the value of various capitals to maximize, for instance, the value of the capital they hold, or to achieve social justice goals. In Bourdieusian terms, agents are always acting strategically to achieve their goals, although some of their knowledge and actions will, by virtue of being part of their habitus, be so natural to themselves as to remain unrecognized. Bourdieu points out that capital is only valuable when there is a field in which it is recognized "both as a weapon and as a stake of struggle, that which allows its possessors to wield a power, and influence, and thus to exist, in the field under consideration" (1992, p. 98, emphasis in original). The concept of cultural capital is valuable for investigating conflicts in a field such as the one I am exploring where there are diverging sets of knowledge claims between groups with identifiable habitus and doxa.

Symbolic violence is also a significant concept in theorizing the work being done to reduce and prevent IPV. Bourdieu identifies symbolic violence as "the violence which is 
exercised upon a social agent with his or her complicity" (Bourdieu \& Wacquant, 1992, p. 167). This complicity comes through the acceptance of the way things are as natural, and can be seen for example, in the normalization of gender domination (which Bourdieu suggests is the "paradigmatic form of symbolic violence" (Bourdieu \& Wacquant, 1992, p. 170)). Bourdieu is careful to note that, while the use of the term complicity could be taken by some to indicate an active responsibility for the situation, he in fact is pointing to the development of the habitus as a reflection of the field and the doxic acceptance of the way things are "due to the immediate agreement of the objective structures and cognitive structures" (Bourdieu \& Wacquant, 1992, p. 168). Domination can flourish when there is a fit between the cognitive structures of individuals and the objective structures of oppression within which individuals are placed. This understanding is in alignment with feminist efforts to call attention to how what is seen as natural regarding gender is in fact constructed: the concept of violence against women can be articulated as theoretical work by feminists to make symbolic violence toward women visible through deconstructing the perceived naturalness of this violence.

While symbolic violence can occur in our acceptance of the way things are, Bourdieu also argues that symbolic violence occurs in the struggle for recognition of a specific point of view as truth. In Homo Academicus (1988), Bourdieu insists that any dominant viewpoint, accepted as truth, is actually a "specific, situated, dated viewpoint... [which has been] misconstrued" (Bourdieu 1988, p. 26) and therefore must be defended in order to continue to exist. As an example, Bourdieu explicates a set of oppositions regarding the exercise of symbolic power within the French academe, between the fields of study aligned with the established social order (law and medicine) and those willing to 
think against normative rules and customs (arts and sciences). Bourdieu's analysis of symbolic power in Homo Academicus can seem almost cynical in that everyone at all times seems to be making decisions based on their own self-interest. Bourdieu clarifies this toward the end of the book when he states that he is referring to a statistical result: the statistical data which reveal how those with power act in their own best interests, and how those without power are looking to increase their power, is an aggregation of many individual decisions. These decisions are not all and every time in the service of personal interest, but they generally add up to reinforcing the status quo. This is a subtle but critical distinction, one that points again to the workings of habitus, and will be significant when analyzing the development of polarized views on the causes of, and worthwhile interventions to, reduce and prevent intimate partner violence between VAW and gender parity adherents.

Bourdieu (1988) also argues that the opponents in epistemological conflicts engage in a kind of collusion and complementarity which is another expression of symbolic violence. "These social oppositions... are predisposed to function as 'epistemological pairs' which lead people to believe that the world of possibilities is restricted to the two polar positions - which thus prevents them from seeing that each of the two camps finds the better justification of its limits within the limits of the opponent" (1988, p. 113). In engaging with these kinds of oppositions, Bourdieu urges researchers to not oversimplify the situation by seeing them as mutually exclusive positions that are irreconcilable (in which case one position must win and one must lose) or that require transcendence (meaning that a greater truth can be found which would unify these positions). He suggests that the situation is more complex and involves the "rival coexistence of several 
relatively independent principles of hierarchization" (1988, p. 113). In other words, as sociologists we cannot be satisfied with an either/or or a both/and resolution. A more complex sociological explanation must be sought to explain the situation being experienced by the research subjects - one that would ideally provide the participants in these struggles with new insights into their own positioning and the positions and positioning of those on the other side. The idea of epistemological pairs was an important signpost for me as I engaged in my analysis of work to reduce and prevent intimate partner violence. Along with the violence against women/gender parity pair, there are several other oppositional pairs functioning within the field of my study, including second-wave/third-wave, and mainstream feminists/feminists of colour oppositions, and cognitive/behavioural approaches and therapeutic approaches to working with male perpetrators.

\section{SITUATING BOURDIEU IN THE SOCIOLOGICAL LITERATURE}

According to Matthew Adams (2006), habitus and reflexivity have acted as dominant tropes in the sociology of identity for the past twenty or more years, representing respectively the structure- and the agency-focused explanations of identity and practice. Proponents of the thesis that individuals in late-modern societies construct their identity through reflexive processes are critiqued for being overly focused on individual agency. Scholars favouring the use of Bourdieu's concept of habitus in the exploration of identity are often seen as erring on the side of structuralist explanations of identity and practice. Bourdieu's repeated insistence that the concepts of habitus and field are generative and support agency has not been found completely convincing by his peers. A number of scholars who see the value of the habitus and field as starting points 
in exploring the integration of the structure-agency dichotomy are working to extend Bourdieu's conceptual framework to address critiques of structuralism. Below I present the work of a sample of these scholars along with one whose work provides a counterpoint. Each of these scholars adds an element to Bourdieu's conceptual framework that makes it more powerful as a tool for understanding the role of both social structures and human agency in theoretical explanations of the social world, and in gaining insights into the interactions of social structures and human agency in social practice. My dissertation explores both these levels of explanation.

Nick Crossley (2001) argues that Bourdieu formulated the concept of habitus against both structuralism and phenomenology. On the one hand Bourdieu contested a rule-based approach to explaining practice, as is exemplified in structuralist approaches. On the other he stressed that the interpretive frameworks of agents emerge within the context of groups - groups that are themselves in relationship with other groups. While Crossley accepts Bourdieu's intention for habitus to account for both structure and agency, he argues that the concept of habitus requires augmentation to explain the emergence of a specific set of responses by a specific set of actors in a specific set of conditions and re-introduces phenomenology to assist him in developing the interrelationships of agency and structure. He brings forward three insights from phenomenology to support this effort: that the relation of habit to action is a two-way street; that the nature and possibility of reflexivity are rooted in habit; and that our perceptions and conceptualizations are embellished by habituated expectations and typifications. These insights point to the iterative interaction of agency and social structures, and tie each to the other. 
In coping with the accelerated rate of change typical of late modernity, Sweetman (2003) indicates that individuals may paradoxically develop a capacity for reflexivity that becomes incorporated into the habitus. It becomes part of one's habitus to continually reinvent one's relationship to, and position in, the world. A further opportunity for generativity is presented by Ricardo Costa (2006) who contends that, while the conditioning of the field "precedes and structures the habitus" (p. 878), the habitus does not reproduce the field but rather produces representations of the field. I would add the further point that fields produce a variety of habitus, which then produce representations of a variety of fields - all of which overlap and interact. Indeed, it becomes astounding when reflecting on this process to think there might be any strict reproduction of social structures. The necessity for the use of power in the reproduction of social structures, as feminists have noted in the case of patriarchy, becomes visible in this articulation.

Some limitations on agency emerge from the work of Matthew Adams (2006) who emphasizes how access to resources plays a significant role in supporting or hindering the enactment of one's agency. The insight that Wee and Brooks (2010) bring to the discussion is that of seeing reflexivity as a commodity. Whereas in the past, privileged individuals and groups had no need to engage in reflexive activity because they could rely on social structures to protect their interests, reflexivity is now valued, and has become an essential tool for self-advancement in capitalist society. Wee and Brooks reinforce reflexivity as a project that necessitates the accumulation of resources in order to support participation.

Together the works explored above extend and refine our understanding of the interworking of habitus and reflexivity. While the relationship between these two 
concepts has often been characterized as oppositional, with habitus representing structure and reflexivity representing agency, we can now see various opportunities for reflexivity in the workings of habitus. Bourdieu himself indicates that opportunities for agency occur when changes in the habitus or field lead to a lack of fit between the habitus and field (Bourdieu \& Wacquant, 1992). The work of the authors above generates further insight into how the concept of habitus could be used to address social change as well as social constancy. Bringing insights from phenomenology regarding the interactions of habit and action, allows us to use the concept of habitus to understand the actions and limitations on specific individuals and groups in specific situations in specific times. Even when habitus and field are reinforcing each other there is some inevitable slippage which results in an imperfect representation and therefore imperfect reproduction of habitus and field. The rate of change within late modern societies points to the existence of a reflexive habitus, with capacity for ongoing adaptation. However this understanding must be held within the context of a capitalist society where social positioning gives some more access and others less access to the resources needed to affect change as a result of increased reflexivity. As well, reflexivity is often a choice between options that do not challenge the status of dominant groups. An example of this is the increasing engagement of reflexivity as a commodity that can in turn be used in the performance of an employable 'self,' and can actually reinforce the status quo and hegemonic forms of power.

\section{Exploring the role of interests in social change}

Jeffrey Alexander (1995) perceives an unwarranted emphasis on structural reproduction in Bourdieu's work and wonders (along with a number of other critics) how 
social change can be explained within the framework of a habitus that is positioned to so closely reproduce the surrounding field. Alexander addresses the realm of knowledge production, so his is a particularly relevant critique for this dissertation. He sees as a contradiction, in light of the strength of the habitus, Bourdieu's claim that sociologists and other social scientists can stand outside their habitus in order to be critical and reflexive. Alexander is also concerned with what he sees as a second contradiction: Bourdieu's claim that critical social science often is in fact reflective of the social structures (rather than representing a rupture with those structures) and is significantly motivated by strategic positioning within the field. In light of Alexander's critique, how do we know when we have indeed created a rupture with the habitus? The concept of habitus includes the understanding that unconscious beliefs about our place in the world can affect our ability to move out of oppressed and oppressive ways of thinking. Feminists have encountered and examined both of these aspects of the sedimentation of belief. For example, a number of scholars address the dangers that attend the feminist identification of women as victims (Ahmed, 2004; Brown, 1995; Collins, 1998; Skeggs, 2004). At the same time, Women of Colour and Indigenous feminists have documented and theorized the oppressiveness of feminist communities even as these communities explicitly work toward inclusion (Arvin, Tuck \& Morrill, 2013; Cunningham, 2006; Sandoval, 2000; Tuck, 2009). Addressing these concerns will be important in explicating the relational positions and positioning of those working to reduce and prevent intimate partner violence.

The seeming inconsistency between Bourdieu's work on the academy, which focuses on how the field is necessarily reproduced, and his work on social transformation 
which explores how the necessity for reproduction could be disrupted by those seeking social change/justice, is also investigated by Costa (2006). Costa argues that between these two, Bourdieu shifts from an analysis based on articulating position-taking and interest-based struggles, to a focus on solidarity and generosity, conversion, authenticity and (good) will. Bourdieu suggests that we get from one to the other through processes of self-awareness and critical reflection. It seems to me that in this Bourdieu has created a new dichotomy - that between critical scholars and others. As we - unfortunately - have hundreds of years of history documenting how solidarity, conversion, authenticity and 'will' have been used to further the interests of those taking action for change, this dichotomy seems problematic. Yet, the intellectual hierarchy implied here is a difficult one to address as a critical scholar. Of course we see ourselves as doing good work certainly better work than those whose perspectives reinforce the status quo. To maintain openness to fully explore, as legitimate because they exist, the views of those not working within a critical perspective can be, in my experience, a source of censure from critical scholars. I find this at the same time both ironic and completely understandable, as well as a sentiment with which I can sometimes align. At some point we must take a stand for what we believe is right, must we not?

These concerns are addressed by Terry Lovell (2000) using the concept of symbolic violence specifically in regard to feminist academia. She notes that academic feminists have expressed concerns relating to interests and representation among women. Lovell asks, "To what extent has it been possible to establish a new field whose practice is not based upon symbolic violence and the exclusion of women who are among the dominated by virtue of class or 'race'?" (2000, p. 26). In addressing this question she notes the 
skepticism of some feminists outside the academy. Lovell argues that "Bourdieu's work is of great importance in the task of identifying the hidden conditions of existence of intellectual communities who have prided themselves upon their openness and objectivity" (p. 27). In taking this approach she acknowledges inherent contradictions in the positioning of critical intellectuals - contradictions that require ongoing attention in order for epistemological communities to avoid having radical ideology actually represent compliance/complicity as Alexander complains is the case in his reading of Bourdieu. Maintaining an awareness of the contradictions within, and use of power involved in, change efforts may at least provide an entry point for ongoing attention to what might be neglected and naturalized in our own work and the work of those 'like us.' Consideration of Bourdieu's reflexive sociology suggests that unless the sympathetic reader experiences challenges to their own sense of what is true and just, the rupture with one's own intellectual community - identified by Bourdieu as necessary - has not been accomplished.

Scholars exploring reflexivity, such as Anthony Giddens (1991), are trying to explain how changing conditions in late modern societies require people to make many more choices about who they will be. The primary goal of Bourdieu in his scientific writing, on the other hand, could be seen as the explanation of constancy rather than the impositions of late modernity on individuals. It is not that he does not believe in agency (i.e. that he is a structuralist), but that he is not as interested in explaining agency as he is in explaining the impact of social structures. In his own academic career he transcended his childhood habitus. I suggest that his concerns lie in why it is that others do not do so. Why is it that people who no longer have to follow the professions of their parents still 
do? How is it that people from two different social classes who have the same academic qualifications end up having a similar social relation to each other that their parents had to each other? Bourdieu is not trying to account for agency but rather why people do not use their agency, or maybe more precisely, why they cannot use their agency to overcome certain social structures. I see this concern as parallel to feminist efforts to address women's agency within constraining social structures, efforts that have required feminists to challenge many myths regarding women victims of IPV (Walker, 1979). Abused women have often been characterized as passive; understanding women's agency as survivors, not just passive victims, has been important for explaining women's responses to IPV (Bible, Das Dasgupta \& Osthoff, 2002; Larance \& Das Dasgupta, 2012).

Bourdieu's reflexivity is somewhat differently focused than that of reflexivity theorists. The reflexivity of these theorists often relies on making choices between available options in order to further a putatively authentic presentation of self. This kind of reflexivity does not require a critical engagement with the social world. A privileged individual can be reflexive about their life without ever engaging with the inequalities inherent in their social positioning and their consequent privileged ability to enact their reflexive choices. Turnbull and Antalffy (2009) state: "Reflexivity for Bourdieu, refers to questioning the social conditions of one's thought..." (p. 553). Bourdieu challenges us to look critically not just at dominant social structures - which can appear as common sense - but also at the critical modes and instruments of thinking that we develop to challenge these social structures, those which can appear as common sense to critical thinkers (Bourdieu \& Wacquant, 1992) as has been explored above. 
Including in the discussion the idea that no field generates a homogenous habitus (and that each habitus exists within intersecting fields) seems to go a long way toward addressing Alexander's concerns regarding how oppositional or radical activism/scholarship can exist when the habitus is so strongly associated with social reproduction. Adding the understanding that reflexivity is based in habit (Crossley, 2001) and can be incorporated into habit (Sweetman 2003) and that the habitus creates imperfect representations of the field (Costa 2006) helps us to further understand opportunities for radical work. Bourdieu (1990) himself argues that the habitus has an, ... infinite yet strictly limited generative capacity [that] is difficult to understand only so long as one remains locked in the usual antinomies - which the concept of the habitus aims to transcend - of determinism and freedom, conditioning and creativity, consciousness and the unconscious or the individual and society. Because the habitus is an infinite capacity for generating products - thoughts, perceptions, expressions and actions - whose limits are set by the historically and socially situated conditions of its production, the conditioned and the conditional freedom it provides is as remote from creation of unpredictable novelty as it is from simple mechanical reproduction of the original conditioning (p. 55).

Making choices about positioning is part of agency. But it is also part of structure in that the choices available are the ones that present themselves within the habitus and field(s).

Alexander (1995) identifies Bourdieu as accounting for social stasis differently than for social change. It is certainly the case that Bourdieu becomes something of an idealist in advocating social change strategies. He shifts from seeing choices as emerging from personal strategies for advancement to advocating for a completely 'disinterested interest' - generating a dichotomy in the process. I seek a middle way, such as that which can be found within feminist epistemologies that assume both interest and disinterest as coresident. 


\section{FEMINIST USES OF BOURDIEUSIAN CONCEPTS}

Feminists have in the last decade or more found power in the use of Bourdieusian concepts for the exploration of gender entrenchment and possibilities for transformation. However, Bourdieu's own (lack of) engagement with issues of gender perhaps delayed feminist engagement with his work. Some have seen Bourdieu as neglecting issues of gender (Mottier, 2002; Adkins and Skeggs, 2004); others have taken a more positive view, noting for instance, that his work has engaged with both women and men as social agents (Krais, 2006), and that Bourdieu, as his work progressed, regularly addressed theoretical questions about "the ways in which masculine privilege may be identified to greater or lesser degrees in all social fields" (Dillabough, 2004, p. 490).

While there are differences in how feminists have assessed the extent of Bourdieu's relevance to an examination of gender, there is general agreement that in his analysis, masculine domination emerges as an almost universal phenomenon with little room for transformation. In his one book on the subject, Masculine Domination (published in French in 1998 and in English translation in 2001), Bourdieu uses as his case study the Kabyle society from his research in Algeria several decades earlier. At this time, Kabyle society was one of strict gender distinctions between men and women. Bourdieu therefore saw Kabyle society as an "ideal type" (Mottier 2002, p.351) for the exploration of the work that gender does in maintaining social structures. However, the use of this stable ideal provides little opportunity to explore the potential for the transformation of the gender order. Bourdieu's research of Kabyle society is not representative of the current state of gender relations in many societies, particularly in terms of how the habitus and field no longer necessarily reinforce each other but show schisms (many generated by 
feminist interventions) which produce one of the conditions for social change identified by Bourdieu himself (Chodros and Curtis, 2002). Further to this, Bourdieu does not use his own theoretical framework to support an engagement with the complexities of masculine domination and the potential for transformation. It seems that masculine domination represents an area of social relations where Bourdieu holds pessimistic views on the opportunities for change. While some feminist scholars have seen this lack of attention to transformative possibilities in the gender order as problematic to feminist use of his sociological approach, Lisa Adkins (2004) argues that Bourdieu's lack of attention to gender is an opportunity to investigate gender, suggesting that "a social theory which does not place the concept of gender as central to its vision of the social - and particularly one which has at its core a critique of idealist thinking-precisely opens itself out to contemporary feminism" (p. 4). Below, I present an overview of how feminists have engaged with Bourdieusian concepts to support the exploration of gendered experience, highlighting how these concepts are relevant to this study.

By establishing the embodied nature of gendered identity, Lois McNay (1999) argues, the concept of habitus allows for a correction of the tendency among some sociologists to overemphasize agency in postmodern societies. The habitus allows us to understand the embodied nature of social positioning, and provides a theoretical tool for understanding the entrenched, but not fixed, nature of gender inequality. The addition of the field provides a lens for an examination of the nuances of social reproduction and possibilities for transformation. Transformations in the gender system as a result of feminist activism have been and continue to be uneven, sometimes even regressive. McNay contends that "such changes cannot be understood through binaries of domination 
and resistance but rather involve more complex processes of investment and negotiation" (p. 105). If this research project involved an examination of the dynamics of IPV, an argument could be made that power imbalances within intimate partner violence make this more complex framing difficult to justify. However, this theoretical framing is eminently appropriate for an analysis of scholarship and practice in relation to IPV such as I am undertaking in this dissertation. However, the gender system does remain in play at this level and an examination of the dynamics of gender is significant to this work.

While McNay sees in Bourdieu a corrective to overemphasized agency, Terry Lovell (2000), like Alexander, finds a tendency toward an overly deterministic view in Bourdieu, which she contrasts to Judith Butler's work on performative agency. She suggests that Bourdieu and Butler each provide a balance to the extremes of the other, with Bourdieu providing grounding in the stability of social conditions, while, "Butler's understanding of the necessary 'leakiness' of all social power, social convention, habitus, heads off the Bourdieusian slippage into political pessimism" (p. 18). In another article, Lovell (2003) argues that the resolution of the structure-agency paradox lies in shifting the search for transformative agency from the narrow confines of individual action to an examination of social interaction. Lovell examines Butler's analysis of the famous moment in Montgomery, Alabama, 1955, when Rosa Parks refused to give up her seat on the bus to a white passenger. Lovell brings into focus the many actors whose decisions and actions resulted in this being a transformative moment. These included the selection of Parks and this specific incident (which was only one among many incidents of civil disobedience at the time) by leaders in the civil rights movement as one around which they would rally, as well as an increasing resistance among the white population to 
changes taking place in racial relations. However, while she advocates for seeing groups (rather than individuals) as the sites of positive social change, she also notes Butler's concern that collectivities form new structures that can try to control or limit agency and attempt to redraw the boundaries of social inclusion/exclusion.

The positioning of McNay is also challenged by Adkins (2003) who contends that McNay may be overestimating opportunities for gender detraditionalization. This is because McNay accepts Bourdieu's concept of 'critical reflexivity' (critiqued by Alexander) which suggests that social agents can stand outside their habitus. Adkins argues that the current reflexivity in gender may not indicate gender detraditionalization but only "new arrangements of gender" (p. 34). Adkins does see potential within Bourdieu's work. She argues that Bourdieu assumes a complete alignment of social norms into the habitus. In not allowing for ambiguity in individuals' incorporation of social norms, he misses an opportunity for individual agency. Adkins contends that this is the core of the disconnection between Bourdieu's theory of practice and his theory of social transformation. Social instability can emerge from the incomplete incorporation of norms by individuals. An acknowledgment of the existence of internal ambivalence shows another way that the habitus can be seen as a site of change as well as stability.

Additional insight is provided by Steph Lawler (2004), who argues that Bourdieu's approach makes visible how inequalities can circulate both on the material level and the cultural. And she comments on Bourdieu's perspective on the power of social structures:

It is clear that Bourdieu... sees resistance going on alongside domination (Bourdieu 2002, p. 80). It is not that people lack agency: rather, there is no 'innocent' position: no resistance that is not in some way complicitous with power (cf. Bar-On, 1993). The complex relationships between habitus and fields may well lead people to behave in ways that are not considered 'progressive'. 
This is not because they are 'lacking' in any way, but precisely because 'people are not fools"' (p. 122).

Lawler points to the complex relationship between self-interest and progressive ideals and behaviours and the delicate balance maintained by those of us working toward these ideals. She also speaks to our need for a community to speak to and to work within.

Bourdieusian feminists are finding, in the work of Pierre Bourdieu, tools for explicating and moving forward on some key sociological and epistemological issues. The concept of a reflexive habitus allows us to avoid the oppositions of dominance and resistance without embracing the reflexivity theorists' disembodied agent who is solely responsible for her or his own life story, or eliding instabilites in social structures with progressive social change. The reflexive habitus supports an analysis of how the past is brought into conceptualizations of the future, affecting our ability to imagine transformational change below the level of conscious decision.

Bourdieu illuminates how difficult it is to do truly emancipatory scholarship that does not emerge from our own interests, work that does not perform symbolic violence through complicity with dominant, or progressive, ideologies. This stance is in alignment with feminist epistemologies which explore issues regarding representation emerging in feminist research with women (Alcoff \& Potter, 1993; Doucet \& Mauthner, 2006; hooks, 2000; Sokoloff, 2005). Feminist efforts in research with women have sought to reduce power differences, identify the social location of the researcher, and understand women as agents of change as well as victims of oppression. Through this work, a rich discourse on reflexivity and accountability has developed.

Feminists have also engaged with issues regarding how we study men. bell hooks (2004) argues that feminists have avoided talking about "men's longing for love." She 
claims, "This is the longing feminist thinkers must dare to examine, explore, and talk about" (2004, p. 5).In 2006, Lois Presser notes that feminists researching women who have used violence generally address the social context of the offending but have not made a practice of this when researching male offenders. She argues that feminist researchers "should also expose the marginalization of those violent male subjects who speak to us" (p. 2068). Doucet and Mauthner (2006) identify remaining epistemological challenges for feminist researchers as including “making sense of, and theorizing, men's experiences" (2006, p. 42). Since these publications appeared, there has been much progress in this area. A powerful example is provided by the fifth annual Because I am a Girl - the State of the World's Girls report, which is subtitled, What about the Boys? (van der Gaag, 2011). This report accesses a wealth of feminist (and other) research to explore the social context of boys' and men's gendered experience. Other scholars are exploring the performativity of feminist narratives of men which, for example, emphasize the power and violence inherent in white masculinity, while neglecting questions relating to the positioning of the feminist researchers, including their whiteness (Eriksson, 2013).

\section{THEORIZING FEMINIST VAW KNOWLEDGE PRODUCTION WITH BOURDIEU}

In the Logic of Practice (1990), Bourdieu unpacks the dilemmas for research aiming to investigate social practice. He begins with a critique of theoretical reason, first analyzing the objectivist and then the subjectivist research traditions and finally offering a logic of practice to guide researchers in avoiding the pitfalls of each. He analyzes the tendency of theorists in the objectivist tradition to think that the models they create actually represent all of reality, arguing that this tendency may even go so far as a misapprehension of the model as revealing a rule of behaviour - in other words eliding 
the model with the reality being studied. In this way a pattern that is recognized in the social world - a regularity that is observed - can unintentionally become, within theory, a rule that governs (Bourdieu, 1990, p .39). Over the past several decades, an awareness of the impact of the research being done in creating the reality that is being revealed has become much more figural within the social sciences and specifically among critical and feminist theorists. However, even among these groups, Bourdieu's concern still has relevance in pointing to the dangers of attachment to our creations. When we experience our theoretical model as a powerful tool for explicating reality (and of course we do!), we can be led to seek to fix the truth within the limits of the knowledge revealed by that model. In doing so, we actually can lose a necessary connection to the complex and changing nature of a social reality which can never be fully theorized or understood.

In addressing the gap which always exists between the model and the reality it purports to represent, Bourdieu points out that a putatively objective explication of reality is actually an intervention: "Simply by leaving untouched the question of the principle of production of the regularities that... [the researcher] records ... objectivist discourse tends to constitute the model constructed to account for practices as a power really capable of determining them" (1990, p. 37). Bourdieu also discusses the separation of the researcher from the research participants; they are each making a different use of the social object. Researchers privilege 'thinking about' and interpretation of the social world and place less value on practical knowledge which cannot be structured into a model. Bourdieu discusses the need to address the "partial, self-interested character of practical knowledge... [and] the discrepancy between the practically experienced reasons and the 'objective' reasons of practice" (1990, p. 36). The creation of a research model designed 
to extract the logic from the practice being studied must somehow account for or, perhaps more accurately, be able to work with, a certain kind of fuzziness, and sometimes actual contradiction, in the logic of practice. Of course, research is also practice; we must also understand and account for our own interests and inconsistencies. This situation presents us with a double bind; we need to use the intellectual instruments of scholarly tradition, but the use of such instruments can lead to "reproduction of the scholarly doxa" (Bourdieu \& Wacquant, 1992, p. 248, emphasis added).

Bringing an awareness of these two gaps - that between the theoretical model and the physical and social reality and that between the logic of the researcher and the logic of practice - to my research has been useful on two levels. The first relates to my own research design, which is presented in chapter three. The second is in the analysis of the practice of my research participants. I am seeking to understand the theoretical models associated with my research object and how these models have developed and have been used in responses to male perpetrators of intimate partner violence in heterosexual relationships. I have needed to remain aware of the gap between both my model and the reality of my research participants and the gap between their model and the reality of the situation of IPV.

Looking at VAW theory in light of the above, one can see that part of the VAW dilemma has been that the foundational concepts are a product of a time in which 'objective' renditions of the world were accepted as exactly that. As expectations within the social sciences have changed, slippage from seeing a pattern of regularity to the naming of a rule that governs has been recognized as problematic. Particularly within qualitative, critical and feminist scholarship, complexity and fluidity are now 
acknowledged as important features of any social system. VAW theories have changed with these developments (as indicated by the current use of 'theories' in plural), with ongoing and increased research and specifically with increased access to voice and power by a diversity of women along with an increasing attention to men's lived experience. VAW theories have changed with developments and increasing fluidity in gender relations and gender identity. They have changed in response to broader developments in social sciences and in society. But VAW theories are still grounded in the attempt to describe and critique an objective reality of violence against women - a 'reality' which is, rather, a theoretical concept. This concept was created against prevailing patriarchal theoretical conceptualizations. It was, and remains, powerful in revealing and describing an important social reality that was neglected in those renditions. And in its turn, it focuses us on what it reveals, thus concealing other aspects of what is happening on the ground. Clement and Shalla (2007) argue that all "theories reveal and conceal; that is, theories signify some features as more important than others, by identifying priorities and orders to relationships" (p. 33). It remains important theoretically to remember the gap between our attempts to theoretically grasp reality and the phenomenal world.

Bourdieu (1990) also critiques subjectivism. He argues that focusing on agency or volunteerism as the basis of practice means that we see each decision as disconnected from the rest of our lives. As part of this critique he discusses rational actor theory. $\mathrm{He}$ suggests that this theoretical framework oscillates between a presenting consciousness which is free at all times in its choices and an intellectual determinism. For if people are at all times acting out of rational processes that conform to objective realities, then there 
is only one objectively rational outcome for action. Variation from this course can be identified as irrational, or wrong, or even evil.

Bourdieu maintains that people do not act intentionally from a conscious and objective evaluation of the situations around them. He insists that we act from dispositions built upon our past, arguing,

... how can one fail to see that decision, if decision there is, and the 'system of preferences' which underlies it, depends not only on all the previous choices of the decider but also on the conditions in which his 'choices' have been made, which include all the choices of those who have chosen for him, in his place, pre-judging his judgments and so shaping his judgments. (1990, p. 48).

In this context, Bourdieu also examines Pascal's analysis of the nature of belief. Bourdieu argues that Pascal's identification of the foundation of belief as 'an act of will to believe' makes belief voluntary and arbitrary. The problem here is that one can't both believe that one believes and know that one made a decision to believe. Belief, says Bourdieu, comes with the "illusion of [the belief's] innateness" (1990, p. 50), rather than with awareness of the conditioning from which the belief arises. This raises an interesting aspect of habitus. If we integrate the conditioning we experience as beliefs, we can see one aspect of the inertia of doxa. We believe because we have been conditioned to believe. But we forget the conditioning and are left with the belief that seems "logically necessary and sociologically unconditioned" (1990, p. 50). When others question our doxa, we experience a questioning of our core being - of whom we are - rather than of who we have been conditioned to be. Researchers and practitioners need to belong to a community in order to do the work of believing. Belonging, Bourdieu says, requires both faith or belief and training. In the case of violence against women, questioning women as the victims of IPV, as is done by gender parity researchers and practitioners, may be experienced by some VAW adherents as both an identity challenge (a challenge to 
beliefs) and a challenge to the fact of violence against women in a patriarchal world (a challenge to training).

How do we take into account these tensions between conditioning and choice in developing a social science research project? Bourdieu argues that practices must be understood in terms of external constraints experienced by the subject in light of their personal dispositions. As well, we need to account for the fields of struggle and the forms of capital available to those we research. Practices can be seen as strategies in so far as they are adopted to increase various forms of symbolic and cultural capital in the context of predictions of the future based on past experience and current constraints. This theoretical work is what the concept of habitus is designed to do. "The habitus contains the solution to the paradoxes of objective meaning without subjective intention" (Bourdieu, 1990, p. 62). The habitus is a product of history, generating practices which undergo sedimentation processes and generate more history, thereby keeping history alive in the form of dispositions that allow for an infinite variety of responses even within the socially structured field in which it exists (Bourdieu, 1990).

Exploring practices of work to reduce and prevent intimate partner violence in light of this conceptual framework allows us to see how the experiences of particular groups leads to the creation of sets of beliefs (based on past experience) and the anticipation of particular futures (based on beliefs resulting from past experience), which Bourdieu sets out as the development of doxa. Before I explore the process of this development I will apply the concepts of field, habitus and doxa to my research design. 


\section{THE THEORETICAL FRAMEWORK FOR MY RESEARCH}

I begin the explication of my theoretical framework with a definition of the research object, Bourdieusian field, habitus and doxa. My research object for this dissertation is the social construction of feminist VAW work relating to intimate partner violence and more specifically to male perpetrators of violence in heterosexual relationships. As discussed above, Bourdieu argues that we must conduct a relational and historical investigation of the research object - in other words we must investigate the research object in the field (in the Bourdieusian sense) in which it exists. The selection of the construction of feminist VAW work on intimate partner violence as the research object for this project generated a field for investigation that included both feminist VAW and non- VAW approaches to reducing and preventing intimate partner violence from the mid-1950s to the current time. This positioning has proven to have analytical traction in two specific ways. First, I found it an entry point to exploring the feminist VAW habitus and doxa. In engaging analytically with positions both within and outside feminist VAW doxa, I could more clearly see the habitus and doxa of each in contrast to the other. Further to this, I could see current shifts taking place within feminist habitus and doxa, some of which are related to the integration of non-feminist theoretical and practical knowledge.

A second consequence was that I was exploring only one aspect of the feminist VAW habitus - that dealing with intimate partner violence - to the neglect of other forms of violence against women. Some of my interviewees found this to be an uncomfortable fit for them as their VAW doxa suggested that it would result in an inadequate analysis of the social issue and the consequences for women. However, I found this disruption in the 
habitus forced more specificity in the conversations with my interviewees and in my reading of the feminist VAW literature. Unspoken assumptions were brought to the surface as we tried to name the edges of VAW in the context of intimate partner violence only and inclusively. For example, it became clear that some interviewees included only coercive controlling violence in their definition of intimate partner violence while others included coercive controlling violence as well as fighting between partners. In other cases it was possible to see the focus on relationship violence between men and women with a corresponding neglect of violence within same-sex relationships. It also served as a reminder for me that the object of my research was not VAW as a social issue but rather the social construction of VAW.

Bourdieu (1992) describes the edge of the field as where influence from within the field ends. I defined the field which I investigated for this project as: the field of work to end intimate partner violence with a focus on the 'care' side rather than the 'control' side of this work. Within the literature there is a tremendous amount of research articulating a clear polarization of feminist VAW and non- VAW, or gender parity, approaches to analysing the issue, to the point that one researcher suggests, "no other single question is as important to identifying one's theoretical and political position among those who are concerned about intimate partner violence" (Hamby, 2009, p. 24). This polarization was also apparent within my interviews and focus group, although I found within my primary research that the habitus and doxa of VAW and gender parity were having a greater influence on each other than is presented in much of the literature. Bourdieu notes that competing doxa in a field tend to develop as antagonistic pairings that focus attention on the pairing, polarizing the available doxa and excluding other possible framings of the 
issues. The feminist VAW and gender parity positions exhibit these characteristics, providing evidence for the appropriateness of defining these two doxa as being part of the same field. Following from this, the VAW and gender parity approaches are defined as forming subfields to the field of work to reduce and prevent intimate partner violence. The definition of these terms and their relationships is conditional and relational. For example, in another project with different research questions, feminist VAW approaches could be the field and work to reduce and prevent IPV the subfield.

As will be discussed more fully in chapter four, the feminist VAW subfield developed against patriarchal articulations of appropriate responses to IPV and within the context of second-wave feminism. The development of a habitus concerned with addressing the oppression of women allowed feminists to see wife abuse through a different lens than that of earlier patriarchal articulations of the causes and correctives to violence in intimate relationships. The feminist habitus began with a commitment to women's safety, a concern previously neglected. This different starting point made common-sense patriarchal assumptions regarding wife abuse visible as (inaccurate) assumptions, and, through their very visibility, open to examination and challenge. A gap could be seen between (i) the feminist habitus which named women's experience of structural oppression within patriarchy and, (ii) patriarchal doxa which suggested that wife abuse represented a deviation from patriarchal values by an individual (often an individual who was being 'provoked' by his female partner). As presented earlier in this chapter, the experience of a gap between the doxa of a field and the habitus provides one opening for human agency in the interruption of the doxa of that field. The identification of this particular gap generated an opening for a redefinition of violence in intimate 
relationships and what would constitute appropriate work to reduce and prevent that violence, supporting the development of the Bourdieusian feminist VAW subfield of work to reduce and prevent intimate partner violence.

In developing this new subfield, feminists were rebutting the problematic assumptions of patriarchal approaches to the issue regarding female victims and male perpetrators. Feminists argued that: (i) abusive husbands were not deviant from patriarchal values and norms but rather were enacting patriarchal values and norms, (ii) abusive husbands were not mentally ill or out of control; they were choosing to exercise patriarchal privilege and to use their power and capacity to control their wives, and, (iii) violence against women was not a personal problem; it was a social issue rooted in the use of male power and control (Dobash \& Dobash 1979; Schechter 1982). These understandings comprise three key elements of the doxa of the feminist field of work to end violence against women. And, while there are still huge gaps in services, VAW doxa have been powerful in "gaining community and government recognition [in Western countries] of men's violence against women as a social problem" (Pease, 2008, p. 5) as well as in the concomitant establishment of social interventions to support women and children fleeing violence. The processes by which this has happened will be discussed below.

The doxa of the gender parity field emerged later and as a rebuttal to feminist VAW doxa. Many of the early researchers in the gender parity field began their research with the goal of supporting work to end wife abuse, scholar Murray Straus (1977) being a prominent example. The identification of the social structural oppression of women in VAW doxa was originally compelling to these researchers. However, they came to the 
issue with different methodological approaches and theoretical frameworks and generated data that they experienced as confounding VAW doxa. These differences in position and positioning led them to a different analysis and eventually to doxa explicitly designed to challenge the veracity of VAW doxa, thus inculcating a new subfield of work to reduce and prevent intimate partner violence. In the growth of the gender parity subfield, we see an example of how experiences that challenge a group's doxa and habitus can lead to the emergence of a new subfield and corresponding doxa and habitus.

\section{The development and "stickiness" of the female victim and the male perpetrator concept}

In working to support the claim that women are victims who deserve help and men who use violence in their relationships are perpetrators of a crime that requires social intervention, feminist VAW scholarship and practice developed a doxa sustaining a feminist VAW subfield within the field of work to reduce and prevent intimate partner violence. I explore this development in chapter eight using the theoretical framework of Beverly Skeggs (2004), which I introduce below. In tracking these processes of knowledge production, I am seeking to understand both the power and durability of these doxa and the current beginnings of transformation in feminist VAW thinking regarding men who use violence in their intimate relationships. Skeggs shows us the processes through which particular categorizations develop, and develop power, and in doing so suggests what must be undone in the transformation of them. Ahmed's (2004) explication of stickiness is also relevant here in understanding the durability of doxa and specific blockages relevant to this transformation. 
Beverly Skeggs is a Bourdieusian feminist who, in Class, Self, Culture (2004) explores "the conditions of possibility that make class" (p. 2). This book is about theory; as Skeggs herself says, "it is not about how class is lived" (p. 2). While Skeggs is concerned with articulating the processes by which class is generated, she opens the possibility of her framework being used to explore how other social issues are constructed, devoting one section of her book to an analysis of feminist theorizing using her framework. Skeggs identifies a need to "think how bodies are inscribed simultaneously by different symbolic systems; how inscription attributes difference in how we learn to interpret bodies through the different perspectives to which we have access" (p. 3). These processes of inscription have been active in the field of work to reduce and prevent IPV, as is explored throughout this dissertation. Skeggs' project is ultimately about knowledge production and its relationship to power. She shows how one group can produce knowledge about another which then forms the dominant interpretation of the inscribed group. Skeggs states that her interest is in making the perspectives taken in knowledge production "obvious and apparent, as working in the interests of particular groups" (p. 7). It is this 'making obvious and apparent' that I wish to do regarding the theorizing of intimate partner violence and the practice of work to reduce and prevent IPV by the various groups involved. However, in doing this work, I must also maintain an awareness of, and explicate the aspects of strategic positioning that are not within the awareness of the individuals involved. As well, we must remember that the workings of interests and altruism among the various groups involved in the field are complex and involve processes of sedimentation of belief as well as reflexive processes 
that include ambiguous relations to, and imperfect understandings of, the field and subfields.

As is traced in the literature analyses of chapters four and five, feminist VAW classifications of men in relation to IPV have changed over time. While early on, men appear only as potential perpetrators, more recent versions have presented men as allies or more recently still, as potential victims (Jewkes, Flood \& Lang, 2015). Ahmed (2004) can help us understand both the durability and the fluidity inherent in these shifting characterizations, through the concept of stickiness. Ahmed describes stickiness relationally as "an effect of surfacing, as an effect of the histories of contact between bodies, objects, and signs" (p. 90). She suggests two ways that signs become sticky. The first is "through repetition: if a word is used in a certain way, again and again, then that 'use' becomes intrinsic" (p. 91). The second way that signs become sticky is through contactful relations. Without contact nothing can stick. The types of relations and the power dynamics among those relations determine what sticks to whom. The repeated use of such signs both develops and hides their association with other concepts, often negative, that must initially be explicitly invoked. Using the concept of stickiness, we can address questions such as, 'How did representations of men gain their stickiness? What has led to them changing? What is revealed about changes in the VAW perspective through an analysis of the classification of men over time?' Ahmed argues that the loss of an object of critique (such as 'men as perpetrators') or an object of attachment (such as 'woman as victim') is “indicative of ... [feminist activism's] capacity to move, or to become a movement... [and] opens up possibilities of action that are not constrained by what we are against in the present" (2004, p. 176, emphasis in original). A relational 
analysis, which shifts from focusing on the properties of groups of people to that of the responses to, or relationships among, groups of people, allows these possibilities to be explored. Skeggs' work supports this analysis.

Skeggs' (2004) framework has four components: inscription, value attribution, perspective-taking, and institutionalization. With inscription, she shows how class is not a pre-existing, objective category, but rather a knowledge category resulting from dynamic processes, being "produced through conflict and fought out at the level of the symbolic... Class must always be the site of struggle and re-figuring precisely because it represents the interests of particular groups" (p. 5). Bodies are inscribed with symbolic characteristics such as class, gender and race, in an ongoing and self-reinforcing process of continuous production, which attributes positive values to some and negative values to others. The process of value attribution impresses upon individuals of all classes their value and positioning in society. And this positioning is done through a process of perspective taking. Skeggs notes that "taking a perspective means taking a position on knowledge. It usually invokes some form of decision (this perspective or that one?) and is thus implicated in judgment" (p. 7). And finally, the institutionalization of values and perspectives reflects and supports these values and perspectives as legitimate in the social world. Below I explore each of these processes and their application to my research.

Inscription is a social operation involving the embodiment of certain values and requiring a continuous exercise of symbolic power. When looking at processes of inscription within a knowledge production context, a Bourdieusian framing would suggest an always and ever present strategic positioning among the actors in relation to each other. Patriarchal framings of wife abuse saw it as a private trouble and the solution, 
often, as better behaviour on the part of the wife. Feminists sought to trouble this account through the articulation of the structural oppression of women in patriarchal societies and women as the primary victims of domestic violence. The relevance of racialization and colonization, ableism and other structural oppressions has also been asserted in the feminist subfield and the concept of victimization itself has been contested and nuanced. Similarly, gender parity scholars and practitioners make knowledge claims that counter feminist VAW understandings, saying that women and men are equally violent. Using Skeggs' model, we would expect to see the exercise of symbolic power in the expression and maintenance of these claims, and this use is visible in the literature and interviews for this study.

Feminist scholars and activists have explicitly sought to intervene in social processes of value attribution between men and women. Shifts that were inculcated by feminist theory and activism include assigning a negative value to men who control the behaviours of family members, and a positive value to women having an equal role in public and private life. In terms of intimate partner violence feminist VAW scholars and practitioners successfully gave social value to conceptions of justice in which men should not control or abuse their female partners. Part of this work has been the naming of women as the victims and men as the perpetrators of domestic violence. In The Battered Woman and Shelters: the social construction of wife abuse, Donileen Loseke (1992), notes that interventions into the "empirical reality that women are the victims of violence" (p. 10) are needed and important. However, she also shows how our interventions have led to the social construction of wife battering. She traces the discursive creation of the violent male perpetrator whose violence is "continuing, 
escalating, and unstoppable" (p. 19). This creation has been a resource with value for the VAW movement, resulting in an extensive network of shelters and rape crisis centres (although it should also be said that these resources are far from fulfilling the need).

Perspective-taking is the third process in Skeggs' (2004) framework. Skeggs draws on Bourdieu in discussing how perspectives are built upon in the construction of knowledge. She also notes the significance of practice and practical knowledge in the development of theoretical frameworks. An example within VAW can be seen in the historical importance of consciousness-raising groups as a method for exploring and developing theoretical understandings of women's oppression. Consciousness-raising groups both generated insights and confirmed theoretical postulations regarding violence against women and intimate partner violence more particularly. This interweaving of theory and practice ensures that the theory is seen as revealing a truth with the "particular resonance [needed] to be effective; that is, it ... speaks to [a specific group of] people and makes sense" (Skeggs, 2004, p. 45). The classifications generated through theory, such as the 'female victim/survivor and the male perpetrator', use inscription and valuing to "confirm the perspective of the classifier" (p. 17). The knowledge created through perspective-taking fixes the classified in place.

However, the classification process can be turned back upon the classifiers, allowing the classifiers to be classified through the categories and frameworks they design and use to interpret others. While feminist scholarship (Das Dasgupta, 2002; Dunn, 2005; Sokoloff, 2005) has nuanced VAW understandings of women's victimization, the early foundational claim of women as pure victims who are not violent (Loseke, 1992) continues to be a source of intense debate and identity claims among 
those who work to reduce and prevent IPV: whether one aligns with the classifications developed within feminist VAW frameworks has become a significant indicator of positioning.

Processes of inscription, valuing and perspective-taking result in the institutionalization of some perspectives and values at the expense of others through the struggle between various doxa in the field. Institutionalized perspectives gain material support, but it is in the conversion to the symbolic sphere that resources (including economic, cultural and moral) become implicated in the use of power. As Skeggs argues, "Legitimation is the key mechanism in the conversion to power" (p. 17). In making this connection, Skeggs (2004) situates her framework within the concept of symbolic economy developed by Bourdieu. She notes that Bourdieu's use of the term 'economy' includes the "organization of the symbolic, which enables exchange and the attribution of value across a range of fields" ( $\mathrm{p}$.15). In the symbolic economy it can be seen how "relative positions and the relations between these positions constitute forms of power, enabling bodies to move in social space" (p. 16, emphasis in original). Loseke (1992) observes the material impacts on women of the institutionalization of wife abuse in the form of shelter services. These include, for example, a concern regarding who is, and who is not, recognized as a victim because they do, or do not, conform to the public image which has been created. In this example, symbolic knowledge directly determines which bodies move into shelters and which do not. Whether perspectives gain legitimacy as dominant categorizations or are excluded is determined through an exercise of both morality and power. It is important to remember that the dominant symbolic both contains and leaks energies "of accumulation, loss and practice through affectivity, 
dispositions and characteristics" (p. 17). The need for these processes of inclusion and exclusion means that work is required to maintain both dominant and oppositional symbolic systems.

Skeggs (2004) discusses feminism explicitly in terms of engagement in these processes of social construction. But she only addresses feminism engaging in these processes as the underdog - arguing, for instance, that our willingness to embrace identity politics leads to a focus on our oppression and does not provide an avenue toward freedom. Within the field of work to reduce and prevent intimate partner violence, which perspective has dominance and which is the underdog is contested. In a somewhat strange twist of power relations, the various groups in the field each claim they are in a dominated position even while they struggle for dominance. Exploration of this situation using Skeggs' framework will provide some clarity regarding these claims.

\section{CONCLUSION}

Through a Bourdieusian lens, all positions in the field of work regarding the reduction and prevention of IPV can be seen as an unavoidable result of the social and political positions and positioning of the researchers and practitioners (Accardo \& Bourdieu, 1999). Bourdieu's approach would suggest that understanding what is happening at the level of the work being done is essential to understanding the issues on the ground. Currie (1990) proposes a reflexive examination of feminist ideology in order to ensure that we do not compare feminist ideals to the real effects of current practices in the justice system. Her proposal is in alignment with Bourdieu's approach. This approach also reminds us that all scholars of IPV, feminist and non-feminist, are explicitly working toward the reduction and prevention of intimate partner violence, although there is dissent 
in the field about what constitutes a helpful intervention and whose work is or is not helpful. The work of Bourdieu and Bourdieusian feminists helps us to understand the socio-historical development of the field of work to reduce and prevent intimate partner violence as explored in this dissertation. The use of Bourdieu's reflexive sociology to address questions of structure and agency and epistemological pairings reveals the necessarily relational, and sometimes oppositional, character of the field. Skeggs' framework helps us gain an processes of social construction 1that generate changes in the field over time.

Bourdieu is adamant that research, theory and method must provide an integrated vehicle for research undertakings. The structure of a dissertation demands some artificial separation of theoretical and methodological considerations, and this chapter focussed on outlining the theoretical framing of my research, particularly in light of Bourdieu's reflexive sociology and other theorists engaging with it. Chapter three gives attention to the methodological aspects of my research study. 


\section{Chapter 3}

\section{Methodology}

What I have called participant objectivation... is no doubt the most difficult exercise of all because it requires a break with the deepest and most unconscious adherences and adhesions, those that quite often give the object its very "interest" for those who study it - i.e. everything about their relation to the object they try to know that they least want to know (Bourdieu \& Wacquant, 1992, p. 253).

\section{INTRODUCTION}

My interest in this area of research was motivated by concerns that came up for me in my Masters study on 'involved fathering.' During this time I had found, and put aside for later exploration, a number of articles which made conflicting knowledge claims about 'what is going on' in intimate partner violence. I was confused by these claims and also felt some sense of responsibility toward how intimate partner violence was framed within feminist work on the issue. I brought my question regarding what was going on to my PhD project. The academic expression of my question evolved during this project but the essential focus on exploring what is going on in work to reduce and prevent intimate partner violence remained. Over the course of this research, my understanding has moved from seeing a variety of dichotomies, paradoxes, conundrums and opportunities to seeing an intertwined and evolving set of knowledges owned (and sometimes disowned) by interrelated and evolving sets of people. In this chapter, I will first address the contribution that the reflexive sociology of Pierre Bourdieu has made to my understanding of how to approach this project on a methodological level. I will then present a discussion of my research methodology, illuminating the research process, describing the methods used in the study and discussing the data analysis process. 


\section{THE METHODOLOGY OF REFLEXIVE SOCIOLOGY}

For Bourdieu, the design of the research project involves the construction of the research object, the theoretical framework and the methodology in an iterative process. The research design "is accomplished little by little, through a whole series of small rectifications and amendments inspired by what is called le métier, the 'know-how,' that is, by the set of practical principles that orients choices at once minute and decisive" (Bourdieu \& Wacquant, 1992, p. 228). As I found out through engaging in this process, a change in any one will require corresponding change in the others.

\section{The construction of the research object}

Bourdieu insists on thinking relationally about the research object. The research object is investigated in terms of (i) its historical and social construction, and (ii) structural homologies among agents and institutions within the field and with other fields. Bourdieu declares that the construction of the object is "the most crucial research operation and yet the most completely ignored" (Bourdieu \& Wacquant, 1992, p. 224). Three significant processes in the construction of the research object are: seeking a point of rupture, exploring radical doubt and engaging in participant objectivation. My research object was defined in chapter two as the social construction of feminist VAW work relating to IPV; here I am explicating the Bourdieusian reasoning behind this definition.

When seeking an appropriate object by which to investigate a topic, we want to look between and among the groups that might stand out as deserving of study, such as victims of partner abuse or feminists working to end VAW. Bourdieu suggests that one "takes as one's object the social work of construction of the pre-constructed object." $\mathrm{He}$ continues, "That is where the genuine rupture is" (p. 229). The rupture Bourdieu speaks 
of is that between the researcher's common sense understanding of the world which emerges from being part of that world and the researcher's orientation to their research design. The researcher must be willing to experience such a rupture or she or he will reproduce previously socially validated understandings of their research topic. This is particularly important when undertaking research in a topic area in which the researcher has already engaged and has adopted a particular habitus and its doxa, as is often the case for those taking a social justice approach to their research. However, this is also perhaps the trickiest positioning from which to understand what constitutes a rupture. Are we not already in rupture when we are taking a critical stance to the social world? Bourdieu would say not. We must be willing to make a further rupture from the critical stance with which we are familiar. The point of rupture then, is where I, as a researcher, move beyond introjecting generally held social categories (even critical categories) to exploring how these categories came to be.

The researcher finds the point of rupture through the exploration of "radical doubt." To move beyond an acceptance of common-sense constructions of categories requires that the researcher question categories that explicate legitimate problems within the social sciences as well as more generally in the social world. Bourdieu argues: "In the social sciences... epistemological breaks are often social breaks, breaks with the fundamental beliefs of a group and, sometimes, with the core beliefs of the body of professionals, with the body of shared certainties..." (Bourdieu \& Wacquant, 1992, p. 241). Putting radical doubt into practice presents us with a double bind: how to use the scholarly tools that allow us to think scientifically and yet to accomplish the necessary epistemological break. Bourdieu suggests that this might be best attained by "people who combine an advanced 
mastery of scientific culture and a certain revolt against it, or distance from... the socially dominant discourse in sociology" (Bourdieu \& Wacquant, 1992, p. 249). For those critiquing critical theory and practice, radical doubt provides a vehicle for naming what one might call a sympathetic distancing from one's topic that can provide one motivation for engaging in research about critical theory and practice.

Finally the construction of the object demands participant objectivation. To achieve this objectivation, it is not enough to explore the relationships between the views of the various participants. These views must be brought into focus through a structural analysis of the field in which they exist. The researcher examines the "nexus of institutions whose effect is to render acceptable the gap between the objective truth of the world and the lived truth of what we are and what we do in it" (Bourdieu \& Wacquant, 1992, p. 255). Addressing the gap between experience and structure allows the researcher to address the subjective and objective truths which together tell a larger truth about the social world under investigation. The process of participant objectivation provides an accounting of the fit between the habitus of the research participants and the field being investigated.

Bourdieu notes that the researcher must account for their own position and investment in the objectivation of the field. He argues that a sociological analysis, particularly one attempting to analyse a field in which the research participants are making their own knowledge claims, requires the researcher to let go of (a possibly inadvertent) desire to secure "victory" (Bourdieu \& Wacquant, 1992, p. 259) for her or his own point of view. The mastery of participant objectivation can only in this circumstance be gained to the degree that the researcher is able to stand aside from his or her own interests in the outcomes. 


\section{Connecting the theoretical framework and methodology}

In Bourdieu's reflexive sociology, insights regarding the research object are achieved through a relational analysis that accounts for the object's position and positioning in the field in which it resides. Constructing the field is thus a crucial next step in designing the project. Bourdieu advises three steps to an analysis of the field. The first is to "analyze the position of the field vis-à-vis the field of power" (Bourdieu \& Wacquant,1992. p. 104). This would involve looking at the field under examination in terms of the position it occupies in relation to the field of power in society. Is it dominated, dominant, or, more likely, is the positioning a complex mix of several positions in relation to other fields? The second step is the mapping of "the relations between the positions occupied by the agents or institutions who compete for the legitimate form of specific authority of which this field is the site" (1992. p. 105). Since the field is always the site of struggle for power, understanding where and how power currently resides, and who are the contenders in the field, as well as how they are constrained, and who is excluded, is a significant step to being able to provide an explanation to address the research question. The third step is the analysis of the "habitus of the agents, the different systems of dispositions they have acquired by internalizing a determinate type of social and economic condition" (1992, p. 105). Examining the habitus of the agents in the field provides the opportunity to understand their actions in relation to the field of power, how they position themselves to take advantage of any possible gains in power, and what the potential is for the actualization of their goals.

In The Weight of the World, Accardo and Bourdieu (1999) speak of how to research antagonistic perspectives. This is a place where participant objectivation becomes an art. 
Accardo and Bourdieu argue that "simple juxtaposition" (p. 3) is a starting point for this kind of investigation. In doing this work,

we must relinquish the single, central, dominant, in word, quasi-divine, point of view that is all too easily adopted ... We must work instead with the multiple perspectives that correspond to the multiplicity of coexisting, and sometimes directly competing, points of view" (p. 3).

The researcher must be able to present each view as inevitable in its existence by making a "systematic search for the causes and reasons ... [people] have for being what they are" (p. 1). It is through articulating these reasons that we can transcend, or at least expand, our own partial view of the field.

\section{METHODOLOGY}

In my primary research, I used multiple qualitative methods in a sociological ethnographic approach. Qualitative research projects such as this one provide the opportunity to generate thick descriptions of the study area. Transparency in the methods, retention of materials, and documentation of the process (including conceptual developments and dead ends, the development of the coding scheme, and other events along the way), as reported on in this chapter demonstrate the validity of the study (Schofield, 1993; Stake, 2000). Ongoing documentation of the process also contributes to the substantive validity of the findings in that the documentation process helps maintain coherence and consistency in the process.

This project involved the study of a social issue whose very name and definition are contentious and provocative in both the public sphere and among those working on the issue. The complex nature of the questions I wished to explore demanded a qualitative research design with a strong connection between theoretical and methodological framings such as that provided by Bourdieu. This approach also supported relational 
thinking, a needed orientation in explicating knowledge production on this field. Finally, Bourdieu's approach also enabled me to acknowledge and draw on my positioning as an active participant in the field while providing an ethical framing for my research activities. Bourdieu provides a map for the examination of the complex, socially constructed, power-ridden situation in which I am implicated as an actor.

\section{My process}

There was a personal journey leading to this project; one that continued throughout the project and will remain as a theme through my academic career. It has been a complex journey and I have been aware that I cannot do it justice in the space I have here. I was at first striving to tell the truth about my journey, but I have had to understand that the snippet of my dissertation explicating my process is homologous with the larger methodology of the research. I have had to select and shape the story that I hope will best reveal to my readers the necessity for this project in the same way that I am trying to show the necessity for the positioning of my research participants.

The story I will tell begins when I came to feminism in the mid-1980s, in my midtwenties. My early feminist contacts and reading explained my life experiences in ways that I had not had access to in the past. It was exciting. But this was also a time when issues with the project of articulating women's common oppression were gaining traction; I saw and experienced the implosion of a number of feminist organizations in Waterloo and Toronto over the years I lived in those places which made clear the stakes involved. In the mid-1990s, I moved to Prince Edward Island. My work at a women's centre there brought me face to face with generational shifts in feminist interests and approaches to activism. The challenges we were experiencing were significant to the 
point of threatening the sustainability of our organization unless we could address them. This was evidenced by the aging of our membership; in the ten years since the organization's opening, the average age of the membership had increased by ten years. We experienced the second-wave/third-wave articulation of these changes as a good fit for that time and place. But this understanding of what was happening also left me personally challenged - I felt that I did not fully identify with either of these groups of women. For our specific organization, there was a 20 year gap between the average age of each group and my age was exactly in the centre of this gap. I found I could really only partially understand the positioning of both the second wavers and the third wavers as we tried to work our way through the inevitable messiness of organizational change.

One of the significant changes in positioning visible between the second and thirdwave feminists regarded the role of men in feminist work. A younger volunteer, who wanted her boyfriend's help with the stuffing of the monthly mailing, ran into the belief (what I would now call doxa) of those on the board of directors that "women's space is safe space.” They did not give permission for this young man to volunteer. Another young woman, who wrote in her column (in Common Ground, our quarterly magazine) that men should be allowed to participate in certain events from which they were now excluded, was named as 'more moderate' although she was experiencing herself as 'more radical' by opposing feminist doxa. It seemed clear to me that there was a shift happening in how 'we' saw men but even as I thought I had a handle on it, a third waver would react to something I said in a way that let me know that I did not!

This project is, at one level, part of my ongoing attempt to reconcile my place in those debates. In my Master's thesis I explored feminist views of 'good' men, analysing 
Andrea Doucet's (2006) book, Do Men Mother? Fathering, Care and Domestic

Responsibility. When I realized that I wanted to do a $\mathrm{PhD}$, I knew that the topic would be feminist views of 'bad' men. An inability to reconcile feminist views of good and bad men has also led me to seek other articulations of who men are and has prodded me to ask the questions that I formed for this research. My experiences include over ten years as an occasional participant-observer within a men's rights activist community, exploration of the gender parity and intersectionality literatures, participation (actually 'lurking') on a list-serve regarding treatment interventions to domestic violence and contact with individuals whose stories of domestic violence as told to me, or as I experienced them, are not explained by VAW theory (including women's use of violence in heterosexual relationships and same-sex partner violence in my lesbian community). These experiences gave me some distance from the common-sense-ness of patriarchal control as the primary explanation for intimate partner violence.

Bourdieu argues that a break with commonly held epistemological understandings is necessary for sociological research. I found this encouraging in the face of the daunting challenge posed by my project. It also helped me understand my position as an insider/outsider: I was no longer wholly comfortable within the theoretical position on intimate partner violence posited by VAW theory as I understood it. However, I also identified issues with the gender parity stance (the prime challenger to VAW theory) in that it does not account for patriarchal oppression of women. This brought me to the exploration of structural and agency-based explanations for social phenomenon. I had learned to understand the impact of social structures through feminist and other progressive engagement. Other life experiences brought awareness of the importance of 
agency; these included growing up in a working class household where independence was valued, undertaking my personal healing journey, and my training and experience as a body-oriented therapist in the alternative healing movement.

Taking an epistemological stance of participant objectivation provided the intellectual and ethical justification for my need to examine both feminist and nonfeminist theories from the point of rupture. As noted earlier, Bourdieu says that radical doubt can best be practiced by people combining a 'certain revolt' with 'advanced mastery.' I came to my $\mathrm{PhD}$ with an internal schism regarding feminist theory that provided the opportunity for Bourdieu's certain revolt. The $\mathrm{PhD}$ process has provided the opportunity for advanced mastery and the opportunity to reconcile mastery and revolt.

As I think about the desire for reconciling my experience of 'between-ness' in PEI, I am reminded of bell hooks' (2000) Feminism is for Everyone. hooks said that this was a book she had wanted to write for twenty years and that it emerged out of the experience of those twenty years. Similarly, this project emerges from my experience of the last thirty years. Looking back is important for understanding where we are. Crossley (2001) argues that: "Habit is as essential to the movement of history as innovation and creation, since history, even the history of rapid change, presupposes the sedimentation of actions that allow them to build upon one another" (p. 116). This dissertation is my her-story of the women's movement - the one I heard about, the one I experienced and the one I hope to grow with in the future. 


\section{Developing the Research Object}

Coming from a Master's Program in Conflict Studies, my first idea had been to study the VAW and gender parity framings as two opposing versions of the truth and to seek to reconcile them. But, while I had felt the radical doubt that led me to have questions about VAW and gender parity framings, I intended to engage in a feminist analysis; this would point toward taking the VAW approach as the more truthful representative of IPV. Another complicating factor was my identity-affiliation as an activist (which has shifted over the years of this project to make room for a researcher identity). At the same time, my sociological training within the program was steering me in directions that I was struggling to integrate. Could I find some perspective from which to engage with this project that allowed me to investigate the situation without having to take a side? Participant objectivation became a useful tool here as I struggled to design an examination of the field of work to reduce and prevent intimate partner violence from a perspective that could offer some novel insights. Below is an excerpt from my research methods course paper, dated April 11, 2011:

So far working with the reflexive sociology of Bourdieu has allowed me to see my insider/outsider status as a strength. However, this 'allowing' could also end up being a challenge. Will the people involved in this work allow me to 'not choose'? Will this stance be a more difficult one in terms of completing my thesis? If I took a clear insider (to feminist VAW theorizing) stance my project would be accepted more readily by my community. This is the group that comprises my primary audience.

Deciding on 'the social construction of feminist VAW work specifically relating to IPV' as my research object has allowed me to find the rupture from both feminist VAW thinking and conflict and reconciliation theory. This finding was a process in itself. Even though I initially came to the project with an interest in violence within intimate relationships as an entry point to exploring how feminists conceptualize (bad) men and 
how that could be changing over time, it was difficult to maintain the focus on the social construction of IPV. I was aware, especially in the early stages of my work, of the tendency for my research object to shift (for myself as well as others) from 'the social construction of feminist VAW work ... relating to IPV,' to 'the work being done on IPV,' or simply, 'IPV.' I found myself thinking about IPV rather than about how IPV was being constructed. Many course corrections along the way were required to maintain my focus on this research object.

\section{Research Process}

I began my dissertation having completed two comprehensive examinations as background research. These papers explored, (i) Bourdieusian explications of social structures and agency, and, (ii) the development of VAW framings of IPV. These formed the basis for my research design even as I continued my review of the literature.

The early framing of my dissertation research proposal explored current convergences and/or divergences between feminist theoretical propositions regarding IPV and the understandings held by feminist activists and service providers. Both Currie (1990) and Smith (1996) argue for the importance of convergence between feminist theory and practice in increasing the potential of both for creating social transformation. I thought that there might be a difference between these two groups since practitioners work with the on-the-ground realities of IPV that may be messier than the reality revealed by theory. As well, their social position does not necessitate the resolution of internal contradictions in their approach and beliefs; they might be more comfortable holding internal space for conflicting beliefs. On the other hand, I also knew that working with theoretical propositions could be an instigator of change when scholars are confronted 
with paradoxes that require resolution, whereas practitioners may hold onto theoretical stances that have been long queried by researchers. The investigation of this situation would allow a reflexive examination of feminist ideology in order to ensure that we understand the real effects of feminist theories on current feminist practices (Currie, 1990) and can in turn incorporate the learnings of practice back into theory. My formal research proposal suggested that the result of the project would be "a strengthened feminist theoretical foundation regarding IPV beyond the female victim/male perpetrator dichotomy."

This all sounded plausible to me at the time, but I have found in doing this research that while positions do indeed align with positionings to a great degree, the explication of these positions and positionings is a messy project indeed. From identifying which organizations or individuals are feminist, to sorting out divergences and convergences, the neat categories of my research proposal were challenged at every stage. I eventually expanded my research subjects to include representatives of positions and positioning both inside and outside of feminist VAW doxa and to engage with a field in which VAW was a player rather than defining the game being played. This allowed me to undertake an analysis which took a more open view to the complexities that might be found.

A range of possible informants to the project were initially considered including academics, practitioners working in the field, and those who have experienced intimate partner violence. The availability of written material from which the habitus and doxa of scholars could be discerned dissuaded me from focusing on this group as research participants. I also decided not to interview people who have experienced intimate partner violence as my inquiry focused on the knowledge creation about intimate partner 
violence rather than the experience of intimate partner violence or the receipt of services. The informant group for my primary research therefore was defined as people working in paid or volunteer capacities to reduce or prevent IPV.

As I committed more firmly to a sociological analysis of the field of the work being done in this area, the goal of making a contribution to feminist VAW theorizing fell away. It was replaced with the goal of explicating the field. I have been harder pressed to define the contribution which would result from this approach. I found the questions I was exploring personally fascinating but have struggled throughout to understand the significance that could be assigned to this contribution by anyone else. The process of gaining a belief in the value of this work has been core to (the learning of) the doing of the work. The training I have received and the sense of belonging within feminist sociology gained through my experience have been integral to the development of this belief (Bourdieu, 1990). I can now assert the value of this project: an explication of the historical trajectory of the problematization of IPV in Canada through the lens of Bourdieu's reflexive sociology helps us to understand how this history has developed and to account for the multiple and contested meanings which have emerged both inside and outside of feminist framings. It also makes visible the current transformative period we are experiencing and why this moment is so difficult for those involved.

There are parts of this story that are not as well developed as they could or should be. I have had to pay ongoing attention to sorting out how an examination of feminist VAW doxa results in privileging gender because that is the context of the research object, and where my own social position as a white, (currently) able-bodied, lesbian woman was playing out in the decisions I was making in my research design. For instance, I was 
aware before I started this project how an examination of the female victim/survivor and male perpetrator concept centred my research on explications of IPV in heterosexual relationships and neglected theoretical and practical engagement with IPV in LGBTQI (Lesbian, Gay, Bisexual, Transgender, Queer/Questioning, Intersex) relationships. It also meant that I was giving less attention to searching out theoretical and practical work that engaged with structural factors other than gender - factors that are very relevant to intimate partner violence within heterosexual relationships.

While some of my interviewees had disabilities and I inquired about the impact of disabilities in my interviews, the specificity which could emerge from an analysis of the impact of disabilities is lacking. One of the significant sites of this lack lies in the very framing of the project as being about intimate partner violence. In a personal communication, the national Executive Director of the Disabled Women's Network (DAWN) stated that a significant amount of the intimate violence experienced by women with disabilities is perpetrated by caregivers. IPV perpetrated by caregivers is not within the scope of my study as it is defined.

Another place that this played out was in a neglect of more recent prevention efforts by Women of Colour in the interview selection process. I had begun my project with an interest in the growing pains in feminist organizing I had experienced between second and third-wave activists and how representations of men were changing in that shift. This meant I began with an internalized list of relevant organizations that included, as Arnold and Ake (2013) put it, "the institutions and organizations that an earlier generation of activists made familiar and iconic" (p. 559-560). For me, this list included shelters, partner abuse response (PAR) programs, as well as private practitioners. Within these 
institutional positions, I sought out workers who could speak to divergence from VAW doxa in terms of racialization, colonial practices, heterosexism and the oppressions experienced by those with disabilities. I also specifically searched beyond these groups for people working with male perpetrators from the point of view of their victimization as I explored these issues. I did not specifically look beyond these for other models of engagement. Thus, the resurgence in VAW movements of efforts by women of colour which address prevention through an analysis of the intersection of structural racism and IPV (e.g. Incite!, 2005) was not represented among my interviewees. As I became aware of this gap, I brought this perspective into the literature analysis of chapter five.

In the field of work to reduce and prevent IPV, the symbolic struggle over objectivity (Bourdieu \& Wacquant, 1992) is sometimes framed by those contesting VAW doxa as movement from feminist ideology to evidence-based research and practice. IPV has the connotation of being based in evidence rather than ideology. In hindsight, and with the assistance of my increased skill in applying Bourdieu's work, I can see that I constructed IPV as more neutral (i.e. less pre-constructed) than VAW. I named it as something real that was happening and had boundaries that could be seen. My attempts to define this 'something' clearly showed me the constructed nature of IPV.

\section{Research Methods}

My primary data collection was comprised of interviews, participant observation (conference participation, on-line list serve participation, participation in the feminist life of the university and attendance at off-campus events within the research study area), a focus group and an early findings feedback workshop. Interviews were completed with 32 research participants. Participant observation activities allowed me to engage in 
dialogue on the issues, showed me the leading edge of the research being done and gave me experience of the field. I kept a journal specifically relating to my experiences as I worked through the project (220 singled-spaced pages as of November, 2015). The focus group allowed me to engage with a group of front-line workers working within a VAW perspective. Finally, the early findings feedback workshop provided feedback on the analysis done to that point in time. Interviewees, focus group attendees and others, from the original recruitment process or met along the way, were invited to this workshop. As it happened, there was only a small amount of overlap in the individuals who participated in the interviews, focus group and feedback workshop.

I chose Ontario, and a specific region of Ontario, as the geographic area of the study as it contained the different positions with respect to VAW and IPV which I was hoping to study. The goal was to provide a study area large enough to illuminate a significant breadth of responses to IPV among service providers and activists, while maintaining the ability to provide enough depth to explore the doxa of the field and habitus of the study participants. As someone who grew up, and currently lives, in a small town I wanted to include both urban and rural communities in this project in order to respond to the interdependence of the urban and the rural. Thus, my research was undertaken in a mid-sized city and two adjacent counties.

The contained study area provides the opportunity to examine relations among the study informants. The knowledge of and interactions with each other that the service providers bring to the study provides a validity check on my findings. This same process provided an opportunity to move beyond a possible idealized presentation of the field by research participants. Seligmann (2005) notes that in ethnographic research, unlike other 
research approaches, after the researcher has been in the field for a time, she/he can ask leading questions to confirm an insight or to have it challenged. This was done in the feedback workshop.

People working on this issue were located through a web-based search for agencies, shelters, sexual assault centres, private therapists and activist organizations as well as from approaching possible participants at conferences and workshops and snowball methods. Attention was given to engaging interviewees from a diversity of social locations and perspectives on efforts to end intimate partner violence. This included searching out individuals who had worked on the issue from a VAW perspective in the past and had stopped or had left the work. A list of possible interviewees generated from this search included a variety of work locations (shelter, private therapists, PAR workers, sexual assault programs, and activists), past and present involvement, and rural and urban locations. While all of the interviewees had worked on the issue within the study area, all of them did not reside within this area at the time of the interviews.

\section{The Interviews}

Bourdieu (1999) presents a number of considerations regarding interview design and participant selection in The Weight of the World. He rejects an interviewee selection process that seeks objectivity through a random selection of participants. Instead he speaks of ensuring that the agents or institutions of particular importance within the field be represented among the interviewees. He further suggests that the structure of the relationship between the respondent and the interviewer should be one that provides for a middle way between a "total overlap... where nothing can be said because, since nothing 
can be questioned, everything goes without saying; and total divergence, where understanding and trust would become impossible" (p. 611).

The social distance between the researchers and interviewees can be negotiated if researchers can indicate that "they are capable of mentally putting themselves in... [the] place of" (Accardo \& Bourdieu, 1999, p. 612) the interviewee. Bourdieu also speaks of the efficacy of multiple engagements with interviewees and speaks of offering an “absolutely exceptional situation for communication... [that allows the interviewee to explore] worries, needs, or wishes discovered through this very articulation" (p. 614). In this way the researcher holds the space for the emergence of the interviewees' stories, helping them to "deliver up their truth" (p. 621). The resultant product becomes a joint creation. The researcher provides the intellectual framing that allows the interviewee's story to be understood in terms of "the invisible structures that organize it" (p. 617). Bourdieu does not allow the researcher to disappear behind the stories in a bid for an objective presentation. He argues that such a strategy would only result in the mystification of the decisions that the researcher must make, in such areas as, among others, the development of questions, coding strategies, and writing up of the interviews.

The above considerations provided direction for me in designing the interviews and in the selection of participants. My analysis of the field provided a mapping of the significant agents to include as interviewees. The interview guide was based on the learnings of the earlier phases of the project, and was designed to further investigate, confirm or deny, and/or extend the perceptions generated therein. The interview questions framed semi-structured interviews (see Appendix C) held with representatives from shelters, service providers working in a variety of other service delivery organizations 
(e.g. community health centres, sexual assault programs, counseling centres), partner abuse response programs and therapists in private practice.

My insider/outsider position allowed me to understand, and to ask questions that in some cases extended participants' understanding as well as my own. In my interview selection process I took the position that everyone working on this issue had a commitment to ending intimate partner violence and that that commitment should be investigated. I expected some pushback from some interviewees in my creation of a field that included both feminist VAW and non-feminist VAW work. This pushback did not occur for the most part. Instead I found support for the conversation that I wished to have. I think this was in part because of my claimed insider status in the feminist community. It was also due to an attitude among the interviewees that dialogue and discourse were important to moving the issue forward.

While I did not conduct multiple interviews with my interviewees, my attendance at events and workshops in the community where I met a number of the interviewees several times and became aware of the issues that were current for them, was helpful in establishing context for the interviews. With several of the men working in this field, phone conversations before the interviews helped to establish trust.

\section{The interviewees}

Forty people were approached to participate in the project as interviewees. Of the 34 responding to the initial email contact regarding the project only two declined to be interviewed. In both cases the contacts indicated that they are no longer working on this issue. This high rate of participation indicates a willingness in the field to engage in conversations across these divergences. 
Thirty-two people who work to reduce or prevent intimate partner violence in their paid or volunteer work were interviewed, twenty nine in individual interviews and three in a group interview. I conducted all thirty-two interviews. The interviews were semistructured and took one to two hours. As the questions included a historical-experiential perspective, people with more years of work or volunteer experience generally took the full two hours allocated for the interview and people with a shorter history of working on the issue took closer to one hour.

Of the thirty-two interviewees, twenty-three identified as female, one as a cisgender female (i.e. her experience of her gender matches her gender assigned at birth) and eight as male. Twenty-two interviewees identified as white, including nine who attached ethnic European identifications. Four interviewees gave an Aboriginal identification; four interviewees gave Asian, African, or mixed race identifications, or other ethnic identifications; two did not respond. Nineteen people identified as not having disabilities, three people as having disabilities and ten people did not respond. Nineteen interviewees identified as heterosexual, six as lesbian, gay, or queer, two as bisexual, and two as not judging of others. Three did not respond. While not specifically investigated, several alluded in the interview to being first or second generation immigrants.

Interviewees included feminists and non-feminists, an identity category which turned out to be less definitive than I originally assumed. For example, when I asked a younger woman who works in VAW services about her relationship to feminism, she said:

Ashley: I am cautious about my use of the word feminism simply because I think it is important to engage men in this as well. Um, and some of them are very cautious when they hear feminism, or completely standoffish, because they -- some of the perception is that feminism means that we hate men, which is not my standpoint at all, right, so I am cautious. I mean there are definitely 
feminist principles that I agree with, but I am cautious about defining, because labels in themselves can be very um, they can box you in right? And they can shut doors that need to be open.

Deborah: Would you say to yourself, 'I am a feminist,' or would you not use that, maybe use a different term or maybe you want to avoid labels? That would be fine too. I don't want to say one or the other is what I want to hear, or need to hear.

Ashley: I am a feminist as long as I am allowed to define that in my way. [Laughs] So that would just be that women are equally valued, there is no difference in respect or equality.

This response of Ashley's brings up Bourdieu's claim that the logic of practice has more room for 'fuzziness' than that often desired by scholars. My categorization of the interviewees into feminist and non-feminist, which had seemed so straightforward to me in the early days of designing this project (and in hindsight seems ridiculously naïve), required a certain amount of negotiation with a number of my interviewees. In the end, of the thirty-two interviewees, I categorized twenty-three as self-identifying as feminist (including Ashley). Of these, nineteen were women and four were men. A further five women and two men aligned with the goal of gender equality as generally represented by feminism. Only two interviewees did not identify as aligned with feminism; this was a contestation of the politics of feminism rather than being based on a declaration of being against gender equality. . For all of the interviewees, the feminist violence against women model is the model that they aligned with or deviated from in defining their own position on the issues.

As my goal was to examine VAW doxa in light of the larger field, I (eventually) decided to present and analyse my interviews in groupings that reflected their position in the field. Again, I encountered the categorization process as something which I had to own as a process of knowledge production rather than a transparent counting up of selfevident responses. A central category I created was 'those using feminist VAW doxa in their work with female victim/survivors.' In doing my interviewee search, I conflated 
doing this work with having a feminist identity and with an organization which was identified as feminist, a conflation which I had to then nuance as I got into the analysis. Chapter six presents the 21 interviewees categorized into this group. All of the programs or organizations represented are working toward women's equality and work with women and women-identified persons exclusively; all were identified by the interviewees as feminist except one. The interviewees who work at this last organization identified as feminist. So what I can say is that either the individual interviewee or the organization they worked with, and in many cases both, were identified as feminist in each of these interviews.

Four of the 21 interviewees in this group identified themselves as aligning with feminist goals of gender equality but declined a feminist self-identity, focusing on respect and equality in defining themselves in relation to gender issues. Of the remaining seventeen who did self-identify as feminist, qualifiers regarding their feminist positioning included being 'for equality' or 'against power imbalances' (6), being third-wave (3), being a radical feminist (2) and being a rural feminist (1). Fifteen of the interviewees had worked in one or more women's shelters, ten at the time of the interviews. The other six worked or had worked in feminist outreach programs, networks, or feminist programs within a larger organization such as a hospital.

Three other categories of interviewee were created. These are partner abuse response workers, private therapists and two interviewees whose primary focus is in working with male victims of abuse. Again, the creation of these categories required decision making on my part. For example, two women who had long-term experience as VAW workers had more recently done some work as co-facilitators in the PAR program. 
I engaged with the concerns of these women within the VAW chapter of the dissertation and reserved the PAR workers section for men who were or had been working full-time in this program. The interviewees in these groups had varying and complex relationships to feminism. Most identified as feminist or pro-feminist, while 3 explicitly did not.

\section{Focus Group}

A one hour-long focus group was held with 19 front-line workers. This focus group covered five questions extracted from the interview protocol. These were (i) What terms do you use for IPV? Why do you choose this term(s)? (ii) Has/how has your understanding of IPV changed over time? (iii)What are the commitments you bring to this work? (iv) What are three significant issues or dilemmas that you see facing feminist VAW efforts to reduce and prevent IPV? (v) What would be required for IPV to no longer be a social issue in Canadian society? I took flip chart notes during this meeting. The participants also filled out a form which allowed them to comment privately on the topics being discussed. Eighteen of these workers self-identified as feminist and one as "for equal rights." Similar challenges to VAW doxa and habitus seen in the interviews were also visible within the focus group regarding how the female victim/survivor and male perpetrator doxa shows up in their work. For example, one woman identified that she used the term VAW because she works in this field, "but," she said, "I am aware that men are also abused and assaulted by their partner." As the issues revealed in the focus group aligned with the findings of the interviews, but did not provide the richness of description that the interviews provided, I did not, in the end, use this data any further in my analysis for this dissertation. There were however, themes that I would be interested in exploring in the future to which this material could contribute. 


\section{Early Findings Feedback Workshop}

The early findings workshop took place after the interviews had been completed and analysis begun. Participants were recruited through an email contact with all who had participated in the project thus far as well as anyone who had indicated interest in the project along the way. Seven women attended. The first scheduled date had to be cancelled; this rescheduling might have impacted on the number of attendees. All seven women had worked on, or currently worked on, the reduction and prevention of intimate partner violence and all identified as feminist. Two were interviewees. Christine Peringer, a professional facilitator, led the workshop and took flip chart notes so that I could focus on engagement with the workshop participants. Parking or taxi reimbursement was provided. Coffee, tea and fruit were available. The workshop began with a welcome to the participants and a round of introductions. The workshop goals were presented as (i) to share themes from early research, (ii) to gather participant views on the implications of these themes. Summary notes were taken at this workshop and distributed to the attendees after the event. This workshop occurred at a stage of my thinking when I was exploring divergence and convergence within feminist thinking as primary themes. A range of thinking on the importance of both convergence and divergence emerged from the group. For some, convergence in thinking was essential for action. Others brought forward lessons from the past, saying, “...we converged before and left out women of colour and others." Others noted the importance of continuing to have the conversation. A further theme regarded the participation of young women in the movement. The comment was made that "Young women are complacent and think the work has been done." A counter was offered by a young academic: "Young women are very engaged." This theme is not explored further in this research but would be of future interest. The 
workshop was very helpful in validating that the issues raised in the research analysis are significant to VAW work.

\section{Data Analysis}

Bourdieu (Bourdieu \& Wacquant, 1992) notes that "one of the main difficulties of relational analysis is that, most of the time, social spaces can be grasped only in the form of distributions of properties among individuals or concrete institutions, since the data available are attached to individuals or institutions" (p. 230). My work in developing my research object and the Bourdieusian field sought to address this difficulty. My interest was in tracing the social construction of the feminist VAW doxa and habitus over time. To do this, I defined a feminist VAW sub-field within a field which includes patriarchal, gender parity and other approaches to addressing IPV. This allowed me to develop a relational story of the emergence and current trajectory of the feminist VAW doxa and habitus. In creating this story I worked back and forth between the literature (chapters four and five) and the interview data (chapters six and seven), responding to the themes that were raised by my interviewees.

Through the chapters there is a movement toward greater specificity from the analysis of the field primarily accomplished in the review and analysis of the literature, toward the analysis of the habitus of the interviewees in the later chapters. A relational analysis of the positions and positioning of the interviewees was significant to developing my understanding of the field. While patterns within the findings of such a small data set can only provide an indication of trends over time, these findings are intriguingly in alignment with Bourdieu's theoretical predictions regarding field development. Bourdieu's work enabled me to understand the various theoretical and practice-based 
positions found on the issue of intimate partner violence as inevitable based on the social conditions experienced by the proponents. This in turn moved the discussion beyond a right/wrong critique to explanation and understanding of the social structural issues and dynamics involved.

Pseudonyms were created for the interviewees and some details of the populations they work with, positions held or personal identities were deliberately obscured to protect their anonymity. Information regarding the general characteristics of the interviewees is presented in Appendix B.

The interviews represent approximately 40 hours of conversation. I conducted the interviews and later listened to the recordings using a Bourdieusian feminist lens. Transcribing a series of interviews is a monumental amount of work. I completed some transcriptions myself and gratefully gave over the rest to a professional transcriptionist in Canada who had had some exposure to the issues and the terms and acronyms in use (and who signed a confidentiality agreement). I then read the transcripts, most while listening to the interview, and bolded common themes and other areas that caught my interest. The areas of bolding were coded using Nvivo data management software, with nodes being created as needed during the process. The categories which were of interest to the data analysis emerged through the accumulation of data in those categories.

When reviewing the interview recordings and transcripts, I was listening and reading for the habitus of my interviewees, as well as the doxa of that habitus and how they positioned themselves in the field. I began to identify these threads even while the interviews were ongoing. I also pulled out specific sections of interviews that seemed to indicate the intersection of VAW understandings with other knowledges (i.e. where doxa 
was challenged) and undertook a more detailed analysis of these sections of the transcripts. Some of these sections began with as long as a 10 page excerpt from the interview transcript which, through iterative readings, was distilled down to (relatively) short quotes. These interview extractions were of great significance in being able to trace the dynamics of doxa and habitus.

As I look back on this process, I think that I became somewhat lost in the coding, as the themes which felt significant were numerous. During the course of interviewing I had very quickly given up using the unwieldly four page long interview protocol and created a one page version with one or two word reminders of the various themes I wished to investigate (Appendix C.) If I was asked for advice for someone beginning such a research process, it would be to generally restrict their use of codes to a short list generated in some such similar way. I think a similar restriction could have saved me several months of time in the analysis phase!

\section{CONCLUSION}

The quote from Bourdieu with which I opened this chapter speaks of the researcher's quest to understand that which "they least want to know." My methodology gave me the structure I needed to undertake this quest. It also supported me to go beyond what I feared learning to a framing of the field that allowed me to reconcile my hopes and fears about how I could best approach work on this topic. I began with a fear that I might get "kicked out of the sisterhood" for even asking the questions I wished to ask. I found a community in the throes of searching for answers to very difficult questions. My work 
was welcomed as part of the search for the answers to these questions. I have been honoured by this process.

In the next two chapters I examine the literature pertaining to the development of VAW feminist work on intimate partner violence, explicating the early development of feminist doxa in an oppositional process to existing patriarchal understandings (chapter four) and examining three encounters that I argue have been pivotal in the further development of VAW feminist understandings and current conundrums (chapter five). 


\section{Chapter 4 \\ The Social Construction of Feminist VAW Doxa Regarding Intimate Partner Violence}

\section{INTRODUCTION}

If socially accredited scientificity is such an important objective, it is because, although truth has no intrinsic force, there is an intrinsic force of belief in truth, of belief which produces the appearance of truth. (Bourdieu, 1988, p. 28).

The work of this short chapter is to document the emergence of feminist VAW doxa as a new 'truth' which generated a specific interpretation and response to the phenomenal world; it is to acknowledge that VAW, as a social category, did not exist before feminists created it. To accomplish this work, I apply the theoretical framework outlined in chapter two to an analysis of mainstream feminist VAW scholarly work in the 1970s and into the early 1980s relating to intimate partner violence. In this analysis I seek to identify processes of doxa formation specifically in relation to men were identified as perpetrators of violence in heterosexual relationships.

I begin with an exploration of the development of mainstream feminist VAW theoretical explanations of patriarchy as the source of wife abuse and the shelter system that exemplifies the resulting activism. The relational and oppositional aspects of these developments are exemplified in feminist scholar Susan Schechter's 1982 critique of the work of Murray A. Straus (1977), a family conflict and gender parity researcher. Following this exploration I examine characterizations of men and approaches to addressing male perpetrators that followed from the development of VAW doxa. This 
chapter positions VAW theoretical propositions as one set of doxa which emerged in the struggle for truth; doxa which succeeded in gaining public support for the view of IPV as a public issue which required intervention over earlier patriarchal framings of IPV as an individual problem.

\section{PATRIARCHY AS THE SOURCE OF WIFE ABUSE}

It took courage on the part of second-wave feminist theorists and activists in the 1960s, 1970s and early 1980s to challenge entrenched patriarchal views of wife battering. Remarkably, in a period of a few decades, their work generated significant change in the public common-sense view of wife abuse and generated a range of services and public policy (Richie, 2000). Early mainstream feminist theorists articulated a coherent and powerful argument that the social situation requiring explanation and redress was that of a socially sanctioned violence against wives, not an individualized version of domestic violence which involves only aberrant (male and female) members of patriarchal societies. In Letters from the War Zone (1989), Andrea Dworkin passionately argues that it is the very pervasiveness of violence against women that normalizes violence and that makes patriarchal politics, history, and the exercise of power involved invisible to most people. This insight allowed the development of new feminist VAW doxa that positioned itself against patriarchal assumptions.

The idea that violence by men toward women was dangerous to all women took root in the public consciousness very quickly. Two relational processes named by Ahmed (2004) as needed for signs to gain stickiness - repetition and contactful relations - are visible in the massive mobilization of women (and some men) in the anti-violence movement. Donileen Loseke (1992) documents the social construction of wife abuse in 
America as a social problem, a construction which was both part of, and provided support for, this mobilization. Although she is investigating the social construction of this social issue, she assures her readers that she sees violence toward women as an empirical reality. Loseke argues that claims-making activities by scholars, feminist activists, and social service providers, working to end wife abuse were required to bring the issue into public awareness in the 1970s; the construction of wife/woman abuse as a social issue required a judgement by the public of the situation as morally intolerable and of battered women as deserving sympathy. She presents three representations which she commonly found among the claims-makers on the issue which supported the development of these judgements by the public. The first is that wife abuse is not limited to any one group of women but rather can be experienced by any woman. Second, wife abuse is a situation "where women are the pure victims..." (p. 15, emphasis in original) which includes the claim that "a woman, ipso factor is not violent, and/or that a woman's violence is limited to 'self-defence"” (p. 15). Finally, she says, "claims-makers agree that men are offenders. ...Although such a man might appear quite normal in public... inside his home he is simply a brute or a monster... he intends the violence he produces... [and uses] violence in order to control and dominate..." (p. 15, emphasis in original). The construction of wife abuse as a social problem was further supported by characterizing this abuse as terrifying for the women being victimized, and as "extreme and repeated and consequential and only grow[ing] worse over time" (p. 20). The prevalence of these characterizations within the media and social services ensured the repetition and contact needed for the doxa being created to stick. 
Doxa evolves against a previous social 'truth' by problematizing that truth through a process that Bourdieu (1988) calls epistemological pairing. This evolution can be seen in the claims above relating to IPV; claims which were successful in countering prevailing interpretations of wife abuse as a private trouble which "was not serious, was victim-precipitated and limited to poor and/or minority women" (Loseke, 1992, p. 20). These doxa also provided the shelters with their reason d'etre:

Since the prognosis that a man will change is poor, it is justified for claims-makers to label a woman's hope for such change as a "false and futile dream." The collective representation of wife abuse leads to the common sense conclusion that a woman should leave such a relationship, and this prescription is a part of the collective representation ... Within claims, a failure to leave is labeled as "maladaptive choice behavior" or as "self-destruction through inactivity"... goal of policy should be to help the battered woman leave the situation"... social service providers tell one another that they should work to ... help such a woman "terminate the relationship" (p. 20)

Loseke notes that shelters responding to feminist VAW doxa regarding wife abuse were "explicitly contrasted" (p. 29) by claims-makers with "shelters of the past" (p. 29) which focused on women as the problem or on mending the family. Loseke's work reveals the oppositional element to the development of services which emerge from new doxa, an element which can lead to a flip-flopping of public consciousness regarding social issues as one or the other set of knowledge claims is recognized as 'truth.'

The singular focus on patriarchy and gender that emerged from this process was contested in these early days by numerous feminist Women of Colour, Indigenous women, lesbians, women with disabilities and others variously affected by intersectional issues, including the Combahee River Collective in a powerful statement that presented Black women's experiences of the intersections of racism, sexism, heterosexism and class oppression (Combahee River Collective, 1982). However, the greatest stickiness in the field at this time emerged from the oppositional positioning of VAW doxa against patriarchal truths of gender relations. Even the strategic choice to position all women as 
vulnerable to violence, an emphasis that emerged from an effort to contest stereotypes of marginalized women, reinforced the invisibility of women who were not white and middle-class (Bograd, 1999; Loseke, 1992; Richie, 2000). The successful challenging of mainstream feminist VAW doxa regarding the primacy of gender oppression would require further developments within feminist scholarship and activism. One aspect of these developments was the later "wide-ranging, albeit uneven displacement [of patriarchy] within women's and gender studies by a number of other terms to frame gender-related oppression, the most important being “intersectionality'” (Patil, 2013).

Processes of belonging were also relevant to the development of mainstream VAW doxa which positioned patriarchy as the source of wife abuse. Women's shelters across North America were created in the 1970s in the context of shared oppression and minimal financial resources. Schechter (1982) notes that the energy to continue to work against the odds was sustained by strong relationships within the movement. As a result, differences in approaches among women were often accorded less importance and remained hidden until they emerged in conflictual engagements between those involved. Women in the movement, coping with huge amounts of (often volunteer) work just to keep shelter doors open, found it challenging to work through these issues of difference. As a result, some women left or felt forced out of the movement. As well as adding emotional work, issues of difference also made decisions regarding the direction of advocacy and political work complex, time consuming, and sometimes impossible to adequately explore (Schechter, 1982). In a context where differences are not adequately explored, and the resources that might enable greater exploration are not available, those whose experience and beliefs are aligned most closely with the dominant beliefs will feel 
the greatest sense of belonging. The beliefs of those who have that sense of belonging continue to be reinforced through greater presence and the neglect of 'difference.' Belonging is important to the establishment and maintenance of doxa which are seen to express the truths in the field (Bourdieu, 1990).

A reliance on patriarchy as the predominant source of intimate partner violence meant that second-wave feminist scholarship on IPV was unable to provide a theoretical explanation for women as perpetrators or men as the victims of domestic violence. For example, Walker (1979) notes that it is hypothetically possible for men to be victims, but she asserts that this possibility is not supported by data. The violence by women that she finds in her research is explained by positing women who perpetrate violence as probable victims: "In a small number of cases, it is the woman who commits violence. I would imagine however... in most of these cases the woman's violence is probably retaliatory in nature" (p.252, italics added). A second example is provided by Russell (1982), who in her study found two serious cases of husband battering among 175 couples where there was violence. Russell interviewed only women and did not ask her interviewees about their own use of violence. She reports that not asking women about their use of violence would not have "too serious" (p. 103) an impact on the reliability of the data in revealing a minimal amount of violence perpetrated by women. She justifies her stance thusly: "Since males seem so much more prone to be violent than females, ... my guess is that the percentage of husbands who have never been physically violent in response to a violent wife is very low" (p. 103, italics added). These two meticulous scholars cite imagination and guesswork in drawing these conclusions. That these conclusions are in alignment with their theoretical foundation of male violence against women suggests that 
their theoretical commitments limited their ability to engage with the potential for women to perpetrate violence or for men to be the victims of such violence. Feminist VAW doxa asserting that violence emerged from patriarchal power and control, made the limitations

of their data invisible to them. Here we see the (mis)application of a theoretical model as a rule, a danger Bourdieu (1990) points to for all social theorists. This danger emerges from the unconscious role that doxa plays in our belief "in the way things are." The scientific construction of truth is always influenced by our doxa which appear as truth to us. Below I explore the use of patriarchy in one feminist response to a mainstream researcher.

\section{'Patriarchy' as a rebuttal to mainstream non-feminist research}

Feminist VAW doxa developed in the context of, and against, a mainstream literature which identified wife abuse as a problem to be explained primarily through a psychological lens, with battered women and their abusers identified as deviant from social norms and in need of individual psychiatric care. The 'deviance' perspective allowed contributors to a 1977 edited volume titled Battered Women: A Psychosociological Study of Domestic Violence to discuss male abusers and female victims as sadistic and masochistic (Shainess) and to describe abusers as "under stress at the time of the offence" (Faulk, p. 124). However, while the scholars in this volume generally focused on family and individual level explanations of domestic violence, they did see the problem as one of wife battery rather than symmetrical violence. And a number, including Murray A. Straus, also acknowledged, or even highlighted, the contribution of patriarchal social arrangements to the issue (Straus, 1977). 
Straus is an American family conflict researcher who is cited extensively by both non-feminist mainstream and feminist scholars in Canada and the United States. He is currently identified with gender parity research (Hamel \& Nicholls, 2007). Yet, in his 1977 contribution to Battered Women, Straus names a variety of causes for wife battery in addition to patriarchal beliefs and conventions, and gives prominence to sexism as a cause of domestic violence and as requiring intervention in order for change to occur. As part of a substantial section of the chapter articulating the significance of sexism he states:

Perhaps the most fundamental set of factors bringing about wife beating are those connected with the sexist structure of the family and society. In fact, to a considerable extent, the cultural values permitting and sometimes encouraging husband-to-wife violence reflect the hierarchical and male-dominant type of society which characterizes the Western world (p. 208).

Examining feminist scholar Susan Schechter's response to Straus's approach in this 1977 article highlights the oppositional nature of knowledge production (Bourdieu, 1988, Ahmed, 2004). Straus' articulation of the issues differs from mainstream feminist VAW analyses of the time in that he presents sexism, while significant, as one of a number of causes rather than as the cause of wife abuse. In the context of, and against, prevailing patriarchal articulations of the causes of IPV, VAW doxa positioned patriarchy as the fundamental cause. Dobash \& Dobash (1979), for instance, argue that "the correct interpretation of violence between husbands and wives conceptualizes such violence as the extension of the domination and control of husbands over wives" (p. 15). With this conceptualization in mind, Schechter (1982) challenges Straus's attention in his 1977 article to a range of individual and social factors as responsible for wife abuse:

Straus declares that only small percentages of wife beating are caused by purely psychological factors like uncontrolled aggression, or purely cultural factors (rules that give spouses the right to hit each other), or purely as a result of the organization of society (unemployment, couples living apart from friends or family); rather, he suggests that a combination of these factors produces 
most wife beating. In his theoretical work, Straus speaks to the question of why individual men may hit their wives at a particular moment. Analyzing this question is important, but it is not the same as designing a theory of why men as a group direct their violence at women. Straus and many other theorists, however, fail to make this distinction (p. 210).

Schechter identifies an important gap in the mainstream work at the time she was writing. However, she also, in some ways, misses the mark regarding Straus's work. In the article she critiques, Straus did identify patriarchal values as central to the issue. In fact a large portion of his article focuses on explicating the specific ways that patriarchal values affect domestic violence. Nowhere in her analysis does Schechter name this focus. Secondly, when we look at Schechter's critique from the vantage point of current scholarly theoretical stances, we see value in social theories that focus on the identification of which individuals we are discussing and when or where they are located, and in theories that address individual, cultural and social factors simultaneously.

Straus' identification of patriarchal arrangements as a central cause of wife abuse supports an argument that the lines between feminist and mainstream analysis may have been, in this early time period, more blurry than is sometimes acknowledged. This insight is supported by the inclusion of articles within the same volume which individually ignore or even support patriarchal social arrangements, in contrast to the opening article which positions wife battering within a historical context of the domination of women by men. Seeing the blurry boundaries between early feminist VAW theories and mainstream approaches suggests that there has been a hardening of VAW and mainstream gender parity doxa over time.

\section{THE SOCIAL CONSTRUCTION OF MALE PERPETRATORS}

Men who were violent toward their female partners are presented in early mainstream feminist scholarship as using violence to enforce their perceived right to a 
dominant place in the family. Men are raised to expect women to serve them, Schechter (1982) asserts, and battering is used by men as "a way of organizing a relationship so that men continue to feel superior to women" (p. 224). Without intervention, a husband's violence against his wife in support of this right was perceived to continue and escalate to the point of homicide and/or suicide (Walker, 1979). Diana Russell (1982) declares that there is "a critical problem in the collective psyche of men that is proving to be lethal - to women, to men, and to the world as a whole" (p. 109). Dworkin argues that even men who do not commit rape or wife assault benefit from violence against women because "...all men benefit from the fact that women are not free in this society; that women cower; that women are afraid; that women cannot assert the rights we have, limited as those rights are..." (1989, p. 142). Within a strict feminist VAW perspective, men can only be treated as agents always benefiting from their social position and willingly taking advantage of that position, an inscription (to use Skeggs' vocabulary) of men which has encountered resistance over time.

There is a lack, in these early years, of analysis of any disadvantages to men, of possible resistance on the part of men, or of the multiple social positions that men occupy. For instance, Schechter (1982) presents women as having a "dream of the good life for themselves and their children [and she says,]... male income often provides this chance" (p. 227-288). The man's role as provider, as being outside the dream, as well as any negative impact on men resulting from this patriarchal dream, is unproblematized. Women, on the other hand, are seen to have internalized the inferior social status that society allocates them in a way that undermines their agency. While in the early shelters abused women were supported in their choices and encouraged to trust their own 
experience, as the shelter network became more systematized, the development of shelter rules began to overshadow these efforts. Women's agency remained undertheorized and possible benefits attendant to women's social position within patriarchy were not acknowledged. Ironically, the feminist commitment to the claim that women are not responsible for the abuse they experience as victims at the hands of their male partners meant that second-wave feminist VAW theoretical work inadvertently echoed patriarchal assumptions of women's lack of agency and for men a corresponding absence of social structural oppressions.

When reading the second-wave mainstream feminist VAW literature, I was struck by how the theoretical propositions relating to early VAW doxa seemed to emerge almost fully formed between 1979 and 1982. Early mainstream feminist thinkers and activists mobilized a single key insight - that women were not the cause of male violence, men's assumption that they should be in control (and patriarchal supports for this assumption) were - and successfully disseminated it to the public consciousness. The creation of an epistemological pair is visible here in the opposition of VAW doxa to the pre-existing patriarchal doxa relating to male violence. Feminists did not have to postulate that men were the ones who were violent - that belief already existed in the patriarchal subfield (wherein women's violence was trivialized). What was being contested was who was responsible for men's violence and whether this was an individualized problem or a wide spread social issue. In developing a doxic understanding of men's violence toward women, mainstream VAW feminists reinforced the pre-existing doxa that men were violent and women were not. In the development of doxa relating to the female victim/survivor and the male perpetrator we can see the relational (retention of women as 
not violent) as well as oppositional (women are not responsible for men's violence) aspects of an epistemological pairing.

There is some discussion in the early feminist literature of male perpetrators as possible childhood victims of violence. Walker (1979) presents violence as transmitted generationally and as learned behaviour. Russell (1982) also allows for the possibility for generational transmission, reporting that Nicholas Groth maintains that there is a high degree of sexual victimization among men who rape women, and that sexually abused boys could grow up to sexually abuse others. Given these considerations, feminist theorists struggled with what approach to take towards abusive men. The understanding that "punishment in jail reinforces violence and bitterness" (Schechter, 1982, p. 178) did not diminish the awareness of a need for social sanctions to stop perpetrators who felt empowered by a culture that condones male violence against women. Dobash and Dobash (1979) argue that wife assault should not be decriminalized but neither should it automatically result in imprisonment for male perpetrators. They speak favourably of family courts which include counseling, but are skeptical of treatment and family reconciliation policies.

One answer to the question of how best to address violent men was presented in the creation of the feminist VAW-inspired Domestic Abuse Intervention Project (DAIP) (also known as the Duluth Model). This approach gained wide acceptance in North America in the 1980s. DAIP was one of the first interventions to work toward a coordinated response between law enforcement, the criminal justice system and services/ agencies. Its creator, Ellen Pence, posited that the failure of previous efforts to end domestic violence reflected societal acceptance of husband to wife violence, therefore, a 
key principle of the approach was for social institutions to take responsibility for ending violence (Pence, 1983). In the DAIP project, police discretion in laying a charge was replaced by mandatory arrest policies which ensured that the police laid a charge when there was evidence that an assault had taken place (an approach which experienced more uptake in Canada than any other jurisdiction (Johnson, H., personal communication)). Conviction rates were increased by providing support to victims throughout the criminal justice process and by eliminating the practice of dropping the charges at the victim's request. The safety of victims of wife abuse was kept central in the program. DAIP staff monitored compliance with the terms of probation, which included group sessions for men who batter and individual counselling for the few female assailants (Pence, 1983).

The Duluth model (as it is more commonly known) of psycho-educational groups for perpetrators has become a foundation of batterer intervention programs around the world, including the Partner Abuse Response Program in Ontario. The program goals for participants are to examine their abusive behaviours, increase their understanding of the impacts of their violence on their families, and learn alternate behaviours. Mederos (1999) states that the groups are based on a dialogic process which,

... sidesteps much direct confrontation with the men. Group members are not seen as demonic beings out to inflict pain and suffering but as people who are acting from a set of beliefs that are harmful and make stable and loving relationships impossible. Furthermore, this process diffuses confrontation even more by acknowledging that men's beliefs originate from their social environment. It is not as if abusive men are bad people who have invented these ideas by themselves. Yet at the same time, group participants are held responsible for perpetuating the belief systems and the harmful behaviours that sound acceptable once one has certain ideas (Mederos, 1999, p. 132).

That Mederos' highlights perpetrators as "not ... demonic" or "bad" illuminates ongoing contestations and shifts in how male perpetrators are perceived. This assertion also represents an intervention regarding how the Duluth model would be most properly 
implemented to respond to male perpetrators. Batterer intervention programs based on the Duluth model have often been enacted in confrontational formats, an approach which has been critiqued as inadequate to generate change (Augusta-Scott \& Dankwort, 2002). In contrast, Ellen Pence, one of the founders of the Duluth model, posited compassion for perpetrators as essential to success in changing abusive behaviours (Das Dasgupta, 2012). In 2012, the year that Pence died, her colleague Shamita Das Dasgupta, wrote about a conference speech Pence had given. Das Dasgupta stated,

In front of an audience of women [activists and service providers] who were tired of, and angry about, the violence they have to deal with on a daily basis, Ellen spoke of meeting abusive men with compassion, treating them as sons and brothers in our communities who are not dispensable but must be redeemed by our efforts (Das Dasgupta, 2012, p. 990).

The impact of divergences within feminist VAW movements between approaches focused on accountability or punishment and those focused on therapeutic goals are significant. Bumiller (2010) reports on a 2006 forum which brought together activists, researchers, and system representatives, noting that group members suggested that "the movement is stalled due to a fundamental contradiction between efforts to punish perpetrators and to reform their behaviors" (p. 184). Issues regarding punishment and/or treatment of perpetrators remain a current point of schism among and between feminist VAW and mainstream gender parity scholarship as well (Gondolf, 2012).

\section{CONCLUSION}

The feminist VAW theoretical insight that domestic violence is an expression of patriarchal privilege on the part of men, rather than an aberration from patriarchal culture, led the mainstream feminist VAW scholars and activists reviewed in this chapter to situate the female victim/survivor and male perpetrator as a foundational concept in their work. This doxic positioning allowed feminist movements to effect significant and 
important change in societal understandings of IPV. However, as identified by Schechter (1982), Smart (1989) and others in the mainstream feminist discourse of the time, adherence to this doxa meant that important issues were neglected on several different axes. In 1982, Schechter identified a number of concerns for feminist VAW scholars, including how battering in lesbian relationships as well as class and race factors fit with feminist VAW theories, how to integrate systemic analyses with individual will and the need to recognize differences among groups of women. Of this last, she names the importance of incorporating the argument of "Third World" and Aboriginal women that male domination is an inadequate explanation for wife battering. While she highlights these issues, they are presented as questions for theory building and remain unintegrated in her analysis. Smart (1989) also named these issues as important, and, in 1989, was able to set them in the context of developments in scholarly thinking driven in large part by diverse women, and to start to flesh out an approach to address them. The creation of mainstream feminist VAW doxa outlined in this chapter sets the foundation for the following chapter which will explore the shifts and adaptations along the way that were required/inspired in response to (feminist and non-feminist) competing articulations. 


\title{
Chapter 5
}

\section{Encounters of Feminist VAW Doxa}

\section{INTRODUCTION}

\begin{abstract}
In the struggle between different representations, the representation socially recognized as scientific, that is to say as true, contains its own social force, and, in the case of the social world, science gives those who hold it, or appear to hold it, a monopoly of the legitimate viewpoint, of the self-fulfilling prophecy. It is because it contains the possibility of this specifically social force that science, in the case of the social world, is necessarily contested, and that the threat of attack which it contains is bound to provoke defensive strategies... (Bourdieu, 1988, p. 28).
\end{abstract}

This dissertation argues that shifts in feminist VAW doxa have been following a slow and painful trajectory that is challenging feminist VAW epistemological knowledge regarding men who have used violence in their relationships. Below, I explore this trajectory through an examination of three encounters within academic and practiceoriented knowledge production from the 1970s to the present. These encounters have been chosen to shed light on and reflect the interview responses of this study; the themes that emerge from these encounters set the interview responses in the larger context of the public discourse among practitioners and scholars. In doing this analysis, I am seeking a socio-historical understanding of the current transformative period in feminist VAW understandings of men who use violence in heterosexual intimate relationships in Canada specifically in terms of our theories of change in relation to male perpetrators.

The first encounter I explore resides in a struggle for recognition within feminist VAW scholarship among the diverging theoretical stances required by the recognition of the need for increasing complexity in theoretical accounts of IPV and the commitment within feminist VAW scholarship to the theoretical foundation of the female victim/survivor and male perpetrator concept. The second encounter is that of feminist 
VAW scholarship with gender parity scholarship. Gender parity scholarship claims the importance of recognizing women's use of violence in efforts to reduce and prevent intimate partner violence, with some arguing that women and men are equally violent. The final encounter explored in this chapter is that of feminist VAW theories with trauma theories. An explosion of work in the field of neuroscience over the past 30 years has resulted in the increasingly ubiquitous presence of trauma-informed practice across the helping professions. I argue that trauma theories present specific challenges to VAW theories and are having an impact on VAW workers' understanding of male perpetrators of intimate violence. An analysis of these three encounters provides an opportunity to explore transformative changes happening within VAW doxa regarding men who have used violence in their intimate partner relationships.

\section{THE FIRST ENCOUNTER: FEMINIST ENGAGEMENT}

This section presents feminist work that both expanded and challenged the early mainstream feminist scholarship presented in chapter four, highlighting the different 'truths' that emerge from different positions in the field. Tensions and nuances resulting from these discourses are visible in the substantial body of feminist literature identifying the significance of the intersections of structural privileges and oppressions such as race and class, processes of colonization, women's agency, women's use of violence, and (although not explored further in this dissertation which focuses on feminist conceptions of male perpetrators of heterosexual IPV) lesbian battering and transgender rights. VAW doxa, as a theoretical model, was not (and was not even close to) a perfect representation of the concerns in the field. Through a Bourdieusian lens we can see that those for whom there was a larger gap between their habitus and VAW doxa have acted to challenge the 
female victim/survivor and male perpetrator concept. While present from the early years of feminist work regarding intimate partner violence, the voices of those who were advocating for a more complex view of intimate partner violence than that supported by the epistemological pairing of what became mainstream feminist doxa with patriarchal doxa were not easily heard. As mainstream feminist doxa became institutionalized, these voices have been part of an epistemological pairing within feminist discourses that has resulted in more prominence. In becoming prominent in the field, their voices have played a larger role in the development of mainstream VAW doxa. I consider the influence of these challenges on doxa relating to male perpetrators of violence. It will be seen that while these articulations more fully explore and integrate questions of agency and structure on the part of women and men, they do not resolve the tensions they generate.

\section{Encountering Intersectionality}

Within feminist scholarship, the term 'intersectionality' invokes both a theoretical approach developed by Women of Colour (Bograd, 1999; Collins, 1998; Crenshaw, 1991; Razack, 1998; Sokoloff \& Dupont, 2005) and the on-the-ground work of women who experience intersectional axes of oppression, including racialization, colonization, ableism, classism, homophobia and transphobia. In this section I will focus on the theoretical concerns of Women of Colour in relation to VAW theories, concerns which have presented significant challenges to the female victim/survivor and male perpetrator concept. That Women of Colour were present in the battered women's movement from its early stages is documented by a number of scholars (Arvin et al., 2013; Hewitt, 2010; Sahota (2005); Sandoval, 2000; Richie, 2000). Women of Colour were also developing 
theoretical tools during this time. Sandoval (2002) maintains that this work was not commonly acknowledged as 'theory' within mainstream feminism but rather seen as descriptions of the lives of Women of Colour. Sandoval comments on the early reception to This Bridge Called My Back (Anzaldúa \&Moraga, 1984), noting that essays from it were first "depreciated as 'insignificant' by institutionally literate feminist activists" (p. 22). Elsewhere she argues that the lack of recognition of the work of Women of Colour reflects the "apartheid of theoretical domains dividing academic endeavors by race, sex, class, gender, and identity" (Sandoval, 2000, p. 3). Women of Colour established intersectionality as a concept that recognizes their positioning in bridging these divisions.

By the 1990s, Women of Colour had developed a body of literature that brought issues of intersectionality to bear directly on feminist discourse regarding intimate partner violence. Kimberlé Crenshaw’s 1991 article “Mapping the Margins: Intersectionality, Identity Politics, and Violence Against Women of Color" is considered classic reading in this area. Crenshaw demonstrates how understandings of racism and sexism developed separately by white women and Black men failed to capture the experiences of Women of Colour, a conclusion echoed by Collins (1998). Collins identifies race scholarship as evoking public violence and feminist scholarship on battered women as evoking private violence. She argues that neither narrative "acknowledges the legitimacy of the other" (p. 919), nor the violence Black women experience: "property crime, assault and sexual harassment in public spaces as well as racial violence against women" (p. 919). The lack of recognition of the theoretical work of Women of Colour can be seen as an impact of the doxa of the female victim/survivor and the male perpetrator. This doxa was powerful 
in highlighting the social significance of male-to-female domestic violence; it also acted as a 'filter' that rendered issues other than gender less significant.

Arnold and Ake (2013) look back at early activism, confirming that the first generation of battered women movement activists successfully put intimate partner violence onto the public agenda, but have been less successful in addressing the needs of survivors from communities of colour, immigrants, LGBTQI communities and people with disabilities. "As a result, a new generation of activists has re-examined the practices of the mainstream movement and now looks to incorporate insights from women's experiences of intersecting oppressions into its everyday practices" (p. 559). In this naming of feminist VAW approaches as mainstream we see the struggle for representation in the field and resistance to the dominance of the VAW approach, built up over time.

Arnold and Ake (2013) argue that this resurgence of feminist community-based activism by "intersectionality-oriented activists... [ is focusing on] changing the cultural and structural underpinnings of the violence in order to get it to end once and for all, rather than intervening after it has taken place" (p. 572). This goal is in alignment with early second-wave efforts to end violence against women, but positioned in distinction to the efforts of mainstream VAW shelters and agencies that have been diverted into service work at the expense of activism (as a result of the dictates of government funding and the lack of, or elimination of, funding for advocacy). Arnold and Ake suggest that "the challenge of telling the story of the movement... is to honor both generations of activist work" (p. 559). They generate a story in which the movement continues to evolve and integrate new insights and directions; however they do not in this story explain why the 
work of many Women of Colour who were present in the earlier generation was not heard.

Understanding the female victim/survivor and the male perpetrator concept as doxa helps to explicate this situation. The creation of doxa to counter existing hegemonic truth claims generates new insights but also new constraints. While the varying experiences of women were identified by Schechter (1982) among others as needing explication - which would indicate that the doxa was not actually believed to encapsulate the full 'truth' about intimate partner violence - this doxa had a force of its own which resulted in an ongoing privileging of gender. In essence, the new doxa in its turn constrained what could be known to be known about intimate partner violence. The 'inability' of the subfield to address racism and colonialism as forces equal to gender oppression in the etiology of IPV was a reflection (Bourdieu would say an unavoidable reflection) of the social and political positioning of feminist VAW scholarship and activism and the social positions of VAW scholars and activists. The greater social capital of white women within the movement, and within the primarily white population of Canada at the time, is visible in stabilizing a particular vision of IPV through this lens.

Intersectionality scholars directly tackle the complexities inherent in accounting for gender in conjunction with racialization and other oppressions. Their methodologies in doing so align with a Bourdieusian approach in that their analyses involve examining the use of power among various positions in the field in relation to each other and dominant power structures. Crenshaw (1991) explores the phenomenon of domestic violence in terms of the domestic violence lobby, the political interests of Women of Colour, antiracist politics and domestic violence support services and 'race.' In undertaking this 
examination she exposes the differential power that resides between different groups of women. She makes it clear that she positions this discussion within the context of groups who are resisting oppression. She resists notions that might blame white women for the disempowerment of Women of Colour. Rather, she says, "I hope to dispel any such simplistic interpretations by capturing, at least in part, the way that prevailing structures of domination shape various discourses of resistance" (p. 1243, n. 4). Here, Crenshaw addresses complexities in the positions and positioning of victims and perpetrators among the groups that work to reduce and prevent IPV.

Women of Colour, who have named their victimization and also their strength in resisting victimization, have been pushed to articulate complexities in their lived experiences which straddle the concerns of white feminists and male anti-racism activists. In exploring this unique positioning, Patricia Collins (1998) discusses the conundrums that come with claiming victim status - namely the loss of power and the potential for victim status to become a mode of social control. While she notes that the identification of victimization is a necessary step because it "allows people to acquire the moral capital that being a survivor of violence engenders" (p. 927-8), she also sees it as a stage that must be passed through in order to reach an empowered positioning. Sara Ahmed (2010) also emphasizes this concern, arguing, "It is important that we do not make feminist emotion into a site of truth as if it is always clear or self-evident that our anger is right. When anger becomes righteous it can be oppressive" (p. 4). Sandoval (2000) translates this insight to the movement level, arguing that the dangers of working to expose victimization include imposing our 'truth' on others (and ourselves): "any libertarian or social movement eventually becomes destined to repeat the oppressive authoritarianism 
from which it is attempting to free itself, and become trapped inside a drive for truth that ends only in producing its own brand of dominations" (p. 59). Doxa can indeed provide significant insight into the societal oppression of a social group. However, once doxa become hegemonic, doxa carry their own power to assert truth against those-outside or within the social group - whose experience they only partially represent.

The work of intersectionality theorists has been successful in shifting feminist VAW framings of male perpetrators of IPV. There is now some differentiation when categorizing male perpetrators of IPV. Men of Colour, Indigenous men, men with marginalized sexual orientations or persons with masculine gender identities who have used violence within their relationships can now also be seen as experiencing structural oppressions relating to this use. Women of Colour render complex relations of victimization and perpetration, where, as Collins (1998) claims, "there are no absolute oppressors or victims" (p. 934). However, they do not ultimately challenge the framework of oppressed and oppressor. This is because they extend the category of 'oppressed' to include those who also occupy structural categories of 'oppressor' (and vice versa) by acknowledging, for instance, the dual position of white women or Black men. This extension allows Crenshaw (1991) to argue that when we treat groups as homogenous, we are in danger of reinventing the very oppressions that we are fighting against by ignoring overlapping and fluid memberships that exist across these groups. She does push on VAW doxa by allowing room for men to fit into this new category of 'oppressor and oppressed.' However, men can only do so on the basis of social categories other than gender. The group named exclusively as oppressors has shrunk, but it still exists in men who are white, able-bodied, middle-class, and heterosexual. Ultimately the 
framework of oppressor and oppressed is not transcended, although I suggest that the insights of these intersectionality theorists could take us to the logical conclusion that it should be. And indeed, the current transformational period in understandings of men who have used violence in their relationships is providing challenges that are moving us in this direction.

My purpose in this review of intersectionality has been to focus on shifts within feminist VAW doxa that have resulted from the acceptance of intersectionality as an explanatory term in distinction to patriarchy. These shifts in feminist understandings have by no means resolved issues arising from racism within feminist academic or other institutional settings (Ahmed, 2009). However, they have resulted in the nuancing of feminist VAW understandings of male perpetrators of IPV. The discourse is continuing to evolve, for instance addressing issues relating to the negative differential treatment of marginalized men in the justice system (Crenshaw, 2011) and how to incorporate insights regarding the oppression of marginalized men into justice system responses (Haskell, 2009).

\section{Encountering Indigenous Feminisms}

While affirming the concerns of Women of Colour, Arvin, Tuck and Morill (2013) note that Indigenous activists are often working toward "independence from a Western nation-state" (p. 10) rather than toward equality or rights within such a state. In an October 9, 2014, lecture at Carleton University, Dr. Audra Simpson talked - passionately - about how the death of Aboriginal women is required to ensure Canada's sovereignty. Despite Canada's story of 'innocence' in the present time, she says there are events that suggest the lack of veracity of such a story - such as the ongoing settling of land. She 
argues that the state has a character. It is male, white and hetero-patriarchal. It seeks to destroy what it is not: Indigenous political orders. Before colonization, women were the holders of significant social power within many Indigenous nations. As such, Simpson maintains that Indigenous women have been and continue to be a danger to the existence of the state. They therefore continue to be subject to ongoing oppressions which must be continually resisted.

Indigenous feminists have identified unique challenges to addressing IPV in this context. Anne McGillivray and Brenda Comaskey (1999) present intimate partner and other family violence as interconnected and normalized within many Aboriginal communities. In accounting for this normalization, they echo Simpson's account, arguing that cultural and spiritual devaluation, as well as patriarchal legal relations established under Canadian law, eroded not just traditional conflict resolution practices but also women's status. Bonnycastle \& Rigakos (1998) reinforce this argument with their review of the actions taken by Western actors to bring about the transformation of gender relations among Aboriginal peoples: “In one Jesuit's words, 'formerly proud and free'... [women] had to be made 'as gentle as little lambs"' (p. 11). In addition, the residential school system and the Sixties Scoop (Johnston, 1983) interrupted the generational transmission of parenting skills and, more generally, culture. For McGillivray and Comaskey the solution to IPV lies in interventions addressing intergenerational cycles of violence in the context of processes of colonization and the resulting degradation of the status of women.

Arvin, Tuck and Morrill (2013) argue that it is now well documented that even critical perspectives can reinforce the still-existing structures of colonialism. However, 
they assert the potential for feminism, "when allied with other key causes [to] hold a unique potential to decolonize the ascendancy of whiteness in many global contexts" (p. 11). They explicate a number of challenges specifically related to feminism in this context, which include taking an intersectional approach to the issues in an active engagement with Indigenous feminist scholarship, recognition of Indigenous epistemologies against ongoing colonial practices and a questioning of the material effects of the academy in the ongoing dispossession of Indigenous peoples. Applying these principles to feminist VAW scholarship and practice poses a challenge to the centrality of the female victim/survivor and the male perpetrator, a challenge that is recognized within the mainstream movement but has not yet resulted in new doxa.

\section{Theorizing violence by women in heterosexual relationships}

An area of agency that was initially discounted in feminist research is the potential for women to be the primary perpetrators of domestic violence, a possibility declared in the early feminist VAW scholarship to be a minimal social issue if existing at all (Walker, 1979; Dobash \& Dobash, 1979; Schechter, 1982). Over time it has become clear that women can be, and are, perpetrators of IPV as well as victims, with women being most often reported in feminist VAW literature as the perpetrators in three to $17 \%$ of intimate partner violence, depending on the definitions and sources used. ${ }^{3}$ However,

\footnotetext{
${ }^{3}$ While it is not within the scope of this dissertation to explore the statistical prevalence of IPV or gendered perpetration rates, I here provide the reader with feminist VAW sources showing that the female victim/survivor and male perpetrator concept has been nuanced over time in response to research findings. It has become increasingly common to find the argument that men commit the 'vast majority' of the violence rather than a positioning of them as the only perpetrators. Bonnycastle and Rigakos (1998) assert that "90\% of partner assault victims in Canada are women" (p. 165) (which leaves women as perpetrators in $10 \%$ of cases). The London Coordinating Committee to Prevent Woman Abuse, in London, Ontario, states that men are responsible for $86 \%$ (one time) to 97\% (on-going) of IPV (London Coordinating
} 
feminist approaches to explicating women's agency in the perpetration of violence have focused on agency in the face of oppression (Caldwell, Swan, Allen, et al., 2009;

Hamberger \& Guse, 2002) arguing that an approach is required which can track both the social context of the situation experienced by an abused woman and her response to this situation given the justice system's inability to resolve ongoing safety issues (Johnson \& Dawson, 2011; Randall, 2009).

Attention by feminist VAW theorists and activists to women's use of violence began in the mid-1980s and has been driven largely by the experiences of abused women in the justice system (Swan \& Snow, 2003). For example, the shift to mandatory arrest and pro-prosecution policies during the early 1980s has been associated with a trend toward increasing numbers of women who are abused being arrested for assault and sent to perpetrators' re-education programs or being denied services because they have been identified as perpetrators (Osthoff, 2002). In the face of the situation confronted by battered women, and in response to research by gender symmetry researchers claiming that women are as likely to instigate a violent incident as their male partners, the use of violence on the part of women has become a significant issue for the feminist antiviolence movement.

In 2002 and 2003, Violence Against Women published a set of special issues (8(11), $8(12), 9(1))$ focused on understanding women's use of violence. A fourth special issue

Committee to Prevent Woman Abuse Website, 2016). Hamburger and Guse (2002) present the results of a study showing that among women using minor violence, $11 \%$ reported that it was always as a first strike. Among women using severe violence $3 \%$ was first-strike violence (p. 1307). Michael Johnson (2011) reported results on past marriages from the US National Violence against Women Survey which showed $17 \%$ of perpetrators using coercive control in previous marriages were women (p. 293). These presentations use a range of sources for their assertions which affects the statistics presented. What is important here is the shift that has occurred to acknowledging that women can be perpetrators. 
followed in 2012 (18(9)). The development of the feminist VAW lens for the analysis of this phenomenon can be traced through these special issues, from 2002-03 to 2012. In 2002-03, the issues were framed by an understanding that women are "neither gentle [and] incapable of aggression... [n]or ... equal to men in perpetrating violence" (p. 1268). The guest editors of issue 8(11) note an increasing urgency to "begin" a discussion regarding women's use of violence as battered women (Bible, Das Dasgupta \& Osthoff, 2002, p. 1268). The editors also note that it is beginning to be understood and acknowledged that most abused women use violence in response to their abusers (Bible, Das Dasgupta, Osthoff, 2002).

Each of the five articles in the first special issue acknowledges the use of violence by women as primary aggressors within intimate relationships, referring to the use of violence by women outside the context of defence or retaliation in the opening paragraphs. In his article reviewing the research Michael Kimmel (2002) states that the use of violence by women outside the context of woman abuse is in the range of $25 \%$. This figure includes two areas sometimes neglected in research: sexual assaults and assaults on ex-partners. When these assaults are not included, Kimmel estimates the ratio to be "somewhat less than symmetrical" (p. 1358). And when looking at intimate partner violence used for the purposes of control, women are identified by Kimmel as responsible for just under 10 percent of the violence. These figures represent a significant level of violence on the part of women (and are much higher than most other feminist VAW research indicates - see for instance, Ansara \& Handin, 2010; Myhill, 2015) and Kimmel suggests that they should be taken seriously. Yet he does not analyze women's use of violence as aggressors. Nor do any of the other authors in this special issue focused on 
women's use of violence. Rather they exclude this violence from their analyses, focusing only on the use of force by battered women for defence or retaliation, or on the ways that women are victimized by the justice system. Feminist work to ensure that women's use of force in the context of ongoing victimization is recognized as defensive or retaliatory is important. What I am pointing to here, is an inability for VAW doxa to account for women's use of violence outside the context of male to female abuse.

Only one article (Perilla et al., 2003) in the 2002-03 special issues focused on women as primary aggressors. The authors note that the women they worked with in Latina communities had requested that they address this dynamic. They discuss the role of theory in inhibiting as well as revealing knowledge development: "Unhindered by theories, philosophies, or academic frameworks... the people with whom we work broke yet another silence and gave voice to women's use of violence" (p. 11). A full exploration of this violence required an expansion of the definition of violence beyond that between intimate partners to include abuse against children and other family members. In order to account for this expanded context, the authors use bell hooks' (2000) definition of "patriarchal violence in the home [which] is closely linked to the sexism and male domination present in our society and acceptance of the use of coercive force by a more powerful individual to control others" (Perilla, et al., 2003, p. 12).

That the feminist VAW commitment to female victim/male perpetrator doxa continues to lead to an undertheorizing of women's use of violence is demonstrated in the focus of the 2012 special issue (18(9)) of Violence Against Women which again examined women's use of violence. The call for papers asked for articles on the topic of: “Contemporary Perspectives on Battered Women's Use of Nonfatal Force in Intimate 
Heterosexual Relationships: A Contextual Approach" (Larance \& Das Dasgupta, 2010). Each of the phrases in this articulation implicitly excludes a topic area where there is the possibility of disrupting the female victim/male perpetrator dichotomy, such as the use of violence by women who are not battered, female-perpetrated homicide, violence in lesbian relationships, and research that does not differentiate between the contextual experiences of women and men who commit acts of violence. Over the decade bracketed by these special issues, feminist VAW scholars developed a theoretical understanding of the use of violence by abused women that is powerful in rebutting assumptions of gender parity in IPV. However this scholarship has not been able to adequately address the aggressive use of violence by women.

\section{Theorizing violence in lesbian relationships}

The identification of violence in lesbian relationships has also been politically charged, as lesbian battering presents an inherent challenge to the female victim/survivor and male perpetrator concept. In a Canadian volume entitled Unsettling Truths: Battered Women, Policy, Politics, and Contemporary Research in Canada, Ellen Faulkner (1998) critiques three main feminist responses to theorizing lesbian violence: liberal feminist approaches which stress individual-level analysis and external stresses on the family and which disregard the effects of social marginalization; radical feminist frameworks which borrow from VAW theory to argue that the roots of violence reside in oppressive patriarchal structures and which may thereby neglect holding women responsible for their use of violence; and cultural feminist ideals of sisterhood which can lead to a denial of the use of violence by women altogether. Faulkner's analysis reveals the difficulties of holding women - whether lesbian or heterosexual - responsible for their use of violence 
(outside the context of being the victims of abuse) when using a theoretical framework based on the concept of the female victim/male perpetrator. My own experience, working with organizations in Ottawa, Canada in the early 2000s to support them in the development of services for lesbians involved in violent relationships, found them illprepared to grapple with the idea of women as perpetrators. It seemed that these organizations could engage with lesbian (i.e. women) victims without integrating that the lesbian perpetrator was, ipso facto, also a woman, not a man. Although the topic was partner abuse, some workshop participants resisted using scenarios of lesbian battering and suggested substituting situations of lesbians being abused by male family members, professional service providers or strangers. Faulkner (1998) insists that "any understanding of lesbian battery must contemplate both social-structural modes of domination and individual agency" (p. 58).

\section{Continuing efforts toward legal change}

While feminist efforts within the legal realm are outside the scope of this project, they have paralleled the processes described and analyzed in this dissertation; therefore I wish to touch on this work. I first note the broad shifts in feminist legal change efforts in Canada over time. Second, I highlight concerns regarding how to address male perpetrators articulated in the context of these changes, concerns that echo those raised in the trauma literature which I address in the third encounter.

Feminist efforts toward legal change have gone through several phases (Majury, 2002). The first occurred during the 1970 s and 1980 s and focused on formal equality and on having violence against women taken as seriously as other violent crimes. The second phase of law reform began in the late 1980s, when gender neutrality, earlier seen by 
feminists as part of the solution, became problematic in itself, with developments such as the dual charging of men and women. It is this phase in which the use of violence by abused women became an issue requiring theoretical articulation. The late 1990s saw the move to the appropriation phase, in which feminist language and concepts developed to protect women have been used to justify a law and order approach to perpetrators of crime, in the context of neo-liberal and neo-conservative trends in Western societies.

Feminist scholars continue to struggle with the conundrums involved in responding to dynamics of woman abuse within a criminal justice system which can only respond to individual incidents and perpetrators. They have also expressed misgivings regarding community-based alternative processes in a social context which supports violence against women (Majury, 2002; McGillivray \& Comaskey, 1999; Stubbs, 2002).

However, in the context of continuing disappointments and ongoing oppressions relating to the use of the criminal justice system to address IPV, there has been some opening to, and exploration of, restorative justice or other alternative community-based processes for dealing with the perpetration of intimate partner violence (Incite! \& Critical Resistance, 2005; Incite!, 2007; Ptacek, 2010; Randall, 2013).

\section{Shifting views of men's role in work to reduce and prevent IPV}

When the Ontario Deputy Minister Responsible for Women's Issues and Seniors Affairs addressed conference participants at the $4^{\text {th }}$ Canadian Domestic Violence Conference in Toronto in June, 2015 (a conference which I attended) with a rousing call to action to end violence against women, she named victims, bystanders, police, justice system and community agency actors as among the groups who would bring about the end of violence against women; perpetrators were (for me) conspicuously absent from the 
list. While a reader could ask how male perpetrators might reasonably be included in such a list, it is also reasonable to see male perpetrators as a key group (parallel to victim/survivors) required to take action against violence against women in order for it to end. I argue that there are visible trends toward this second approach as feminist VAW doxa regarding violent and unredeemable men are being challenged by changing perspectives regarding men's role in work to reduce and prevent intimate partner violence.

Hamby (2014) tells the story of a specific shift that occurred in her own understanding of the role of men who have used violence in their relationships. She first contextualizes this story by naming her previous belief that perpetrators cannot change. In the story Hamby, speaks of her response to a male presenter at a conference who talked about his past abusive behaviour as wrong and who said he had changed. Unlike other events Hamby had attended where men made this kind of presentation, this man was treated "like a peer and a colleague by the presenters and staff" (p. 188); in other words, as someone who actually had changed. Although Hamby had already developed an understanding of the intertwining of victimization and perpetration, she reports:

I thought that this seemed like a very bad idea at the time. I found myself staring at him, looking for any kind of 'tell' that might betray an underlying evil. ... At the same time, along what was for a long time a completely parallel and separate track in my mind, I was incredibly impressed by men's involvement in this program... there were substantial numbers of men in attendance and they seemed to be really involved and engaged.

Hamby realized sometime after this incident that the acceptance of this man who had perpetrated violence was not incidental, but rather central, to inculcating the substantial involvement of men in this program. She says, about victimization and perpetration. I believe the frank, yet non-blaming, discussion about how 
perpetrator and victimization gets intertwined for some is how they were reaching segments of the population who normally would never get involved in the anti-violence movement (p. 186).

Hamby closes this story by arguing that we need to (continue to) move toward approaches that encompass a "committed belief in the possibility of change" (p. 187). Her story suggests that violence against women will not end without involvement on the part of men who have been abusive and a change on the part of feminist VAW advocates, activists and service providers to be willing to work with such men toward change. From this perspective a political call to action which excludes male perpetrators, such as that with which I opened this section, is a call to action against male perpetrators: male perpetrators are the problem to be addressed. I identify this conflation of behaviour and the person as a key point of contention between feminist VAW doxa and the emerging doxa of my interviewees who work with men who use violence. In turn, these emerging doxa are contributing to changes within anti-violence movements as is evidenced by Hamby's experience.

Jewkes, Flood and Lang (2015) review the development of work to end violence against women, showing the early focus on the victim/survivors and general neglect of boys and men except as potential perpetrators. The notion that men could play a positive role as allies-in-change appeared in the 1990s. Since that time programs such as the Canadian-based White Ribbon Campaign have expanded around the globe (Minerson et al., 2011). Even though many allies may have previously been involved in violent relationships, recognition of a role for men who use or have used violence in ending violence against women is newer still. That this recognition is uneven is apparent in the above examples. 
Cismaru and Lavack (2011) argue that perpetrators should be addressed in community prevention work as among those potentially seeking to change, rather than as the problem that the victim is seeking to address. They argue: "This suggests that when communication materials include a section addressing perpetrators, this is superior to the "victim" only approach ... or the "victim" and "bystander" approach in which only information for the victim and friends and family is provided" (p. 195). Peacock and Barker (2014) go further, suggesting that, while work with men and boys to end genderbased violence should "remain accountable to women's rights movements" (p. 582), it also “should embody support for men's efforts to change positively and affirmation of positive and health-promoting formations of manhood, and in reducing the impact and harm of violence in men's lives" (p. 583). This approach challenges the positioning of male perpetrators as an unchangeable 'other,' instead bringing men who have used, or continue to use violence - even those identified as abusers - into the community of people who must be engaged in efforts to end VAW. This new positioning aligns with the scholarship of Crenshaw (1991) and Collins (1998) in addressing the intertwining of victim and oppressor within groups and individuals in which no individual is a pure victim and none is a pure perpetrator.

From a perspective which acknowledges the intertwining of perpetration and victimization, prevention approaches can be positioned as most effective in creating change by focusing on the social ecology "in which different individuals, in different positions, all have positive parts to play for prevention and equality" (Jewkes, Flood \& Lang, 2015, p. 1581). A current trend within innovative prevention programming addressing violence against women is to engage in community conversations about 
diverse and gendered experiences of victimization and perpetration across the life span (Abramsky, 2014; Jewkes, Flood \& Lang, 2015; Minerson, 2011). This stance relies less on 'telling' what 'right' gender relations would look like (an approach which has created resistance to anti-violence efforts) and more on creating relational opportunities for engagement around issues of power where social structural inequalities such as gender are identified and explored in the course of the dialogue, a stance in alignment with Siltanen and Doucet's (2008) claim that feminist research must ask questions about, rather than assume the significance of, gender in any specific place and time.

Questions regarding men's lived experiences of power and oppression on the basis of gender remain a subject of robust debate within feminist movements (Cismaru, 2011; Crooks et al., 2007; New, 2001; Perilla et al., 2003). The idea of men being oppressed or even just constrained on the basis of gender is an uncomfortable fit with feminist VAW doxa on intimate partner violence although at this point in time many feminists may not see this as contentious; the movement toward complexity and fluidity in critical theories, including feminist theories, has provided openings to explore this question (Connell, 1987; New 2001; Gardiner, 2002). At the Critical Perspectives: Criminology and Social Justice Conference on May 4 and 5, 2012, I asked the members of a panel on "Men and Violence" if they thought that men could be oppressed on the basis of gender. All three members of this (student) panel said that yes, under certain conditions, they thought that men could be oppressed as men. This was a question and answer which raised a reaction from some members of the audience, providing evidence for ongoing resistance to this formulation. It also signaled change; I suspect that this is a different answer than would have been given 10 or 20 years ago at such an event. I take these responses as an 
indicator of increasing complexity in the analysis of gender rather than a movement away from feminist analyses. However, the question of whether men can be oppressed on the basis of gender remains a divisive one and one that contributes to a particular political stance toward how to address male perpetrators of violence in intimate relationships.

\section{THE SECOND ENCOUNTER: GENDER PARITY}

Murray Straus is a prominent quantitative researcher, who in the late 1970s developed a survey tool called the Conflict Tactics Scale (CTS) (Straus, 1979), which has become the basis of most surveys investigating family conflict and some investigating spousal violence, such as Statistics Canada's victimization survey (Johnson, 2015). The CTS asked the same questions of both men and women and generated rather startling data: women and men in equal proportion said that they used physical violence and both were equally likely to report initiating physical violence. Feminist VAW researchers pointed to problems in the CTS which raised questions as to the legitimacy of the findings of studies using this tool (DeKeseredy, 1999). Concerns included the framing of violence as the result of an argument, a lack of attention to the motivation for the violence, the equation of a 'hit' with a 'hit' without reference to severity and/or injury and a short reference period of one year which erases the impact of long time abuse and coercive control. In addition, sexual assault was not investigated (Kimmel, 2002; Hamby, 2009). In 2003 the CTS was redesigned in an attempt to address problems that may have falsely led to findings of gender parity. Included among the changes were the creation of a sexual coercion scale and an injury scale, both of which reveal significant gender differences (Hamby, 2009). 
The revisions have not quieted feminist VAW critiques of the CTS2 as this tool still individualizes acts of violence and is not able to accurately represent relationships of coercive control (Johnson, 2015). In addition, the Sexual Coercion Scale is often omitted by researchers who are reluctant to address such issues and/or may find resistance to addressing such a sensitive topic from research ethics boards (Hamby, 2009). Those taking a gender parity stance counter that many studies worldwide have replicated these results which they point to as attesting to the reliability and validity of this approach (Dutton, 2005). In this section, I explore the development of the gender parity position in relation to VAW understandings, seeking to illuminate the emergence of doxa, habitus and the subfield associated with this position and the impact of these developments on feminist VAW positionings.

The early second-wave feminist VAW case for the seriousness of wife abuse as a social issue was compelling and attracted researchers from a variety of disciplines. A number of prominent researchers who are now associated with gender parity positions, including Murray Straus, Donald Dutton and Linda Mills, engaged with the violence against women lens in their early work. When Dutton's (1988) book on the topic, The Domestic Assault of Women, was published, it was hailed by Peter Jaffe, himself a wellknown researcher in the field of VAW, as "the first book by a Canadian psychologist on the issue of battered women and their partners" (Jaffe, 1989). Donald Dutton is now a staunch proponent of gender parity as the best model for theorizing IPV, believing that use of the VAW model misrepresents the evidence and that psycho-educational interventions with male perpetrators are ineffective (Dutton, 2007). Straus (2011, 2014) has taken a somewhat different tact arguing that while there is gender parity in 
perpetration, women suffer more injuries than men. He suggests that addressing women's perpetration of violence is needed (in addition to that of men) to reduce the injuries experienced by women in IPV as women get hurt more, and more often, no matter who is the aggressor. In this framing addressing women's aggressive violence is one route to a corresponding reduction in the injuries experienced by women. Mills used a VAW frame in her analysis of the issues until as recently as 1999, but in 2003 published Insult to Injury: Rethinking our Responses to Intimate Abuse. In this book, Mills draws on a gender parity perspective in developing her thesis regarding the need to rethink mandatory charging policies as a response to IPV. Over the past few decades, the dichotomy in the research findings between the feminist VAW asymmetry position and the gender parity position has become entrenched in the research communities themselves, "consum[ing] a considerable amount of scholarly time and effort" (Myhill, 2015, p. 371). Hamby (2009) notes that allegiance to an asymmetry or gender parity position has become central to the positioning of researchers in the field. We see here the intersection of belonging, training and belief that instill the dispositions of habitus that individuals experience as natural rather than conditioned.

Co-editors John Hamel and Tonia Nicholls identify what they call a 'genderinclusive' approach to addressing domestic violence in, Family Interventions in Domestic Violence (2007); Murray Straus and Donald Dutton both contributed to this volume, which also includes work from a number of other gender parity scholars. The editors acknowledge the pioneering efforts of the battered women's movement in getting the issue of domestic abuse onto the public agenda and note that their own efforts build on this work. They also state that the early public policy focus on men as perpetrators and 
laws in the United States forbidding the recognition of modalities other than batterer intervention programs for mandated offender programs made some sense in the context of the extreme nature of the abuse being identified at that time and the lack of appropriate assessment tools or knowledge of the dynamics of domestic violence among mental health professionals. However, they claim, as knowledge regarding causes and interventions has expanded since the introduction of mandatory arrest policies in the 1980s, traditional (read feminist VAW) approaches can now be seen as inadequate to address the problem.

Hamel and Nicholls (2007) argue that more proactive responses from the justice system have resulted in a more extensive range of types of domestic violence being identified. Further to this, research has expanded understandings of the relational complexities involved and treatment modalities have been developed. They assert that batterer intervention programs have not shown great success as an intervention tool. Thus, they argue for more complex articulations of domestic violence. In the introductory chapter, Hamel (2007) presents a set of ten interrelated principles for work to reduce and prevent domestic violence within what he calls a gender-inclusive approach. While Hamel claims to have constructed an evidence-based model, a review of these principles reveals that each presents an implicit counterpoint to feminist VAW doxa, suggesting a foundational link with feminist doxa and the creation of a countering set of doxa. The principles articulated by Hamel are: (i) Interventions should be based on a thorough, unbiased assessment, (ii) All treatment modalities and options should be considered, based on the facts of the individual case, (iii) Both men and women can be victims and/or perpetrators, and everyone is responsible for his or her behaviour, (iv) The 
causes of partner abuse are varied but similar across genders, (v) Victim/perpetrator distinctions are overstated, and much partner abuse is mutual, (vi) Both genders are physically and emotionally affected by abuse, (vii) "Gender inclusive" does not mean "gender neutral" or "gender equal", (viii) The gender-inclusive approach is a feminist approach, (ix) Regardless of perpetrator gender, child witnesses to partner abuse are adversely affected and are at risk for perpetrating partner abuse and becoming victimized as adults, and (x) Family violence is a complex phenomenon, with reciprocal interactions between the individual members.

Hamel concludes his list of principles with an explicit reference to the development of what I am identifying as the subfield of the gender-inclusive, or gender parity, approach and feminist VAW approaches:

The gender-inclusive approach seeks to correct for ... shortcomings [in VAW approaches] while retaining the original feminist values of fairness and social justice as well as the twin priorities of victim safety and perpetrator accountability that advocates have championed for years. Rather than simply presenting new ideology, the gender-inclusive approach is, at its core, empirically based, guided by the data, and loyal only to interventions derived from them (Hamel, p. 18).

Hamel's claim to an empirical foundation to this approach is a claim to scientific truth; however, examination of the polarized positioning of gender parity doxa in relation to VAW reveals the ideology involved in these claims of scientific evidence-based positioning. Bourdieu argues that the hardening of epistemological claims in relation to the 'other' is a reactive process which strengthens the truth claims of each subfield by creating a polarized understanding of the issues; this polarization reduces the potential for the development and uptake in the field of understandings that fall outside the dichotomy. Hamby (2009) for example, points to an alternative 'evidence-based' possibility that has not received attention in the field: she says that as women account for $20 \%$ to $30 \%$ of all 
violent crime, an expectation of moderate asymmetry should be the starting point when researching IPV.

While Hamby (2009) points to the neglect in the field of alternative 'evidencebased' explanations of IPV, feminist scholar Michael Johnson's (2006) work on typologies of intimate partner violence shows the problems inherent in the concept of evidence as an objective source of truth. Johnson's typological framework differentiates between three kinds of intimate violence: intimate terrorism (which he recently refers to as coercive controlling violence (Hardesty et al., 2015)), violent resistance, and common couple violence. ${ }^{4}$ In this model, intimate terrorism is primarily engaged in by men seeking control of their female partners, with the potential for concomitant violent resistance for self-protection or retaliation from their female partners. Common couple violence is physical violence which periodically occurs between intimate partners who lack conflict resolution skills. Common couple violence can include significant injury or even mortality but lacks a focus on coercion or control. Johnson argues, therefore, that the feminist VAW and gender parity approaches are talking about two different phenomena: VAW scholars focus on intimate terrorism and gender parity scholars on situational couple violence. Johnson affirms the insights of both sides, but argues that each is seeing only a part of the whole. The notion of typologies of violence is gaining acceptance at the current time. Myhill (2015) notes a "developing consensus in the IPV literature that different types of abuse, with different motivations and underlying dynamics, require different strategies for both prevention and intervention" (p. 372). An

\footnotetext{
${ }^{4} \mathrm{He}$ has elsewhere articulated a fourth type: separation-instigated violence. This type of violence emerges at the end of a relationship and is said to be equally perpetrated by women and men (Kelly and Johnson, 2008).
} 
understanding of IPV as differentiated also has impacts on how researchers might assess various measurement strategies.

Sampling methods may differ in their representation of the various types of violence. Johnson (2011) argues that "all of our major sampling methods are biased with the result that they yield samples that differ dramatically in the representation of the major types of intimate partner violence" (p. 290). He maintains that feminist research conducted with shelter samples overestimates intimate terrorism because women who go to shelters are more often victims of coercive, controlling violence. On the other hand, family violence researchers putting forth the gender symmetry hypothesis extrapolate from population survey data that over-represents what he calls common couple violence, because those involved in intimate terrorism would often, he maintains, refuse to respond. Johnson's work shows that evidence is affected by the questions asked, the collection methods used and what data is considered relevant. The consolidation of data into truth and belief through processes of professional experience or training is an iterative development that occurs within an embodied habitus. As the doxa solidify, a subfield may form around this new set of doxa that are experienced as unconditioned truth.

Johnson presents his typology as the currently accepted feminist version of IPV. While he may be somewhat overstating its acceptance, feminist scholars are engaging with his work. Holly Johnson and Myrna Dawson (2011) assess his framework as a "feasible starting point for future research on the gender symmetry/asymmetry debate, [and one which] ... more importantly, may help us move beyond [it]" (2011, p. 71). Evan Stark (2006), while maintaining that Michael Johnson's typology requires further elaboration, also sees it as useful, suggesting Johnson has "provided an explanation that 
was obvious once he proposed it, that the parties involved [gender asymmetry and gender symmetry proponents] are measuring different phenomenon" (p. 1020).

According to Johnson (2011) shifts in public perspective on the issue can be understood using his typological framework. Prior to feminist interventions, Johnson argues, most major institutions "had generally assumed that all intimate partner violence was situational couple violence, a private matter for the couple to work out themselves" (p. 292). The shift from patriarchal expressions inculcated by early feminist work was toward viewing domestic violence as intimate terrorism. Johnson sees a further, more recent, shift in public policy and perceptions: "differentiation" he argues, "is the new catchword in the courts and law enforcement" (p. 293). A public policy view of IPV as differentiated, in Johnson's view, is an indicator of support for, and engagement with, his typology, wherein criminal justice institutions start to develop tools to differentiate between intimate terrorism and common couple violence.

In contrast to Johnson's characterization of current shifts in public policy as being toward differentiation, many feminists see the current uptake of gender parity understandings in the public sphere as a swing back toward patriarchal articulations of IPV and as a trend supported by, and supporting, neo-liberal and neo-conservative developments. Feminist scholars argue that the claims of gender parity/symmetry researchers - that women are equally violent to men - activate equality discourses in the service of restabilising patriarchal norms (Dragiewicz, 2008; Minaker \& Snider, 2006). Feminist successes are eroded by forcing feminist organizations to defend their claims to resources and respond to reductions in services and shifts to mainstream service providers who claim to serve all equally. With neo-liberalism comes a shift in governance goals 
from the delivery of "social justice work: when or how to guarantee minimum standards of living to those on the bottom" (Minaker \& Snider, 2006, p. 765), to that of service to free market forces, with responsibility for one's participation left up to individuals regardless of the social position occupied. Kennelly (2014) argues that the experience of this responsibility is gendered, with women experiencing a retraditionalization in which their public work includes care for others. Gotell (2007) adds to this articulation in presenting the neo-conservative ideal of individualized heterosexual citizens: the cautious female and the responsible male. Here, sexual violence is viewed as abnormal and criminal and heterosexuality is treated as natural and without power implications. Sexual violence is no longer a social issue reflecting male oppression of women, rather, sexual assault is a failure on the part of men to live up to their responsibilities. These feminist scholars identify a current transfer of patriarchal authority from the male head of the household to patriarchal institutions, in a re-entrenchment of patriarchal social patterns.

While representational struggles in the field in the context of an epistemological pairing may give the effect of a pendulum swinging one way and then the other, changes over time add complexities to shifts in doxa that cannot be understood in binary formulations. The feminist concerns above provide insight into the dangers of addressing common couple violence as the form of intimate partner violence; however they do not fully account for the positioning of current gender parity researchers many of whom take a critical stance toward patriarchal social arrangements. As I found when 'lurking' on a gender parity list serve during this research and as is visible in the literature, many name themselves as feminists working "to make good on th[e]... early promises of feminism" (Hamel \& Nicholls, 2007, p. 14). 
The parity/asymmetry debate is a central issue in scholarship on IPV between feminist VAW and mainstream family violence researchers, one that clearly goes beyond conflicting research findings to involve the creation of habitus, doxa and subfield on the part of both groups. Linda Mills' shift from a VAW perspective (1999) to a position which reflects the concerns of the gender parity camp (2003) provides a mini-case study. Below I explore the shift Mills has made between these two subfields.

\section{Linda Mills: a (mis)reading of feminist VAW history in the creation of gender parity doxa}

In 2003, Linda Mills' book Insult to Injury: Rethinking our responses to intimate abuse, caught the attention of the field and the public. This book, when considered in comparison with Mills' (1999) article from four years earlier, "Killing her softly: Intimate abuse and the violence of state intervention," provides a fascinating mini-case study of the ideological claims that support Mills' shift from a VAW social structural framing to a psychological and relational gender parity framing. Mills makes this shift between the publication of these two pieces of writing, and in doing so moves from positioning herself as part of a group of feminist professionals engaged in work to make the world a better place for abused women, to naming (and standing outside) the positioning of a group she calls "mainstream feminists" as the problem to be addressed in order to achieve further progress in ending intimate partner violence. While she is not explicit that she is drawing the term "mainstream feminists" from Women of Colour, Mills credits the work of Women of Colour in helping her achieve a new understanding of the issues. In the analysis below, I will use Bourdieu's conceptual framework to trace the (mis)reading of feminist VAW history which supports Mills' new doxic positioning. 
Both Mills' article (1999) and book (2003) present an argument for reassessing and moving away from mandatory policies in addressing intimate partner violence. In many ways the book is a reworking and extension of the 1999 article, with the book in some instances incorporating introductory sentences and paragraphs from the article. However, a number of the terms change between these two pieces of writing. For example, in 1999 she addresses intimate partner violence as a "violent dynamic imposed on the battered woman by the batterer" (p. 555), while in 2003 she refers to Michael Johnson's distinction between patriarchal terrorism and common couple violence, the second of which, she says, "reflects the more common dynamic I describe throughout this book" (p. 7). This is not to say, however, that she has shifted her topic from intimate terrorism to common couple violence; instead, the change is in two parts. First, she is naming noncoercive family conflict or common couple violence as the most common form of domestic violence and therefore the one she focuses on, and second, she believes that women who are involved in conflictual relationships andlor are the victims in abusive relationships have a role in "perpetuating violence, in violence coaching, and in relational dynamics that foster abuse" (p. 143). Her claim is that mandatory policies focusing only on the responsibility of the (male) perpetrator and the victimhood of the (female) victim are not helpful in either case.

From a feminist VAW perspective, Mills' shift represents a reversion toward patriarchal interpretations of women as responsible for the abuse they endure. Using a typologies lens, we see an elision between common couple violence and male-to-female abusive relationships. Although she invokes Johnson's typology, Mills is not diligent in 
addressing intimate terrorism and common couple violence as differentiated social phenomenon and this affects her analysis of feminist VAW efforts.

While a repositioning has clearly taken place in the three years between the article and the book, Mills takes an ahistorical stance to her new positioning throughout much of the book. This leads to the creation of a gap between her 1999 presentation of the issues and her 2003 presentation. While in 1999 she refers to battered women throughout her essay, in 2003 she says, "Like men, women are frequently oppressive in intimate settings and therefore may be more accurately referred to as 'women in abusive relationships' a term which... I prefer to the more common usage of 'battered women,' 'victim,' or 'survivor"' (p. 8). Mills makes this statement without reference to her own (recent) past use of these terms, positioning herself in an enlightened relationship to feminist VAW efforts which are likewise presented as unchanging. This distancing from feminist VAW doxa which she herself held four years previously allows her to make much more sensationalizing claims and universal categorizations in relation to feminism, as well as engaging more polarizing language than in her earlier 1999 article.

In 1999 the problem is identified as "state policies [of mandatory intervention which] have the inadvertent effect of rendering battered women less, rather than more, safe from violence" (p. 555) and which are in effect an enactment of emotional abuse on the victim by the state. She also sees the replication of the violent relationship in justice systems interventions:

Assuming that the state inadvertently responds to domestic violence in an emotionally abusive way, we must rethink the dynamics of the relationship between the battered woman and the state and develop an alternative paradigm for the state's response (p. 596). 
Mills frames the state's violence toward abused women as "inadvertent" multiple times in this article. She acknowledges that, "Mandatory policies have many advantages that merit discussion" (p. 563) and that the focus on mandatory policies was a response to a "system [which] clearly colluded with the batterer and replicated the violence endemic to patriarchy by failing to take the victim's complaints seriously" (p. 563). She also states that, "Not until recently have we become aware of the ways these policies fail the particular interest of women and hence, have raised questions about their ongoing effectiveness as feminist strategies" (p. 565). She talks about how 'we' must rethink current approaches, at least implicitly implicating herself as one of those who must rethink.

State actors form the central figures of critique in this work; advocates and feminists are secondary. In fact in this 1999 piece feminists appear to still hold the role of the good guys albeit misled by their enforced participation in a patriarchal society: "My argument is that many women, as members of the patriarchal society, are so deeply influenced by male expressions of power that their ability to reflect on these dynamics is hampered, even destroyed" (p. 568).

By 2003 Mills inserts "mainstream feminists" along with the "state actors" referred to in 1999 as part of the problem. The mainstream feminists are not only part of the problem; they become in many cases the instigators. This discursive effect is created by collapsing criminal justice approaches with mainstream feminist approaches. Over the course of the book Mills' focus shifts from a critique of "mainstream feminist approaches", to the "feminist influenced system," and finally to changes needed in the criminal justice system, in a way that imposes responsibility for the state of the legal 
system on "mainstream feminists." Feminist VAW efforts are homogenized with words and phrases such as, "monolithic legal approach" (2003, p. 4) and "mainstream feminism labels victims as helpless, dependent, and ill” (2003, p. 126). The 1999 sentence beginning, "For many battered women's advocates and state officials, mandatory reporting policies represent significant political progress...” (p. 557, emphasis added) becomes, in 2003, "For many mainstream feminists, policies such as mandatory arrest, mandatory prosecution, and mandatory reporting represent significant progress..." (p. 33, emphasis added). Here we see the development of a doxic positioning which is creating and defining mainstream feminists as a problematic 'other' whose distinct and entire idea of progress is that of the implementation of mandatory processes.

In the 1999 article Mills talks about developing responses that will "provide the long term results we all hope to achieve" (p. 612) using inclusive, de-escalating language that models the kind of non-violent approach that Mills says she is looking for. In 2003 Mills argues that a new feminist analysis is needed,

“... one that starts with women's perspectives. Re-viewing why women choose to stay in abusive relationships from a less judgmental and more self-reflective stance allows us to understand and embrace the complexities of their decision making and to see these decisions in a new light. It forces us to question what we assume about women in abusive relationships, and it helps us to understand that the professional's goal must be to see each relationship as uniquely as the couple sees it" (p. 66).

Between 1999 and 2003, Mills moves from an approach to change where she positions herself as a part of a problem that is the inadvertent result of efforts to end violence against women and that needs to be collectively addressed, to one in which a 'new' approach (or doxa) is needed in order to force the questioning of assumptions.

Bourdieusian feminist Beverley Skeggs (2004) talks of how institutionalization can be used to maintain a point of view. In Mills' work we see an example of how 
institutionalization can be used to challenge a point of view. Mills' claims that 'we' must start this new analysis with women's perspectives which would allow 'us' to embrace 'their' decision making and would challenge what 'we' assume and would help 'us' to understand what the professional's goal should be. In this rendition, Mills' 'we' is clearly professionals rather than women in abusive relationships. Mills' social location as a professional and as one of the group who should generate this new analysis which is grounded in 'women's perspectives,' is quite distinct from that of the women who began the work to end violence against women in the 1960s and 1970s. Those women were volunteers, many of whom had experienced violence and been sent back to their husbands by system actors with the injunction to be better wives. They were acting on their own behalf and on behalf of the women in their community against a patriarchal system that did not recognize their distress or their victimization. They had to work hard to see and to name what was happening as victimization rather than as something that they deserved for one reason or another. They began with only their experience to draw on.

Mills identifies herself as a feminist and as a survivor of a violent relationship. She clearly wishes to support a move to a more effective feminist model for addressing domestic violence, one that, she says, "would move us beyond the modernist framework within which mainstream feminist politics developed" (2003, p. 142). She acknowledges that research has given us more understanding of intimate partner violence than existed in the past when the VAW framework was developing, saying, "There is now little doubt that violence experienced in childhood affects adult functioning" (p. 88, emphasis added). 
However, throughout this book she uses language that polarizes and seems to blame mainstream feminists for not getting it right before we had this knowledge (p. 35).

The complexities of feminist efforts to end violence against women have been lost in this account and, ironically, the neglect of the theoretical and practical involvement of Women of Colour in early second-wave efforts reinforced. Mills claims, "We need to develop a more accurate picture of women in abusive relationships in order to figure out how to help them" (p. 60). I would argue that we also need to develop a more accurate picture of early feminist accounts in order to understand our history and current dilemmas and transitions. I include transitions because the ahistorical account offered by Mills does not address feminist struggles to deal with victimization, survivorship and perpetration that have resulted in a much more complex picture (even in 2003) than she presents. She injects an artificial gap between her own analysis which focuses on the need for professionals to acknowledge and address women's agency and mainstream feminist efforts which she locates as concentrating purely on women's victimization. While Mills notes on pages 7 and 107 of the book that she is focusing on common couple violence, she does not identify the difference that this might make to her analysis given that mainstream feminist efforts to end VAW have focused on coercive, controlling violence. If we accept the existence of these two types of violence as Mills says she does, we can see that she has shifted the topic to be addressed in efforts to end IPV. The result is a framework for change that is not able to support change within feminist VAW efforts but has been powerful in inculcating negative attention toward those efforts.

Bourdieu's conceptual framework can help us here to understand the always partial view of each of us as well as the struggle for power and recognition of one's truth. Mills 
raises some extremely important points. However, she generates an inaccurate picture of feminist VAW history. The first feminist VAW activists, who took on making an invisible phenomenon visible to a whole culture, were not professionals. The feminist scholars who took up the cause were acting to bring the experience of women victims to light in a way that could make their victimization known against the prevalent social conceptualization of wife abuse as a private trouble in which the women were implicated. Forty or more years of research on the issue and the creation of significant cultural and social capital attending to violence against women perspectives have generated a situation where VAW efforts have become institutionalized (to however unstable a degree) in state funded organizations. For Mills, mainstream feminist VAW efforts are dominant in the field. In 2003 she gives her full effort to challenging this perspective. She sees her own perspective as dominated. On the other hand, VAW scholars such as Holly Johnson see a brief opening for VAW perspectives in influencing public policy beyond the support systems developed by feminist actors - an opening which began to close almost as soon as it opened (Johnson, 2015).

For Mills, as for many others who are foregrounding a psychological approach to the problem, the responsibilities of both women and men in IPV should be emphasized. However, even within these accounts, women are still visibly the victims of the most severe violence. John Hamel's (2007) assessment of gender differences in the use of violence indicates that women experience more physical injuries, are more fearful of their partners, and that, "while women engage in high degrees of unwanted sexual behaviour toward men... men perpetuate the overwhelming number of rapes in intimate partner violence" (p. 11). In the final reflections in Insult to Injury, Mills states that the 
"oppression of women remains significant" (p. 143) and that "women need not think of themselves solely as victims anymore" (p. 143, emphasis added). In the same way that VAW adherents do not actually believe that all women are victims and all men are perpetrators, the gender parity proponents do not appear to really believe that women's and men's violence is equal.

In sum, an epistemological pairing can be seen between the feminist VAW subfield and the gender parity subfield which emerged in opposition to feminist VAW doxa. The gender parity subfield accepts feminist claims of IPV as a significant social issue but contests the positioning of women as the always and only victims. Feminist VAW thinking has moved beyond this exclusionary positioning and gender parity scholars and practitioners acknowledge women as the ones who experience the greater harm; but the epistemological opposition remains in the field. The gender parity lens is often associated by feminist VAW scholars and practitioners with the men's rights movement who might claim that we have reached gender equality and that there should be equivalent services for men. However, many gender parity scholars and practitioners position themselves as feminist (Mills, 2003; Hamel \& Nicholls, 2007). This opposition also engages debates regarding the efficacy of various approaches to working with male perpetrators to end their use of violence: feminist VAW cognitive/behavioural approaches such as the Duluth method are being positioned against therapeutic models in an either/or framing. Next I turn to an exploration of the third and last encounter to be explored in this chapter: the engagement of trauma-informed theory and practice. 


\section{THE THIRD ENCOUNTER: TRAUMA-INFORMED THEORY AND PRACTICE}

Trauma theories emerge from a significantly different starting point than that of feminist anti-violence frameworks but are currently being brought into mainstream feminist VAW practice to support understandings of female victims of intimate partner violence. Trauma theory is visible in the training and work of women's shelters, sexual assault crisis centres, activists, and feminist therapists among others. For example, as part of its Annual General Meeting in 2013, the Ontario Association of Interval and Transition Houses (OAITH) held a day-long training which I attended entitled "A Knowledge Collaboration of Survivors, Scholars and VAW Advocates: Trauma Informed Approaches." The training focused on trauma-informed approaches to working with women and children who had experienced or witnessed abuse. This workshop included a presentation by feminist psychotherapist Lori Haskell, who has developed a specialty in understanding the impacts of trauma. Trauma theories have also been embraced by gender parity proponents and those working with male perpetrators of IPV and thus provide a significant access point in studying the intersections and interactions of the doxa of these approaches with feminist VAW doxa. In this section I first introduce the relationship of feminist work and developments in neuroscience that are supporting the generation of theory related to trauma-informed interventions. I then explore how trauma theories have influenced the development of work to address male perpetrators of IPV and have inculcated support among some feminists for restorative justice options.

When feminist anti-violence movements began, the more recent developments in neuroscience and trauma theories had not yet provided the basis for understanding the specific role trauma can play in inculcating violence and the potential efficacy of 
compassion in interventions with perpetrators of intimate partner violence. Neither were we necessarily aware of the trauma suffered by men who are violent in their relationships with their female partners. During the formative years of feminist VAW theory, the societal belief was that the neurology of the human brain was more or less fully formed by early adulthood and further brain development was in the direction of 'pruning' unwanted or unused neural networks (Cozolino, 2010). More recent developments in neuroscience technologies have made it possible to view the brain in action and it is now clear that the adult brain has much more capacity for generating new neural connections than was previously known (Cozolino, 2010; Wilkenson, 2010).

These insights from the science of the brain have supported the development of approaches in the helping professions specifically geared to addressing trauma impacts. It is now argued that the presence of trauma can inhibit the childhood development of neural connections required for engaging in a healthy relationship (such as empathy and self-reflection) and that these neural connections can later be developed (Cozolino, 2010). (It should also be noted that trauma in adulthood can similarly lead to the development and/or reinforcement of neural pathways associated with, for instance, posttraumatic stress syndrome.) A number of scholars and practitioners engage with attachment theory in arguing that the generative work of healing past trauma can be supported through relational experiences of positive attachment within a therapeutic relationship (Augusta-Scott \& Dankwort 2002; Briere \& Scott 2013; Wilkenson 2010). In this process, it is posited that the therapeutic relationship "serves as a scaffold within which a client can better tolerate the stress required for neural reorganization" (Cozolino, 2010, p. 342). While brain scanning technologies such as the MRI (magnetic resonance 
imaging) were developed as early as the 1970s, and the uses of these technologies were explored and refined in the 1980s, it was only in more recent decades that the new understandings emerging from these advances have reached beyond the discipline to affect psychotherapy and social services. In the 1980s, I experienced and participated in the 'buzz' within social services regarding the importance of brain development during the early years of life and the corresponding public investment in what was called early years programming (Rushowy, 2011); a current buzz is about the plasticity of the adult brain and the need for trauma-informed approaches in social services with adults (Haskell and \& Randall, 2009).

While some trauma frameworks only engage with factors relating to interpersonal experiences and often focus on singular events rather than chronic situations, feminist researchers Haskell and Randall (2009), along with many other scholars (Herman, 1992; Kinniburgh, et. al., 2005; van der Kolk, 2005, van der Kolk et. al, 2009), argue for the use of a complex trauma framework that can account for social context factors such as gender, racialization, class, colonization, sexuality and abilities as well as experiences of ongoing abuse or other trauma. This more complex framework is necessary, in the view of these scholars, to adequately address situations such as childhood abuse, intimate partner violence or community trauma such as that experienced by Aboriginal communities in the context of (post-) colonial practices. Thus, articulations of complex trauma can respond to feminist concerns that issues of violence against women not be individualized.

Complex trauma can be viewed as "a defining and organizing experience that forms the core of an individual's identity" (Harris \& Fallot, 2001, p. 11-12). Research 
regarding the impact of trauma on children has shown that cognitive, affective and psychosocial development can all be impaired through traumatic experiences of neglect, abuse and social marginalization. Haskell and Randall (2009) highlight that "the coalescing of... trauma-related processes, and the adaptations developed in response, typically results in inadequate self-capacities" (p. 64). MacIntosh (2013) argues that the link between trauma and these incapacities is found specifically in deficiencies in the ability to mentalize. Mentalization refers to the capacity for self-reflection, without which internally motivated change, or healing, is not possible. Without healing, the generational cycle of self-harming or abusive ways of relating are more likely to be repeated in adult relationships.

The feminist anti-violence movement has long recognized the traumatic impacts of abuse on women and children and is engaging with trauma theories in their complex form to gain further insight into how to support and help victim/survivors. However, a number of feminist scholars and practitioners/activists go beyond using trauma theories in work with women and children victim/survivors of violence to propose that trauma-informed approaches should inform work with male perpetrators of abuse. This suggestion builds on insights from research showing a relationship between trauma and the perpetration of IPV. Fisher and Goodwin (2009) note that "It is by now well-known that most domestically-violent men have histories of childhood maltreatment" (p. 107). In a selfreport study of 595 men on a college campus, Lisak, Hopper and Song (1996) found that nearly half acknowledged having been physically or sexually abused before the age of sixteen. Among the 120 men in the study who admitted to perpetrating violence, the childhood victimization rate rose to $70 \%$. As only $38 \%$ of the 221 abused men had 
perpetrated abuse as adults, childhood victimization is not said to stand as a cause of perpetration but is linked to it. A recent meta-analysis by Stoltenborgh et al. (2011) generated a combined prevalence rate of childhood sexual abuse of $8 \%$ for boys in Canada and the United States. Brassard et al. (2014), in their clinical sample of 302 Canadian men undergoing counselling for aggression-related issues, report that $18.5 \%$ indicated that they had experienced childhood sexual abuse, a rate more than double that found in the general population by Stoltenborgh et al. The impact of childhood abuse on males is summarized by Jewkes, Flood and Lang (2015) who state, "boys who are exposed to abuse in early childhood become prone to aggression, impulsivity, and an absence of empathy and remorse, and are more likely to perpetrate violence" (p. 1583). This research suggests to many that trauma-informed approaches should be foregrounded in work with male perpetrators of violence.

Randall and Haskell (2013) highlight that the beliefs and behaviours a person enacts when coping with trauma can result in harm to both "self and others, including conduct which is criminal" (p. 525, emphasis added). Using a trauma-informed approach, they suggest that the impact of trauma on these grown-up children who are using violence in their relationships can be addressed and potentially 'healed.' Randall and Haskell (2013) specifically address the impact of trauma in relation to offenders in the justice system, arguing that a trauma-informed approach can support both accountability and rehabilitation through the development of "more sophisticated appreciations of what causes offending, as well as ... assisting people to develop meaningful appreciation of the harms they have inflicted" (p. 524). The use of the word "assisting" here is significant in pointing to the shift required from feminist VAW doxa in order to consider trauma- 
informed approaches. Assisting perpetrators has a very different flavour than holding perpetrators accountable, although feminist VAW scholars and practitioners advocating for a trauma-informed approach with male perpetrators posit that these two are more amenable than is sometimes acknowledged (Augusta-Scott \& Dankwort, 2002; Randell and Haskell, 2013).

\section{Edward Gondolf (2012), in The Future of Batterer Programs: Reassessing}

Evidence-Based Practice, positions debates about the use of trauma-informed approaches to working with male perpetrators as part of a larger divide between cognitive-behavioral approaches based on social learning theory/feminist research, and psychodynamic approaches which Gondolf names as part of a "so-called new psychology" (p. 91). The new psychology is often associated with gender parity approaches. He notes that batterer intervention programs have always spanned the uneasy gap between accountability and care for men. However, there has been an increasing call in more recent years for an evidence-based approach which diverges from social context-based programs such as the Duluth model towards the new psychology model, many of which take trauma into account. Proponents of the new psychology argue that the evidence shows that cognitivebehavioural models do not work. Gondolf refutes this idea, presenting his research showing that the evidence-based movement is, at the current time, relying on a few studies which are narrowly focused, preliminary and inconclusive (p. 124). He presents a review of the research which examines batterer intervention programs in the context of the system they reside in and shows a moderate benefit. Consequently he advocates for retention of cognitive-behavioural approaches, which he argues are still supported by the research, along with the incorporation of "treatment for the special needs of 
batterers...[which] may assist in reducing dropout and re-assault rates" (p. 125). Overall, he argues that the debate between these two approaches is "significant but may be overwrought" (p. 125) and may present a false dichotomy. In Gondolf's assessment of the debate, we hear the reverberations of the feminist VAW and gender parity debate and the doxa that support these antinomies.

Engaging with trauma theories in work with men who use violence in their relationships does present specific challenges to feminist VAW theories. Using a traumainformed approach when dealing with perpetrators of intimate partner violence requires a shift from seeing male perpetrators' motivations as arising from patriarchal privilege to seeing motivation at least partially arising from abusers' past traumatic experiences often as children in their families of origin or from marginalization arising from social structural issues. The work of Gondolf and other researchers would suggest that the approach that we use to address perpetrators could become more complex, addressing men's attitudes, norms and behaviours in relation to women in a psycho-educational context and including trauma-informed approaches to engage with the victimization experienced by male perpetrators.

Augusta-Scott and Dankwort (2002) argue for such an approach. They contrast educational approaches to working with male perpetrators of IPV, such as the Duluth model, with that of a narrative therapy approach for group interventions. Augusta-Scott and Dankwort validate feminist concerns with therapy models in use before feminist education models were developed, models which individualize violent behaviours and ignore the role of social level factors such as patriarchy. However, they maintain that the dismissal of therapeutic approaches has led to the neglect of a discourse in the literature 
among narrative therapists who have foregrounded the twin goals of women's safety and men's accountability. They further suggest that negative assumptions regarding therapeutic approaches have "obscured the limitations of the educational model and deprived group facilitators [in partner abuse response programs] of vital opportunities to build on and enhance their practice" (Augusta-Scott \& Dankwort, 2002, p. 785). In explicating this argument, they maintain that,

Congruent with [feminist] education model directives, narrative therapists would decline all invitations from men to collude with their excuse-making and their justifications, yet they would additionally regard the offensive behavior to be, at least in part, undesired and unrewarding for the men. This opens the way to rejecting the categorical notion that it is inappropriate to feel empathy for men experiencing shame for having perpetrated domestic violence. ... Empathy, in other words, does not equal assent (p. 792).

Empathy is engaged by those using a trauma-informed approach to working with male perpetrators. In this approach, the practitioner employs their relationship with the perpetrator to create and model a healthy relationship in which the man can experience 'healthy' attachment. This relationship will include empathy or compassion for men's experiences of abuse both in childhood and in adult relationships. Augusta-Scott and Dankwort (2002) argue that what might seem a more common-sense approach of confronting abusers is problematic because it replicates the relationship experiences that these men carry as wounds from childhood, reinforces entrenchment in their ways of thinking and does not lead to healing of traumatic wounds. Thus, in this way of thinking, confrontation does not effectively address the violent behaviours or the trauma of which violence may be a symptom. The positioning of feminist men such as Augusta-Scott, who began their work using the Duluth model in work with perpetrators, bridges concerns with the potential for therapeutic benefits for perpetrators and issues of accountability and the safety of women and children. 
Bringing trauma theories into work to address perpetrators of intimate partner violence also opens the door to the consideration of restorative justice, something that has long been held by many VAW activists, workers and scholars to be counter-indicated in cases of IPV. Feminist concerns regarding restorative justice include a focus within restorative justice on incidents rather than ongoing coercive behaviours, a lack of analysis of the ways that violence can limit women's capacity to genuinely participate in a relational process and a lack of recognition that the formal legal system works for some women (Stubbs, 2002; Ptacek, 2010). As noted above, Randall and Haskell (2013) argue that more satisfying outcomes in cases of intimate violence could be achieved from the justice system through the use of trauma-informed approaches in the context of a restorative justice framework. They articulate the potential of restorative justice thusly:

\begin{abstract}
"Without threat of traditional criminal punishment and loss of connection to others, perpetrators have a better chance of developing empathy and the capacity to mentalize, which describes the ability to grasp one's own thoughts and mental processes. This is most emphatically not the same as suggesting that offenders should escape accountability for their actions through this approach; to the contrary, a trauma-informed restorative justice approach has the potential to impose much greater and more personal and intimate forms of accountability for offenders who must publically grapple with the harms they have inflicted and participate in constructing their own sanctions" (2013, p. 525).
\end{abstract}

Randall (2013) presents her own shift from a "vaguely hostile skeptic to cautious convert" (p. 461) in a separate article also published in the same year. She positions herself in this paper as arguing for the desirability of feminist critical engagement with restorative justice approaches. In arguing for this position, she notes a current lack of legal remedies for IPV that respond to victims as well as the importance of feminist input as restorative justice approaches are developed.

Feminist VAW doxa regarding patriarchy as the source of IPV led feminist activists and scholars to resist mainstream therapeutic interventions with male 
perpetrators which neglected gender. Over time, feminist men who began working with male perpetrators in partner abuse response programs have been troubled by the lack of attention to men's trauma and life experience. They have found value in therapeutic approaches which are used in conjunction with strategies to address women's safety and are bringing these learnings into conversation with feminist doxa. At the same time, diverse feminist VAW researchers have noted the significance of trauma and oppression to our understanding of marginalized men. Here we can see how challenges to doxa emerge through the development of knowledge over time.

\section{CONCLUSION}

This chapter presents the argument that an increasing complexity in accounting for IPV is coming up against the continuing commitment to the VAW theoretical foundation of the female victim/male perpetrator. I maintain that the engagement of feminist VAW doxa with that of other doxa is generating the transformative movement underway in VAW feminist understandings of male perpetrators and how to address them. In the following two chapters I address the themes identified through this literature analysis as they appeared in the interviews with people working in the field. 


\section{Chapter 6 \\ Feminist VAW understandings of perpetrators}

\section{INTRODUCTION}

As long as there is a generative habitus... one will never cease to discover new data (Bourdieu, 1990, p. 9).

"At an earlier age, if someone had told me we're going to start helping the men who are the perpetrators in this situation, I would have been like, 'That's really dumb!" - Jessica

The sentiment expressed by Jessica above distills the heart of a slow and painful transition that I argue is happening within feminist VAW work today. Jessica, one of my interviewees, had been working in VAW services for close to five years. Before she began doing this work, Jessica would not have thought of helping male perpetrators. At the time of the interview, she had moved to thinking that it comprised an essential part of the work to reduce and prevent violence against women. Jessica suggested that other service providers in her organization, which served Aboriginal women, would identify Aboriginal men who perpetrate violence in their intimate relationships as victims of colonial practices as well as perpetrators of IPV. However, she asserted that the conversation around male victimization, and men's need for healing from this victimization, was difficult to have. When I asked her if she had had this conversation with others at work she exclaimed, "No!" I heard similar concerns expressed by other VAW interviewees about both the healing of men who use violence in their intimate relationships and the difficulty of having this conversation in feminist VAW circles. For example, Judy, a long-time VAW service provider who had also worked with PAR programs, noted that a conversation in her VAW community about the victimization experienced by PAR participants was needed but had not yet happened. Melissa, who 
worked in an abuse response setting, said that while she discussed the topic of male victimization often in her work, she was, "not popular in certain areas that I'm in for having that conversation." How can we understand the need among some VAW workers to have this conversation in conjunction with the perception by these same workers of the lack of feminist VAW space for this conversation to happen? This chapter will explore this question using a Bourdieusian feminist conceptual framework and the paired sociological concepts of social structure and agency.

The use of Bourdieusian theoretical tools supports an explication of both the generative and sticky aspects of knowledge production. Bourdieu presents knowledge as socially constructed but also insists that knowledge is generated within a "socially constituted system of structured and structuring dispositions acquired in practice and constantly aimed at practical functions" (Bourdieu \& Wacquant, 1992, p. 121, emphasis added). This reminder of the socially constituted and practical focus of my interviewees is important for me as I undertake the analysis of the primary research data. First, I must explore the interviews within the context of both the subfield and the larger field within which they exist. Second, I must remember that the knowledge needs of those in practice are quite different than those of researchers who desire to construct models which reflect that practice.

In this chapter, I build on the theoretical work of chapter two and the literature review and analysis in chapters four and five to engage with primary data from interviews with 21 women who worked or had worked within a feminist VAW framework. (See Appendix B for a demographic breakdown of the interviewees.) I analyze the interviewees' reports of their early feminist VAW habitus and associated doxa regarding 
men who use violence in heterosexual relationships. I then present their understandings of changes in this doxa as they look back on their experiences over time. I focus this reflection through reported changes in their positioning on the role of compassion in work with male perpetrators (work which is done by others or by these workers in other contexts). Finally, I explore the challenges to their feminist VAW doxa presented by this evolution, as described by the interviewees, as they personally engage with increasingly complex knowledge regarding male perpetrators in three encounters: with the lived experience of men, with diverse cultural values and with theoretical developments in the research literature in the areas of typologies of violence and trauma theories. I begin below with an exploration of the interviewees' naming of, and meaning attributed to, intimate partner violence and how these reflect the positions and positioning of the interviewees over time.

Before proceeding, however, I wish to remind my readers of the discussion in chapter two regarding the gap between theoretical explication and the really real. An exploration of the work done by VAW doxa in the naming of IPV does not constitute a contestation or confirmation of the facts behind the concepts being explored. What the use of doxa does do is allow us to see the struggles within the field and the engagement of conflicting and ambivalent habitus in that field and associated subfields. An investigation of doxa of the field of work in this area can help us understand the positions and positionings of ourselves and others relationally, and leads to a very different explication than that which would have been demanded by my original research question (colloquially expressed as "What's going on in IPV?") which implied an answer expressed in terms of evidence regarding what is happening on the ground. My 
examination of the field of work to reduce and prevent intimate partner violence supports a socio-historical understanding of that field; this exploration does not address what is happening in situations of IPV. Nor does it support a discussion of which scholars, practitioners and activists are 'right' and which are 'wrong.' Far from determinations of right and wrong, and therefore legitimate and illegitimate, a reflexive sociological approach holds that each position in the field exists because of, and in relation to, the existence of the others.

\section{EXPLORATION OF VAW DOXA IN THE NAMING AND MEANING OF IPV}

The terms used to identify intimate partner violence vary widely among the VAW workers and have changed over time. 'Wife abuse' and 'Woman abuse' were identified by the interviewees as terms in earlier usage. 'Woman abuse' is still preferred by two of those who also use 'violence against women'; Aurélie identified herself as "old school” for using woman abuse. Others used 'domestic violence,' which was identified as coming into common usage after 'woman abuse' and as one which, although nominally gender neutral, contained a connotation for the interviewees of women as victims and men as perpetrators within a heterosexual context. Intimate partner violence is a newer term which was seen to have advantages in expanding inclusivity but also presented problems in the loss of the gender focus. There was also a suspicion expressed in terms of the origin of this term: Lisa said, "It's not something that I embrace; I feel that it's often generated by the men and by that movement." Influences on naming IPV among the interviewees included the interviewees' personal experiences and identifications, the age of the interviewee, population served, their entry point to the work and time of entry, and 
the degree of their personal commitment to the core doxa of the female victim and male perpetrator as the only or primary expression of intimate partner violence.

At the beginning of each interview I identified work on intimate partner violence as the topic I was researching and acknowledged IPV as a contested term. I then asked each interviewee what term they used. Ten women said that they used the term intimate partner violence, five of these identifying it as a term that is more inclusive of same sex and transgender relationships. This is illustrated in the following quote from a long-time VAW worker:

Pamela: Well, I like that term. I like it for several reasons. I like the fact that it can be same-sex couples as well... If you call it wife abuse or something like that, it doesn't cover the picture. I'm happy to call it intimate partner violence and to make it very broad-based.

Other reasons given for this preference included: the need to not shut down men who are victims even though they may be few in number ( 1 interviewee comment), sector changes in usage of terminology (with the note that ongoing shifts in terminology are difficult for the public) (1), and, that the term captures the intimacy that has meaning for the client (1). Mary, who had been involved in feminist anti-violence work and LGBTQI activism for eight years, positioned intimate partner violence as a newer term in the movement in noting her preference for it:

Mary: I think by the time I started this work, that word [wife abuse] was not as commonly used. I started about eight years ago... I have used violence against women, but that has been a product of where I have been working and not necessarily my own preference or framework. But I think intimate partner violence is one I use a lot ...

Karen, who worked in the VAW movement for more than 10 years from the 1970 s to 1990s, said that intimate partner violence was not a term she used, again positioning it as a newer term in explaining her preference: "I don't know if it's age or old school." She also made a reference to her aversion to the term 'domestic violence' stating, 
Karen: I cringe when I hear 'domestic violence' - it just, it turns my stomach. And I try to explain to people why that's not okay, you know?

Deborah: Um-hum. So tell me.

Karen: Well, domestic. There's nothing domestic about violence and it would indicate that [pauses] that it's, it fits in with the cooking and the cleaning, the domestic things of the home. So.

Deborah: It attaches itself to those things as natural?

Karen: Exactly.

In contrast, Nancy, a counsellor in an organization that works with immigrant women, noted that in her organization they prefer the term domestic violence:

Nancy: As I said, seldom do we talk about intimate partner [violence]. Because intimate partner is a little bit more sensitive than when we talk of family. ... Domestic is a more general term. That means that people find it easier to talk. But if you talk about intimate partner then people are, "Oh, my" [makes a gesture of distaste].

Domestic violence was also used by three other interviewees, while partner abuse, and 'power and control,' were used by several interviewees.

Six interviewees preferred the term 'violence against women' in order to maintain a focus on the gendered nature of the violence that the interviewees addressed in their paid or volunteer position. Stacy noted that she does use intimate partner violence in some situations, as "the term comes out of a noble intent, which is to capture violence in same-sex relationships, for example.” But Stacy feels violence against women is more accurate. She argues,

Stacy: The problem we're actually trying to describe is violence against women. The vast majority of what we are talking about is violence against women, typically perpetrated by men. So, the problem we encounter by using 'IPV,' as a very generic term, is that we lose the accuracy of the description of the problem we are talking about.

I asked Stacy how she would distinguish if she was talking about intimate partner violence or other kinds of violence against women. Stacy responded: "I usually say violence against women. And then I qualify it and say violence between intimate partners 
happens in a number of ways and describe it. That's typically the way I would say it."

Another shelter worker, Jennifer, concurred with Stacy's positioning, saying,

\begin{abstract}
Jennifer: We do not use intimate partner violence. We find, or I find, that it's too vague and doesn't actually speak [to] what's really happening in these situations. I have used domestic violence solely because that's what's recognized legally. But for the most part I work hard to try to make sure I'm using the words women abuse. So I would describe it as any form of violence, of systematic violence, that is perpetrated towards females. And it can include domestic violence or violence between partners. I would also include child sexual abuse, pornography - so any forms of violence that happen in our society towards girls and women. I would also talk about the need to identify it as women abuse and acknowledging that primarily, by huge majority, the victims of this form of violence are women, usually at the hands of men.
\end{abstract}

Feminist doxa regarding the female victim/male perpetrator of patriarchal violence could be seen in the above discussions as a significant influence in the naming of the issue, with concerns regarding inclusivity toward same-sex relationships, cultural comfort, and a desire to not associate domesticity with violence, also present. And, although just less than half (10 out of 21$)$ interviewees used the term 'violence against women' when talking about intimate partner violence, a large majority of VAW interviewees defined heterosexual intimate partner violence in alignment with VAW doxa along two dimensions. The first is that of agreement with the female victim/survivor and male perpetrator comprising the dynamic in the vast majority of cases with several interviewees defining it specifically and only in terms of male to female violence (e.g. "any form of systemic violence that is perpetrated toward females"). The second is that of the abuse of power and control by the perpetrator as comprising the core of IPV. Fifteen interviewees defined IPV as the abuse of power with the rest allowing room for the presence of common couple violence. An example of 'woman' as the victim/survivor in IPV can be seen in Christina's response. Christina prefers the term intimate partner violence to VAW, but in alignment with the definitions given by Stacy and Jennifer 
above, both of whom use the term violence against women, she still refers to the female

partner as the victim/survivor of controlling abuse:

Christina: I think in intimate partner violence ... [the public] ... think[s] of hitting first. And so I actually, consciously, don't mention hitting first but mention what women are actually reporting more often which is verbal, psychological and financial [abuse] and so I tend to kind of skew it a little bit purposely.

Karen, who discussed her past work on IPV in terms of addressing "abuse ... by the male partner" illustrates the doxic nature of the concepts of the power and control in defining intimate partner violence, in naming these as 'obvious':

Karen: "What do I include? Obviously, physical abuse, sexual abuse, financial abuse, psychological abuse. [pause] I'm sure there are lots more. Emotional, psychological, psychological having an element of fear. Um. [pause] Threats and intimidation, probably ties into the psychological. And manipulation and coercion, being a part of - [pauses]. And just using that 'power over'."

While these responses show that the female victim/male perpetrators doxa is still

firmly in place, some shifts in this doxa can be seen. Emily, a younger woman doing

youth work, maintained a focus on the imbalance of power in her description but did not

identify men as the perpetrators:

Emily: I'd say that dating violence is, like when you break it all down or boil it all down, it comes down to power and control. So, it's when two people who have an intimate relationship are together and there is an imbalance of power and whether somebody abuses in any way then, you know, that's where you're going to have that dating violence. And it can happen across the board. It doesn't matter age, race, social status - anything. So it can happen to anyone. And I think that's something that not a lot of people are that aware of. So that's how I would kind of define that.

Mary expressed an interest in the idea of typologies of violence that she had learned from

Michael Johnson's work. And while she had reservations about the implications of this typology for victims of coercive controlling violence she also noted that common couple

violence does happen:

Mary: I get where he and his research are coming from ... and I can also imagine how that would be a giant minefield for a lot of people, with the idea of common couple violence where both parties are participating in it, because then you start to get questions about blame and instigation. 
Nine other VAW workers also expressed some openness or even commitment to the notion of typologies of violence at some point in their interview.

For several of the interviewees openness to typologies co-existed with a definition of IPV that focused on the abuse of power. For Karen, this overlap occurred because she had left the work before typologies were presented in the research literature. Her old definition stood beside the new concept of typologies introduced in the interview which she responded to positively as explaining some of her experiences as a VAW worker. Stacy maintained through the interview that intimate partner violence was about men abusing their power over women, at one point saying, "it's because of inequality that men can control women the way they do." Toward the end of the interview I asked about her response to Michael Johnson's work identifying typologies:

Stacy: I think he is describing something that's true - that there are different kinds of violence. And different intentions. The purpose is different. So I think it's important that we understand those distinctions because we don't have the resources to respond -- and we shouldn't be responding -- the same way to every case. We should be able to recognize what's in front of us and put the right response in place to deal with it.

Deborah: And the ones that are not coercive... is there sometimes conflict rather than...

Stacy: Yeah. I think that in every case if you look at the context of what you are talking about, then you can figure out what the intention of that violence is. And whether it's serving a bigger purpose in that relationship. So is it a one-off thing? Is she normally feeling like she is free to come and go as she wants, and do what she wants or whatever? Or is it part of a pattern with a purpose? And I think it's important to recognize that the best source of the information is the woman. She may be able to describe to you what's going on. But she may also be coping with it in such a way that she doesn't recognize it. And so you need to be bringing your own lens to it and saying 'hmmm, help me understand this'. You need experienced advocates who understand the problem in front of them and who can dig around enough to understand what's really going on.

Stacy identified IPV as the abuse of women by men. She also, when explicitly asked, agreed with Johnson's analysis showing the existence of typologies of violence which go beyond coercive control to include common couple violence (which he identifies as the most common form of IPV). Bourdieu's conceptualization of the logic of practice can be 
of use in understanding this. Bourdieu notes that practice uses only the amount of logic necessary for the work being done. The logic of practice balances the need for coherent principles which respond to perceived real-world conditions with the need for usefulness. Practical use requires that these principles be "convenient, that is to say, easy to master and use" (1990, p. 86). The balance between these two needs results in an "economical logic" (p. 86) that is experienced as internally consistent and an appropriate response to objective conditions. However, inconsistencies in the logic of practice can exist when contradictory beliefs are not brought into confrontation. Stacy described how an investigation into the context of the violence can reveal the presence or absence of coercive control, but she included only the context as presented by the woman in the situation with the assistance of the VAW worker. She neglected the potential for mutual violence or for a male victim, both of which figure in Johnson's typologies (Johnson, 2011), but neither of which are within her scope of practice. This is congruent with Bourdieu's argument that practice only relies on the logic necessary for practice. As her VAW doxa and the specific aspect of typologies theory that would stretch her VAW doxa further were not brought into confrontation in her work, this 'fuzzy' logic was not challenged. (Nor was it necessary for her to challenge it in order for her to be successful in her practical application of her knowledge in this area.)

The power of the foundational doxa can make the framing of IPV as 'male abuse of women' seem natural to those of us using a VAW lens and working only with women and feminine-identified individuals. However, the contained elision can be jarring to those who have one foot outside the VAW framework. Ashley was both a student studying trauma-informed approaches to service provision and a VAW volunteer. From 
this less immersed place she identified the exclusive focus on violence against women as troubling to her:

Ashley: That actually comes back to how I define myself as a feminist. Because I have seen within my volunteering certain people who are asked about women being violent against their partners regardless of sex, right? And they are like,' yes it happens, but the majority...' it's like they jump back to that innocence that - I get the feeling that they are shutting it down... I think that violence is violence and regardless of whom the perpetrator and/or victim are we need to address the violence, you know. It is not about the perpetrators so much as how can we address the problem, right? Because no violence should be okay.

A questioning of VAW doxa could also be seen in the responses of Judy and Pamela,

both long time VAW workers who had more recently co-facilitated in the PAR program.

Pamela's observations also brought class into focus as a social structure with impact on

IPV:

Pamela: I look at these guys and I say, 'you aren't some patriarchal uber-lord. You can barely get yourself together for the day, let alone control another person.' There are a huge number of people just staggering through. With addictions, and unemployment, and kids being taken, and you know with serial relationships. They are just nowhere.We do have a set of guys [who say] "I'm in control and blah, blah, blah". And with them we talk about negotiating and decisionmaking and how their outlook isn't constructive to a good relationship, and how does that make your partner feel ... So that is the range.

Deborah: What proportion of the people you see are in that controlling realm?

Pamela: Very few. If there are 20 guys in a group, I doubt three of them. And they would be the older ones. Actually the older middle-class guys are way worse than the younger, punky, unemployed, occasionally unemployed guys with that.

Bourdieusian feminist understandings of the reflexive habitus explored in chapter two

help us see the ambivalence shown by these VAW interviewees as evidence for a shifting understanding of intimate partner violence. One pathway to change in the habitus is experience which contest the field's doxa, which may otherwise be experienced at the level of unchallenged belief. The reflexive capacity of these workers in the context of their experience provided a pathway for them to make the VAW doxa visible as knowledge that can be challenged. We can also see here the dual role of social change groups as the sites of social change but also as collectivities that attempt to maintain 
(redrawn) boundaries between what 'we' know to be right and what we know to be incorrect.

After interviews with 21 women working in the field, I cannot provide an accepted terminology and definition of intimate partner violence that is used in the field in this local area. The boundaries of this topic are stretched in various directions depending on the habitus of the interviewee and their relation to the doxa of the subfield over time, although 'everyone' clearly knows what the topic is that we are talking about. In thinking about this situation and my need to name and define, I note the difference in the use to which this information will be put in my work versus that of my interviewees. My research goals obligate an interpretation, and ideally a distillation, of intimate partner violence as conceptualized by my interviewees; their purpose is more practical. Bourdieu (1990) argues that practical expertise is embodied knowledge that does not require explication for coherent practice. For my interviewees, as long as 'we' all know what we are talking about, the purpose of practice has been served, in that the work can move forward. Within their own subfield or field, practitioners do not necessarily need to address the fuzziness in their logic. Bourdieu locates my (practical) research dilemmas regarding the definition of IPV as inherent to the principles and practices of research rather than as a judgement on the researched.

Further to this, the term intimate partner violence is not the term under which these practitioners are united; it is terminology I have imposed for the very purpose of making the doxa under discussion comparable to other "universes of practice" (Bourdieu, 1990, p. 87) such as that of the PAR workers and private practitioners. Within practice, the need for rigorous logic is limited as the various universe[s] of practice are unlikely to confront 
each other, so that "the same thing may, in different universes of practice, have different things as its complementary term and may therefore receive different, even opposed, properties depending on the universe of practice" (Bourdieu, 1990 p. 87). In designating the field I am investigating as the field of "work to reduce and prevent intimate partner violence' and in investigating this work across various subfields, I am bringing separate universes of practice into confrontation. This produced some consternation among those in the field but also was welcomed as an opportunity to express deviation from, or confusion about, the prevailing doxa. There are a variety of habitus in each field, with varying degrees of adherence and ambiguity toward the field's doxa. In my position as a qualitative researcher engaging with the theoretical framework of reflexive sociology, I see the explication of doxic practice in relation to other practices as an opportunity that can ultimately support efforts to reduce and prevent intimate partner violence. In making this assertion, I betray my bias toward scholarly practice.

\section{THE FOUNDATIONS OF PATRIARCHAL AND VAW DOXA AS SEEN IN THE INTERVIEWS}

Gloria was, as she said, "a feminist with a capital F." Gloria was an early member of a VAW service and worked in feminist anti-violence movements for over 25 years in various positions. She said that in the years before the battered women's movement began, “wife assault was not visible as a social issue. We weren't aware of it. If a man murdered his wife, well, she probably deserved it. You know? The police didn't even investigate all that much in those days." Patriarchal doxa regarding how intimate partner violence should be addressed, as described in chapter two, are visible in Gloria's story of how the murder of women by their husbands was seen before feminist interventions. The 
assumption by the police as well as the public that "she probably deserved it" was based on the belief that the 'good' husband/father would never do such a thing without due cause. As well, patriarchal doxa supported wife abuse as a private relationship trouble for which society did not have responsibility (as in "the police didn't even investigate..."). The habitus associated with this doxa allowed police and the public to remain unconcerned about the violence of which they were aware and to neglect the violence that lurked under the surface of social life (although there were efforts at the time to address it as a psychological or relationship issue). The patriarchal habitus regarding wife abuse began to become visible to Gloria when she attended a presentation on violence against women. With exposure to this feminist doxa, Gloria began to look around her with new questions in mind. She expressed how shocking and painful it was for women in that time to actually begin to 'see' the endemic nature of relationship violence that had previously been invisible to them when inhabiting a patriarchal habitus regarding the reduction and prevention of intimate partner violence.

Although shaken by the widespread nature of the problem, both Gloria, and Pamela another long-time VAW worker, felt an initial optimism that wife abuse could be brought to an end. Gloria said, "I figured in 10 years it would be looked after. Just tell people and it will stop..." Pamela said, "We really thought, when we started - five years we'd be done... I just thought, as soon as you let people know, 'Well of course we're stopping!"” At another point in her interview Pamela comments, "I thought we could ... do public education events... educate women and empower them... so they got to recognize that they were a force... yeah. I thought that would pretty much do it." Both these activists identified themselves, from their current knowledge, as naïve in their 
assumptions that wife abuse could be brought to an end in such a short period of time. And while this 'just say no’ approach does seem naïve from today’s knowledge base, I interpret the early optimism of these activists as emerging from the patriarchal habitus itself: good men protected women, they did not assault them. Therefore telling men and women that what these men were doing was wrong (i.e. that they were not acting as 'good men') should be enough to inculcate a change.

Feminist VAW activists made the existing patriarchal doxa of the field of work to reduce and prevent intimate partner violence visible. But as they discovered, this new visibility was not enough to change the habitus of those engaging in violence. Many of the men who were battering their wives, as Gloria mentioned in her interview, maintained a public persona of a "nice guy" who would never do such a thing; these men were able to maintain this fiction with the support of patriarchal doxa. Women's initial optimism that men would stop their violence when they understood what they were doing diminished as the violence continued. Gloria reported that over time her experiences taught her that even the men who looked like 'good men' were capable of dreadful acts of betrayal toward their female partners. Pamela moved from her early confidence that of course they would stop to a belief that men who engaged in this kind of violence were unsalvageable: "Put them away, throw away the keys!" As these women engaged with the entrenched nature of wife abuse, a subfield of feminist VAW doxa began to emerge from their experiences that repudiated the patriarchal doxa in the field and overrode their initial optimism. The feminist naming of violence as endemic to patriarchy, as a choice to not give up patriarchal privilege, and finally, as rooted in patriarchal structures requiring intervention were visible in the comments of the interviewees as I explored below. 
Gloria reported how she and others became aware of how patriarchal expectations were enacted as they listened to the stories of women who were being abused. As they worked with abused women, they saw that these women were not deserving of abuse. Yet, their abusive husbands continued to be accepted in the community as 'good men'. Far from abusive behaviour being an aberration from patriarchal expectations of husbandwife relationships, it became clear to Gloria and others that the expectation to be in charge of the family gave men permission to engage in abusive and controlling behaviours.

Feminist anti-violence activists also identified that men who were violent seemed well able to control their behaviour in the community. It was in the privacy of their family that their violence came forward. Judy had been a feminist anti-violence activist for over 20 years. She identified her early view of male perpetrators as a simple one: "Like the guy's just a jerk and he chooses to beat on his wife and his children." The man's choice was based on the experience of privilege and entrenched beliefs about women's and men's roles. Jennifer discussed her understanding, saying, "I have not seen many cases where adult men have been able to change their patterns and their behaviours and the way they believe that women's roles are in society.... I am not sure how much an adult male is truly able to change that type of behaviour." Whether unwilling or unable, in the VAW doxa that developed, men have been seen to be unlikely to change.

Finally, feminist anti-violence against women activists began to argue that abuse was not a personal problem but a social issue rooted in male expectations of patriarchal control. When asked about why abused women were thought to deserve the abuse, Gloria drew an explicit connection between the personal and the social: "Well, you see she 
would speak - talk back to him - and women weren't supposed to talk back to their

husbands. They were to be subservient, eh?" Later in the interview Gloria added:

Gloria: It's a society that still places the male as the - it's a misogynist society. So, it's historical. You look at the church; you look at our government, which is an adversarial system; you look at our justice system, which is adversarial. Um. Males have power, dominance, and [pauses] - and it's bizarre when you think about how smart women are [laughs]...

When I asked Judy about the causes of intimate partner violence, she said, "The inequality that exists. That's the root of much of this. You know, until women are equal partners economically, government, parliamentary -- they are left in a position of less power."

In the context of the social acceptance of wife abuse, feminist VAW doxa developed with the intertwined goals of having such abuse taken seriously as criminal behaviour on the part of male perpetrators and ensuring the safety of female victims. Lisa brought forward the continuing issues for women seeking justice:

Lisa: The systems are [filled] with barriers for women to seek justice so, has my view changed? Not so much. Have I become much more cynical about some of the realities? For sure. Because you know we're fighting the same issues, often. You know? And until the system demonstrates that a perpetrator of violence is going to get a, you know, a substantial kind of a consequence in the justice system, it's hard to tell women they can seek justice and be successful in doing so.

Kathleen presented the safety aspect of feminist concerns in the form of her organization's mission statement: “"to provide safety and support for women and children who are fleeing abuse and to work for change.' That's my mission, that's our mission, why I was hired here."

Second-wave feminist VAW activists laboured to (once again) bring into public consciousness the disturbing situation of abused women and the agency abusive men were exercising (and refusing to let go of) with the support of patriarchal privilege. They explicated the need for societal interventions to protect women who, within the 
patriarchal doxa of the field, had been told to 'go home and be better wives,' and they took steps to develop supports. Their interventions successfully changed the Bourdieusian field of work to reduce and prevent intimate partner violence dramatically. In doing so they/we brought into being doxa that asserted men's power and women's victimization within patriarchal societies, in Bourdieusian terms creating a field of work to end VAW, which I position in this dissertation as a subfield of the field of work to reduce and prevent intimate partner violence. They powerfully explicated the role of social structures in intimate partner violence. However, as this insight became doxic, the claim that women are the victims and men the perpetrators in abusive relationships perhaps inadvertently reproduced patriarchal understandings of the power relations between women and men by reinforcing the notion of men's power over women within patriarchy. This also erased the potential for victimization on the part of men who use violence in their relationships.

\section{A CHANGING PERSPECTIVE ON HETEROSEXUAL MALE PERPETRATORS}

It is now more than five decades since second-wave feminist efforts to end wife abuse began. The doxa of feminist VAW work has become more complex and sophisticated over time in response to research findings and as a result of the activism of diverse women within the movement. However, the concept of the male perpetrator and female victim/survivor continues to be foundational to VAW scholarship, practice and activism. In the interviews with women who worked with or had worked with VAW organizations, I found both a commitment to this foundational doxa and a questioning attitude that in many ways presents a challenge to the doxa that men who use violence in their relationships are acting from privilege and using patriarchal power to control their 
female partners. While this questioning attitude could be seen to be part of the increasing sophistication of VAW doxa, for many of the interviewees there was a siloing of knowledge rather than integration into VAW doxa, providing evidence that this shift is one that resides in uneasy coexistence with feminist VAW doxa. There is also evidence within the responses of the interviewees that this is a time of transition in VAW understandings of men who use violence in their intimate relationships. The habitus of VAW workers is conditioned by a belief in VAW doxa to remain grounded in that doxa. However, the habitus also exists within a set of intersecting fields that provide experiences that challenge this doxa. There exists an infinite variety of habitus even within the limits "set by the historically and socially situated conditions of its production" (Bourdieu, 1990, p. 55).

The next section explores how the interviewees were engaging with the transition in feminist understandings of male perpetrators. Below, I introduce this engagement using the concept of compassion. Among my interviewees I found that a view of compassion as a relational tool with efficacy in work with men who use violence in their relationships was an indicator of the presence of challenges to foundational VAW doxa. A comparison of the responses of interviewees in this area revealed generational differences. Following this exploration I present three themes relevant to the interviewees' explanations of changes in their views of men who use violence over time. These themes are: encountering the lived experience of men, encountering diverse cultural values and oppressions, and encountering theoretical frameworks. 


\section{Compassion as an indicator}

I found 'compassion' to be an indicator of the difficulties experienced by my interviewees in integrating understandings of male perpetrators' victimization with their VAW doxa. The interviewees identified compassion as essential to their work with female victim/survivors; many of the interviewees also identified compassion as necessary for efficacy in work with male perpetrators of violence. This requirement was framed within the context of an increased awareness that these men were, in many cases, also trauma survivors and thus had likely suffered (gendered) developmental impacts. This knowledge complicated and challenged the doxic belief that the male perpetrator, for instance, as expressed by Judy, was just "a jerk."

Hannah Arendt (1965) defines compassion as "the capacity for suffering with others" (p. 81, emphasis added) and suggests that a relationship of compassion must be more or less an equitable one. If we experience others who are in difficult situations as too different from us we will not be able to experience compassion. The most we could experience is pity. Instead we must be able and willing to bridge the gap between the experience of the 'other' and ourselves. A second aspect of compassion that Arendt discusses is a sharing of suffering. And, she says, this 'suffering with' is not that "of the one who is spared with the man [sic] who is stricken..." (p. 85). Rather, in order to feel compassion for someone we must be willing to experience their suffering.

Compassion was a central concept for VAW interviewees, a quality seen as essential in working with clients, in workers' relations with each other and in workers' capacities for self-care. The qualities noted by Arendt as necessary for compassion are visible in what the interviewees had to say regarding compassion toward their clients. 
Alishba offered this definition of compassion: "the ability to feel for someone whose life is so dissimilar to yours - to try to put yourself in their shoes and feel for them." Kathleen noted that it was important that women coming into the shelter "see compassion within the team. You know, everybody helps each other out ... Its role modeled.” Many interviewees also highlighted compassion as needed in relationships among VAW workers and for one's self. Jennifer described the integral role of compassion in the work with women, saying, "I think for the workers... [compassion] means you need to be able to feel what the woman is feeling and understand the impact." She also recognized the costs there may be in doing this for the workers: “... right there is that ongoing struggle ... to do this work long term you have to still be able to connect with women emotionally that way and still do it in a way that protects yourself."

The need for compassion in order to do effective work with abused women has long been understood. A requirement for self-care on the part of VAW workers in order to avoid 'burn out' or 'compassion fatigue' is of more recent origin but also well recognized at the time of the interviews. What was surprising to me was the degree of mindfulness among these interviewees regarding compassion for male perpetrators as an essential ingredient to effective work with these men. It seemed that the positioning of the VAW interviewees had been impacted by the introduction of trauma-informed practice.

In the interviews, after discussing compassion in their work with abused women, I noted that compassion is a 'feeling word' and asked interviewees for a feeling that would be appropriate for workers to have toward clients who were male and perpetrators of violence. Here is the response from Karen to the question of compassion in services to male perpetrators: 
Karen: You know, I think compassion works for perpetrators as well...

Deborah: I'm guessing that this is a different analysis than you would have had in the 1970s?

Karen: Yes! Definitely. Yes. Yes. 'Kill the bastard.'

As happens in qualitative interviewing, the structure of this question did not strictly adhere to this framing in each interview. I did not anticipate that compassion would be so central to the analysis and was not as rigorous as I would be now in the framing of the question within each interview. Sometimes the entry point was from another direction and sometimes the interviewee addressed the question spontaneously. As well, in one interview, compassion was not discussed at all. In this last instance, the interviewee (Ashley) did discuss what services should be available for male perpetrators in terms of healing from trauma:

Ashley: “...there are definitely crimes being committed and those need to be punished as such. But there is this missing piece of, often -- not always -- missing piece of -- whether it be counseling or you know education or programming of some other sort, or just giving perpetrators resources for whatever is going on for them. Because it is not typically just someone who is choosing to be violent right? There is something going on for them whether it be, you know, they have experienced their own traumas or maybe they have an addiction or maybe they have mental illness or something that can be behind it, right?"

While not naming compassion here explicitly, Ashley did talk about the perpetrator "needing resources" and this need being a missing piece in the available services. She imagined the likelihood that these men have "experienced their own traumas..." implicitly comparing male perpetrators' 'own traumas' to the traumas of women victim/survivors. Her response to the perpetrators' suffering demonstrated compassion as a needed ingredient for change.

The belief that compassion for perpetrators is necessary for effective intervention was not an unusual positioning. Seventeen of the 21 women working or having worked with organizations using a feminist VAW approach, talked (many in a conflicted way) 
about the need for compassion, empathy, or in one case 'kindness', for men's diverse life experiences of trauma in order for work with male perpetrators to be effective in reducing recidivism. For all of these women, this was a significant shift from their early VAW understandings of appropriate responses to male perpetrators. I want to emphasize before moving on, that I am not identifying here whether these women feel compassion for male perpetrators, but whether they feel that this approach is required for effective work in reducing recidivism. This positioning is explored as an indicator of openness to the applicability of trauma-informed approaches to working with male perpetrators. As trauma theory proposes that healing is possible and moreover provides a road map for that healing to happen, I also connect an acceptance of trauma theory with the belief in the capacity for men who use violence to end their violent behaviour through a process of healing.

Four interviewees - Stacy, Kathleen, Carol and Denise - did not engage, in the interview, with the concept of compassion as necessary in work with male perpetrators. These women remained focused on the need for male perpetrators to take responsibility for their actions and/or for punitive sanctions in order to reduce recidivism. Stacy also argued that the route to ending intimate partner violence involves greater equality for women and meaningful access to resources such as housing.

As noted by both Gloria and Pamela, women who first engaged with the issue of intimate partner violence in their communities expected a rapid end to IPV through their efforts to educate the public. When this did not happen, the subfield of feminist VAW work began to form and to articulate a doxa that asserted men's attachment to patriarchal privilege as the cause of violence in counter-distinction to patriarchal explanations that 
highlighted men's mental health issues or women's dominance and/or masochism. This feminist VAW doxa was what each of the other VAW interviewees encountered as they took on this work. Below I explore the generational differences that emerged in how the interviewees addressed the question of what feelings on the part of workers would be needed for effective intervention with men who have used violence in their intimate relationships.

\section{Generational Differences}

The sample size of this qualitative research is too small to draw anything but highly tentative conclusions. However there are indications that the differential placement of three groups of VAW workers in relation to the development of feminist VAW doxa has had an impact on the development of their habitus specifically in relation to their belief that compassion would be necessary for effective work with male perpetrators of IPV. Below I explore the positioning of (i) those who were part of the early development of the field, (ii) those who entered the field in its formalization or institutionalization period and (iii) those who entered the field more recently as trauma-informed approaches were becoming more common in social services. (See Appendix B.)

As presented earlier in this chapter, Gloria and Pamela are two interviewees who began their work on the issue of wife abuse in the 1970s as VAW doxa was developing. While they each identified their early optimism regarding the potential for ending wife abuse as naïve from their current perspective, it is interesting that both maintained an interest in and investment in men's change. Gloria commented that men have the capacity for change and communicated her compassion for the trauma they experience. Pamela spent many years working with abused women and had in more recent years worked as a 
co-facilitator in the PAR program. While she saw only small changes in most of the program participants she expressed the belief that this work is necessary to end IPV. She commented that she felt she was working on behalf of women victims and against violence against women although she had felt ostracized by her feminist community for a perceived 'shifting of allegiances' in moving to working with men. Both Pamela and Gloria lost their initial optimism during the formalization period of feminist VAW doxa; however adopting VAW doxa that men cannot change required a significant shift; they began with this hope and it had resurfaced even though they had had contrary experiences.

A further 12 of the interviewees who were over 40 years of age had entered a field which had a fully formed doxa. Five of these women had worked in the field for over twenty-five years. Two had between 20 and 25 years' experience. Four had between 11 and 20 years' experience and three had worked in the field for between six and 10 years, two of these having come to it in mid-career with an already-developed VAW habitus. Sylvie provided an example of a woman encountering VAW doxa in the late 1980s. Sylvie worked in a number of volunteer and staff positions at several shelters. She first engaged uncritically with the movement but as time went on, she said, “... they were explaining violence against women and it was just patriarchy, and I just said, 'Well it's too easy. It's too simple. There's more to it.'... I learned fast that you don't say things like that." Sylvie, unable to integrate what she was experiencing with the VAW model being used, left the work in the early 2000's as her personal views developed and diverged from a strict VAW perspective. Other women remained in the movement and continued to struggle to integrate VAW with the insights brought to them in their work 
and from other life experiences. All four interviewees who did not identify compassion for men as integral to effective work with male perpetrators were from this second group of interviewees.

The women in this group who did name compassion as needed for effective work with male perpetrators tended to struggle to integrate it with their VAW framework. A number of these women also reported the experience of not having a place or community in which to talk through their conundrums regarding new insights they are having in relation to ending violence against women. The belief that compassion is needed for effective work with perpetrators was connected with trauma-informed knowledges that they had acquired in their work with abused women or in other training or work settings. However, there was a lack of integration of this knowledge into VAW doxa regarding male perpetrators for most women who were long-time VAW workers.

Jennifer provided an example of the lack of integration between trauma-informed knowledge and VAW doxa in relation to male perpetrators. Early in the interview she positioned herself firmly within a VAW perspective with the statement that male perpetrators would not, or could not, change their beliefs about women from which the violence emerges. She continued, "So, I am one of those people who think it is too late to address men who are already using abusive behaviour in their relationships." Thirty minutes later in the interview, Jennifer had shifted to using a trauma lens as we spoke about women's capacities to change, and following this, the potential for change in boys:

Jennifer: So I think just by changing the ways we socialize our girls and boys we could probably change what the outcomes for these kids would be if little boys were being taught other ways of handling their emotions and using words. So even under the trauma-informed [approach] it's learning to connect feelings with actions and using both parts of your brain, the right side and the left side. Learning to work through, adding new coping strategies and how to deal with a flash 
back that doesn't involve lashing out at someone else. I think that's one place where you could start to address the different ways the genders react to trauma.

Deborah: And so, if you did this with men, do you think then there would be the chance of their healing?

Jennifer: I do, yes.

When inhabiting VAW doxa, Jennifer saw little or no possibility for men who use violence in their relationships to stop doing so. VAW doxa suggested the unlikelihood of them changing their (patriarchal) views on women's role in society. But later in the interview when she was immersed in a trauma-informed view of the issue, she could see the potential for a trauma-informed approach to support men's healing - and that this healing would have a positive impact in reducing their use of violence. This section of the interview continued with a discussion of the role of compassion in work with women who are victimized; Jennifer noted the role of compassion as "integral" to this work. We then moved on to talk about how to approach work with perpetrators. In her response Jennifer presented the dilemma for women who work with abused women on a daily basis:

Deborah: What feeling word would you use for services for perpetrators?

Jennifer: For service providers who work with that issue? I don't know. Is 'challenging' a feeling word?

Deborah: No. [Both laugh]

Jennifer: I have a list [on my desk] right in front of me of feeling words. I can just look - I don't know. Exhausted? Does that count? [pause] I think, you know, I think that's a tough job. But I do believe there is a need for it - especially when you apply the knowledge that chances are that man was abused as a child and witnessed violence. And when you think about men who lived those childhoods and the impact to them, they are more likely to express themselves outwardly, and that's how they have learned to cope. So if I apply that then I can see compassion for them.

Deborah: Do you think compassion would be necessary for that work in the same way that it is -

Jennifer: Yes, I do. ... if your client was somebody who used violence in the relationship, I think, yeah, that you would need to apply compassion. Because I would say that that person has a story, and has likely dealt with trauma their whole life as well.

Deborah: I hear that it's hard to go there - with what you see every day. 
Jennifer: Yes. And that's why I've also identified that I couldn't do that work.

While Jennifer's approach could be seen as an increasingly complex framing of the violence against women - that we can heal individual trauma within a gendered social system that gives men permission to use violence against their female partners - what is of interest to me here is that Jennifer herself has siloed these two understandings of IPV. While she found it easy to present an integrated view of VAW and trauma with regard to female victims/survivors - and I note here the substantial work done within women's anti-violence movements to nuance issues of women's victimization and agency - she was not at the time able to integrate these understandings in relation to men who perpetrate violence, providing an indicator that trauma-informed practice provides challenges to feminist VAW doxa regarding male perpetrators.

Judy explained the changes in her thinking over the years in these terms: "I guess I would say that my understanding has broadened. And it's deeper. And it's more complex. I always said that I would never work with men... and then I started working with men [co-facilitating PAR groups] and I understand much more about [sighs] their lack of tools, skills, whatever..." Judy first responded "no" when asked if a traumainformed approach was being used in the PAR program she was involved in and then reconsidered. In the excerpt below, as she tried to describe what needed to happen in terms of a shift in the public conversation, this poised and articulate woman has trouble expressing her thoughts. As she moved on from discussing the shame experienced by male perpetrators to describing their responsibility, her voice gained volume and her language became less hesitant:

Judy: I shouldn't say 'no'. I think that in [our town] we've got some defining to do. I don't know about other cities. That shame and blame and that whole piece is, is - yes. Um.[pause] 
Deborah: Could you say more?

Judy: Well, in terms of coming from, um [pauses], the men are feeling very, um. I guess that [pauses] there is shame in what has happened in their childhood. And then they're blamed in terms of perpetrating their own violence. And yes, we can acknowledge that. And yes we need to do work on it. [Voice gets stronger] But it doesn't give permission, or excuse what they do and have done.

In this final sentence, Judy was able to assert her doxic knowledge that 'victimization does not excuse abuse' with much more confidence than her conviction that 'we need to work on the shame and victimization experienced by male PAR participants,' a conviction that clashed with VAW doxa.

Both Jennifer and Judy show the difficulties of integrating trauma-informed understandings with a pre-existing commitment to VAW doxa. In the context of patriarchal explanations of violence that often pointed to women as being responsible for the violence they endured in abusive relationships, much early VAW theoretical work drew as clear a distinction as possible between the victim and the perpetrator. Jennifer and Judy demonstrate that a trauma-informed approach erodes this difference: while the perpetrator must be held accountable for the violence inflicted on their partner, both the victim and the perpetrator can be approached similarly in terms of their need for healing. These difficulties were also present in the accounts of other women within this group, as will be explored in the next section.

A third group of interviewees came to VAW work within the previous ten years and were under 40 years of age. Three of these women were in the 20 to 29 age group and four were in the 30 to 39 age group; all had entered the field with a desire to end women's victimization within intimate partner violence. However, this group experienced the conundrums presented by trauma theory as already existing in the field when they entered it and indicated less internal conflict raised by the juxtaposition of the VAW and 
trauma-informed approaches to understanding male violence against women. Six of the seven presented compassion as appropriate or necessary in work with male perpetrators, with the seventh commenting, "It depends on the violence..." While most had clearly thought about this issue previously, Emily worked her way through her views on this in the interview. After discussing the role of compassion in work with female victims, I asked Emily what feeling words would express qualities needed in work with perpetrators:

Emily: Um, feeling words? I think there's a lot of sorrow there. A lot of sadness, a lot of hurt. Um. I think a lot of, ah, trying to... Drawing a lot of blanks - but it's... also having compassion for them as well because, you know, they've been through it themselves. They've [perpetrators] been taught this... Doesn't mean that it's right. But, you know, they're human as well. So you know what? [Voice gets firmer] If they're willing to accept help, like, let's get them the help that they need as well. So, it's also having compassion for them.

Each of the interviewees in this last group had connections, contacts, and/or theoretical commitments outside the feminist VAW doxa that supported a belief in compassion as an appropriate and needed response for service providers to have in work with male perpetrators. These included having a male contact who works with Aboriginal men, membership in queer communities, work with male youth, a third-wave feminist standpoint which includes men as allies, encounters with theoretical typologies of violence, education regarding trauma-informed approaches to caring work and exposure to a feminist intersectionality lens. Overall, the seven interviewees who were more recent to the field, having less than ten years' experience and being less than forty years of age, presented a version of VAW doxa that more easily allowed for an analysis of intimate partner violence as gendered while including multiple contributors to intimate partner violence - including family trauma or social marginalization - seemingly without experiencing the high level of internal dissonance between the two approaches 
experienced by many of the women who entered the field more than 10 years earlier. Six out of the seven women in this group specifically said that they discuss these issues with one or more of their peers either within or outside the movement. The seventh made a more general comment indicating the importance of having these kinds of conversations.

\section{Bringing 'the efficacy of compassion for male perpetrators' into the VAW discourse}

The responses of interviewees in this study indicated that many women within the movement believe ending violence against women will require that the trauma experienced by male perpetrators be addressed. As discussed in the last chapter, work to heal trauma requires a compassionate connection with the client/participant. All 17 interviewees who expressed the need for compassion in work with perpetrators in order for that work to be effective also added that understanding trauma as an underlying contributor to violence does not excuse the violence or reduce the need for accountability for that violence. Specifically, eleven said that trauma does not excuse the violence, three addressed the need for systems to hold abusers accountable, and three maintained the need for the perpetrator to commit to doing work to heal and change their behaviours. All three respondents who specifically spoke of the need for healing work by men, work with or identified as members of marginalized communities who have experienced the worst of justice system interventions. A number of interviewees also expressed the fear of violence being excused within a trauma-informed approach in the context of the current justice system and/or community-based interventions available to address intimate partner violence. 
In the opening paragraph to this chapter, I presented Jessica, Judy and Melissa's sense of singularity within their collegial relationships in having these thoughts and feelings regarding the need for a compassionate response to male perpetrators. The conversation regarding the efficacy of compassion in healing work with male perpetrators was not yet happening at the level of organizational or system discourse in this Ontario city and adjacent counties in the settings I examined. That this finding is representative of a larger gap in the discourse is indicated by my search for 'compassion' in the journal Violence Against Women, from its first issue in 1995 to the July, 2014 issue. Using the 'Search this journal' button on the journal archives page (http://vaw.sagepub.com/content/by/year) returned a positive response of 54 articles. Forty-two articles, published between February 2002 and March 2013, addressed compassion for female survivors. A further eight, published between September 2005 and January 2014, dealt with compassion fatigue among workers. The remaining four articles dealt with compassion for perpetrators: two of these were about victims' compassion for their perpetrators and one was a rebuttal to Linda Mills' book From Insult to Injury. Only one, a reflection on the life of Ellen Pence, founder of the Duluth Model for working with male perpetrators, made positive mention of providing service to male perpetrators with compassion (Das Dasgupta, 2010). This comparison points to a disconnection between the public scholarly, activist and service provider conversations and the private or semi-private thoughts of VAW practitioners interviewed in this study.

\section{Explanations of change}

Below, I present three themes that emerged in the interviews as the 17 VAW interviewees discussed how a shift developed in their positioning on addressing the 
victimization of men who have used violence in their relationships. These are:

encountering the lived experience of men and male perpetrators, encountering diverse cultural values and oppressions, and encountering theoretical frameworks of typologies and trauma.

\section{Encountering the Lived Experience of Men and Male Perpetrators}

Several long-time VAW workers said that in the early days of feminist work they didn't think about the male perpetrators beyond the horrific abuse they were inflicting on their female partners. This sentiment is in line with Jewkes, Flood and Lang's (2015) presentation of the stages of change in feminist understandings of men's roles in VAW in which they note that a lack of focus on men meant that men were invisible except as potential agents of violence. Sylvie specifically noted that the context of the work she was doing affected how she thought about the perpetrators.

Sylvie: When you work in a shelter, you have compassion for the women. And I just realized [in this interview, over 10 years after leaving the work] that by having compassion for women you don't have compassion necessarily for the person who committed the violence. And [now] I think we need more compassion that way too, to understand what brings this violence.

As Sylvie suggested, her views on this have changed over the years. Other interviewees also noted that their views have changed and brought forward experiences in relation to men that challenged the inscription of men as only perpetrators. Eight of the interviewees spoke of encounters with boys or men as relevant to the development of their belief that compassion for the lived experience of male perpetrators as victims of trauma was needed for services to male perpetrators to be effective. These included working or living with male children and youth (4), experience of or in marginalized communities (6), and conversations with men who work with male perpetrators (1). The life experience of these interviewees led them to change their interpretations over time - changed 
interpretations that they have had some difficulty reconciling with their VAW doxa, as compassion for men as victims is not congruent with a focus on their agency as perpetrators of patriarchal controlling violence.

Part of the change that Sylvie, when working in a women's shelter, made in her approach to intimate partner violence was brought about by a call out from her son who said "Mom, stop this... we're not all like this!" This incident led her to realize that she was projecting her experience of seeing battered woman after battered woman coming into the shelter onto all men, including her young son whom she had many times admonished never to hit a woman. Gloria brought in her experience of working in a community where families of male perpetrators are known generationally: “... abusive men can change and often their lives have been hell and so we can't ignore that." Gloria positioned male perpetrators' life experience as relevant to feminist efforts to end violence against women.

Nancy, a counsellor with immigrant women, discussed the significant impact of racism encountered by immigrant people in Canada as a concern for service provision. For example, she found that women sometimes contest the view of their husband as an 'abuser'. They might say, “No, no. My husband is also a victim... He is a doctor in his country ... but here he cannot do anything. He cannot find a job.... We need to start from the beginning. We have several kids ... He is very upset. That is why he...' Nancy saw that the lack of known and trusted supports in an overwhelmingly stressful situation can be a causal factor leading to violence (although, she asserted, not providing a justification). 
Women working on this issue also had had exposure to Partner Abuse Response programs, which have been operating in Ontario for several decades now, through talking with their staff (1), as co-facilitators of sessions (2) and in encounters with the participants (1). This has had an impact on how these women see male abusers. Judy's experience co-facilitating groups for male perpetrators informed her understanding that the perpetration of violence was only one part of his life: "I think that compassion comes where we begin to not just look at the man as abusive, but be compassionate and not just label him. Yes, that's a part of his life. But it's not him. It's not defining him." She continued with recognition of the effect of trauma on male perpetrators in reducing the capacity for emotional expression: "It's so hard for them too, you know - they know 'anger' and they know 'happy' and anything in-between is kind of hard."

Judy argued that it is essential that the feminist VAW movement begin to work with non-violent men as allies. She said,

Judy: ... we have been doing this for so many years and we're just not getting there. We're still in a society where men have power and men have money and so we have to somehow. ... I'm just tired of all of us women working night and day, no money, you know, trying to do fundraising and then you just go, oh my gosh. We've got to bring men into this. And I think that that, for me, is a huge, huge shift.

Deborah: Yeah. And I think that's true for many women. Do you think you're ahead of the curve in making that shift?

Judy: No, I think that we're coming there together. Yeah. I see that more and more people that I talk to go, yeah, we have to bring boys into the picture. We have to, as feminist women, we have to raise our men very differently and I think that that's been going on sort of for years. That thinking. And now it's time to turn to the grown up men. [Laughs] And say, yeah.

Working with men as allies destabilizes the female victim/survivor and male perpetrator doxa in that men become visible as more than potential perpetrators. This work also makes men's potential victimization visible as the men who engage as allies have may 
have experienced their own past or current victimization as I will explore in the next chapter.

Karen brought forward research she and a co-researcher had done as students in which they interviewed several couples who stayed together through and past the ending of violence. She reported that the findings challenged her VAW-informed beliefs. In the small interview sample, each of these relationships began to change when the woman took control of her life, perhaps getting a job, increasing her contact with her family and community, and often revealing the violence to others for the first time. Karen reported: "My belief system really had a bit of a struggle and a conundrum in that it was the woman who had made these kinds of changes in the home that actually, um, triggered other changes. So it wasn't about him changing his behaviour, it was about her changing, which I struggled with at first." Karen's story reiterates the incompatibilities some workers are naming between VAW doxa and experiences they have had of men and/or male perpetrators and female victim/survivors in their work and other parts of their lives. These encounters with the lived experience of men lay the groundwork for shifts in feminist doxa regarding whom we think men are. Next I will examine the impact on these interviewees of encounters between VAW doxa and diverse values and oppressions.

\section{Encountering Diverse Cultural Values and Oppressions}

Eight interviewees referred to values from, or experiences that they have had in, Aboriginal communities, communities of colour, and LGBTQI and disability communities as impacting on their understanding of how to address male perpetrators of IPV. The Aboriginal cultural heritage of some respondents (2), as well as exposure to Aboriginal principles (1), or learning about the impact of colonization on Aboriginal 
communities (2), was referred to by five respondents as impacting on their work and their beliefs about how best to address male perpetrators, bringing them toward a sense of the need for community healing. Jessica, an Aboriginal woman in the under-forty age group, was, early on in her work on VAW, "pretty closed to looking at what ... [male perpetrators'] issues might be". She referred to learning about the historical traumas of residential school as bringing her to her current beliefs that "in most cases both parties are victims," and that without the healing of male perpetrators, Aboriginal communities will not be able to heal. Lisa, a shelter worker, stated, “...one of the things I've learned [in my contact with Aboriginal communities] is to think about valuing everybody in the process." She adds that every service organization does not have to work with perpetrators for this to happen, as long as everyone has access to the services needed.

Connections across genders were mentioned by Aurélie who noted that there was an impulse among lesbian feminists in the early days of feminist anti-violence work to create a community separate from men. But, she concludes, "We weren't any happier, frankly." This contributed to her current belief that we cannot do it alone; we somehow need to engage men in work to end violence against women. Nancy brought forward a focus on the maintenance of the family that she hears among some of her immigrant clients. When clients expressed an interest in couple counselling she supported that work saying, "it might not be necessarily good for the client to separate. Maybe she finds it is happier to be with him. If they try, and after they try, they come together, why not?" Nancy found herself diverging from her sense of 'proper' feminist doxa in supporting this approach. The cultural values that these women had, or had encountered, had impacted on how they have internalized VAW doxa in the creation of their individual habitus. 
Stacy noted the excellent groundwork laid by early VAW activists and scholars that remains the basis for the work today. But, she noted, there was not enough attention given to an intersectional analysis:

Stacy: So bringing that lens to the work I think is really important. For me it happened in shelters in the 90s and it continues to evolve from that point. But there are workers who are involved in the work and don't have that herstory, and that come in -- well, for some it's like... [that antiracist work] never happened and they come in pretty - oh dear, it's positively frightening. Ah, but. So there's that. Sort of bridging that - 'Hey remember that. We decided that was important.' You know.

Jennifer, a shelter manager, referred to her commitment to "making sure that all women - including those with diverse ethnicities and race and disabilities and gender identity and sexual orientation - that their needs are met. And that I continuously apply an anti-oppression framework so that they are not revictimized in our system. Because we are a system." She also addressed the challenges in this work, identifying the need for ongoing staff and resident education, and expanding the capacity of the shelter to meet spiritual and nutritional needs, for example.

Areas of lack were also identified by the interviewees. Jennifer noted that her shelter was not yet able to consistently meet the needs of transwomen. Jocelyne found that the women coming to the Aboriginal women's shelter at which she works identify that their cultural needs were not being met in many shelters across Canada. Mary discussed the successes of the movement and how learnings over time are leading to the identification of further effort required to meet the needs of victim/survivors:

Mary: The movement is pretty old, which is awesome. And, it has done an incredible amount of work, and a lot of really amazing work and I think that has had a huge impact in sort of society and how intimate partner violence is seen and understood. ... But, we are starting to see all of these things, like let's focus on perpetrators of violence now... And, let's look at queer and trans relationships, let's look at race more, let's look at immigration, let's look at all these other contextual pieces and let's look at all these different intersectional oppressions and, 'Why aren't you doing it already?' ... Why don't you have anti-oppression training for all your workers, why don't you engage with different communities more and find out what might be useful to them? 
She noted how difficult it is to keep up to date and to negotiate diverse needs as our ideas

of social and gender justice change over time:

Mary: ... Some are doing really radical work and really progressive work and are saying, 'Yes, absolutely, let's deal with that.' But I think it is very hard for a lot of service providers and agencies because this is already very hard work and we have already done all of this and with very little thanks a lot of the time. ... And, you know, we are not necessarily the enemy here. But we are lacking and how do we rectify that? How do we shift that and so not lose all of our funding and public support? How do we balance between communities who are saying, police are totally unsafe for me and have been really violent to me, where it is a racialized community or a queer community? And so how do we recognize that and support that... and also still have partnerships with different police programs and work through systems where you do need a police report a lot of the time, where you need to go through a court system?...

Finally, she saw the movement struggling with how to address these additional demands

in the context of limited resources:

Mary: So I think that, one of the big things now, is that the intimate partner violence movement is, sort of, in the middle of all of this and trying to figure out where do we go from here. And also being really tired too. I think a lot of service providers are not well compensated both financially and in terms of agency support too, there is a lot of turnover, there is a lot of burn out, there are a lot of people working above and beyond and [who] are really tired. So I think that is hard to have all that on your shoulders and then, here, you still are not doing 'good enough'. You have done some good but like you need to pick it up. Which I agree with, we do need to shift. You need to do it while recognizing everything that has happened and all of this.

Mary's articulation captures many of the various dilemmas facing the movement in the encounter of VAW doxa with diverse cultural values. The final encounter I will examine is that of theoretical frameworks of typologies of violence and trauma.

\section{Encountering theoretical frameworks of typologies and trauma}

Exposure to the research literature was noted by a number of interviewees as nuancing their views of intimate partner violence. As Judy put it, "Through research we have learned... so much. We talked a lot about the Duluth Model and we worked only from the Duluth Model and now we're looking at different models of different kinds of violence." Two areas of research and theory development that do not specifically emerge from feminist work were addressed in the interviews for this research. These were the 
development of typologies of violence and the development of trauma and attachment theories. In the interviews, I raised the topic of typologies of intimate partner violence with a question as to whether the work experience of the interviewee reflected the presence of various types of violence beyond the coercive controlling violence described in the power and control wheel.

While 15 of the $21 \mathrm{VAW}$ interviewees maintained a focus on power and control as comprising the crux of intimate partner violence, ten interviewees came to the interview having previously integrated the notion that there are typologies of power and control and situational violence in intimate partner violence. Seven of these referenced Michael Johnson's (2008; 2011) work on typologies of intimate partner violence in describing their understanding of intimate partner violence. For a further two women who had left the work in the late 1990s or early 2000s, the introduction of the concept of typologies in the interview gave them new insight into areas which were unresolved for them from their time working with VAW services. Karen was one of these women, having worked in VAW services for over 10 years. She was introduced to the typologies framework in the interview. She first responded by taking stock of how different this way of thinking of IPV was and the different interventions that could emerge from the use of typologies, interventions that would be counter-indicated within VAW doxa:

\footnotetext{
Karen: ... that would be very different than, say in the seventies, certainly in terms of my understanding of intimate partner violence... So if this is a phenomenon - um. Then certainly that would be an avenue that really needs to be delved into in terms of providing support because I mean, um, you know couples could be in groups doing sessions on fair fighting and all kinds of, you know, strategies for mediation... So that would be very cool, actually.
}

She then went on to discuss how big a shift this would be for her. As she worked through her response she moved in and out of VAW doxa, trying out this new-to-her perspective by providing an example that fits situational violence, then letting her concerns about this 
framing emerge and then moving to identify it as exciting in some ways and potentially

problematic in others:

Karen: As, as a person providing support I have to get my head around it. ... we have told these women all of their lives that they're in abusive relationships: this is abuse; it's not okay for him to do this. And then she's saying, 'Yeah, but I threw the chair at him, you know, and he stomped out and then we came back and it was okay,' kind of thing. So, I guess, um, certainly it's a shift. A big shift.

Deborah: Yeah.

Karen: [pause] I guess my concern would be, would one partner be... [put in danger by returning to relationship]? I'm just thinking ... often times that was the issue in the past, you know? When she went back it was only a matter of time. And we knew that it would happen again. ...

Typically they want to stay together, a lot of the couples, so. ... [pauses] Wow! That's new to me. I've never heard of it, so. That's kind of exciting in some ways. In other ways [pauses], is that kind of just watering it down or masking the power and control? [pause] That's the old girl in the back, saying that. [Laughter]

In her last sentence, Karen took a stance in which she comments on her VAW response from outside this doxa. This is not to say that Karen had abandoned VAW doxa, rather simply that she used her reflexivity to generate a more nuanced understanding of IPV. The 'old girl in the back' did not have this more complex understanding.

Melissa, who worked primarily with female victims, linked her understanding of typologies to the development of her sense that male perpetrators deserved compassion. Melissa engaged the research of Michael Johnson in expressing her positioning regarding male perpetrators, research she encountered when searching for a way to reconcile her experience of men who use violence with her VAW training. Other women spoke of complexities in intimate partner violence without naming the dichotomy of coercive control versus family conflict. Alishba, a younger woman who had been working in VAW services for over three years, provided an example of this, noting that research has shown us more gray areas and has made visible "a lot more types of abuse." 
The significance of trauma and attachment theories is also visible. Mary provided an example of a younger woman educated with a trauma lens: "I think the number of people who are completely unredeemable and unchangeable is really very little...

Restorative approaches I really strongly advocate for because they say, 'Okay. We want to find out from everybody's perspective what happened and why. And then, what do you need to heal and move on?" Aurélie, a feminist who has worked with women victim/survivors over 25 years, explicitly noted trauma in her explanation of the conundrums she experienced as a long-time VAW activist and service provider trying to create a coherent picture of abusive men:

\begin{abstract}
Aurélie: “...it is really that whole aspect of our society's creation of mini-monsters. Instead of treating the trauma we're just perpetuating it. We are just nourishing it to make these boys, these lovely little boys into these possibly monsters, really. ... But I think that in terms of trauma for women, for children, I really think that's where we need to look. And again it's every time I see these guys [in the PAR program], you see they are just little boys. You really see it. They are 35 years old and they are still wearing their hats the wrong way. ... Basically they are still just a little boy who needs to be heard, have a hug and just be told it will be okay. So it is like the woman who keeps going from abusive partner to abusive partner.
\end{abstract}

In the quote above, the male perpetrator shifted from being the (society-created) 'monster' of the VAW perspective to the trauma-informed vision of a boy who needs to "be told it will be okay" and who is very much like the woman survivor. The use of the term 'monster' for men who use violence in their relationships is one which was not an uncommon characterization in society during the VAW formalization period and can still be found in news items about IPV (e.g. Brown, 2015). The opposing views of monster and trauma survivor present in Aurélie's account indicate a dramatic schism that is not easy to reconcile for those of us who came of age with the VAW habitus. Aurélie shifted back and forth between these views throughout the interview without being able to reconcile them for herself. How can we understand this inability? I suggest that Aurélie 
was embodying two polarized doxa within the field of work to reduce and prevent intimate partner violence that together form the nexus of the current transformational moment for the feminist VAW habitus. In the interview she flickered between VAW and trauma doxa; focusing on the one sent her back to the other. Neither provided an answer she could fully reside in because each neglects one end of the pole - men's agency and accountability for their violence or their structured vulnerability and/or need for healing. Aurélie had not found the opportunity within the feminist VAW community to unpack the meanings attached to these (for her, at that time) conflicting knowledges.

The difficulties experienced by the interviewees visible in the interview excerpts presented above show the engagement of the reflexive habitus. Some women, such as Sylvie, left the movement when their experience and VAW doxa diverged and they did not see the opportunity for change in the doxa in the field. (Interestingly, in this interview Sylvie said that if the notion of typologies had been available to her at that time she might not have left the work.) Others were holding VAW doxa and experiences which challenged this doxa as siloed knowledges. Examples of this were found with Aurélie who moved back and forth between VAW and trauma-informed doxa and Nancy who supported her clients in ways that she believed diverge from VAW doxa. Further examples were provided in the unfulfilled desire, on the part of Jessica, Judy and Melissa to engage the community in a conversation about male perpetrators' victimization. Finally, there were examples of moving through to new articulations of doxa and habitus, one being Judy's description of the "huge, huge shift" in habitus for her and other women in the movement who were engaging with non-violent men as allies in addressing VAW, a shift also discussed other interviewees. 


\section{CONCLUSION}

I began this chapter with the question, "How can we understand the need among some VAW workers to have a conversation about the victimization experienced by male perpetrators of IPV in conjunction with the perception by these same workers of the lack of feminist VAW space for this conversation to happen?" I have addressed this question using a Bourdieusian feminist conceptual framework and the paired sociological concepts of social structures and agency. The use of this theoretical lens suggests the development of gaps in the fit between the habitus and doxa of the field such as I argue is being experienced by many within the field. In this chapter, I have discussed the increasing complexity within feminist VAW framings, and the challenges and opportunities that are now being raised with the introduction of typologies of violence and trauma theories. The VAW service providers and activists interviewed were engaging a variety of knowledge management strategies as they variously gained an increasingly sophisticated picture of IPV within a field in which the polarized female victim/male perpetrator remains institutionalized as a foundational concept. Institutionalization creates a certain stickiness of these foundational doxa that can make for uneven social change (McNay, 1999; Ahmed, 2004).

The habitus is developed through an internalization of the doxa of the field (in this case the subfield of VAW work) as 'truth'. So the gap between the need to have a conversation regarding male perpetrators' possible experiences of victimization, and the perception that the space to have this conversation is not present, may be explained theoretically as a judgement by the interviewees on their need. Jessica, one of the women 
who suggested the difficulty of having this conversation, exclaimed, "No!" when I asked if she had discussed this topic with her co-workers. She had not yet moved beyond her own internal scepticism to be able to stake a claim for her point of view within the movement. Skeggs (2004) argues that perspective-taking involves a moral judgement. The assumed morality of the framing of the women victim/survivor and the male perpetrator can make questioning this perspective difficult to imagine as a legitimate undertaking. Even when one becomes personally convinced of the need to have the conversation, the assumed, or actual, belief of others in the doxa can de-legitimize a questioning attitude toward that doxa (e.g. Sylvie). That 17 out of 21 interviewees suggested a need for a compassionate approach in work with male perpetrators in order for this work to be effective suggests that the actual belief of others in the field is more in alignment with Jessica than not. However, for all of these women this was a significant shift from their early understandings and all of them experienced difficulties in discussing the topic within formal VAW contexts - although those who were under 40 years of age with less time in the field, such as Jessica, experienced less internal conflict and most often had had these conversations with at least one peer confidant.

The existence of powerful doxa can create the illusion of a coherent and stable field and mask the existence of ambiguity or resistance. Processes of institutionalization exist independently of the habitus, and can lag behind changes in the habitus (because they incorporate the inertia of the 'institutional') of those in the field. Among the interviewees, the doxa were more confidently and coherently expressed than deviations from it (e.g. Judy). An incomplete incorporation of norms into the habitus may remain unexpressed in a bid for belonging, because of insecurity, or because of lack of conceptual framework 
within which to express the ambiguity being felt toward the doxa of the field (e.g. Ashley, Jessica, and Aurélie). Those who are unable to reconcile the doxa with their habitus are most likely to leave the field, removing one source of contestation (e.g. Sylvie). The development of epistemological pairs (such as VAW and gender parity framings of IPV) may leave little room for questioning the doxa within the subfield and thereby support its reproduction. The interpretation of research data by those in practice, through the lens of the doxa in ways that support the doxa, can also sustain the status quo by neglecting interpretations of the research that challenge this doxa.

Bourdieu (1988) notes the application of power required in both the maintenance of dominant doxa and in challenges to that doxa. He argues that this power does not have to be consciously exercised by particular individuals to a particular end but is more often exercised in the sum of the many decisions that emerge from individuals' positions and positioning in relation to the structures that have been created in the building of the field. A comment by one of my interviewees (Ashley) who was concerned that the VAW perspective did not adequately deal with male victimization illustrates this situation: "We are focusing on women in our work because that is the way it is structured. However, acknowledging and validating other experiences is just as important to me personally.” Ashley experienced a gap between her habitus and her work as structured by the doxa of the field.

The interviewees presented in this chapter were engaging in the subfield of VAW from a variety of positions and positioning experienced over time. Their uneven positioning was reflected in the uneven incorporation of the doxa of the VAW subfield into their habitus. Opportunities for change in the habitus emerge when the experienced 
truth of the field's doxa are challenged (Bourdieu \& Wacquant, 1992) or experienced with ambiguity (Adkins, 2003). Feminist VAW theoretical propositions have been challenged, and in response made more complex, through the incorporation of theoretical work on the impacts of racialization, heterosexism and other social structures as they impact on marginalized communities as well as the exploration of women's agency. The incorporation of theoretical understandings such as typologies and trauma are adding further sophistication to our understanding. These have not yet come into alignment with each other in terms of the implications for VAW theory, and perhaps may never do so. However, the engagement of these various understandings reveals doxa as a situated viewpoint, one that is subject to ongoing evolution (Bourdieu 1988).

Having experiences that challenge one's doxa can be stressful and disorienting. As doxa are by definition almost unknowable as knowledge - we experience doxa as truth conversations 'across' doxa can seem frustrating and seemingly lead nowhere. This is where the fuzziness of practical logic becomes of practical concern to practitioners. My VAW interviewees were interested in my project because they were experiencing the fuzziness of their practical knowledge as fuzziness rather than as truth. While they use various knowledge management strategies to deal with their concerns, fully discerning the difficulties and how to address them requires a process of engagement across the subfields involved. This engagement will be undertaken in the following two chapters of this dissertation. Chapter seven presents an analysis of the interviews with partner abuse response program workers, private practitioners and two interviewees who work with male victims. While VAW doxa had provided a foundational understanding in their work, 
these interviewees had had experiences in their work that provided a greater challenge to this doxa and thus they had to reconcile the inconsistencies in order to be effective. 


\title{
Chapter 7 \\ The Problem is the Problem
}

\section{INTRODUCTION}

\begin{abstract}
Sociologists cannot be unaware that the specific characteristic of their point of view is to be a point of view on a point of view. ... And it is solely to the extent that they can objectify themselves that they are able, even as they remain in the place inexorably assigned to each of us in the social world, to imagine themselves in the place supplied by the objects (who are, at least to a certain degree, an alter ego) and thus take their point of view, that is, to understand that if they were in their shoes they would doubtless be and think just like them (Accardo \& Bourdieu, 1999, p. 625-6).
\end{abstract}

"The person isn't the problem. The problem is the problem." (Kenneth, quoting researcher Michael White)

Central to the tension explored in the last chapter is the development of a more multidimensional view of the men who use violence in their relationships with their female partners than that contained in VAW doxa. A more complex understanding of men who use violence was also visible among the interviewees whose responses are discussed in this chapter. These interviewees included four men who worked with male perpetrators in the Partner Abuse Response (PAR) programs, five interviewees who were private therapists and two interviewees who worked with men who have experienced victimization. These interviewees most often reported that they had begun their work on the issue of intimate partner violence within the VAW habitus, or experienced this habitus as central in the field of work to reduce and prevent IPV. However, unlike the interviewees working only with women victim/survivors, these interviewees experienced more immediate challenges to VAW doxa both in relation to their own positions in the field and from working with perpetrators of violence. They had to address these challenges in order to do their work effectively. Thus, the concerns being expressed by 
the VAW interviewees were also found among the PAR workers and the private practitioners, although the resulting habitus and doxa presented by these interviewees differ to greater or lesser degrees in their formulations. For some there was significant integration of VAW doxa and gender parity doxa. With others one can see a polarization of VAW and gender parity framings.

I argue in this chapter for an emergent PAR habitus and doxa, visible in the discursive strategies used by these workers, standing in explicit distinction from VAW doxa. The private practitioners and the two interviewees who work with victimized men also positioned themselves in relation to VAW doxa. For the private practitioners VAW doxa are less central to their own positioning on the issue as these doxa have less of a disciplining power in their field. However, they have each addressed these doxa in developing their positioning, providing further evidence that VAW doxa has been dominant in the field of work to reduce and prevent IPV. The interviewees who worked only with male victims directly contest this doxa in their work. The common theme among all of these positions was that of a generative approach to working with men who use violence in their relationships - an approach which assumed that men could change and supported them to do so. This approach challenged 'the male perpetrator' as an identity category. I argue that the development and existence of this common theme among the positions and positioning explored in this chapter has had an impact on feminist VAW framings in providing alternative ways of thinking. These alternatives, on the one hand, had opened some VAW workers to the need for healing on the part of male perpetrators and on the other provided the opposition that fuels a dominant epistemological pairing which Bourdieu notes as common in any field. I address each of 
these positions in turn, introducing the interviewees, describing their work and the positionings taken over time in relation to feminist VAW doxa. I spend more time with the partner abuse response workers as this work has the greatest direct relation to feminist VAW doxa.

\section{PARTNER ABUSE RESPONSE (PAR) WORKERS}

Deborah: Would you say that you use a feminist model?

James: I am one of few men who have actually done performances at the Vagina Monologues. So, being accepted on that level and being able to talk to these issues, you know, if that qualifies me as [feminist] then so be it. I don't identify with a label. I renounce violence. I'm in favour of matriarchal systems. And, you know, the goddess feminine kind of belief system is where I think we need to go as a society. Love and compassion and that kind of stuff is like, that's where we're going. Like, there is a social evolution taking place in the world .... and I'm trying to push it as hard as I can.

All four of the male partner abuse response (PAR) program workers whom I interviewed aligned themselves with feminism in their work on gendered violence, either naming themselves as feminist, pro-feminist or giving examples of their stance as James does in the quote above. They also presented their motivation in doing the PAR work as emerging, at least in part, from a desire to improve the safety of women and children.

David named himself as a feminist and said that he first learned about the issue from the work his feminist mother was doing as he was growing up. Steven, on the other hand, noted that he got involved through his concern with the "displacement of the father from an effective role in the family." James got involved through his own healing journey, having grown up on the streets. Kenneth indicated that he became active in addressing violence against women as a younger adult when he became involved in efforts within his community to develop programming for men who use violence in their relationships. 


\section{Defining IPV}

The PAR workers used a variety of terms to name intimate partner violence, including intimate partner violence, violence against women, family violence, domestic violence and intimate violence. All four of the interviewees defined the violence and abuse between intimate partners dealt with in the PAR program broadly to include, as Kenneth said, "a whole range of behaviors that are hurtful and damaging to a relationship." Steven reported that he uses intimate partner violence for physical violence and abuse for other types of violence. He added, "I tend to split it up into different types of abuse, but I also have a pretty firm belief that the impact is pretty much similar, except I think sexual violence has a greater impact." The power and control wheel, used in feminist VAW work to provide indicators of coercive control, provided a reference point as to the range of abusive behaviours. Kenneth, James and Steven also explicitly identified that some violence and abuse occur outside a power and control model. The mixed usages of the terminology employed to address intimate partner violence comes to the forefront in Kenneth's explanation of this differentiation:

Kenneth: Grabbing someone [could] be seen as a real warning sign because it is part of this larger context [of power and control]. On the other hand, the grab might simply be a grab, right? It is not a good thing to do and we should be helping people find other ways of communicating when they are frustrated, unhappy or angry or hurt than grabbing their partner and saying, 'Hey listen. Talk to me.'

Typologies of violence were brought forward as a way of understanding this difference. While many interviewees associated the development of typologies with the research of Michael Johnson, James noted that the social service organization where he worked in the 1980s had two different classifications of abuse ("the typical batterer syndrome and situation abuse") at that time. 
The PAR workers also spoke of the existence of abuse by women and mutual abuse within the relationships of PAR participants:

Steven: That woman has had two husbands who've both completed suicide and she was working on the third. [Laughs] Fuck. ... the first guy I knew for five years, the second guy I knew for 15 years and the third guy I've known since he was five years old. And he got sent to the program and he went, 'Holy fuck, I'm in an abusive relationship. Maybe I should get out.'

Deborah: He realized he was the victim in an abusive relationship?

Steven: Yeah.

Deborah: In the PAR program?

Steven: Oh, absolutely.

Deborah: Does that happen very often?

Steven: Oh, yeah. Yeah. A lot. Not that they also weren't abusive. They were. And they would quite frankly go, 'Yeah I pushed her. I was trying to get the fuck out of the house and she was hitting me and I hit her back.' 'She had me around the throat with the phone cord, so I did. I hit her.' So, yeah. Mutually abusive relationships. I mean, Johnson looks at—have you looked at his typologies?

Deborah: Um-hum.

Steven: Not too far off my experience.

What is noticeable here is an elision between relationships where men are victimized and mutually abusive relationships. The woman who is 'working on her third husband' is categorized with mutually abusive relationships; although Steven affirms that the husband is the victim in an abusive relationship, he quickly returns to a naming of "mutually abusive relationships." The other examples he gives could also be seen as violence initiated by the woman, with the man in one case being attacked as he tries to leave the house and in the other being strangled. Steven does not move to define these men as 'victims,' which would require an epistemological break with feminist VAW understandings; rather he maintains a focus on the responsibility of the male partner.

\section{The Partner Abuse Response Program in Ontario}

The Ontario partner abuse response program was created in the early 1980s and based on the feminist VAW Duluth model. The late 1990s saw the enhancement of 
justice system interventions to address IPV, including the expansion of domestic violence courts and pro-prosecution policies which brought a corresponding expansion of PAR programs as a sentencing option. This expansion shifted the participant base of many programs; while previously significant numbers of participants were there voluntarily, from this point on, participants were primarily mandated to attend. In 2015 government funding for the program was reduced from 16 weeks to 12 weeks in length.

Kenneth and James were both involved in PAR work during the program's formative years. Kenneth noted that in the design of the early groups they "were taking stuff from here and there." The direction of his work with male perpetrators became more formalized after attending a conference on working with batterers in the mid-1980s. In the quote below, Kenneth described the shift to using the feminist VAW Duluth model, an approach which he said remained unchallenged for about ten years.

Kenneth: There was a big debate at the conference and there were the Duluth folks on one side and the therapy folks on the other side. ... so the one group was more of an anger management focus and so [for that group] we need to be paying attention to men's experience of trauma as children ... so they need therapy and counselling. And then the Duluth folks were more, well, ... men's individual violence towards individual women has to be understood in the context of patriarchy and misogyny and inequality and gender relations generally speaking. ... the Duluth folks certainly won the day.

In the quote below we see indications of changes that came later as Kenneth qualified his descriptions with comments such as "the belief at the time" and "that was the work that we did":

Kenneth: I think the belief at the time was that for men that we were working with, it was their intention to demonstrate masculine superiority and privilege through the use of those tactics on the power and control wheel. And in order for long term change to happen, core values and beliefs about women and men have to change. And so that was the work that we did. In those days we were working with relatively small numbers of clients ... referred through the criminal justice system.

James was also involved in the early years of the program. He had a more critical perspective with regard to the formalization process: 
James: Back when they were developing the PAR system in Toronto at the big conferences where there were three or four hundred people, I became an annoyance because after almost every statement or presentation I would stand up and I would say: 'We need to show these men respect and compassion and honour and integrity. Gating people through court to get help is not okay, that's not about change. That's about shaming someone. And you want to use power and control methods to beat them into change when you're trying to tell them not to use power and control to change somebody. Like, come on! ... That doesn't work.'

James relied on his Aboriginal culture to provide a different compass for addressing violence in intimate relationships:

James: The bottom line as I see it is that men and women need to learn how to talk and to respect each other on that level. And then they can teach the professionals what to do. [Laughter].... One of the things that I see as the foundation to the group is what I call self-care and it is based on intention around taking care of yourself, physically, mentally, emotionally, spiritually. The foundation to that piece is around self-acceptance, self-trust, self-forgiveness.

Steven came into the program after it had been developed. He talked about the gap between how the program was framed and how it was actually done. He said that the PAR program was positioned as being "strictly psycho-educational: 'Here's the book deliver." I asked him if this was how he did the program. He replied, "No. [pause] That's not how anybody does it." Steven raised the debate between the Duluth model and healing work and insisted on the need to address the trauma histories of the people involved. In working with perpetrators of IPV, the PAR workers were continually faced with the gap between VAW doxa regarding perpetrators and the complexities and fluidities of the lived realities of people who have used violence in their relationships.

\section{The participants}

The groups of male participants attending the PAR program have changed over time in terms of their beliefs about women and relationships, their class status and the kind of violent behaviours seen. These changes had affected the PAR workers' experience of the goals of their work as well as their relationship to VAW understandings of how this work should be done. 
During the first 10 years of operation, the PAR program in Ontario provided programming to relatively low numbers of people. In Kenneth's understanding, this changed in 1997 when the Ontario government revamped the program as part of an attempt to address domestic violence more effectively. As fewer cases were diverted out of the system, the numbers in the program jumped exponentially. In the early years, it generally seemed to him that male program participants accepted the analysis of the Duluth model and could identify behaviours that they used in their relationships as part of a pattern of control. However, after the expansion, program facilitators started to get push back from some men who said that they did not want to be in control of their partners:

Kenneth: Men were saying, 'this model that you are presenting, and this way that you are describing us, doesn't fit with my experience.' And ... the partners of the men and women were telling our outreach workers 'generally he is a pretty good guy. Yeah, we had a problem that night ... but really I am not afraid of him and I think generally he is a pretty good guy.' And, other women were [still] saying, 'I am scared of him and...'

It was around this time that Kenneth became aware of the work of Michael Johnson on typologies, an awareness which he used to understand the changes he was seeing in the program participants. He began to believe that, as domestic violence was taken more seriously, men who were involved in situational violence (previously under the radar) were now coming to the attention of the system.

James' account highlighted a different aspect of the development of the PAR program, that relating to class. In the early years of the program in his community James said that they had community funding that allowed them to do prevention and public education work. They also ran groups for non-offending female partners. Their recent funding was only through the Ministry of the Attorney General and was strictly for courtordered participants. He said that, while in those earlier days $85 \%$ of the program participants were self-referrals and included people from all economic levels, 
James: Now... we get the poor and the working poor. It's very rare to get a professional or anybody of an income of say above $\$ 20,000$ - $\$ 25,000$... basically we're dealing with functionally illiterate people. However, in the program's standards in terms of the province, they don't want to consider 'change' or what they would call counselling. ... So in 40 hours, we are to educate people who do not think in a didactic kind of two-dimensional way ... in a classroom. It just doesn't work. They just can't process that kind of information.

Kenneth and Steven concurred that the people who come to the program are generally those marginalized in society.

David noted that the men (and women) who attend the PAR program have not engaged in severe physical violence. James echoes this, asking,

James: So where is this group of people that would fit what we used to call the batterers? Nobody can answer that. I don't think they just disappear because we change the law and access to a service. There's still got to be a certain percentage continuing with that kind of stuff because there really wasn't anything done to change that. So I don't know where the serious situations go. We do have a high risk committee and typically in that committee what comes out are these people, that, there's a condition of [coercive, controlling] abuse taking place. And sometimes they come in here and sometimes they don't.

Several interviewees, among both the VAW workers and PAR workers, raised the idea that the PAR program and the shelters do not necessarily address 'parallel' populations of victim/survivors and perpetrators (i.e. those who are in partner relationships with each other). Part of the difference in the emerging doxa of the PAR workers to that of the VAW workers may be an actual distinction in the populations they work with. The victim/survivors of the worst violence are more likely to require the services of a shelter. The perpetrators of serious violence, when convicted, are less likely to be mandated to attend the PAR program and more likely to go to prison. This difference affects the positioning of those within each group of workers.

The concept of typologies of violence was central to the understanding that the PAR interviewees had of the program participants. Their experience had forced them to confront the question of differences among the program participants' use of violence on a daily basis. They saw the impact of structural oppressions other than gender in the lives 
of the men with whom they worked. They also saw the impact of class privilege, noting that the coercive controlling perpetrators tended to come from the middle and upper classes and often did not get sentenced; and thus did not appear often in their programs. Once more we can see the impact of position on positioning. Next, I will explore the relationship of the PAR workers to the notion of patriarchy as the source of VAW.

\section{Patriarchy as the source of VAW}

While the men who worked in the PAR program took patriarchy and the negative impacts of patriarchy seriously, it was clear from how they described the program that they diverged from VAW doxa in several ways. One was in clearly naming and describing the power patriarchy has over men as well as the power it extends to them. A second aspect was the identification of power and control issues relating to patriarchal privilege as only one of a number of sources of violence. In these explanations, they exhibited a certain amount of concern with how their analyses would be received.

In expressing his views on patriarchy as a source of violence, Steven referred to research showing that having patriarchal expectations and beliefs regarding relationships is not in itself a predictor of IPV. What matters is what men think of their female partner: "As long as they respect and honour their partner, the odds of them actually perpetrating intimate partner violence is not high." Picking up on the idea of male socialization noted by David, Steven said that patriarchy is pertinent because "the social performative for males is emotional constriction." Steven found a contradiction for men in how they are required to behave in the workplace and other public venues and the emotional vulnerability required for successful relationships. As a result, he articulated the impacts of patriarchy quite differently than the VAW workers. For instance, Steven discussed the 
relationship dynamics that come out of generational physical and sexual abuse suffered

by both men and women. He articulated trust and control issues emerging from childhood

trauma as often being more clearly connected to current abuse than patriarchal privilege

in the adult relationships of the men he worked with.

Steven also presented a heartfelt analysis of patriarchy in which he identified how

patriarchy impacts on men and impacts on them differentially in terms of class:

Steven: ... patriarchy is a requirement of our society in terms of capitalism, in terms of militarism, in terms of nation-states - in terms of all that stuff. That's all patriarchal construct, right? So, like, that's the world we live in. So, to tell men who are essentially powerless to change that, that they're bad because they adhere to that, and that they have the power is, like, that's kind of like - to tell these men that they're patriarchal control freaks who - Do you understand what I'm driving at here? Like, that they have the power over women. They just look at you like, "What the hell are you talking about I have any power?" You know? "I've got no power."

Deborah: When you say 'these men,' are you talking about working class guys?

Steven: Yeah. Rich guys don't get sentenced.

Deborah: Okay. Say more about that.

Steven: Well, they can afford lawyers.

Positioning patriarchy as only one possible source of violence was articulated as a divergence from feminist VAW doxa. Kenneth explains below. He has clearly presented his positioning before, and has a practiced story to tell:

Kenneth: When I started this work ... the dominant discourse was that any action of violence in a relationship was always embedded in a power and control dynamic. ... Now I think there are many of us who are kind of willing to say that we think that there can be times when the push -and I don't want to say 'just' -- but is just a push. But it is still a crime. Because pushing someone is an assault in Canada. ... [As] Johnson says, it can be chronic, it can be serious, [but] it is just not what we originally conceptualized of as domestic violence.

Steven and James readily acknowledged that women are the ones who get badly hurt or killed most often, but they challenged feminist VAW doxa of male patriarchal privilege as the underlying cause, at least among most of the men they see in the PAR program. James talks about the life experience of these men (and women) as being one of 
powerlessness: "Try and tell some of these guys who make $\$ 10$ and $\$ 12$ an hour with no breaks and no benefits and no respect and no dignity and they're working and getting hurt every day at work and you tell me they think they have power." He identified the issue as one of needing training in alternate ways of being in relationship.

The beliefs and values expressed by the PAR workers were explicitly related to feminist VAW doxa. Deviations from this doxa were explained and justified as such by the interviewees. VAW doxa continued to provide a touchstone for the positioning of both PAR and VAW workers in relation to their work, but the position of the PAR workers moved them toward more emphasis on the problems of VAW doxa in explaining the experience of male perpetrators of IPV. While VAW doxa focuses on the people involved in violent relationships, to be found believable by the people working on the issue it must also account for the workers' experience of the people involved in these relationships. The PAR workers had varying levels of acceptance of VAW doxa as an adequate explanation for IPV which overlapped with those of VAW workers. However, they had developed a number of strategies which could be clearly differentiated from that of the VAW workers.

\section{PAR extensions of VAW Doxa: The strategic naming of the problem and solution}

I argue that the commitments, beliefs and values expressed by the PAR workers form the basis of an emergent habitus and doxa relating to PAR work in this geographic region. A set of discursive strategies visible in the interviews with male PAR workers together reveal the outline of this habitus and doxa. These strategies relate to the challenges and tensions which I explore in the literature and in the VAW interviews, 
providing further evidence that differences in positions and positioning between feminist VAW and PAR workers have developed through relational processes and that VAW doxa are present as the dominant doxa even among those who diverge from it.

The first set of strategies described below is based on the explicit claim that 'men can change.' This claim supports a shift in both how perpetrators are named and in how accountability is understood. The second set of concerns presented addresses the impact of the lived experience of men as well as the impact of diverse cultural values and is aligned with concerns and dilemmas expressed by the VAW interviewees. Two theoretical stances visible in influencing the VAW interviewees were also present in these interviews: typologies of violence and trauma theory. The strategies explored in the discussion below explicate the outline of a habitus that can provide hope for people working with perpetrators, sometimes slightly shifting and other times clearly (and respectfully) rebutting feminist VAW doxa that do not identify hope for change among perpetrators of violence.

\section{From 'men can't/won't change' to 'men can change'}

I earlier presented and analyzed data from feminist VAW workers indicating that VAW doxa conceptualizes male perpetrators of violence as unable or unwilling to change. A number of VAW workers struggled with this doxa while others endorsed it. In contrast, the PAR workers all strongly expressed the belief that men can change. Kenneth was an interviewee with a strong political alignment with feminist VAW doxa. In the excerpt below I asked him to tell me three commitments he brought to his work. Kenneth very quickly and strongly responded, "Men can change". After expressing this commitment which is in opposition to feminist VAW doxa, he then appeared to become 
confused about the question. When he resumed his list with points two and three, he presented points that are aligned with VAW doxa. In making his last point he softened the positioning of his first one and noted the priority for holding men accountable and keeping women safe:

Deborah: I am asking everybody for three commitments you have ... or values that you bring to this work, three core things that maybe distinguish you from other work, or just get you out of bed.

Kenneth: Men can change. [Long pause] I am just thinking. Wow, huh. I am not sure. Ah, so you mean, are you talking about values that I bring to the work, or -- [pause]

Deborah: It's pretty open ended. What is important to you if you were writing down what this program is about? ... Men can change is a really significant one because we didn't always think that men could change, right? And when you say men can change you are talking about male perpetrators, right?

Kenneth: Right. Well I think the other side of that is that women have the right to live lives free of control and violence. And I do think, and not in a punitive way, but I do think there is - given the kind of work that we do; it is separate from but still embedded to some extent in the Criminal Justice System - there is still an importance of accountability. So, men have the capacity to change. When men make decisions not to change we need to have a system in place that holds them accountable and provides safety to women.

Kenneth had clearly thought about these issues and was very articulate in expressing them. However, he did not yet have a way to fully integrate his commitment to the notion that men can change, which highlights working on their issues in a therapeutic context, with feminist doxa prioritizing the need for accountability within a justice system context and with women's safety. Kenneth's strong commitment to the notion that 'men can change' was becoming doxa for him in approaching his work with men who have used violence in their relationships. However, this emergent doxa was still being moderated by his commitment to feminist VAW doxa with which it sat in uneasy coexistence.

The experience of working with men who have used violence in their relationships, in a process designed to engage them in changing their behaviours, is an intimate one. The facilitators must hold space for change in order to do the work that they do; David 
commented that he would feel "ineffective and depressed" if he did not see change happening as a result of his work. These men believe that the kind of change they are seeking comes from supportive and therapeutic processes rather than from cognitive learning processes. James noted that he focuses his interventions on changing how people see themselves: "My goal is to get people to leave here with some of those skills and that change inside themselves in terms of how they see themselves. So they bring that to a situation instead of the shame-blame-guilt stuff that usually leads to some kind of reaction and power struggles."

The commitment to the capacity of men to change in positive ways is foundational to the emergent habitus of the PAR workers and can be seen to be related to the position held by men working in this field. For male workers, the VAW identification of men as perpetrators who cannot or will not change because they are attached to the privileges that come with patriarchy creates a personal dilemma related to potentially being "part of the problem.' In response, Steven spoke of patriarchy as a problem for both genders: "Like, I get that the patriarchy is a problem. It's as much a problem for men as it is for women ... It's incredibly, emotionally restrictive. It's bad for our health. It's, you know, it's bad for our relationships. It's bad for our understanding of who we are." This claim regarding the impact of patriarchy is a claim for cultural capital on the part of men generally: men also have a need for change in the current systems; they have a stake in the game. This stake allows them to exist in the field (Bourdieu, 1992) as other than perpetrators.

The shift to understanding patriarchy as a problem for men as well as women accomplishes several specific things for PAR workers. First, as noted above, it allows 
men to exist as allies in the work to end violence against women. Second, it provides a justification for all men, including participants in the program who have used violence, to resist the demands that patriarchy makes of them. And finally it provides a rationale for why men who have used violence in their intimate relationships would want to change their violent behaviour as well as a route to such change.

For Steven, the belief that men can change provides an antidote to the despair that comes with a belief that men who use violence will never change. That this despair exists among those subscribing to feminist VAW doxa is evidenced in the use of terms for men who use violence in their relationships that identifies them with the abuse; terms such as 'perpetrators,' 'abusers' or 'batters.' The ongoing and common usage in society of the term 'monsters' (Brown, 2015) further exemplifies that men who have used violence are often identified with their violent or abusive behaviour (Corvo \& Johnson, 2003). None of these four interviewees used these terms in reference to PAR group participants. Rather, these interviewees spoke of "the men" without using labels. This was also true of the two female long-time VAW workers (included in chapter five) who have worked with men in the PAR program. These two women spoke of "men who were abusive to their intimate partner" or "men engaging in violence behaviour." A third VAW interviewee who works with men as allies spoke of "men who want to change their behaviours." In contrast, all the other VAW interviewees referred to male 'abusers' or 'perpetrators' at least once and as often as 15 times during the interview. While this shift in language could be an unconscious reflection of their shifting habitus on the part of PAR workers, I suggest that it is a conscious strategy designed to break down stereotypes regarding men 
who have used violence in their intimate relationships. The quote from Kenneth below supports this contention:

Kenneth: [We tell participants that] we are looking at behaviors that many of us have to be aware of in our relationship. I think it allows them to feel like 'I am not just being stereotyped as an abuser or as a batterer but they are trying to understand the whole, who I am as a person,' and that includes them.

Kenneth had heard from most of these men that they have values that do not align with enacting violence. He found that exploring the mismatch between their values and their behaviours was helpful in supporting them to move more toward their values in their behaviours. This approach becomes possible when the behaviour is seen as only one part of who these men are. Moving away from feminist VAW doxa that men can't or won't change is necessary to achieving this attitude. This shift also raises issues regarding the meaning of accountability.

All four of the PAR interviewees spoke of the need for accountability among the men in the program to end their violent behaviours. They all held commitments to the safety of women and children whom they named as the ones who experience the most injury from intimate partner violence. However, their expression of this accountability differed from the VAW/Duluth model as it is applied in the PAR program design. VAW doxa relating to the expression of accountability entails men being "held accountable" for what they have done. The focus is on past 'bad' behaviour. In the experience of these interviewees this focus can be ineffective or even detrimental when seeking change. When I asked David for words he would use to describe the Duluth psychoeducational model he said: "Dated. Shaming." David noted that the Duluth approach can make men defensive, and he said, "People don't change when they are defensive." While the PAR interviewees absolutely agreed with the need to hold men accountable for their violence, 
their interpretation of this accountability took a future focus. As described earlier, their attention was on supporting the desired change in behaviour and finding accountability through that change. The PAR interviewees argued that being accountable is doing something differently in the future, a framing that both required, and built on, a belief that perpetrators can change. Below, Kenneth talked about a movement away from the Duluth approach to accountability in how he worked. As he described the 'rigidity' of past VAW ideas his language faltered; as he got into the newer approach, he gained more momentum:

Kenneth: I think then -- again, there was, I think, there was a - we had some very rigid ideas, I think, about how to work with the men. And I think one of them was, don't let them talk about this other stuff because that detracts from where the focus should be, which is on accountability for abusive behavior. And I think we still, you know -- accountability is still an important objective for our program. But I think the roadmap has changed a little bit. And I think we are much more willing to invite the whole person into the room. And allow him to talk about some of those issues, um, as a way to get to accountability.

James discussed the difference between the 'whole person' approach described by

Kenneth and what he saw as the justice system focus on accountability. He argued that a

narrow focus on accountability can actually inhibit change:

James: We get the statement [from the victim-witness people and the Crown's Office] that, 'We want them to plead guilty because pleading guilty is taking responsibility.' And I can't get it through to them that that's not taking responsibility. That taking responsibility is a process of change. And that people are pleading guilty just to get out of your face and to get out of the legal system. And in the county here at least 10 percent of the people who come to see me say they've been arrested without any kind of evidence and they're in jail until they plead guilty.

Deborah: Wow.

James: And because we're dealing with the poor and the working poor... They're pleading guilty because they don't know what else to do and they don't want to keep going to court and keep missing work or paying the costs of whatever. And they're also convinced that if they plead guilty they're going to get back into their family right away, which doesn't happen. So, by the time people end up in the program they are contaminated by the system. That's working against change because there's this whole new block that's built on shame, aggression; a kind of stance that is inflexible in itself.

Both James and Steven aligned with feminist scholars and activists such as Wendy

Brown (1995) and the Incite! Collective (2006) in arguing that the criminal justice system 
is a problematic tool in looking for accountability and social change As James put it:

“This idea of using the law to create social change doesn't work. You just get more people in prison. And we get more poor people in prison." Steven concurred:

Steven: ... it doesn't help anybody to get arrested. It doesn't help society to arrest people. Punishment doesn't work. Punishment works when it's immediate, irrevocable, and harsh. If I ever get away with it, punishment doesn't work. If it's two years later, punishment doesn't work. ... States with capital punishment have the highest murder rates. Right? It just doesn't work.

These interviewees saw accountability and change as processes. They knew that some men refuse to change. They knew that sociopaths or psychopaths would not change through what their program had to offer. They knew that many men, even those who expressed appreciation for the learning they gained in the program, would still engage in violent behaviours. They remained involved in their work through their belief that men could change. They passionately believed that their work offered the opportunity for change for the program participants and saw men's capacity for change as the key to ending violent behaviours. Accountability was a living concept to them, one they approached over and over each day through inculcating a belief in, and the skills required for, personal change among the program participants.

One VAW worker noted that the PAR facilitators often wrote glowing letters of progress for participants even when abuse was still being reported by the female partner. She questioned whether the PAR facilitators were sometimes 'duped' by the participants. An explication of the PAR workers' habitus as including an understanding of accountability as engagement in a process of change helps us understand the different expectations of these two groups of workers in relation to the behaviours of the men in the PAR program. The PAR workers recognized and valued progress toward change; the VAW workers saw the impact of the relapses. 
I argue that in identifying male perpetrators with their violence, and as unable, unwilling, or at least unlikely to change, VAW doxa as described by both the VAW and PAR interviewees generated a specific conundrum for these men who worked with men who use violence in their relationships. This conundrum had to be resolved in order for them to do their work. The discursive strategies that they used to rebut VAW doxa represented deliberate moves toward a habitus that could admit the possibility of, and the necessity for, change in men who engage in violence in their intimate relationships. Bourdieu speaks of a disjunction between doxa in the field and personal experience as an opportunity for the development of shifts in the habitus. These interviewees exhibited such a shift as they negotiated a new doxic response to their experiences in response to feminist VAW doxa.

\section{Including the lived experience of men}

James noted that the framing of PAR work has changed over the years and suggested that he believes that the Duluth model has changed as well. However, the foundational intentions of the Duluth model - to challenge the abuse of power and control among male participants as a route to ending their violence - remains central to explanations of the work to be done in the PAR program given by both the program literature and the men I interviewed who work in the program. Each of the interviewees addressed and/or challenged this goal in their explanations of how they worked, successes they had had, changes that were occurring and frustrations they experienced. In alignment with feminist VAW doxa, Kenneth highlighted the presence in the program of participants who fit the coercive control model of IPV. He also spoke of a second group "who are dealing not only with their use of violence in relationships but ... are struggling 
with mental health issues, with addictions, with chronic unemployment and poverty and homelessness - sometimes, guys living in shelters." Kenneth noted that from the Duluth perspective, IPV “... is not an alcohol problem, it is a violence problem; it's not a mental health problem, it's an abuse problem; it's not a problem of poverty and unemployment..." Kenneth's experience suggested that these issues are in fact important to address in efforts to reduce recidivism. And he saw an acknowledgement of this within the wider field of people working to reduce and prevent IPV:

Kenneth: I think again we are now in a position -- at least in our program, and I think I see it happening more widely as well -- is that we are kind of able to have a conversation that situates people's choices in the context of the lives that they are living. ... Not to excuse it or necessarily to explain it, but to contextualize it.

All four of these interviewees saw an articulation of the need to take men's lived experiences into account as a movement away the original precepts of the Duluth model. And, as can be seen in the quote from Kenneth above, they saw this as an approach that was gaining acceptability beyond their program.

The PAR interviewees also noted a gap between legal and program definitions of violence and abuse and the understandings of what constitutes violence among the men in the program (and the public). David found that some of the men didn't understand why they had been sent to the program. They said, 'I didn't even hit her.' They didn't see threats or breaking objects as warranting a justice system intervention. David saw part of his job as educating the men about how and why emotional abuse was problematic. James also had experienced this disconnect among participants. He said, "The public's general understanding of what's abusive is not very well developed. So, ... they might not even recognize that they've been doing it all along and it's abusive." James also argued that direct confrontation may not be the best way to support change: 
James: People are conditioned into seeing things that way, in a polarized way - right and wrong, good and bad. 'I'm not bad. I didn't do it.' [laughs] You know? And then a lot of people want to call that resistance or denial, but it's like, ... If I don't believe I did something - you know, the more that I try to push you into that it's pretty normal that most people are going to say 'No.'

So James took a different approach:

James: I try to get to... the nuts and bolts of things. 'What are the actions that demonstrate being respectful?' 'Compassion. What does that mean? How does it feel? How does it taste inside of you?' ... For most women, I find it a little easier ... but guys are also pretty open to that, too. Because they are starving to understand that stuff. Even the ones that want to save face. [laughs]

Deborah: Can you tell me more? I just hear such a tender place when you say they're starving.

James: Their life is full of stress and emptiness and they keep filling it up with this artificial food that doesn't feed them. And so I try and feed their souls with something that has nutrients to it. The compassion, the love, you know, what fills you up? What makes you happy? What allows you to walk through whatever it is you're facing with your head up? Without shame? And I depend on them for the actual examples...

James strove to give the offenders he worked with an experience of relating to the world around them with compassion and without shame. And he knew this to be radical work that subverted the very basis of Western societies:

James: Because if you understand compassion, it's a non-linear thing. You can't explain that in a logical way. So how do you use English, which is a linear language, to explain something nonlinear? It comes in a package so I do that in a, a circular way in terms of a spherical wave bringing in a variety of things to that point.

Steven also talked about subverting expectations that are grounded in patriarchal and capitalist values as a route to change. He noted the demands of the 'social performatives' in patriarchal and capitalist societies that set men up to fail, further saying that in his more recent social service work he had realized that both men and women are set up in this way. He brought to his clients the idea of replacing the societal ideals of material success with a set of personal performatives, involving a "sense of purpose and a sense of connection to what I know is right, to the people I love and that love me back.... So I have my boundary; I have my self-respect; I have my 'other-respect'.” He added that social agencies have not addressed men in this way: 
Steven: [They] don't get how to deal with men because we're just 'bad.' We're just the problem, right? Not recognizing that we're doing the level best we can with the little that we've got here and against a [patriarchal and capitalist] system that's way bigger and way more powerful than me or anybody else that might be slagging me and what I'm trying to do here. I can't change the world. I would love to. And that's the biggest thing for these guys, it's like, 'I get no respect here.' You know? 'I'm actually trying really hard here, but it's not, it's not working.'

Deborah: Yeah. And I think that's where the blame and shame piece doesn't help, right?

Steven: No [it doesn't]. Like, to some degree, whether or not it's patriarchal control that they're acting out or if it is trauma control, I don't think that blaming and shaming is going to take anybody to another place. How do we change it is the bottom line. You know? And that's a problematic construct because it's pretty ingrained at this point.

These goals exhibit a striking similarity to the radical feminism that VAW ideals emerged from. The focus on moving away from patriarchal hierarchies as well as the contextual emphasis reflect the basis of these goals in feminist values even as at the same time they challenge how these values have been expressed in VAW doxa regarding men.

\section{Addressing the impact of justice system interventions}

The PAR workers noted negative impacts from justice system interventions including detrimental material effects (often for the family) and problems in responding fairly to the accused. The interviewees had numerous stories of financial and other material impacts as an outcome of justice system interventions on men and their families. These ranged from the impact of no contact orders (a family that ended up homeless when the man lost his caretaker position which came with an apartment, others that lost family-owned farms because they couldn't work them) to the financial costs to the family of dealing with the justice system. James decided to add up the cost of criminal justice interventions to the people who attended his program. Over one year, a million dollars in costs was reported to him. He noted the huge impact of this amount of money coming out of people's personal incomes. James' belief is that we need,

... to re-examine what are the basic assumptions and who really wants to solve the problem as opposed to give a political, reactionary response to an incident [as the justice system does now]. 
Because when you approach it that way it becomes an incident. It's no longer about intimate violence. And then you want people to then understand what intimate violence is and say, it's not an incident. Well, yes it is at that level. And I think that that's a loss of where people wanted things to go in 1979 .

Both James and Steven provided examples of how the system was not working in providing a fair hearing for perpetrators, whether male or female, although James noted that women can use physical violence as self-defence and men cannot:

James: [He] can't even get out the door .... Because even if you just brush her shoulder, that's assault. Or, if you had a fight three or four years ago and you pushed past her, you go to jail for that.

Deborah: If it happened three years ago? And she calls now and reports that that happened?

James: Yeah. Or even if it didn't happen. Because how can you prove it? The thing is, without that 'innocent till proven guilty,' how do you prove you didn't do something? And especially when you have no resources and no intellectual capacity to understand the nuances of this stuff in court. ... And I don't see it as a men or a women's issue, I see it as a people's issue because I see it as happening to both men and women. You know, I have just as many stories for men and women [who have been identified as perpetrators] in terms of how the system is treating women exactly the same as how the men have been treated.

James noted that although the police have protocols regarding how to determine the

primary abuser, in his experience they often went with the presentation from the person

who called, whether male or female. The focus was on what could be proven in court and, "If you don't listen to the other side, there isn't any contrary evidence." James continued,

I had one guy tell me, there was a no-contact order between him and his partner. The screen door was closed - his place - she comes up to the door. He wasn't going to open it because he didn't want to get breached. There was some garden shears by the door. She picks them up, cuts her way through the door, slashes him to ribbons. He runs outside, is going down the street covered in blood, and all cut up. The police take him to jail. ... there are women examples, too. I have used both gender examples in groups with men and women because they think that it's all about a gender issue. It's like, no. This is a systems issue and what's lacking is information to make decisions based on integrity as opposed to the outcome of a court case: what's chargeable; what's convictable. ...

For James, the focus of justice system interventions should be on community safety rather than based on what can win in court.

Steven spoke of issues regarding the definition of 'assault' in the Criminal Code.

He said that, as he understood it, an assault is "anything that causes fear in another human 
being. Right? So, that's a subjective sensation, fear." He had had conversations with men who had been charged who said, 'I didn't hit her. We were having an argument. I yelled at her, the cops showed up because the neighbours or my mother-in-law or sister or somebody phoned.' He continued,

Steven: The cops came in, she said, 'He never hit me, he yelled at me.' And they asked her, 'were you afraid?' 'Yeah, he scared me.' 'Okay.' You're now guilty of assault. Right?

Deborah: That's pretty tough.

Steven: These guys would say to me 'I'm going to fight that, I...' . There's huge consequences to being guilty of assault, right? For the whole family. Right? Financial consequence, emotional consequence, psychological consequence - how do you hold your head up in the community anymore? And for the woman as well, who is going to the cop, 'I don't want him charged... 'We [just] need a cooling off period' or something like that.

While Kenneth thought that the structures which have been built into the justice system were appropriate for coercive, controlling violence, he spoke of problems that system intervention can cause for partners involved in situational violence and specifically what he called "fights." Kenneth said as the PAR support workers talked to female partners they often hear women say,

Kenneth: 'I wanted some help in this situation but I never thought that we'd be apart for six months or he'd have to pay thousands of dollars for a lawyer or he would have to live in a homeless shelter because he can't afford two rents.'

He then went on to question how much of the justice system's resources we wanted to put into responses to fights between partners:

Kenneth: I know people are always worried about the slippery slope. We have fought so hard to criminalize violence against women, but I think, again, even VAW activists are saying, we need to at least have a conversation about what have been the consequences, both intended and unintended, because I think there are ... enough women saying, 'I will not call the police [again].' Is that really what we want? Because maybe the next time is when they should be calling the police.

For the VAW workers, who were continually confronted with the impact of coercive controlling violence, the risks of using typologies of violence to create differential approaches to addressing violence by men were central. For example, Melissa spoke of 
the default use of the coercive control lens of IPV as the safest approach. The PAR workers had a different perspective which emerged from their position in the field. Kenneth and the other PAR workers identified the problems that could emerge from responses which assume that all IPV is coercive and controlling violence. The PAR workers, who from their position saw primarily situational violence, identified the need for interventions to respond in a way that makes life better for the individuals and families involved in situational violence (in addition to taking appropriate responses to coercive controlling violence). This is a powerful example of the incompatible truths in which various habitus and doxa in the field are grounded.

\section{Men and women both need to do their work}

Kenneth referenced the work of researcher Evan Stark in discussing the fighting

that could occur in a dysfunctional relationship. He characterized this violence as,

... the kind of stuff that gets captured in some of those general social surveys that Stats Canada records where they talk about $8 \%$ of women and $7 \%$ of men [using physical force]. ...You are having an argument and one or the other pushes and it is sort of seen as not particularly appropriate, [but is] ... an understandable way that some people express themselves when they are having argument. I think for some of the men and the women that is who we are getting. We are getting people who aren't particularly equipped to communicate in the kind of way maybe you and I would if we were having a disagreement about something. It is as though they get to the point where [they say], 'screw this,' push the person and walk away from the argument.

James noted a lack of healthy relationship skills in both women and men:

James: ... I talk to men about, you know, you haven't been trained into this [non-violent way of communicating]. ... And I tell women the same thing. Because women don't know how to listen to men. They don't listen to men. Men don't listen to women. It's like, so, we have problems? Of course. [laughs] You know?

Steven took the strongest stance in discussing women's role in ending intimate partner violence. Steven shared his experience of what happened over time as the men he worked with in the program learned to let go of the patriarchal demand to ignore their feelings and instead began to recognize and take responsibility for them. Steven located a 
primary cause of violence (among those he saw in the PAR program) in generational abuse patterns and named a joint responsibility for change between those in the relationship. Steven was clearly aware that he was telling an aberrant story according to feminist VAW doxa. He was aware that he could be accused of victim-blaming. He regularly stopped his story to check in with my reactions and understanding. This stood in clear contrast to Kenneth's relative comfort and belief that his story, which is more explicitly aligned with feminist VAW thinking, would be heard by a feminist researcher. After pointing out that the men who had been using violence needed to learn alternate behaviours, Steven continued with a discussion of the need for victim/survivors to make some changes in their behaviours and beliefs:

Steven: The last two years I worked ... [in the PAR program], the number of referrals to the program for women [specifically partners of men who had taken the program] tripled. So why is that happening? I talked to the guys and they say, "When she's screaming at me now, I tell her 'I'm taking a time out. I'll come back and talk to you."' ... What they were running up against were women who'd been through abuse, after abuse, after abuse, trauma, trauma, trauma, and [the woman's] need for control. And their means of control in the relationship is not primarily physical. It's verbal and emotional. And the thing about any level of control is, if the control behaviour that used to work doesn't work anymore, then the control behaviour escalates. And it escalates from relatively minor sort of sulking, whining, and victim-posturing to increasing aggression. ... And I mean, I'm not saying that that's just women, I'm saying that's a human characteristic. We continue behaviour as long as it works and once the behaviour stops working we don't stop the behaviour, we simply escalate the behaviour. You know?[pauses]

Deborah: Yeah. Until, you're stopped or until -

Steven: Until you understand it won't work anymore.

Deborah: Yeah.

Steven: And I think there has to be [from workers], 'It will not work anymore -- And, oh, by the way there's another option here.'

He noted that the program generated the best outcomes in situations where the female

partners were able to set a clear boundary that reinforced the learnings of the program:

Steven: Yeah. And you know - and, I'm not, like, I don't want -- This is not victim-blaming. This is about [pauses]. This is about a clear recognition that abuse strips away self-boundary and self-definition and self-respect. Right? And it could have been that male partner's abuse. But what I saw increasingly was it was childhood abuse to relationship abuse to relationship abuse to 
more relationship abuse. You know? And the question is why. And I mean, women ask me this all the time [in current social service work]: 'What is it? Where's the sign on me that says abuse me?' You know? And it's that lack of clear self-boundary, lack of clear self-respect and it's that historical need to control what's around you, which leads to that abusiveness, eh? And because sometimes they're controlling what's around them by just satisfying whatever anybody asks of them, right?

Deborah: Being a 'pleaser' is controlling?

Steven: Yeah. Well, it's, it's a self-preservation thing, right? It's a survival thing. If we strip away the moralizing off of it, it's just what people do to survive. You know? And the blameshame thing is really destructive of a dialogue about this. Like, um, and that, I guess that's a problem I have with the patriarchy idea.

Steven clearly did not expect his point of view on this to be heard by a self-

professed feminist researcher. He had had experiences of being 'shut down' by feminists on this issue. He did not return my first phone calls/email and when we did first talk on the phone he put forth his views and followed that by saying "I'm probably not in your study parameters," giving me an easy way out if I did not want to continue the conversation. Steven offered an explanation of why victims end up getting charged with IPV that engaged the responsibility of the victim/survivor, challenging the VAW presentation of the victim as innocent of blame. Several VAW interviewees presented the idea that men learn how to manipulate the system in the PAR program and that is why their female partners end up being charged as perpetrators. Steven offered an alternative (not 'alternate') explanation of women's use of violence that was based in his traumainformed understandings.

For Steven, the idea that women who are victimized also had emotional work to do which would include taking some responsibility for the violence they experienced, did not replace the need to protect abused women:

Steven: We need the shelter movement. We need to protect women who are being abused. We need to protect children who are being abused. And we need to recognize when people are being victimized and help them own that they have been a victim. ... They are genuinely a victim of somebody else controlling them. But if they stay there then they're screwed because they don't have to take responsibility for moving forward with their own life. It will always be somebody 
else that is the oppressor of them. And then they will require somebody to rescue them instead of being able to have control over their own life - which is the only answer to being abused.

The notion that women, men, perpetrators and victims all need to do emotional healing work moves away from VAW doxa which dichotomizes the experiences of women and men as well as perpetrators and victims. The experiences of the PAR workers highlighted these issues in relation to VAW doxa. The final two strategies I explore in relation to the PAR workers relates to the impact of theoretical framings of trauma and typologies of violence.

\section{Impact of trauma theory on how the work is conceptualized}

The PAR workers had been exposed to trauma theory in workshops and at conferences on working with perpetrators as well as in more general contexts. Steven brought forward the conundrum created by the awareness of the significance of trauma for him and other workers as the PAR program design focuses only on psychoeducational approaches:

Steven: ... everybody knew that the guys that we were dealing with, and the women that we were dealing with, were coming from huge trauma and abuse histories and so, it just - if you don't work with that in some form or fashion then you don't go anywhere. Right? So everybody knew that, but we weren't supposed to talk about that. Or deal with it. There was a specific thing in the [program], where [it was made clear that] you do not deal with family of origin issues.

Using a trauma lens provides a different view of how the dynamics of violence can play

out in some instances:

James: From a mental health point of view, trauma is the anticipation of harm. It's not the harm itself. When you're anticipating something bad, that's traumatizing. The event itself is the release, it's the catalyst. So when I talk to people about, 'why does she push my buttons?' It's like, well, think what the build-up was. That anxiety, it's like you sit in front of the office at school waiting for trouble or wait till your dad comes home. Think of what that does to you and how that builds up. You need to release it. So she's going to find a way to release it by pushing your buttons or spending your money. You know? Then it's over. Doesn't matter if she got hurt. She doesn't have to worry about it anymore. That is an explanation of trauma, and one of the 'why' questions that sometimes people come up that I'll answer. 
All of the PAR workers noted the impact of childhood and adult trauma on the program participants. David asserted that the need for power and control was there among participants but said, "The question is why they need power and control." His own answer included both male socialization and childhood trauma. He estimated that, in his experience, perhaps $80 \%$ of the men had experienced childhood abuse. He noted that there was not time in the program to deal with this beyond showing empathy and providing a referral. Kenneth also cited childhood abuse, noting that 15 to $20 \%$ of the men in the program acknowledged childhood sexual abuse on a survey done by the program. He noted that the actual number is likely significantly higher than this. Steven said that, in their intake interviews, $30 \%$ of participants stated that they had been sexually abused (he thought that there was under-reporting of this issue) and $80 \%$ indicated physical abuse. James also noted the importance of working on past trauma with both perpetrators and victims.

Kenneth noted that there are (a limited number of) programs available for men who have experienced childhood abuse, so referral is possible. And while they do weave trauma into the PAR program to the degree possible, he would like to develop a program that would give men the option of addressing intimate partner violence in the context of trauma recovery. This is not something that could be done within the current standards from the Province which respond to VAW doxa.

\section{Impact of theories of typologies}

Theories relating to typologies of IPV lead to the idea of screening PAR participants and creating a differential response based on the type of perpetration. Kenneth indicated that the Ministry of the Attorney General had not been open to taking 
such a response. He identified issues relating to liability - "What if you make a mistake or what if you decide that someone is situational when it is really intimate terrorism?" as one specific issue that would have to be addressed.

Kenneth: And yet, the system is kind of, scooping everyone up into a fairly big net, putting them through the Criminal Courts. And I think sometimes now people who work in PAR Programs feel that we are now the dumping grounds for everyone who has committed an offense, whether that offense is part of, again, what we would consider to be intimate partner violence in that larger context or not. And, I think there is some debate, I think not everyone accepts or wants to talk about typologies and so on, but it's -- to me, from who I see that we are working with, seems to make some sense. And it seems to be that it would be good if we put some more effort at the front end around assessments and looking at risk and then tailoring the intervention to what we find. As opposed to what is now a one-size fits all approach where everyone, notwithstanding their history, their risk assessment for future violence, gets the same kind of thing.

The PAR workers saw the issues that emerged in the delivery of services from the current 'one size' response. They also identified the material effects on families as noted earlier. James' experience of doing PAR programming before the service was mandated also impacted on his sense of how these services play out. He argued that people want to be able to get help without having their lives "torn apart" as happens through the current approach in the justice system.

The notion of helping perpetrators brings us back to Jessica's quote which opened chapter six, in which she said that she had at one point thought that helping perpetrators would be "really dumb." Early VAW doxa focused on supporting women victim/survivors of VAW to change their lives, usually by leaving abusive relationships (Loseke, 1992). VAW workers have viewed the potential for change by male perpetrators with scepticism, and efforts to support this change as, in Jessica's word, "dumb." While the PAR workers saw their role as challenging perpetrators to be accountable for ending abusive behaviours, they saw this role in the context of a (professional) relationship that could provide support for the process of change. This is a key difference to VAW doxa: 
the emerging PAR doxa takes a generative view of men who use violence in their relationships, providing a map to therapeutic change within those relationships.

The PAR interviewees spent time with, heard the stories of, and worked with, perpetrators (primarily male but also some female) rather than female victims as is the case in the VAW sector. Thus these interviewees were challenged to see the violence being perpetrated in the context of the lived experience of the perpetrator. These interviewees also were men; male violence could not be something done by an othered 'them.' Their goal was to reduce recidivism and they had seen the shortcomings of the Duluth model (as it is enacted in the PAR program in Ontario) in supporting that goal; they noted that change comes from hope not shame. From trauma theory they understood that hurt must be healed in order for change to happen. They saw the impact of justice system interventions on the offender and the family. The PAR workers identified that there were fewer coercive controlling men coming into their programs than those using incidental violence. The experience of PAR workers as men and in working with male perpetrators necessarily provided them with the basis for a revised habitus and doxa which was related to VAW doxa in complex ways. These doxa reside in a nuanced coexistence in the field of work to reduce and prevent intimate partner violence.

\section{PRIVATE THERAPISTS}

Liz: I was part of that feminist movement. I'm at that age, right? There were so many feminist courses that I took in graduate school and all of that. But I don't see myself as a feminist [pause] by at least the definition of feminist in the late 60s and early 70s: Man against woman; unisex; we're all the same. I am not of that ilk any more. ... We [still] have tons of work to do. But when I say we haven't achieved equality I see that in terms of men too...

All five of the psychotherapists interviewed for this study aligned themselves with goals

of gender equality. Three of the therapists identified as feminists (William, Margaret and 
Cynthia). As is visible in the quote above, Liz noted that, while she had a feminist education and believed in goals of gender equality, she no longer identified as a feminist. Kevin also had had a feminist education as part of his educational training but distinguished his approach at the time of the interviews from feminist VAW approaches. For all five of these interviewees, feminist VAW doxa was formational to their current practice, or was something they constructed their practice against, speaking to the hegemonic space VAW doxa held in the field. Similarly to the VAW and PAR workers, feminist VAW doxa could be both foundational and contested at the same time for those in this group. However, the private practitioners did not have a relationship of authority with VAW doxa within the structure of their work and they encountered a wide range of client experience that did not fit with VAW doxa. Thus, their training and beliefs, and consequently their sense of belonging in their professional community, were not as closely related to VAW doxa. While this doxa was still significant to their explanations of their positioning on the issues, their understanding of work to reduce and prevent intimate partner violence had a greater sense of distance from this doxa.

The position held by these interviewees as private therapists affected the clients they saw, the attitudes of their clients and, in Michael Johnson's (2011) terms, the typologies of the violence in which their clients were involved. Four of these interviewees worked with couples as well as both victims and perpetrators (William, Liz, Kevin, Margaret). Liz did not do relationship work when there was current physical violence in a relationship but all four worked with couples where there had been violence in the past and/or current emotional or other kinds of abuse happening in the present. When they were confronted with a situation of ongoing violence they used a range of 
strategies to care for safety issues, ethical issues and confidentiality of the partners. Kevin saw the task of discerning what is going on and addressing it as a difficult but necessary part of his job: "It's like a firefighter or paramedic who comes to a crisis situation, a crisis scene, and you just got to do your job. It's no time to crumble, right?" Liz noted that all of the clients came to her by choice; they were looking for change. This can be very different than the work done by the PAR workers with perpetrators who have been mandated to attend the program. While private therapists might be expected to have a client base with sufficient financial resources to pay for private therapy, William, Kevin, Margaret and Cynthia all identified some agency-based involvement that gave them the experience of working with people who did not necessarily have significant resources.

\section{Naming and definition of IPV}

'Domestic violence' was the most common term used by these interviewees (William, Cynthia, Kevin). Liz used intimate partner violence. Margaret objected to the use of 'intimate' in relation to violence suggesting that 'partner violence' would be a better fit as "intimacy is something that people who are involved in partner violence actually don't experience." Kevin and William both responded to intimate partner violence as a newer term that they had not used but thought was a good fit.

The private therapists all include physical violence and emotional abuse in their definition of IPV. Cynthia and Margaret explicitly included spiritual and financial abuse and positioned IPV in the context of an imbalance of power. Liz's definition included the idea that violence affects the one doing the violence: "It's words and actions that are negative in origin and are meant to harm or hurt their partner in the process. So I see IPV 
as not just projected outwards. Any time we are feeling, thinking, behaving violently, we are harming ourselves as well as our partners."

\section{Relationship to VAW doxa}

The private therapists interviewed had a complex relationship to VAW doxa relating to the female victim/male perpetrator. Each of them provided examples of this as I review below. Cynthia was a feminist therapist who had been in practice for less than five years. As part of her work she saw victims of domestic violence who are referred through the court system. Cynthia initially identified that she used the term 'domestic violence,' which was the one commonly used in her professional community. During the first hour of the interview, the story Cynthia told of domestic violence fit within the feminist VAW doxa. The term domestic violence did not raise issues of female to male violence or mutual abuse. The presentation of the scenario from my study interview guide (in which a woman's violent behaviour escalates until her male partner strikes back) opened up a new area of exploration in which she shifted to using the term "abuse" rather than domestic violence and discussed her experiences of female and male clients who are being emotionally abused. Toward the end of the interview, in response to a question regarding mutual violence, she talked of "toxic relationships" in which both partners are engaging in behaviour that is abusive.

While these three kinds of intimate partner violence identified by Cynthia were presented as distinct, she noted that there are always grey areas, and certainly some overlaps were visible that remind us of Bourdieu's claim that practice only engages the degree of logic necessary for the practices in question (Bourdieu, 1990). For Cynthia, the logic invoked is in response to three sets of clients: women identified in the justice 
system as victims of domestic violence, clients who experience emotional abuse from their partners and, clients who are involved in chaotic and mutually abusive relationships with both partners suffering from attachment and trauma issues.

I asked Cynthia if she thought that the scenario I presented was an uncommon one. She replied, “No, I don't. I think it's hidden. But I don't think it's uncommon.” Cynthia said, "I have never had a man come to me because of domestic violence issues. ... I do have men clients who will admit to being emotionally abused in their relationship." Cynthia described the emotional abuse suffered by her male clients as significant. When I asked if men are as impacted by emotional abuse as women are, she began with, "to a certain degree, yes" before saying, "If we were just looking at emotional abuse, in and of itself, I would say that it's pretty even". She however, noted that physical and sexual abuse was experienced more by women than men.

For Cynthia, domestic violence was a term reserved for criminal violence by men toward women. The kind of emotional abuse she identified men experiencing at the hands of women was not named as IPV even when she identified it as comparable and even though she included emotional abuse in her definition of domestic violence. Likewise mutual violence is not named as domestic violence. Cynthia exemplified the definitional problem of work in this area and how the positions of the interviewees impact on their definitions and use of terminology. Cynthia's work with victim services has provided a specific boundary around the term domestic violence. A general inquiry about intimate partner violence drew out her experience with work in this area. Further inquiry was required to fully explore the range of partner violence and abuse she saw in her practice. 
Liz noted that she used to think of perpetrators and victims as primarily male and female respectively and that the "perpetrator is this terrible person who needs to be punished, or you know, we need to set him straight ... And the female is this poor victim person, who really needs to learn how to be assertive, stand up for herself. That whole attitude, that whole mindset, has changed drastically [for me]." Liz changed her attitude through her own "personal, spiritual growth, as well as working with some 'perpetrators'." In terms of working with the abuser, she said:

Liz: Often people are trying to make them feel guilty and shaming them for their rage towards others [laughs - the implication here that people doing the shaming should look at their own behaviour]. They might get that intellectually. But until they really get ... the violence and harm they are doing ... to themselves - I haven't seen anybody really change, by just through sheer willpower.

While Liz did not think we had reached gender equality between women and men, she saw society as disempowering both women and men in different ways and abuse as emerging from disempowerment, whether connected to gender issues or generational experiences of abuse. She also named physiological factors such as mental illness and culture as possible components. She said, with emphasis, that regardless of whether they had been labelled as perpetrator or victim, "I treat them the same." She worked with her clients to show them the choices they had in how they acted in the situation in which they found themselves. Perpetrators commonly name someone else's actions as the cause of their behaviour and she named the issue to be addressed as both parties learning to assume complete responsibility for their behaviour and their life.

Liz understood feminist VAW doxa as drawing a firm distinction between the victim and the perpetrator and she described her own practice in distinction from this characterization. She believed that the abuser can change - she had often worked with people who were emotionally abusive and/or had been physically abusive in the past. She 
had also worked with people who were victims in an ongoing abusive situation. Her position as a private therapist means that she had a different client base (whether victims or perpetrators) than the VAW workers or the PAR workers as her clients are voluntary participants with the resources to access her services. She did not see perpetrators who did not attempt to change and excluded people with psychosis from her practice and therefore her analysis - something that VAW or PAR workers could not do.

Margaret argued that IPV is a multi-factored issue not one that can be understood using any single-factored lens, whether a pre-feminist blame of women or a feminist view of 'patriarchy.' Margaret provided counselling supervision to a women's organization and says that they were more open to the view of IPV as multi-factored as a result of her work with them. She used a gendered lens in her analysis of intimate partner violence, and saw men as the primary perpetrators of physical violence within relationships. She saw this as a result of size, testosterone levels, and higher levels of anger and sometimes entitlement: "Not because women don't want to hurt men. Some of them really do, and some of them do, but they don't do it as much." On the other hand, she said, "Verbal stuff goes both ways. Oh, boy! Verbal stuff. Hitting below the belt goes both ways." Margaret worked with couples who come to her when there is physical violence currently occurring. She challenged the man (and she spoke of the perpetrator as a man) regarding his violence and supported the woman to take action:

Margaret: I am going to make sure that this doesn't happen again and I'm going to get the wife to figure out how to call the police when it happens. So I'm helping her take back some of the control in the relationship: 'If you hit me again [Margaret] said it was okay if I called the police.'

Margaret said that if she thought the woman was in serious danger, she would not see the couple for relationship work. She would offer to refer each person to separate therapists 
to work on their individual issues and behaviours. She would tell them that once she believed that the violence has stopped (and the one who is being hit was the one who got to say when this point had been reached), she would then do couples therapy with them. Sometimes couples made it to this next step, other times they did not.

Margaret had worked extensively with survivors of childhood abuse using a trauma and attachment model. She believed that men are the primary perpetrators of sexual childhood abuse although there are similar levels of victimization of girls and boys. About the gender of perpetrators of child abuse other than sexual, she said,

Margaret: I hear just as much about abuse by mother, mother using the strap, mother using force, putting people in cupboards, closing the cupboard doors, all kinds of things. Men tend to be more physical. Women tend to be more verbally abusive and they lash out with instruments more than just beating their kids up. In other words they'll use a rolling pin or they'll use something else.

The survivors of childhood abuse whom she saw often had adult relationships that involved some form of violence. She said that usually neither party "wants to be in this kind of relationship." People often think they are fighting about money, sex, kids, in-laws and the division of household labour. But, what was underneath was:

Margaret: ... 'Do you really love me, do you value me? Am I okay?' You know? 'Am I a priority in your life? If you don't take out the garbage I must not be a priority.' Right? They use these five things to fight about issues of power.

Deborah: ... they're fighting about issues of power. And what you're describing seems to be common couple violence. And then there's this other thing [coercive, controlling violence] -

Margaret: That is very different.

Deborah: What do you think the proportion is between those two?

Margaret: I would say about $10 \%$ is intimate terrorism.

Deborah: And the women who go to shelters, are they the ones who are involved in relationships where there is intimate terrorism?

Margaret: I don't think so. I think that some people who even do the day to day violence can be quite terrorizing ... But they're not psychopathic. 
Margaret aligned with VAW doxa in describing the power and control behaviours involved in partner violence and the male perpetrator of physical violence; she described women and men 'fighting' as a result of past trauma. She addressed IPV in the context of trauma recovery for both partners in the relationship as did the other private therapists. For the male therapists I will describe next, a further impact from VAW doxa could be observed.

The male therapists had been personally affected by feminist doxa regarding the male perpetrator as 'other.' The identification of all men as potential perpetrators had impacted the lived experience of these interviewees (interviewees who would now be accepted within the movement as allies in the fight against violence). William commented on the challenge feminist thinking on IPV posed to him as a progressive man and a therapist coming of age in the 1960s:

William: All of my adult life I have been aware of being disenfranchised because I'm not a monster yet but I could be ... if you aren't awful because of your behavior, you're awful because of your potential. You could be that. You aren't now. But you could be.... there was no place for an ordinary, emotionally aware male.

William shows the struggle men faced in the early years of VAW work in finding a position from which they could engage with the work. Kevin's experience echoed that of William.

Kevin was a counsellor in private practice. In his social science undergraduate program in the 1980s he was trained to use a feminist analysis of men's violence against women which brought forward men as a danger to women:

Kevin: I took that as, 'Oh, okay, well this must be the truth.' Although, paradoxically, as a male who was growing in my social consciousness, there was an inner conflict. Because wait a minute: I wasn't one of those [angry, violent] males. .... Oh, okay, well, we're talking about only a small percentage of the population? No, it was, like, everybody. 
Kevin provided an example of the role of training and belief in developing a sense of belonging as well as the role communities play in supporting the work of believing (Bourdieu, 1990). As he moved further from his feminist training he struggled with the beliefs which had come with that training. Finding a men's rights group to belong to was a significant part of his journey of knowledge transformation as he moved from training which suggested to him that men are "inherently bad" toward a view of masculinity that he could adopt "as his own." This new group fulfilled his need for belonging and provided him with positive conceptualizations of men. However, it also provided him with training that he eventually found problematic:

Kevin:... and so the pendulum swung over to that side for a while. ... Being identified as one of these guys ... going, 'Yeah! We're wounded, too, and you know, we're not always the perpetrator here, sometimes we're at the butt end of being the victim.' Then eventually I moved out of that wounded male consciousness.

Finally, Kevin found his current community, a finding which also involved training as well as belief in the rightness of this new lens:

Kevin: And so, I came into another bit of training. ... it really does involve ...owning masculinity... the positive qualities... as well as the dark side. ... So that it no longer becomes, you know, we're the victims and women are the perpetrators, right? It's more, 'You know what? We both have our dark sides.' ... And how can we form partnerships that are about being conscious of both and working with both? And that's where it is now, for me.

For Kevin, his feminist training was a direct challenge to seeing his own positive qualities. After becoming a member of a men's rights group, and thereby going to the other side of the epistemological pair, he found an intellectual framing of men and women which, for him, provided a basis for working as a therapist with individuals of both (all) genders in terms of their agency to form healthy partnerships.

In the accounts of William and Kevin we see the impacts on men of the opposition of male and female experience in VAW doxa. Patriarchy as an explanation for abuse 
countered the blame previously apportioned to women, an important and needed change. However, for these men working in the field, this provided an unsettling and unsatisfactory explanation as men and masculinity became the problem. Their position meant that they had to work with and through the positioning imposed upon them.

While all the private therapists began with a VAW lens in their work to address IPV, they all had diverged from this lens, at least to some degree because of working with male clients or by virtue of being male. One of the key areas of divergence was the unambiguous articulation of the need to address perpetrators with compassion in order for change to happen. The private therapists addressed compassion or empathy for all those involved in violent relationships as integral to generating change within a psychological model.

Margaret referenced neuroplasticity and attachment in talking about compassion as essential to therapeutic work: "You have to care about your clients. You have to love them ... It's in that attachment that healing and neuroplasticity take place. Those are when the new patterns form in the brain." William said:

\footnotetext{
William: When I suspect that the violence originates in the wounds of deprivation, compassion is the most powerful emotional intervention that the therapist can provide. ... You make the response that the child needed in the first place ... There is no other - What are you going to do, didactic teaching?

Deborah: That's what PAR [says it] does.

William: I know. I don't agree with that.

William saw the behaviour of female victims and male perpetrators as acting out patriarchal values learned by each before they are old enough to recognize it or resist. He said, "Patriarchal privilege is the framework in which that wound gets acted out. And it's
} 
a readymade framework. You don't have to discover it - you [are given] it." He also

noted changes over time in how perpetrators are addressed generally:

William: It's a bit like the movement in justice. There was a similar idea of pedophilia. ... now we have this approach to justice that involves the criminal and the victims of the crime coming together in a safe environment. I think that this is eventually where this other stuff will go. Because there is an acceptance of the wholeness, the interconnected relationship of everything to everything.

Cynthia identified the need for compassion for victims of domestic violence and for those

involved in what she called 'toxic relationships' of mutual abuse,

Cynthia: Because you have to picture that again they learned it somewhere, they were probably in survival mode most of their childhood and so they didn't have the opportunity for those things to develop in sort of a natural way. Right? So, there has to be some compassion and you have to give them credit for trying to get help. You have to give them, you know, those kinds of things.

For perpetrators of domestic violence, she said,

Cynthia: ... I think we still have to be open-minded and empathic to their story because they didn't get here by choice. They're making choices, there's no doubt about that, but to some extent something has happened in order to make them like that. Okay? ... I don't know if I would go as far as to use the word compassion only because I do think that they are adults and they are making choices.

For Kevin the role of compassion was that it allows for the expression of shame and

allows for change in a way that judgement cannot:

Kevin: Compassion ... allows people to speak about what could potentially be unspeakable. Or very, very hard to admit to themselves or be honest about, right?... compassion I think creates a space for all of it. ... My firm belief is that if anyone is going to address anything in their personality, their being, it has to be met with and embraced by compassion, which is, you know, an innate part of the human spirit. I have never really seen anyone grow or change from a place of self-condemnation.

Kevin also noted that for many clients the therapeutic relationship may be the first time

they have encountered true compassion. This experience can show them that it is possible

to hold themselves in compassion. Liz reiterated many of the themes above, saying that

"Judging doesn't heal... we are just doing it back."

In sum, the private practitioners were open and articulate about their divergence

from feminist doxa regarding the male perpetrator and female victim. Liz, William, 
Margaret and Kevin had an already thought out analysis of their divergence from this doxa. Cynthia thought of domestic violence as controlling violence generally by men against women in alignment with VAW doxa; her experience of emotional abuse experienced by men and toxic relationships were not analysed using the VAW lens. All five of the interviewees addressed compassion in a therapeutic relationship as needed for efficacy in that relationship. They also noted that there must be willingness on the part of clients and that there are people with psychopathologies whom this approach will not reach. Both the exploration of experiences of traumatic victimization as well as being accountable for their behaviour in the present were seen as integral to this work. Theoretical framings of typologies did not figure as strongly in the accounts of these interviewees as it did for the PAR workers, perhaps because their work was not defined by VAW doxa that required them to justify a deviation from a lens of coercive controlling violence, as is the case for the PAR workers.

Interestingly, these practitioners had perhaps the hardest line for perpetrators in terms of "you will end this behaviour" of any of the interviewees. The VAW workers did not work directly with perpetrators and had a structural analysis which led them to expect that perpetrators would not change. The PAR workers worked with mandated participants and knew that many of the program participants were likely to continue to be violent even if, and as, the violence diminished. Neither the VAW nor the PAR workers could 'screen out' psychopathologies, ongoing physical violence, or lack of engagement on the part of the perpetrators as the private practitioners could. As well, the private practitioners had a sense of professional belonging that hinged on beliefs and training regarding the efficacy of healing and the personal agency of their clients. Their clients came to them with an 
agenda for change - either personal or imposed by their partner. The private practitioners provided the structure of a demand for the end of physical violence from their clients as a condition attached to doing work with the client. The ultimate goal of this healing work was internal change that could be sustained by the individual outside of that structure.

\section{INTERVIEWEES WORKING WITH MEN WHO HAVE BEEN VICTIMIZED}

Two interviewees did not fit into the previous groups presented thus far. These are Theodore and Marcus. Theodore worked at an agency which provided services to men who have experienced childhood abuse and/or were experiencing problems in their current lives. He noted that intimate partner violence was not their primary focus although they did address it in the course of their work. Theodore identified himself as pro-feminist and credited feminist movements with doing the groundwork that allowed domestic violence and childhood abuse to be addressed. He said that the organization at which he worked was "informed by feminism."

Theodore noted that early efforts to end woman abuse identified the most extreme forms of coercive controlling violence by men toward their female partners. But, he said, “We know now the lion's share of domestic violence is not like that, it's situational.

[And] at least half of the violence is bidirectional." Theodore suggested that the system needs to screen IPV offenders to determine who is treatable:

Theodore: There is psychopathy, and many of them might be considered to have antisocial personality. They have very diminished empathy, not very amenable to treatment, certainly not in a talking process. And really in some ways, there are some concerns about those guys being in a treatment program. ... their abuse may become even more complex, more sophisticated because of that. So obviously the system needs to screen out and differentiate between different types of offenders. I wouldn't think that we have any of those guys coming into our anger management program but I do know that those guys often get caught in the criminal justice system and in PAR programs. 
Similarly to the private practitioners, Theodore's experience of IPV was largely situational violence. He was not working in a mandated service. Michael Johnson's (2011) argument that men who are engaging in coercive controlling violence would not show up in survey data because they would refuse to be interviewed (and because intimate terrorism is a much smaller proportion of IPV) can be extended to suggest that neither would these men easily deliver themselves up to treatment (which they pay for). As with the other interviewees, Theodore's position affected his positioning. He saw that situational violence comprised the 'lion's share' of intimate partner violence and he saw mutual violence as a significant component of the problem. This positioning moved the majority of men from the category of "monster" to the category of "treatable." When I asked Theodore for three commitments regarding his work, he responded: not to make assumptions of who is hitting whom; that both the victim and the perpetrator require support; that change is possible.

The work done at this organization with male victims of abuse used a lens which was differentiated from, yet in relation with, that of feminist understandings of how to work with women victims:

Theodore: Men's lives are quite governed by the conventions in masculinity...[We use this understanding and] a number of other concepts from male-centered psychology ... [to]engage with men. ... That approach to treatments or psychology informs every program we offer. So it does look at the larger social structure, it does look at the constricting roles of masculinity ...[and] femininity and certainly in some ways we are informed by feminism on that front.

Here we see 'masculinity' as a structure that constricts, rather than as primarily enabling agency. However, Theodore's organization avoided using the term 'victim' in relation to men who had experienced childhood or adult abuse. In this avoidance they had built on the work of others (such as the '1in6' organization). They approached victimization and perpetration as intertwined concepts rather than as polar opposites, thinking that "no one 
lives in polarity." This response to men who have experienced victimization allowed them to normalize and address problematic (and potentially abusive) trauma-based behaviours that the men may direct toward themselves or others within a healing modality. An understanding of masculinity as constricting aligns with Steven's comments regarding his experience of PAR participants and Liz's approach to her clients wherein she treats the identified perpetrator and victim 'the same.' It also aligns with the comments of William regarding patriarchy as a framework that is acted out by people in violent relationships. A view of victimhood and perpetration as intertwined also supports a view of men as capable of change through therapeutic intervention.

Theodore's position and positioning led him to be a fierce advocate for services to address men's historical and current trauma. He saw the female victim/survivor and male perpetrator concept as one that is problematic in not addressing men's victimization in heterosexual relationships or violence in same-sex or transgender communities. As he is a men's advocate, he sees the lack of services for victimized men as problematic, even as a violation of human rights:

Theodore: If you look around, how come men can't go into shelters? Well because of their sex? How come, how come gay men can't be in a support program for those abused? Is it because of their orientation? You know, this is all around us and yet you'd like to think that this sector would be most progressive in encompassing human rights and it is not. It is quite regressive.

The construction of epistemological pairs can be seen here between the service provider working with male victim/survivors of childhood abuse and those working with female victim/survivors. The experience of providing services to men, and in working with men who have been victimized, provides a visceral challenge to the feminist VAW habitus. From Theodore's situated experience of the field, providing shelter only to women 
fleeing violence is a human rights violation. From the feminist VAW perspective, male violence against women is the human rights violation.

While differences in positioning can be experienced by those involved in the field as oppositional (or even heretical) to their beliefs, belonging and training - in other words a challenge to their identity - these differences can be seen through a Bourdieusian lens as inevitable in the context of ever-evolving knowledge production in the field and the struggles for cultural capital in this field. Theodore first worked with men within a Duluth model. He was disgusted by the lack of attention to the victimization many of these men experienced within their families of origin; he felt that they were not being treated as human. He began working with men who had been victimized to fill a gap in feminist work, a gap that was a result of doxa. This gap was visible to him in a different way than it was to women because he was a man and (as noted by William and Kevin) the doxa challenged his humanness as well as those of the participants. His work almost necessarily contested feminist VAW doxa in that he began with men who have been victimized rather than those who had been identified as perpetrators. However, he clearly was not working in opposition to feminist goals of ending men's violence toward women. Understanding that knowledge production is a situated and embodied process, helps us understand that the engagement of men in work to reduce and prevent IPV will unavoidably result in differences in habitus and doxa among those involved in the work.

The final interviewee to be presented is Marcus, the key volunteer in an on-line support line primarily for men who are victims of false allegations or gender bias in the system. In my interviewee search, I explicitly wanted to find an interviewee working from a gender parity perspective. Marcus' was the closest of my interviewees to this 
positioning, identifying the root causes of violence as "a personality disorder and/or a mental health problem" with an anger problem being a secondary cause, often as an outcome of childhood abuse. Marcus saw the experience of childhood abuse as one that required sensitive services for those who have been victimized while addressing the generational aspect of abuse in that healing process:

Marcus: It's very important when people are dealing with problems such as childhood sexual abuse, that they get an education as to how and why the abuser became an abuser and [that] they are at grave risk of becoming one themselves because of what happened to them. [This] is not what is comprehended. [The service providers] are going to treat them as victims but they are going to forget the next part: you are now a grave risk of being an abuser yourself.

While he noted both women and men as potential victims and perpetrators, Marcus

identified a lack of resources for men who are victims of violence:

Marcus: There are no resources. Anywhere they turn ... it is going to be their fault. So [service providers] are going to say that they instigated it, they must have provoked the woman. It's inconceivable in the minds of feminists that a woman can be violent without provocation. So they can only use all the excuses that they will not accept themselves. If you say, she must have provoked him, they are automatically trained, "Well provocation has nothing to do whether someone is innocent or guilty. It only ... [impacts] sentencing." Well, if you are going to apply that for the gander then apply it to the goose. ... When do suddenly people wake up and smell the coffee and say gender doesn't matter?

Marcus was an outlier in my study in holding a gender parity position to the degree that he did. He was also an outlier in that he did not have professional training in social services. His personal and volunteer experience informed his position and positioning on the issue of IPV. I struggled with whether to include this interviewee in my study as I found that his situation and views differed from other participants to such a great degree. However, I did not feel comfortable excluding him simply on the basis of being an outlier.

Marcus represents an important position and positioning in the field. His position can be seen as a reaction to the partial view of feminist VAW doxa and is thus a reflection on our work. As we never can have a complete view of the field, and as 
positionings develop in the field from the complex interaction of these various partial views, the views of those who are 'against' our positioning have much to tell us about the shortcomings of our doxa. Since before I began this project I have heard stories from, or about, many men who have been the victims of abuse by their female partners (as well as stories of abuse within LGBTQI relationships). The partners of these men have their own stories of which I only know a few. I have heard enough to believe that abuse within intimate partnerships is, as the interviewees in this chapter illustrate, complex and multifaceted.

One difficulty in undertaking social justice work is to avoid creating an injustice in the course of seeking justice for one's own group. As we address the injustice we are experiencing we construct doxa which counters this oppression in an epistemological pairing. We begin to relate to this doxa as truth; but it is actually situated and partial knowledge. The way out of this problem is not to create 'better' truth; Bourdieu (1992) would argue that no single approach could ever address every aspect of IPV. But it may be enough to be alert for the aspects of a social issue that our approach cannot adequately address and make to room in the field for these aspects to be identified and addressed. This requires us to be open to ongoing engagement with our doxa as situated truth that will change over time. Interviewees in my research demonstrated this engagement to varying degrees and with varying degrees of comfort.

\section{CONCLUSION}

The PAR workers, private practitioners and the interviewees serving men who have experienced abuse most often began their work on the issue of IPV with a belief in the female victim/male perpetrator doxa. Their work with perpetrators and victims, male and 
female, led them to incorporate experiences and training which challenged this doxa and to some degree to internally reconcile the VAW doxa with other knowledges. This is not to say that they have found a more enlightened or 'truer' positioning. My goal here is not to find a way to transcend the divisions among my interviewees by explaining the 'right' position, but rather to explain the social relations involved in the field (Bourdieu, 1988). Working only with women victim/survivors within a VAW context has not required the same degree of engagement with other explanations of IPV, including typologies, trauma theory or gender parity. However, this is changing as the number of positions in the field expand and as VAW service providers and activists encounter models which add complexity to their situated knowledge to the field.

While a number of the VAW interviewees came to new insights during the interview, this did not happen with the interviewees in this chapter. This clearly showed me my own feminist VAW habitus which, while it had been challenged before I began this project, was still essentially intact with trauma-informed doxa residing in a siloed parallel universe of knowledge. My questions formed a challenge for many VAW workers; the PAR workers, private therapists and men working with male victims had already engaged with these questions. In the next chapter I bring the views of my interviewees and the literature together in a relational analysis, showing the shape of the field and the interactions of power that are in play. 


\section{Chapter 8 \\ The Struggle for Recognition in the Field: Why is it so difficult?}

\section{INTRODUCTION}

... it is not enough to explain each point of view separately. All of them must be brought together as they are in reality, not to relativize them in an infinite number of cross-cutting images, but, quite to the contrary, through simple juxtaposition, to bring out everything that results when different or antagonistic positions of the world confront each other - that is, in certain cases, the tragic consequences of making incompatible points of view confront each other, where no concession or compromise is possible because each one of them is equally founded in social reason (Accardo \& Bourdieu, 1999, p. 3).

In this dissertation I have illuminated the habitus and doxa of various subfields in the field of work to reduce and prevent intimate partner violence. The field as I have defined it includes patriarchal, feminist VAW and gender parity subfields. I have raised issues regarding position and positioning that have emerged among the habitus and doxa of various subfields in this field over time. In this chapter I will further analyse, as Bourdieu says, "everything that results" when these habitus and doxa are brought into relationship with each other. Within the field, epistemological communities have built upon, related to, and reacted to each other in the development of their respective positions and positioning. In doing so they have each been integral to the development of the others' habitus and doxa. I will explore these relations through Bourdieusian feminist Beverley Skeggs' (2004) framework for the analysis of the construction of social issues. My project is about knowledge production, exchange, resistance and integration regarding work to reduce and prevent intimate partner violence and specifically about how feminist conceptualizations of male perpetrators of intimate partner violence are 
changing over time. There are many positions and positionings in the field being taken in response to the changing landscape in this field. Skeggs' four processes of inscription, value attribution, perspective taking and institutionalization provide key points of entry to understanding the struggles for recognition that have led to the current transformational period.

In chapter five I explored three encounters of feminist VAW doxa in the literature. Two of these encounters, intra-feminist engagement and gender parity positionings, have over the past number of decades each played a significant role in shifts within feminist VAW framings of men who have used violence in their relationships. The debates generated in these encounters have resulted in relational positionings and counterpositionings which vary among those within and between subfields. The debates have also resulted in significant efforts to address (in the case of intersectionality) and resist (in the case of gender parity) the impact of these knowledges among those with a feminist VAW habitus.

Similarly, trauma theories are currently emerging in the field as having a significant impact on feminist VAW positionings. In light of this emergence, the role of trauma theory is further explored in this chapter, highlighting several opportunities and challenges this theoretical framework is bringing to VAW movements. I close the dissertation with a brief reflection on my personal learnings in the process of undertaking this study. 


\section{FIELD, DOXA AND HABITUS}

I have shown in this dissertation that - while the doxa of the female victim/survivor and the male perpetrator became dominant in the field of work to reduce and prevent IPV during a VAW institutionalization phase during the 1980s and 1990s and while it remains foundational to feminist VAW efforts - there has been ongoing struggle in the field over this binary characterization which is resulting in a current transformational period. Doxa has a 'life' that is separate from the people engaging with it. Even if everyone has a critique of a particular doxa, the doxa still exists through the very need for that critique. Critique can serve both to problematize doxa and to make doxa more complex and sophisticated in its response to, or expression of, a social reality. Even though a critique can appear to represent a fundamental challenge to the doxa, the challenge represented is often constrained by the conceptual foundation in such a way that it is limited in its impact. This has been the case in feminist discourse regarding women's agency, which has remained focused on women as victims or survivors and neglected the potential for women to be abusive in intimate relationships.

The inclusion of interviewees who were VAW workers, PAR workers, private therapists, and two interviewees who address male victimization in their work provided the opportunity for me to explore the interaction of foundational VAW doxa with the "incompatible points of view" noted by Bourdieu in the quote that begins this chapter. The people holding these points of view define their work in relation to the foundational VAW conceptual framings of IPV. However, the positions held, and the situated knowledge and positionings on the issues generated through these positions, have led to the development of new subfields that contain their own foundational doxa in a relational 
counterpoint to the concept of the female victim/survivor and the male perpetrator. These different doxa are, as Bourdieu says, "equally founded in social reason."

There is an essential incompatibility of subfields in the IPV literature of the past several decades when viewed through the lens of the situated knowledge of each subfield. This incompatibility has been expressed, for example, in the epistemological pairing of the VAW subfield and the gender parity subfield. The ongoing and entrenched opposition between these two subfields has consumed significant intellectual resources, and, according to Evan Stark (2006) delayed progress in efforts to address intimate partner violence. An increased recognition of the concept of typologies of IPV has created recent movement toward an understanding that gender parity and VAW proponents are perhaps speaking of 'different' social phenomena. This has opened the possibility of the deescalation of the opposition between these two groups (Johnson, H. \& Dawson, 2011). Both the epistemological pairing and the shifting understandings brought by the theoretical framing of typologies were visible among my interviewees who were variously grappling with the implications of these typologies.

While Michael Johnson's (2008) theoretical framework of typologies does much to assist understanding of the variation in positioning of many in the field, it also creates a new dichotomy between that of coercive controlling violence/violent resistance and common couple violence. This dichotomy creates its own obfuscation. The creation of typologies adds nuance to our understanding of IPV but does not resolve the issues relating to perpetration and victimhood. Many of my interviewees recognized that they had encountered these two types of violence but also noted many grey areas and complexities not resolved by these typologies. As well, recent additions to the literature 
indicate that this new acceptance could have the effect of hardening the doxic lines between these two approaches as researchers may move to examine one type of violence without reference to the other, as is the case within a recent contribution by Hamby (2014). However, even with this hardening, views of male perpetrators may be substantially repositioned.

In 2009, Sherry Hamby argued that both sides in the parity-asymmetry debate would have to show that they have a greater truth claim against statistics which show that women overall engage in violent crime at a rate of 20 to $30 \%$ of that of men. Her 2014 book, entitled, “Battered Women's Protective Strategies: Stronger than you know, fully inhabits the woman as victim/survivor and male perpetrator dyad without the introductory disclaimer common in the feminist VAW literature over the past several decades that women are the victims in the 'vast majority' of cases (Stubbs, 2002). Even so, when speaking of men in terms of the use of coercive, controlling violence, Hamby (2014) argues for approaches "that do not disparage and condemn people for their involvement in violence, no matter the role, and that incorporate a committed belief in the possibility of change" (p. 187). This approach encompasses a very different view of men who use violence than that within the VAW movement in earlier decades as recalled by my interviewees.

The dominance VAW doxa has held in the field is demonstrated in the construction of other doxa that addressed the 'social reason' of VAW doxa. PAR doxa, as visible in my interviews, explicitly addresses the limitations of VAW doxa. The private therapists similarly constructed their practice in relation to VAW distinctions and articulations. All of these interviewees had training in VAW approaches and all had diverged from this 
approach to varying degrees, indicating it did not provide a sufficient basis for ending IPV. I argue that the existence of these positions and positioning in the field has had an impact on feminist VAW framings in providing alternative ways of thinking. These ways of thinking, on the one hand, have opened some VAW workers to the need for changes in how male perpetrators are addressed, and on the other, have provided the opposition that can fuel the kind of dominant antagonist pairing that Bourdieu notes as common in a field. The interaction of the subfields contains the opportunity for significant changes to doxa, but also contains the possibility for entrenchment.

Challenges to doxa play out in the context of shifting power relations. In these engagements, those defending the dominant doxa may appear less "reasonable" and less willing to engage in dialogue than those (either within the dominant subfield or in other subfields) who are raising challenges. This is because those challenging the doxa engage with the dominant doxa as a starting point. This dynamic can be in place even when, or perhaps especially when, the dominant doxa is threatened as is happening at the current time with VAW doxa. To challengers, who may misrecognize or underestimate their own power in the field, the dominant doxa may seem to have retained its dominance long after they themselves have acquired significant (unrecognized) power. Or challengers may feel that the dominant doxa should have already shifted or crumbled given the 'truths' they have brought forward to challenge this doxa. For those defending the dominant doxa, the loss of ground may be figural even as the dominant doxa maintains its dominance. They may not recognize that dominance in the field was ever achieved; within the VAW subfield there are those who experience VAW positionings as always dominated. There are also challenges regarding doxa within subfields, such as that sustained by Women of 
Colour and identified in the naming of 'mainstream' feminist VAW approaches. Any of the contenders in the field may perceive themselves to be dominated within the field and conceptualize the work to be done as fighting for recognition regardless of their actual positioning in these relations of power. Thus, individuals and groups within the field may have quite different views of which subfield holds power and how much power, and more specifically, what should be done about it.

Doxa are difficult and slow to change because they express a truth relating to the situated knowledge of people in the field. The concept of habitus captures this embodied positioning which includes the intellectual and emotional commitment of the individual and a social location which reflects that commitment. Bourdieu talks of the relationship between belonging, training and belief as requiring ongoing alignment in order to sustain the conditions for a habitus that experiences a good fit with the doxa of the field in which it exists. Training, research or experience that challenges the doxa of the field, by providing alternative theoretical explanations, research data, or suggested interventions, can call into question beliefs previously held as unquestioned. Belief in the unconditioned nature of a belief is required for that belief to continue. The end of belief signals the end of pure belonging. It signals a habitus that is no longer comfortable simply reproducing the doxa of the field - an emotionally as well as intellectually challenging realization. In such a case, the representation of the doxa must be adjusted to reflect the new knowledge with which the habitus is engaged. However, as long as this new knowledge provides an 'alternative' to the old doxa rather than a required 'alternate,' the habitus can continue to work, in practical terms, within the old doxa. Alternative knowledges can be acknowledged, but will be held separate, siloed from the institutionalized knowledge on 
which practice is based. This explanation describes the experience of a number of my VAW interviewees. They acknowledge, for instance, that women can be violent and men can be victims, but any impact of this acknowledgement is resisted in their conception of their day-to-day work with their clients, who are, by definition, women who are 'abused' by their (most often) male partners.

For women who came of age during the 1960 s to early 1980 s, the violence being revealed and their increasing understanding of the social support for this violence, required the development of, and belief in, a strong counter position to the existing patriarchal doxa. Women entering VAW work later, who had encountered training in intersectionality theories or trauma-informed social service practice before they began working in the VAW sub-field, could more easily integrate these various new knowledges. They could do this because they encountered these issues as part of the field as they entered it (and therefore the issues were not as threatening or frightening), but also because the work that is needed to maintain a subfield is quite different than that required to develop it. During the development phase the subfield is held together solely through belief and belonging. It is belonging and belief from which the courage to challenge the dominant doxa is drawn. Over time other cultural capital is developed that supports the subfield. This capital takes the form of individual dispositions which are aligned with the doxa (the habitus), cultural values and goods (e.g. support for the work at the societal level), and institutional recognition (e.g. educational qualifications and funding). The establishment of cultural capital allows for the exploration of difference and complexity. Beverly Skeggs' (2004) framework can help us further conceptualize the social processes through which doxa are developed, sustained and challenged. 


\section{EXAMINING THE DEVELOPMENT OF THE FIELD}

Skeggs (2004) discusses feminism explicitly in terms of engagement in processes of social construction. But she only addresses feminism engaging in these processes as the 'underdog' - arguing, for instance, that our willingness to embrace identity politics leads to a focus on our oppression and does not provide an avenue toward 'freedom.' Within the field of work to reduce and prevent intimate partner violence, which perspective has dominance and which is the underdog is contested. In a somewhat strange twist of power relations, the various groups in the field each claim they are in a dominated position even while they struggle for dominance.

Exploration of this situation using Skeggs' framework of inscription, valuing, perspective-taking and institutionalization provides some clarity regarding the trajectory of these claims in light of the current transformational period. Processes of inscription can be seen in struggles over, and changes in, characterizations of men who use violence in their relationships. Changes in the valuing of men are also visible; the 'othering' of men has been challenged through the use of therapeutic approaches to male perpetrators and in the development of a role for men as allies in the fight against violence against women. Intra-feminist debates, the introduction of the concept of typologies, and a growing understanding of the impact of trauma and the resulting opportunities for healing are all affecting the perspectives taken on men who have used violence in their relationships. As a result, institutionalized responses to men who use violence are also being challenged. Rather than seeing the exercise of symbolic power as a single hegemonic imposition with a resulting polarized resistance, the use of Skeggs' 
framework supports an examination of the field as a place of intersecting hierarchies of embodied, and yet evolving, knowledges (McNay, 1999).

\section{The changing inscription in the field regarding men who use violence}

The inscription of the feminist VAW doxa required the exercise of symbolic power, the use of which depends on access to cultural capital. One of the few 'items' of cultural capital held by women working to end IPV in the 1960s and early 1970s emerged from patriarchal doxa itself: moral outrage against men who were not being good men but who were instead abusing their positions of power within the family. The cultural capital of feminists working to end woman abuse was deployed to reclaim the woman victim as one of 'us.' It was understood that the female victim could be a sister, mother or friend, and that any of us could one day find our self the victim of a violent man. This scarce and precious cultural capital was not expended on behalf of violent men, who remained 'othered.' The concept of the (rescued) female victim and the (un-reclaimed) male perpetrator, both of whom were now understood to be potentially anyone in society, was inscribed as part of the feminist VAW doxa. The feminist analysis of the gendered and systemic power differential experienced in heterosexual relationships led to the inscription of 'every' (heterosexual) man as having the potential to abuse their female partners. The potential for every man to abuse the systemic power he holds, together with the patriarchal story of the abuser as 'other,' combined to create a doxic inscription of men as only perpetrators or potential perpetrators (and as the only perpetrators in IPV). This positioning, which emerged from an epistemological pairing of patriarchal doxa and feminist doxa, did not disrupt, but rather supported, the story of the male abuser as 'other.' 
The focus on rebutting the dominant doxa can engage people in a sense of shared mission that may initially override differences. Over time the sense of a common understanding of the issue may be challenged as complexities revealed by the lived realities of those involved assume greater significance. Those whose habitus is most aligned with the new doxa remain closest to the centre of the new (sub)field while others move (or are pushed) further from the centre of efforts to bring the doxa to dominance in the field. This selection process was visible in the positions and positioning of both the scholars in the field of work to reduce and prevent IPV and among my interviewees in relation to the 'universe of knowledge' represented by VAW theories regarding men who have used violence.

In the literature, the impacts of these selection processes have been visible in the epistemological pairing of doxa such as patriarchal and early feminist VAW framings of IPV or the more contemporary VAW and gender parity framings. A number of scholars who are now writing in alignment with the gender parity framing of IPV began their work within a VAW framing. For example, Mills' response to the epistemological pairing of gender parity and VAW perspectives ultimately led to movement out of her feminist VAW identity group. In 1999, she remains within (but stretches) the boundaries of what it is possible to say from within VAW doxa. By 2003, an epistemological break has occurred and she positions herself outside VAW doxa (what she now names as mainstream feminism), inscribing mainstream feminists as the problem when discussing IPV.

The interview responses track the literature in illuminating the exercise of power required to maintain the prominence of epistemological pairs in a field. Kevin, for 
example, came of age in a time where he experienced only the epistemological pairs of the feminist VAW position and the men's rights/gender parity framing. He moved from an early adherence to a feminist VAW positioning to its opposite in shifting from his training in VAW where 'men are the problem', to inhabiting a doxic positioning that 'women are the problem.' He finally found an approach that reconciled the dilemma for him by addressing the agency of both women and men and the capacity of both for good or evil. He defines himself as outside feminist VAW doxa in his current positioning. The exercise of power can also take the form of siloed knowledge held at the same time but experienced as irreconcilable, as Aurélie, a long-time VAW worker demonstrated in relation to trauma-related insights she has regarding male perpetrators. Theodore's response to his moment of insight in 'seeing' the problematic inscription of men as perpetrators within Duluth approaches to working with men resulted in his shift from working within this model to his current therapeutic trauma-recovery work with male childhood abuse survivors. His current positioning is an explicit response to VAW approaches.

\section{The valuing of men who use violence}

The valuing/evaluation of men who use violence in their relationships as 'other' has been pervasive in the VAW literature as revealed, for example, in the use of the term 'monster' (Brown, 2015; Hamby, 2014; Loseke, 1992). This valuing was also present in my interviews, generally in a problematized form that indicates this characterization is no longer accepted as one that can dismiss these men, but is still in place to the degree that it has to be in some way addressed or countered. While this was true for the VAW as well as other interviewees, those who work with men had an impetus to deal with this 
understanding of male perpetrators that went beyond that of VAW workers. They, therefore, had integrated challenges to this characterization to a greater degree.

The focus on women supporting women in early feminist work to end violence against women meant that feminist VAW efforts did not relate to men as possible agents of change (Jewkes, Flood and Lang, 2015), a claim in alignment with the reported experiences of several of my male interviewees. For men to be part of the movement to end violence against women, and specifically intimate partner violence, a shift in how men are valued has been required in order to counter the potential for any man to be a perpetrator of VAW at any point in time. As William noted, seeing men as 'monsters' meant that there was "no room for an emotionally aware man" to be an ally in addressing perpetrators and in prevention work, a role which men are increasingly taking on. By their presence in the field, male allies are changing the field - through their experience of that field and through women's contact with them. As well, the work of these male allies is, for them, and increasingly for women in the VAW subfield, shifting the valuing of men who use violence (at least those who attend the PAR program) from an inscription of the identity category of 'perpetrator' to an inscription of 'the men in the program.'

In this new inscription, the men in the program are recognized as multidimensional (and often marginalized) people, many of whom face significant challenges as well as having aspirations of healthy relationships which they struggle to meet. There are also oppositional positionings in the field, with men such as Theodore rejecting the apparent demonizing of men in programs based on the Duluth model, and women such as Stacy insisting on the functionality of the VAW model. The presence of psychotherapists in the field who work with both women and men provides another challenge to the 'valuing' of 
male perpetrators as monsters, as these practitioners claim the need for both women and men to do their own emotional healing work and use trauma theories to develop interventions which increase the potential for this work to manifest in positive change. The interaction over time of the positions and positioning of women working in VAW services, men working with perpetrators, psychotherapists and others working to address men's experiences of victimization have had, and continue to have, a tangible, and diversifying, impact on the inscription and valuing of men who have used violence in their relationships.

\section{The impact of trauma theory on perspectives taken}

In feminist VAW work to illuminate the 'invisible' doxa of patriarchy that support violence against women, articulating women's victimization was emphasized over examining women's agency. There was a parallel but reversed emphasis on men's agency in perpetrating violence with less attention to gendered structures which might result in men's victimization. As a result of the hard work of many feminist activists and scholars, the feminist VAW lens has become increasingly sophisticated over the past decades in terms of how we perceive the structuring of women's victimization and of women's agency in addressing that victimization. There also has been work done to address how men's lives are structured in terms of racialization, class, disability and other social hierarchies and how that might contribute to men's violence toward their female partners. However, there has been less focus on how men's behaviour is structured in ways that are harmful to others (and to them) in terms of gender itself. An emerging insight regarding this structuring is forming in the field at this time and resulting in a further nuancing of VAW doxa in relation to the interweaving of individual agency and social structures in 
men's experience as men. Engagement with trauma-informed therapeutic frameworks is providing a significant impetus for this shift.

Trauma-informed approaches to addressing men who use violence in their relationships erode one of the doxic differences between female victims and male perpetrators. The erosion of difference between the victim/survivor and the offender presents a complication to the foundations of VAW doxa in that the perpetration of violence is not viewed as necessarily emerging from the unfettered agency bestowed by a privileged position, but rather must be understood in the complex interplay of past or current psychological harm being enacted through the lens of this privilege. Traumainformed doxa understand perpetrators as acting, however improperly, from their own childhood or adult trauma - trauma which may come as an outcome of men's experience of physical and/or emotional violence or neglect within the family or as a response to symbolic or physical violence in the larger society. As such, complex trauma theory may illuminate structured and gendered violence experienced by boys and men and, further, provide a framework for possible healing interventions based on insights brought by recent advances in neuroscience and trauma theory. Trauma theory and trauma-informed practice were discussed by many of the interviewees as presenting a possible opportunity for a shift within the VAW habitus: this time back toward cautious hope for greater successes in reducing and preventing much intimate partner violence. Such a shift engages deep changes in VAW doxa regarding male perpetrators of intimate partner violence.

When VAW doxa was developing, neuroscience had not yet allowed us to peek into the brain to glimpse the biological incapacities inculcated by abuse or the plasticity of the 
adult brain that allows for growth of healthy attachment and mentalizing capacity within adults. The vision of healing for male perpetrators made possible by the (new) belief in the plasticity of the adult brain has become part of the perspective and hence the habitus of many of the interviewees working in, or having worked in, feminist organizations in their many roles as mothers, sisters, friends, community workers, childcare workers and diverse community members. The development of this new perspective has been supported at the practical level through interactions between psychotherapists, PAR workers and VAW workers which have impacted the habitus and doxa of each group.

\section{Changes in the institutionalized understanding of men who use violence}

This dissertation has explored the institutionalization of feminist VAW doxa and habitus over time, and the transformative changes currently impinging upon institutionalized understanding of men who use violence in their relationships. A Bourdieusian reflexive sociological perspective supports a view of these shifts that does not associate them with right or wrong, or with the failure or success of feminist theorizing and practice, but rather with relational processes among people holding situated, and therefore always limited, knowledges. These processes inevitably lead to change in the dominant doxa within a field as epistemological understandings continue to evolve. As Bourdieu allows us to see, the shifts can be hard and painful for those involved as they tend to be invoked through oppositional processes. Changes to doxa are resisted precisely because we believe in doxa as expressing a shared truth. Even naming our truths as doxa, making them visible as constructed, may in itself be experienced as a betrayal of deeply held beliefs challenging our sense of belonging within our epistemological community (Skeggs 2004), or in other words, our identity. 


\section{THE OPPORTUNITIES REVEALED IN THIS RESEARCH}

When universes of knowledge are colliding, the fuzziness of logic contained in practice can be a source of frustration, fear and defensiveness for those involved, leading to judgement and disdain for the "ideological" or "dangerous" positioning of the other(s). Applying Skeggs' processes in the context of Bourdieu's conceptual framework provides a framing for understanding other participants in the field who are committed to the reduction and prevention of IPV but who are approaching it through different lenses. What is offered by an understanding of the necessarily different doxa and habitus held by those in different positions and positioning from our own and the processes that lead to epistemological pairings of these doxa and habitus?

I believe that there are a number of opportunities and challenges that emerge from this understanding. The first is the potential for a new level of respect for, and openness to, the situated knowledge produced by those using a different epistemological framework to our own. We do not have to agree with these other approaches, but we can understand that their positioning is based on embodied experience to which we do not have access. This understanding implies an opportunity for learning from this knowledge; the embodied knowledge held by others could be a source of information that could add nuance to our own (and others') doxa, making it, and us, more responsive to a broader range of experience and thereby more powerful in accomplishing our goals of, in this case, reducing and preventing intimate partner violence.

In approaching the knowledge of others from this positioning, there is an opportunity for compassion in our interactions - a quality that my interviewees noted is a requirement in the work to reduce and prevent IPV. Modelling compassion at the level of 
theory development and practice is essential to the development of theory and practice that engages compassion as an element of the work. Modelling a different orientation to the 'other' is also relevant beyond the Bourdieusian field examined in this dissertation, as Western systems, institutions, communities, families and individuals desperately need to learn how to support and incorporate compassionate relationships across difference.

Beyond this general shift in orientation, the emergence and ongoing integration of trauma theories with VAW doxa are providing specific benefits and opportunities - even responsibilities - for feminist anti-violence movements specifically in relation to men who have used violence in their relationships. Three of these opportunities each relate to support for a specific group: VAW front line workers, workers in batterer intervention programs and VAW scholars. First, my primary research shows that many practitioners on the front line are quietly struggling to integrate the implications of trauma theories with violence against women theories in relation to work with men who are violent with their partners. Opening up the discourse on this issue and closing the gap between the public conversation and the personal struggles of practitioners and activists would be an act of solidarity with, and support of, these workers.

The second opportunity emerges from the first: to make partner abuse response programs more effective. While the impacts of trauma on abused women have been recognized among VAW workers for many years, the use of trauma theoretical insights is an emerging phenomenon. Trauma theory is valued by the women I interviewed for providing a framework for understanding and working with abused women and children. Trauma theory can also help us understand the behaviour of the portion of these children who grow up to become abusive in their relationships. Using a trauma lens reveals many 
male perpetrators to be childhood victims who have used violence in their adult relationships and yet have the potential to heal and change. These developments point to practical ways to support healing while continuing to hold perpetrators accountable for ending their violence.

Finally, complex trauma theory can support the ongoing evolution of VAW theoretical approaches toward increasing sophistication and the ability to handle complexities in two ways: first by explicating the mechanisms through which colonization, racialization and sexist practices can traumatize communities, leading to increased rates of family violence. Second, trauma theories support the development of feminist therapeutic approaches for working with perpetrators. Complex versions of trauma theories provide a basis for linking the perpetration of violence to past childhood trauma as well as social marginalization, addressing a feminist concern to not individualize solutions to intimate partner violence at the expense of a focus on social structural issues or on women's safety.

As well as opportunities, the inclusion of trauma-informed doxa in approaches to work with male perpetrators presents some dilemmas for feminist anti-violence theory and practice. Perhaps the biggest conundrums are found in the further nuancing of the polarized victim and perpetrator. If the victim and the perpetrator are both likely victims of childhood trauma, how does this affect the services to be offered to men who use violence? The PAR program has been at the centre of ongoing struggles regarding how to address both trauma recovery and the need for accountability within a single service. As well, both PAR and VAW interviewees raised issues relating to women's use of violence which suggest a need for accountability to be addressed within VAW services. The 
system set up to address IPV was also implicated by a number of interviewees who problematized the symbolic violence done to women and men and the sometimes negative material effects of our interventions. The question of culpability becomes a more complex issue as our understandings of violence and the role of violence in maintaining social structures become more nuanced. A growing awareness within feminist work more generally - that there is no innocent position (Collins, 1998; Lawler, 2004; Shotwell, Forthcoming) - provides further incentive to take into consideration our responsibilities in how we position ourselves within these always evolving processes of change.

This dissertation has highlighted that epistemological pairings of 'us' and 'them' do not capture the complexities and nuances experienced by groups, and by individuals within groups, involved in social change efforts. Each of the positions within the field explored in this dissertation demonstrates the capacity for ongoing creativity and complexity exhibited by the habitus in social processes of knowledge production. In the social interaction of these habitus we see the emergence of a transformative period in feminist VAW doxa (and in the larger field). We also see the dramas and dilemmas in this transition for individuals and groups as they negotiate and attempt to control these shifts (Lovell, 2003). The epistemological pairing of gender parity and feminist VAW efforts has not posed an effective challenge to the female victim/survivor and male perpetrator doxa; rather, this pairing has been part of a polarization in the field which has made it difficult to address nuance and change within feminist VAW thinking regarding male perpetrators of IPV. Nevertheless, relational processes of knowledge production and exchange (feminist and otherwise) are resulting in a visible weakening of the characterization of the male perpetrator as 'other.' As shown in my dissertation, this 
weakening is variously encountering welcome, confusion, resistance and, more often over time, integration.

\section{PERSONAL REFLECTION ON THE PROCESS}

The gifts I have received in undertaking this study have included the internalization of a theoretical frame from which to analyze my own discomforts and stretched allegiances as well as to understand the importance of my position and positioning to the VAW movement. I have moved from experiencing my concerns as 'other' to VAW systems, to realizing the significance and centrality of my concerns regarding our work to the success of feminist efforts to reduce and prevent IPV. I have also begun to understand what my voice can offer. I look forward to further engagement with the field as we move through this transformative period. 


\section{Bibliography}

Abramsky, T., Devries, K., Kiss, L., Nakuti, J., Kyegombe, N., Starmann, E., ... Watts, C. (2014). Findings from the SASA! Study: a cluster randomized controlled trial to assess the impact of a community mobilization intervention to prevent violence against women and reduce HIV risk in Kampala, Uganda. BMC Medicine, 12, 122.

Accardo, A., \& Bourdieu, P. (1999). The weight of the world: social suffering in contemporary society. Stanford, Calif.: Stanford University Press.

Adams, M. (2006). Hybridizing habitus and reflexivity: Towards an understanding of contemporary identity? Sociology, 40(3), 511-528.

Adkins, L. (2003). Reflexivity: Freedom or habit of gender? Theory, Culture \& Society, 20(6), 21-42. http://doi.org/10.1177/0263276403206002

Adkins, L. (2004). Introduction: Feminism, Bourdieu and after. In L. Adkins \& B. Skeggs (Eds.), Feminism after Bourdieu (pp. 3-18). Boston: Blackwell Pub.

Adkins, L., \& Skeggs, B. (2004). Feminism after Bourdieu. Boston: Blackwell Pub.

Ahmed, S. (2004). The cultural politics of emotion. New York, NY: Routledge.

Ahmed, S. (2009). Embodying diversity: problems and paradoxes for Black feminists. Race, Ethnicity and Education, 12(1), 41-52. http://doi.org/10.1080/13613320802650931

Ahmed, S. (2010). Feminist killjoys (and other willful subjects. The Scholar \& Feminist Online, 8(3), 1-8.

Alcoff, L., \& Potter, E. (1993). Feminist epistemologies. New York: Routledge.

Alexander, J. C. (1995). Fin de siècle social theory: relativism, reduction, and the problem of reason. London; New York: Verso.

Ansara, D. L., \& Hindin, M. J. (2010). Exploring gender differences in the patterns of intimate partner violence in Canada: a latent class approach. Journal of Epidemiology and Community Health (1979-), 64(10), 849-854.

Anzaldúa, G., \& Moraga, C. (1983). This bridge called my back: writings by radical women of color (Second edition). New York: Kitchen Table, Women of Color Press.

Arendt, H. (1965). On revolution. New York: Viking Press.

Arnold, G., \& Ake, J. (2013). Reframing the narrative of the battered women's movement. Violence Against Women, 19(5), 557-578. http://doi.org/10.1177/1077801213490508

Arvin, M., Tuck, E., \& Morrill, A. (2013). Decolonizing feminism: Challenging connections between settler colonialism and heteropatriarchy. Feminist Formations, 25(1), 8-34. http://doi.org/10.1353/ff.2013.0006

Augusta-Scott, T., \& Dankwort, J. (2002). Partner abuse group intervention: Lessons from education and narrative therapy approaches. Journal of Interpersonal Violence, 17(7), 783-805.

Bible, A., Osthoff, S., \& Das Dasgupta, S. (n.d.). Guest editor's introduction. Violence Against Women, 8(11).

Bograd, M. (1999). Strengthening domestic violence theories: Intersections of race, class, sexual orientation, and gender. Journal of Marital and Family Therapy, 25, 275-289.

Bourdieu, P. (1988). Homo academicus. Cambridge: Polity Press.

Bourdieu, P. (1989). Social space and symbolic power. Sociological Theory, 7(1), 14-25.

Bourdieu, P. (1990). The logic of practice. Stanford: Stanford University Press. 
Bourdieu, P. (2001). Masculine domination; translated by Richard Nice. Stanford, Calif.: Stanford University Press.

Bourdieu, P., \& Wacquant, L. J. D. (1992). An invitation to reflexive sociology. Chicago: University of Chicago Press.

Brassard, A., Darveau, V., Péloquin, K., Lussier, Y., \& Shaver, P. R. (2014). Research on male victims of abuse: Childhood sexual abuse and intimate partner violence in a clinical sample of men: The mediating roles of adult attachment and anger management. Journal of Aggression, Maltreatment and Trauma, 23(7), 683-704. http://doi.org/10.1080/10926771.2014.933464

Briere, J., \& Scott, C. (2013). Principles of trauma therapy: A guide to symptoms, evaluation, and treatment (Vol. 2). Los Angeles: Sage Publications.

Brown, I. (2015, January 31). Of men and monsters. Globe \& Mail, pp. 1, 4-7. Toronto, Canada.

Brown, W. (1995). States of injury: Power and freedom in late modernity. Princeton: Princeton University Press.

Burawoy, M. (2005). For public sociology. American Sociological Review, 70(1), 4-28.

Burawoy, M. (2014). Introduction: Sociology as a combat sport. Current Sociology, 62(2), $140-155$.

Caldwell, J. E., Swan, S. C., Allen, C. T., Sullivan, T. P., \& Snow, D. L. (2009). Why I hit him: Women's reasons for intimate partner violence. Journal of Aggression, Maltreatment \& Trauma, 18(7), 672-697. http://doi.org/10.1080/10926770903231783

Chodos, H., \& Curtis, B. (2002). Pierre Bourdieu's masculine domination: A critique. Canadian Review of Sociology and Anthropology, 39(4), 397-412.

Cismaru, M., \& Lavack, A. (2011). Campaigns targeting perpetrators of intimate partner violence. Trauma, Violence, \& Abuse, 12(4), 183-197. http://doi.org/10.1177/1524838011416376

Clement, W., \& Shalla, V. (2007). Work in tumultuous times: Canadian perspectives. Montreal: McGill-Queen's University Press.

Collins, P. H. (1998). The tie that binds: race, gender and US violence. Ethnic and Racial Studies, 21(5), 917-938. http://doi.org/10.1080/014198798329720

Combahee Rive Collective. (1982). A black feminist statement. In G. T. Hull, P. B. Scott, \& B. Smith (Eds.), But some of us are brave (pp. 13-22). Old Westbury, NY: Feminist Press. Retrieved from http://circuitous.org/scraps/combahee.html

Connell, R. W. (1987). Gender and power: Society, the person and sexual politics. Cambridge: Polity Press.

Conners, D. E. (2011). Feminists researching fathering: What do we see through a reconciliation lens? Peace Research: The Canadian Journal of Peace and Conflict Studies, 43(1).

Corvo, K., \& Johnson, P. (2003). Vilification of the "batterer": How blame shapes domestic violence policy and interventions. Aggression and Violent Behavior, 8(3), 259-281.

Costa, R. L. (2006). The logic of practices in Pierre Bourdieu. Current Sociology, 54(6), 873895.

Cozolino, L. J. (2010). The neuroscience of psychotherapy: healing the social brain (Vol. 2). New York: W.W. Norton.

Creese, G., McLaren, A. T., \& Pulkingham, J. (2009). Rethinking burawoy: reflections from Canadian feminist sociology. Canadian Journal of Sociology, 34(3), 601-622. 
Crenshaw, K. (1991). Mapping the margins: Intersectionality, identity politics, and violence against Women of Color. Stanford Law Review, 43(6), 1241-1299. http://doi.org/10.2307/1229039

Crenshaw, K. (2011). From private violence to mass incarceration: Thinking intersectionally about women, race, and social control. UCLA Law Review, 59(6), 1418-1472.

Crooks, C. V., Goodall, G. R., Hughes, R., Jaffe, P. G., \& Baker, L. L. (2007). Engaging men and boys in preventing violence against women: Applying a cognitive-behavioral model. Violence Against Women, 13(3), 217-239. http://doi.org/10.1177/1077801206297336

Crossley, N. (2001). The phenomenological habitus and its construction. Theory and Society, $30(1), 81-120$.

Cunningham, M. (2006). Indigenous women's visions of an inclusive feminism. Development, 49(1), 55-59.

Currie, D. (1990). Battered women and the state: From the failure of theory to a theory of failure. The Journal of Human Justice, 1(2), 77-96. http://doi.org/10.1007/BF02627467

Daly, K., \& Stubbs, J. (2006). Feminist engagement with restorative justice. Theoretical Criminology, 10(1), 9-28.

Das Dasgupta, S. (2002). A framework for understanding women's use of nonlethal violence in intimate heterosexual relationships. Violence Against Women, 8(11), 1364-1389. http://doi.org/10.1177/107780102237408

Das Dasgupta, S. (2010). My friend, advocate Ellen Pence. Violence Against Women, 16(9), 985-991. http://doi.org/10.1177/1077801210379254

Das Dasgupta, S., Osthoff, S., \& Bible, A. (2003). Guest editors' introduction. Violence Against Women, 9(1), 4-9. http://doi.org/10.1177/1077801202238428

DeKeseredy, W. (1999). Tactics of the antifeminist backlash against Canadian national woman abuse surveys. Violence Against Women, 5(11), 1258-1276. http://doi.org/10.1177/10778019922183363

Dillabough, J.-A. (2004). Class, culture and the "predicaments of masculine domination": Encountering Pierre Bourdieu. British Journal of Sociology of Education, 25(4), 489506.

Dobash, R. E., \& Dobash, R. (1979). Violence against wives: A case against the patriarchy. New York: Free Press.

Dobash, R. P., Dobash, R. E., Wilson, M., \& Daly, M. (1992). The myth of sexual symmetry in marital violence. Social Problems, 39(1), 71-91. http://doi.org/10.2307/3096914

Doucet, A. (2006). Do men mother? Fathering, care, and domestic responsibility. Toronto: University of Toronto Press.

Doucet, A., \& Mauthner, N. S. (2006). Feminist methodologies and epistemologies. In C. D. Bryant \& D. L. Peck (Eds.), Handbook of 21st Century Sociology (pp. 36-42). Thousand Oaks, CA: Sage.

Dunn, J. L. (2005). "Victims" and "survivors": Emerging vocabularies of motive for "battered women who stay." Sociological Inquiry, 75(1), 1-30. http://doi.org/10.1111/j.1475682X.2005.00110.X

Dutton, D. G. (1988). The domestic assault of women: psychological and criminal justice perspectives. Boston: Allyn and Bacon.

Dutton, D. G. (2007). The complexities of domestic violence. American Psychologist, 62(7), $708-709$. 
Dutton, D. G., \& Nicholls, T. L. (2005). The gender paradigm in domestic violence research and theory: Part I The conflict of theory and data. Aggression and Violent Behavior: A Review Journal, 10(6), 680-714.

Dworkin, A. (1989). Letters from a war zone: writings, 1976-1989 (Vol. 1st American ed.). New York: E.P. Dutton.

Faulk, M. (1977). Men who assault their wives. In M. Roy (Ed.), Battered women: A psychosociological study of domestic violence. New York: Van Nostrand Reinhold Co.

Faulkner, E. (1998). Woman-to-woman abuse: analyzing extant accounts of lesbian battering. In Unsettling truths: battered women, policy, politics, and contemporary research in Canada (Vols. 1-Book, 1-Section, pp. 52-62). Vancouver: Collective Press.

Fisher, A., \& Goodwin, R. (2008). Men \& healing theory, research, and practice in working with male survivors of childhood sexual abuse. Cornwall, ON: The Cornwall Public Inquiry. Retrieved from http://proxy.library.carleton.ca/login?url=http://books.scholarsportal.info/viewdoc.html?i d=/ebooks/ebooks0/gibson_cppc/2010-08-06/2/10276943

Gardiner, J. K. (2002). Masculinity studies \& feminist theory: new directions. New York: Columbia University Press.

Giddens, A. (1991). Modernity and self-identity: self and society in the late modern age. Cambridge, UK: Polity Press.

Gondolf, E. W. (2012). The future of batterer programs: Reassessing evidence-based practice. Retrieved from http://www.scopus.com/inward/record.url?eid=2-s2.084894814293\&partnerID=40\&md5=725ce3742dbc60b064f832b24f6bd664

Gotell, L. (2007). The discursive disappearance of sexualized violence: feminist law reform, judicial resistance and neo-liberal sexual citizenship. In S. B. Boyd, D. E. Chunn, \& H. Lessard (Eds.), Reaction and resistance: feminism, law, and social change (Vols. 1Book, 1-Section, pp. 127-163). Vancouver: UBC Press.

Gruber, A. (2012). A "neo-feminist" assessment of rape and domestic violence law reform. Journal of Gender, Race and Justice, 15(2-3), 583.

Hamberger, L. K., \& Guse, C. E. (2002). Men's and Women's Use of Intimate Partner Violence in Clinical Samples. Violence Against Women, 8(11), 1301-1331. http://doi.org/10.1177/107780102762478028

Hamby, S. (2009). The Gender Debate about Intimate Partner Violence: Solutions and dead ends. Psychological Trauma: Theory, Research, Practice, and Policy, 1(1), 24-34.

Hamel, J., \& Nicholls, T. L. (2007). Family interventions in domestic violence: a handbook of gender-inclusive theory and treatment. New York: Springer Pub.

Hardesty, J. L., Crossman, K. A., Haselschwerdt, M. L., Raffaelli, M., Ogolsky, B. G., \& Johnson, M. P. (n.d.). Toward a Standard Approach to Operationalizing Coercive Control and Classifying Violence Types. Journal of Marriage and Family, 77(4), 833-843. http://doi.org/10.1111/jomf.12201

Harris, M., \& Fallot, R. D. (2001). Envisioning a trauma-informed service system: A vital paradigm shift. New Directions for Mental Health Services, 89(Journal Article), 3-21.

Haskell, L., \& Randall, M. (2009). Disrupted attachments: A social context complex trauma framework and the lives of Aboriginal peoples in Canada. Journal of Aboriginal Health, $5(3), 48$.

Herman, J. L. (1992). Trauma and recovery. New York, N.Y.: BasicBooks. 
Hewitt, N. (2010). No permanent waves: Recasting histories of U.S. Feminism. New Brunswick, N.J: Rutgers University Press.

hooks, b. (2000). Feminism is for everybody : Passionate politics. Cambridge, MA: South End Press.

hooks, b. (2004). The will to change: men, masculinity, and love. New York: Atria Books. Incite!, \& Critical Resistance. (2005). Gender violence and the prison industrial complex: Interpersonal and state violence against women of color. In Domestic violence at the margins (pp. 102-114). Piscataway, NJ: Rutgers University Press.

Incite! Women of Color Against Violence. (2006). Color of violence: the Incite! anthology. Cambridge, Mass.: South End Press.

Incite! Women of Color Against Violence. (2007). The revolution will not be funded: beyond the non-profit industrial complex. Cambridge, Mass.: South End Press.

Jewkes, R., Flood, M., \& Lang, J. (2015). From work with men and boys to changes of social norms and reduction of inequities in gender relations: a conceptual shift in prevention of violence against women and girls. The Lancet, 385(9977), 1580-1589. http://doi.org/10.1016/S0140-6736(14)61683-4

Johnson, H. (2003). The cessation of assaults on wives. Journal of Comparative Family Studies, 34(1), 75-89.

Johnson, H. (2015). Degendering violence. Social Politics: International Studies in Gender, State \& Society, 22(3), 390-410. http://doi.org/10.1093/sp/jxv021

Johnson, H., \& Dawson, M. (2011). Violence against women in Canada: research and policy perspectives. Don Mills: Oxford University Press Canada.

Johnson, M. P. (1995). Patriarchal terrorism and common couple violence: Two forms of violence against women. Journal of Marriage and the Family, 57(Journal Article), 283294.

Johnson, M. P. (2008). A typology of domestic violence: intimate terrorism, violent resistance, and situational couple violence. Boston; Hanover, N.H.: Northeastern University Press; Published by University Press of New England.

Johnson, M. P. (2011). Gender and types of intimate partner violence: A response to an antifeminist literature review. Aggression and Violent Behavior, 16(4), 289-296. http://doi.org/10.1016/j.avb.2011.04.006

Johnston, P. (1983). Native children and the child welfare system. Toronto, Canada: James Lorimer and the Canadian Council on Social Development.

Kelly, J. B., \& Johnson, M. P. (2008). Differentiation among types of intimate partner violence: Research update and implications for interventions. Family Court Review, 46(3), 476-499.

Kelly, T. (2015, June). Have we got it right? Working with men who use violence against women and children. Presented at the Canadian Domestic Violence Conference 4, Toronto. Retrieved from http://www.canadiandomesticviolenceconference.ca/?page_id=60

Kennelly, J. (2014). “It"s this pain in my heart that won't let me stop': Gendered affect, webs of relations, and young women's activism. Feminist Theory, 15(3), 241-260. http://doi.org/10.1177/1464700114544611

Kimmel, M. (2002). "Gender symmetry” in domestic violence - A substantive and methodological research review. Violence Against Women, 8(11), 1332-1363. 
Kimmel, M. S. (2005). The gender of desire: essays on male sexuality. Albany, N.Y.: State University of New York Press.

Kinniburgh, K. J., Blaustein, M. E., Spinazzola, J., \& Van der Kolk, B. A. (2005). Attachment, self-regulation, and competency: a comprehensive intervention framework for children with complex trauma. Psychiatric Annals, 35(5), 424-430.

Krais, B. (2006). Gender, sociological theory and Bourdieu's sociology of practice. Theory, Culture \& Society, 23(6), 119-134. http://doi.org/10.1177/0263276406069778

Lawler, S. (2004). Rules of engagement: Habitus, power and resistance. In L. Adkins \& B. Skeggs (Eds.), Feminism after Bourdieu. Oxford, UK: Blackwell Publishing.

LCCEWA. (2016). London Coordinating Committee to Prevent Woman: Abuse Myths and Realities. Retrieved February 1, 2016, from http://www.lccewa.ca/issue/myths

Lisak, D., Hopper, J., \& Song, P. (1996). Factors in the cycle of violence: Gender rigidity and emotional constriction. Journal of Traumatic Stress, 9(4), 721-743. http://doi.org/10.1007/BF02104099

Loseke, D. R. (1992). The battered woman and shelters. Albany, N.Y.: State University of New York Press.

Lovell, T. (2000). Thinking feminism with and against Bourdieu. Feminist Theory, 1(1), 1132. http://doi.org/10.1177/14647000022229047

Lovell, T. (2003). Resisting with authority: Historical specificity, agency and the performative self. Theory, Culture \& Society, 20(1), 1-17.

MacIntosh, H. B. (2013). Mentalizing: An exploration of its potential contribution to understanding the challenges faced by CSA survivors in couple therapy. Couple and Family Psychoanalysis, 3(2), 188-207.

MacKinnon, C. A. (1987). Feminism unmodified: discourses on life and law. Cambridge, Mass: Harvard University Press.

Majury, D. (2002). What were we thinking? Reflections on two decades of law reform on issues of violence against women. In M. Eichler, J. Larkin, \& S. Naysmith (Eds.), Feminist utopias: Re-visioning our futures (Vols. 1-Book, 1-Section, pp. 125-140). Toronto: Inanna Publications.

Mathen, C. (2004). Transgendered persons and feminist strategy. Canadian Journal of Women and the Law/Revue Femmes et Droit, 16(2), 291-316.

McGillivray, A., \& Comaskey, B. (1999). Black eyes all of the time: intimate violence, Aboriginal women, and the justice system. Toronto: University of Toronto Press.

McMahon, M., \& Pence, E. (2003). Making social change. Violence Against Women, 9(1), 4774. http://doi.org/10.1177/1077801202238430

McNay, L. (1999). Gender, habitus and the field: Pierre Bourdieu and the limits of reflexivity. Theory, Culture \& Society, 16(1), 95-117.

Mederos, F. (1999). Batterer intervention programs: the past, and future prospects. In Coordinating community responses to domestic violence: Lessons from Duluth and beyond (pp. 127-150). Thousand Oaks , CA: Sage Publications.

Mills, L. G. (1999). Killing her softly: Intimate abuse and the violence of state intervention. Harvard Law Review, 113(2), 550-613.

Mills, L. G. (2003). Insult to injury: rethinking our responses to intimate abuse. Princeton, N.J.: Princeton University Press. 
Minaker, J. C., \& Snider, L. (2006). Husband abuse: Equality with a vengeance? Canadian Journal of Criminology and Criminal Justice, 48(5), 753-780. http://doi.org/10.1353/ccj.2006.0053

Minerson, T., Carolo, H., Dinner, T., \& Jones, C. (2011). Issue brief: Engaging men \& boys to reduce \& prevent gender based violence (p. 1 to 35). Status of Women Canada. Retrieved from

http://www.google.com/url?sa=t\&rct=j\&q=\&esrc=s\&source=web\&cd=1\&ved=0CB0QFj AAahUKEwi8vamWoZLGAhVJCpIKHZ5DAIU\&url=http\%3A\%2F\%2Fwhiteribbon.ca $\% 2$ Fwp-

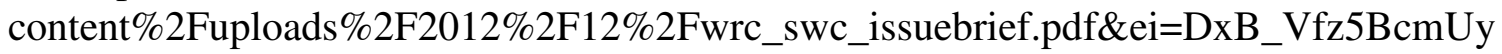
ASeh4GoCA\&usg=AFQjCNEet39F47Pc5TLtHmCu0a7_uhQMlQ\&sig2=AIAQOqjhilPq pta5FEf93Q\&bvm=bv.95515949,d.aWw\&cad=rja

Mottier, V. (2002). Masculine domination. Feminist Theory, 3(3), 345-359. http://doi.org/10.1177/146470002762492042

Myhill, A. (2015). Measuring coercive control: What can we learn from national population surveys? Violence Against Women, 21(3), 355-375. http://doi.org/10.1177/1077801214568032

New, C. (2001). Oppressed and oppressors? The systematic mistreatment of men. Sociology: The Journal of the British Sociological Association [Cambridge], 35(3), 729.

Osthoff, S. (2002). But, Gertrude, I beg to differ, a hit is not a hit is not a hit: when battered women are arrested for assaulting their partners. Violence Against Women, 8(12), 15211544.

Osthoff, S., Das Dasgupta, S., \& Bible, A. (2002). Guest editors' introduction. Violence Against Women, 8(12), 1420-1423. http://doi.org/10.1177/107780102237963

Patil, V. (2013). From patriarchy to intersectionality: A transnational feminist assessment of how far we've really come. Signs, 38(4), 847-867.

Peacock, D., \& Barker, G. (2014). Working with men and boys to prevent gender-based violence: Principles, lessons learned, and ways forward. Men and Masculinities, 17(5), 578-599. http://doi.org/10.1177/1097184X14558240

Pease, B. (2008). Engaging men in men's violence prevention: exploring the tensions, dilemmas and possibilities. Issues Paper 17, (Monograph). Retrieved from www.adfvc.edc.au

Pence, E. (1983). The Duluth Domestic Abuse Intervention Project. Hamline Law Review, 6(2), 247-275.

Pence, E., \& Shepard, M. (1999). Coordinating community response to domestic violence: lessons from Duluth and beyond. Thousand Oaks, Calif: Sage Publications.

Perilla, J. L., Frndak, K., Lillard, D., \& East, C. (2003). A working analysis of women's use of violence in the context of learning, opportunity, and choice. Violence Against Women, 9(1), 10-46. http://doi.org/10.1177/1077801202238429

Powell, C. (2013). How epistemology matters: five reflexive critiques of public sociology. Critical Sociology, 39(1), 87-104.

Presser, L. (2005). Negotiating power and narrative in research: implications for feminist methodology. Signs, 30(4), 2067(24)-2091.

Ptacek, J. (Ed.). (2010). Restorative justice and violence against women. Oxford ; New York: Oxford University Press. 
Randall, M. (2004). Domestic violence and the construction of the "ideal victims": Assaulted women's image problems in law. St. Louis University Pub. Law Review, 23(Journal Article), 107-154.

Randall, M. (2013). Restorative justice and gendered violence? From vaguely hostile skeptic to cautious convert: why feminists should critically engage with restorative approaches to law. Dalhousie Law Journal, 36(2), 461-499.

Randall, M., \& Haskell, L. (2013). Trauma-informed approaches to law: Why restorative justice must understand trauma and psychological coping. Dalhousie Law Journal, 36(2), 501-533.

Razack, S. (1998). Looking white people in the eye, (Generic), 246.

Richie, B. E. (2000). A Black feminist reflection on the antiviolence movement. Signs, 25(4), $1133-1137$.

Rigakos, G., \& Bonnycastle, K. D. (1998). Unsettling truths: battered women, policy, politics, and contemporary research in Canada. Vancouver: Collective Press.

Ristock, J. L. (1994). “And justice for all?” ... the social context of legal responses to abuse in lesbian relationships. Canadian Journal of Women and the Law, 7(2), 415-430.

Rushowy, K. (2011, November 17). Dr. Fraser Mustard was on a relentless crusade to better the lives of children and he convinced governments to invest in supports for families. The Toronto Star. Retrieved from

http://www.thestar.com/news/gta/2011/11/17/dr_fraser_mustard_world_renowned_for_w ork_in_early_childhood_development.html

Russell, D. E. H. (1982). Rape in marriage. New York: Macmillan.

Sahota, P. K. C. S. (2006). "The personal is the private is the cultural": South Asian women organizing against domestic violence. In Color of violence: the incite! anthology (pp. 231-242). Cambridge, MA: South End Press.

Sandoval, C. (2000). Methodology of the oppressed (Vol. 18). Minneapolis: University of Minnesota Press.

Sandoval, C. (2002). AfterBridge: Technologies of Crossing. In G. Anzaldúa \& A. Keating (Eds.), This bridge we call home: Radical visions for transforamtion (pp. 21-26). London, England: Routledge.

Schechter, S. (1982). Women and male violence: the visions and struggles of the battered women's movement. Boston: South End Press.

Schofield, J. W. (1989). Increasing the generalizability of qualitative research. In E. W. and P. Eisner A. (Ed.), Qualitative Inquiry in Education: The Continuing Debate (pp. 201-232). New York: Teachers College Press.

Seligman, L. (2005). Ethnographic methods. In Doing research: Methods of inquiry for conflict analysis. London: Sage Publications.

Shainess, N. (1977). Psychological aspects of wifebeating. In M. Roy (Ed.), Battered Women: A Psychosociological Study of Domestic Violence (Vols. 1-Book, 1-Section, pp. 111118). New York: Van Nostrand Reinhold Co.

Shotwell, A. (Forthcoming). Against Purity: Living Ethically in Compromised Times. Minneapolis and St. Paul, Minn.: University of Minnesota Press.

Siltanen, J., \& Doucet, A. (2008). Gender relations: intersectionality \& beyond. Oxford University Press. 
Simpson, A. (2014, October). The chief's two bodies: Theresa Spence and the gender of settler colonialism. Presented at the Chet Mitchell Memorial Lecture, Carleton University, Canada.

Skeggs, B. (2004). Class, self, culture. London: Routledge.

Smart, C. (1989). Feminism and the power of law. London; New York: Routledge.

Smith, E. (1996). The Birth of CCLOW at that time was no coincidence. Convergences and Divergences in Feminist Theorizing and Organizing Practices During the Second Wave Women's Movement: A Case Study of the Canadian Congress for Learning Opportunities for Women (CCLOW). Carleton University, Ottawa.

Sokoloff, N., \& Dupont, I. (2005). Domestic violence at the intersections of race, class, and gender: Challenges and contributions to understanding violence against marginalized women in diverse communities. Violence Against Women, 11(1), 38-64. http://doi.org/10.1177/1077801204271476

Sokoloff, N. J., \& Pratt, C. (2005). Domestic violence at the margins: readings on race, class, gender, and culture. New Brunswick, N.J: Rutgers University Press.

Sprague, J. (2008). Sociology: the Good, the Bad, and the Public. Gender \& Society, 22(6), 697-704. http://doi.org/10.1177/0891243208323924

Stake, R. (2011). Data management and analysis methods. In N. K. Denzin \& Y. S. Lincoln (Eds.), The Sage handbook of qualitative research (4th ed.). Thousand Oaks, Calif: Sage.

Stark, E. (2006). Commentary on Johnson's “conflict and control: Gender symmetry and asymmetry in domestic violence." Violence Against Women, 12(11), 1019-1025.

Stark, E. (2007). Coercive control: the entrapment of women in personal life. Oxford; New York: Oxford University Press.

Statistics Canada. (2015). General Social Survey - Victimization (GSS) (No. 4504). Ottawa, Canada: Statistics Canada. Retrieved from http://www.statcan.gc.ca/eng/survey/household/4504

Stoltenborgh, M., van Jzendoorn, M. H., Euser, E. M., \& Bakermans-Kranenburg, M. J. (2011). A global perspective on child sexual abuse: Meta-analysis of prevalence around the world. Child Maltreatment, 16(2), 79-101.

Straus, M. A. (1977). A sociological perspective on the prevention and treatment of wifebeating. In M. Roy (Ed.), Battered women: A psychosociological study of domestic violence (pp. 194-238). New York: Van Nostrand Reinhold Co.

Straus, M. A. (1979). Measuring intrafamily conflict and violence: The Conflict Tactics (CT) Scales. Journal of Marriage and the Family, 41(1), 75. http://doi.org/10.2307/351733

Swan, S. C., \& Snow, D. L. (2003). Behavioral and psychological differences among abused women who use violence in intimate relationships. Violence Against Women, 9(1), 75109. http://doi.org/10.1177/1077801202238431

Sweetman, P. (2003). Twenty-first century dis-ease? Habitual reflexivity or the reflexive habitus. The Sociological Review, 51(4), 528-549. http://doi.org/10.1111/j.1467954X.2003.00434.X

Tuck, E. (2009). Suspending damage: A letter to communities. Harvard Educational Review, 79(3), 409-427,539-540.

Turnbull, N., \& Antalffy, N. (2009). Bourdieu's distinction between philosophical and sociological approaches to Science Studies. The Sociological Review, 57(4), 547-566. 
United Nations General Assembly. (1993). Declaration on the Elimination of Violence against Women. A/RES/48/104. Retrieved from http://www.un.org/documents/ga/res/48/a48r104.htm

van der Gaag, N. (2011). Because I am a girl - The state of the world's girls 2011: So, what about the boys? Plan International. Retrieved from http://citeseerx.ist.psu.edu/viewdoc/download?doi=10.1.1.400.461\&rep=rep1\&type=pdf

Van der Kolk, B. A. (2005). Developmental trauma disorder: toward a rational diagnosis for children with complex trauma histories. Psychiatric Annals, 35(5), 401-408.

van der Kolk, B. A., Pynoos, R. S., Cicchetti, D., Cloitre, M., D’Andrea, W., Ford, J. D., ... others. (2009). Proposal to include a developmental trauma disorder diagnosis for children and adolescents in DSM-V. Unpublished Manuscript. Verfügbar Unter: Http://www. Cathymalchiodi. Com/dtd_nctsn. Pdf (Zugriff: 20.5. 2011). Retrieved from http://w.traumacenter.org/announcements/DTD_papers_Oct_09.pdf

Violence Against Women Journal. (n.d.). "Search this journal." Retrieved from http://vaw.sagepub.com/content/by/year

Walker, L. E. (1979). The battered woman. New York: Harper \& Row.

Wee, L., \& Brooks, A. (2010). Personal Branding and the Commodification of Reflexivity. Cultural Sociology, 4(1), 45-62. http://doi.org/10.1177/1749975509356754

Wilkenson, M. (2010). Changing minds in therapy: Emotion, attachment, trauma, and neurobiology. New York: W. W. Norton \& Co.

Young Larance, L., \& Das Dasgupta, S. (2010). Call for papers: Contemporary perspectives on battered women's use of nonfatal force in intimate heterosexual relationships: A contextual approach. Violence Against Women, 16(5), 613-613. http://doi.org/10.1177/1077801210367644

Young Larance, L., \& Das Dasgupta, S. (2012). Guest editors' introduction. Violence Against Women, 18(9), 1004-1007. 


\section{Appendices}

\section{Appendix A: The Study Participants}

Table 1: Primary data collection

\begin{tabular}{|l|l|}
\hline $\begin{array}{l}\text { Method of Data Collection and group } \\
\text { affiliation }\end{array}$ & $\begin{array}{l}\text { Number of } \\
\text { respondents }\end{array}$ \\
\hline Interviewees & \\
VAW workers & 32 \\
PAR workers & 21 \\
Private practitioners & 4 \\
Those working with male victims & 5 \\
\hline Focus Group & 2 \\
$\quad$ Front-line workers & \\
& \\
\hline Early Findings Feedback Workshop & 19 \\
$\quad$ Study participants and other & \\
interested practitioners & \\
\hline
\end{tabular}




\section{APPENDIX B: THE INTERVIEWEES}

Table 1: Interviewees Working with Women Victims of VAW - Entering the field

\begin{tabular}{|l|l|l|l|l|}
\hline $\begin{array}{l}\text { Period in VAW } \\
\text { Work when } \\
\text { interviewee } \\
\text { entered field }\end{array}$ & $\begin{array}{l}\text { Number of } \\
\text { interviewees }\end{array}$ & Age & $\begin{array}{l}\text { Years Working } \\
\text { in VAW }\end{array}$ & Pseudonym \\
\hline Early (1970s) & 2 & Over 60 (2) & Over 25(2) & Gloria, Pamela \\
\hline $\begin{array}{l}\text { Formalization } \\
(1980 \text {-1990s) }\end{array}$ & 12 & Over 40 (12) & $\begin{array}{l}6-10(3) \\
11-15(4) \\
16-25(2) \\
\text { Over 25(3) }\end{array}$ & $\begin{array}{l}\text { Aurélie, Carol, } \\
\text { Denise, Judy, } \\
\text { Karen, } \\
\text { Kathleen, } \\
\text { Jennifer, Lisa, } \\
\text { Jocelyne, } \\
\text { Nancy, Stacy, } \\
\text { Sylvie }\end{array}$ \\
\hline $\begin{array}{l}\text { As trauma- } \\
\text { informed } \\
\text { approaches infused } \\
\text { social services } \\
\text { (2000s) }\end{array}$ & & & $\begin{array}{l}\text { Alishba, Ashley, } \\
\text { Christina, } \\
\text { Emily, Jessica, } \\
\text { Mary, Melissa }\end{array}$ \\
\hline
\end{tabular}

Table 2: Interviewees Working with Women Victims of VAW - Demographics

\begin{tabular}{|c|c|c|c|c|}
\hline $\begin{array}{l}\text { Education - } \\
\text { general; on } \\
\text { IPV }\end{array}$ & $\begin{array}{l}\text { Sexual } \\
\text { Orientation }\end{array}$ & Disability & Ethnic identity & $\begin{array}{l}\text { Urban/ } \\
\text { rural }\end{array}$ \\
\hline 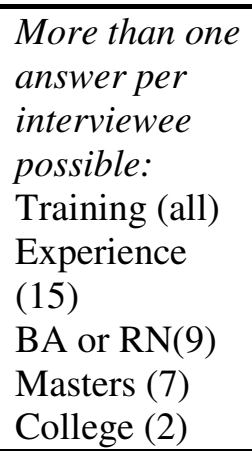 & $\begin{array}{l}\text { Heterosexual (10) } \\
\text { Lesbian/gay/queer } \\
(6) \\
\text { Bisexual (2) } \\
\text { Non-judgemental (2) } \\
\text { No response (1) }\end{array}$ & $\begin{array}{l}\text { No }(9) \\
\text { Yes (3) } \\
\text { No response } \\
(9)\end{array}$ & $\begin{array}{l}\text { Anglo \& white (12) } \\
\text { Aboriginal (3) } \\
\text { Women of Colour/Mixed (4) } \\
\text { Francophone \& white (2) }\end{array}$ & $\begin{array}{l}\text { Urban } \\
(13) \\
\text { Rural } \\
(8)\end{array}$ \\
\hline
\end{tabular}


Table 3: Interviewees who are PAR workers, private practitioners, and men working with male victims - entering the field

\begin{tabular}{|l|l|l|l|l|}
\hline $\begin{array}{c}\text { Period in VAW } \\
\text { Work when } \\
\text { interviewee } \\
\text { entered field }\end{array}$ & $\begin{array}{c}\text { Number of } \\
\text { interviewees }\end{array}$ & \multicolumn{1}{|c|}{ Age } & $\begin{array}{l}\text { Years working in field of } \\
\text { reducing and preventing } \\
\text { intimate partner violence }\end{array}$ & Pseudonym \\
\hline Early (1970s) & 3 & $50+\quad(3)$ & Over 25 years (3) & $\begin{array}{l}\text { William, Kenneth, } \\
\text { James }\end{array}$ \\
\hline $\begin{array}{l}\text { Formalization } \\
\text { (1980s-1990s) }\end{array}$ & 4 & $\begin{array}{l}40-49(1) \\
50+\quad(3)\end{array}$ & Over 20 (4) & $\begin{array}{l}\text { Margaret, Liz, } \\
\text { Theodore, Marcus }\end{array}$ \\
\hline $\begin{array}{l}\text { As trauma- } \\
\text { informed } \\
\text { approaches infused } \\
\text { social services } \\
\text { (2000s) }\end{array}$ & 4 & $\begin{array}{l}20-29(1) \\
40-49(2) \\
50+\quad(1)\end{array}$ & $\begin{array}{l}\text { Less than 5 (2) } \\
\text { Over 5 (2) }\end{array}$ & $\begin{array}{l}\text { Kevin, Steven, } \\
\text { Cynthia, David }\end{array}$ \\
\hline
\end{tabular}

Table 4: Interviewees who are PAR workers, private practitioners, and men working with male victims - demographics

\begin{tabular}{|l|l|l|l|l|}
\hline $\begin{array}{l}\text { Education - general; } \\
\text { on IPV }\end{array}$ & $\begin{array}{l}\text { Sexual } \\
\text { Orientation }\end{array}$ & Disability & Ethnic identity & $\begin{array}{l}\text { Urban/ } \\
\text { rural }\end{array}$ \\
\hline $\begin{array}{l}\text { Masters (5) } \\
\text { Undergraduate degree (3) }\end{array}$ & Heterosexual (9) & No (10) & Caucasian, Anglo (7) & Rural (5) \\
PhD, Clinical Psychology & & No response (1) & French Canadian (1) & Urban (5) \\
(2) & & Aboriginal (1) & Both (1) \\
$\begin{array}{l}\text { Training (5) } \\
\text { Experience (5) }\end{array}$ & & & No response (2) & \\
\hline
\end{tabular}




\title{
APPENDIX C: INTERVIEW DATA COLLECTION TOOLS
}

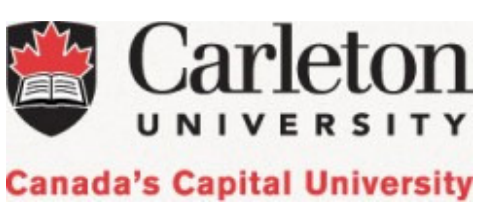

\section{Participant Consent Form}

\author{
Title of the study: $\quad$ Feminist Commitments and Conundrums: Mapping the field of work to \\ reduce and prevent intimate partner violence \\ Researcher: Deborah E. Conners, PhD Candidate \\ 613-257-8483; deborah_conners@carleton.ca \\ Thesis supervisors: \\ Dr. Jacqueline Kennelly, Dept. of Sociology and Anthropology, \\ Carleton University 613-520-2600 ext. 8103 \\ Dr. Diana Majury, Department of Legal Studies, Carleton University \\ 613-520-2600 ext. 8863
}

Ethics Clearance: $\quad$ Ethics clearance for the collection of data: June 13, 2013

Ethics clearance expires: May 312014

June 18, 2013

Dear participant,

The information below outlines the responsibilities and rights of participants in my PhD research project.

The intention of my research is to examine the field of work on the reduction and prevention of intimate partner violence. As part of this project, I will be interviewing 35 to 40 service providers and activists in the Ottawa area. I am interested in hearing about the work you and others are doing, about how you approach your work, and about what concerns you might have regarding the further reduction and prevention of intimate partner violence. I will be using concepts from the discipline of sociology to analyze my research data. My goal is to can help us to better understand how work on this issue has evolved and to provide support for the further development of progressive social policy regarding intimate partner violence.

Your participation will take the form of a two-hour long interview (with a possible followup interview) which will be audio-recorded and transcribed. The interview will inquire into your understanding of intimate partner violence and how your approach to working on this issue may have changed over the years. You will have the opportunity to review the transcript of your interview, and amend your comments or ask for sections to not be used in the research. I am also interested in attending some topical events hosted by, or attended by, interviewees and so will ask you to suggest events that would be reflective of your work.

You may also be invited to participate in a focus group session later in the project. You will also have the opportunity to access the dissertation once complete and/or follow up articles that I publish based on this research. Risks of participation include possible emotional or 
psychological effects of discussing the topic. If you were referred to the project by your supervisor at work, both you and your supervisor should agree that your participation is completely voluntary. As a benefit of participation, the project could provide you an opportunity to step back from your day to day work to think about the larger context of the work you do to reduce and prevent intimate partner violence.

You are under no obligation to participate and may refuse to address specific questions or choose to withdraw from the project at any time before December 15 2013. After this date it will not be possible to extract your data from the study. If you choose to withdraw before this date, the data that has emerged from your participation will be destroyed. Anonymity will be maintained for all interview participants.

The interview data will be used in my PhD dissertation and may be used in future studies including a post-doctoral research project on this topic. The data (digital recordings and transcripts of the interviews and focus group) will be kept in a secure filing cabinet in a secure office, for up to 10 years, at which point it will be destroyed. Only the researcher and the research supervisor will have access to the data.

\section{Acceptance:}

I, agree to participate in the above research study conducted by Deborah E. Conners of the Department of Sociology and Anthropology at Carleton University. This research is being conducted under the supervision of Dr. Jacqueline Kennelly and Dr. Diana Majury.

If I have any questions about the study, I may contact the researcher or her supervisor.

If I have any questions regarding the ethical conduct of this study, I may contact the Chair of the Carleton University Research Ethics Board. The chair's name and contact information is as follows:

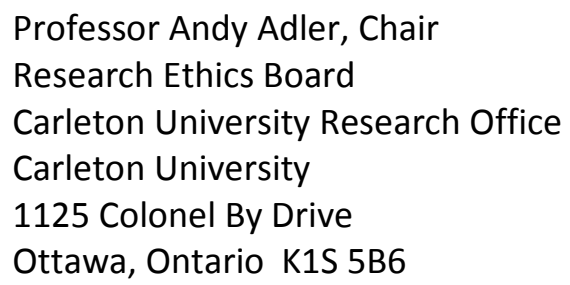

Tel: 613-520-2517 E-mail: ethics@carleton.ca

There are two copies of the consent form, one of which is mine to keep.

Participant's signature: (Signature) Date: (Date) 


\section{RESEARCH PARTICIPANT PRE-INTERVIEW QUESTIONNAIRE}

\section{Commitments and Conundrums: \\ Mapping the Field of Work to Reduce and Prevent Intimate Partner Violence (IPV) \\ Deborah Conners, PhD Research, Carleton University, Ottawa Ontario}

Please complete the brief survey below and email to Deborah Conners at deborah conners@carleton.ca at least 3 days before your interview. You may take as much space as you need in answering the questions.

1. How many hours each week do you spend (on average) working on the reduction and prevention of intimate partner violence (IPV)?

over 20 None; Less than 5 hours; between 5 and 20 hours;

2. How many years have you been working/did you work on this issue?

3. Do you do paid work on this issue with/for an organization? yes _no If so, what organization(s)?

What is the work that you do in relation to IPV with this organization(s)?

4. Do you work on this issue in private practice? yes no

If yes, what is the work that you do in relation to IPV in private practice?

Do you have a website? What is the address (URL) of your website?

5. Do you work on this issue as a volunteer? yes no

If yes, what (if any) organization(s) do you volunteer with?

What is the work that you do in relation to IPV as a volunteer?

6. What municipality(ies) do you work within?

7. What languages do you or your organization provide services in? 
I would also like to collect some demographic information. Please know that you do not have to answer any question which you do not wish to answer.

8. What is your age:

18-24,

25-29,

30-39,

40-49,

50-59,

$60+$

9. How would you describe your ethnic identity?

10. Are there any issues that you deal with relating to personal disability?

11. How would you describe your sexual orientation and gender identity?

12. What is your education/training background regarding intimate partner violence? 


\section{Interview Guide for Dissertation Research, June 18, 2013 \\ Deborah Conners}

\section{INTRODUCTION (15 minutes):}

This research project is examining the work being done to reduce and prevent intimate partner violence. The research is part of my $\mathrm{PhD}$ dissertation in Sociology at Carleton University on this topic. I am interested in speaking with service providers and activists in the Ottawa area as part of this research. My research supervisors are Dr. Jacqueline Kennelly and Dr. Diana Majury.

The title of my project is: Commitments and Conundrums - Mapping the field of work to reduce and prevent intimate partner violence (IPV).

You have been asked to participate because of your volunteer or paid work on this issue. I am interested in understanding:

- how you came to be working on this issue

- How you position yourself on the issue in relation to feminist work

- your understanding of IPV and your values and commitments in terms of your work

- Your concerns regarding the work to end intimate partner violence - internal debates or things that are not resolved for you

- how you think that IPV could best be brought to an end

\section{[Go over the consent form and sign. Leave a copy with interviewee]}

As I indicated in our earlier conversation, you will remain completely anonymous as a participant in this study.

I would also like to acknowledge that 'intimate partner violence' is a term with political ramifications. I have chosen to use this term to indicate that I am addressing intimate partners only, not other family violence, and yet to keep a broad focus in terms of the range of work being done to address violence between intimate partners. ${ }^{*}$ I am also using the broadest definition of violence, including physical, emotional, intellectual, sexual, social, economic, or spiritual violence between current or past intimate partners.

Before we get into the interview, I would like to know what term you prefer to use when referring to IPV?

*I use the term intimate partner violence to identify physical, emotional, intellectual, sexual, social, economic, or spiritual violence between current or past intimate partners, who may or may not currently cohabitate or have cohabitated in the past. In this framing I seek to include, and therefore maintain the ability to examine, work being done on violence by men, women and transgender people toward their intimate partners in heterosexual and homosexual relationships, as well as the types of violence that are particularly prone to asymmetrical use by men (such as battering and sexual violence).

NOTE: interviewees will have been asked to complete a brief questionnaire 


\section{INTERVIEW THEMES:}

(I) BACKGROUND ON HOW YOU CAME TO BE INVOLVED IN WORK TO REDUCE AND PREVENT IPV (10 MINUTES)

Can you name an experience which first led you to understand IPV as a social problem?

What year did you first get involved in work (volunteer or paid) to reduce and prevent IPV?

What has been your involvement over the years?

What training have you had in this area?

Who are your clients or the groups which you are assisting with your work?

(II) HOW YOU POSITION YOURSELF IN RELATION TO FEMINIST WORK ON THE ISSUE (OR NOT) (10 MINUTES)

If applicable: the organization that you work for identifies itself on its website as feminist. Can you tell me how this affects the work that the organization does?

How does this affect your work?

Do you consider yourself to be feminist in your approach to your work?

What does feminism mean to you?

OR for those in private practice:

Your website indicates that you use a feminist analysis; or if not known - Do you use a feminist analysis in your work in intimate partner violence?

Can you tell me how this affects the work that you do?

What does feminism mean to you?

If feminist, do you qualify your feminist identity in other ways? For instance, do you identify as a $2^{\text {nd }}$ wave feminist? Or $3^{\text {rd }}$ wave feminist? Do you use another term to describe your own feminism?

If other, how you position yourself in relation to feminism? [these questions will be framed in response to the information already provided].

If not feminist, what does feminism mean to you?

What relationship do you have to feminism?

What values do you bring to your work?

How do these values affect your practice?

Do you think feminism/how do you think feminism has shaped work to reduce and prevent IPV?

(III) YOUR UNDERSTANDING OF IPV AND THE COMMITMENTS THAT YOU

HAVE REGARDING THE ISSUE (50 MINUTES)

How do you define "intimate partner violence"? (or term used by interviewee)

What kinds of violence do you include?

What is your understanding of the basic dynamics of intimate partner violence? [capture interactions of victimization and perpetration]

Has your understanding of the basic dynamics of IPV changed over the years?

What was your early understanding?

What is your more current understanding (same or describe change)?

If not yet stated: What do you see as the most important factors that give rise to IPV?

What words do you use to describe people who have been/are being abused?

(victim/survivor/ other? -Not mutually exclusive)

What words do you use to describe people who are/have been abusive? (perpetrator/other? Not mutually exclusive) 
Do you serve both women and men in your work? \% of men and women served.

Explore the following in terms of gender/race/colonization/ability/gender identity/sexual orientation:

What differences (if any) do you see in the experiences of IPV among the men and women who you serve (if applicable)? What similarities do you see? Do you ask the same/different questions to men and women who are involved in IPV who you see in your work? How have transgender issues affected your approach?

What are three important commitments or assumptions that you hold regarding intimate partner violence and your work to reduce and prevent it?

What are three significant dilemmas/tensions/conundrums in your work to reduce and prevent IPV?

Do you feel that your identity as a [insert appropriate, e.g. disabled lesbian] has shaped the way you work on the reduction and prevention of IPV?

\section{SCENARIO:}

A woman moves in with her partner after a long distance relationship of most of a year. Over the next six months, she escalates from yelling and slamming doors, to breaking her things, to hitting her male partner. For a few months he stays out of her way as much as possible or walks out of the house when this happens. One day her reacts by hitting her - she falls against the corner of the kitchen table and needs stitches in the back of her head.

What do you think happens after this?

What do you think should happen?

What would you put in your notes about this case?

\section{(IV) ANY CONCERNS IN RELATION TO INTERNAL DEBATES OR UNRESOLVED UNDERSTANDINGS (15 minutes)}

What/who are the sources of your understandings of intimate partner violence come from?

How do you stay up to date on the issue? Do you have a 'go-to' book(s), web-sites or researcher(s)? Do you attend workshops? Conferences? Are there some conferences/workshops that you avoid?

What relationships sustain your work? (individuals, networks and/or communities of practice)

Are the colleagues that you work with on this issue optimistic or pessimistic about ending IPV?

What internal debates or unresolved issues are there for you in how IPV is addressed?

Is there anything you feel hesitant or embarrassed to tell others in your communities of practice regarding how you approach your work?

What do you see as the most important factors that give rise to intimate partner violence? Research:

What would you like to say to the researchers and other practitioners or activists who work in this area?

Are there questions you would like researchers to investigate that do not seem to be on the radar now?

There are many conflicting statistics regarding intimate partner violence. Some say that men are the perpetrators 90 to $95 \%$ of cases. Others suggest that women and men are equal in their use of intimate violence. What is your perception on these statistics?

Given the great differences in the statistics found in research, do you have concerns about how research findings are used?

What do you think are the most common public misperceptions regarding intimate partner violence? 
(V)YOUR IDEAS OF HOW IPV COULD BEST BE ENDED (10 MINUTES)

What are your hopes for the reduction and prevention of IPV?

What are your fears regarding the reduction and prevention of IPV?

What would be required for IPV to no longer be a social issue in Canadian society?

\section{(VI) CONCLUDING QUESTIONS (5 MINUTES)}

Are there any issues that I haven't covered that you think are important?

Do you have thoughts or hopes for what benefits might come out of a project like this?

Do you know of any other activists or service providers who might be willing to participate in this project?

How did you find out about the project? [if unknown]

\section{INTERVIEW CONCLUSION (5 minutes):}

I would like to attend some events as part of my research. Would you be willing to have me come to one or more of your work events? This could be a training session or a networking event for example.

I will also be hosting several focus groups to report on my early findings to the people who I have interviewed. Would you be interested in receiving an invitation to such a group session?Great! Thank you so much. I look forward to... [as appropriate in response to above]. 
Bring:

\section{Sept 52013 - Interview Checklist:}

- Teal file folder:

○ Questionnaires

- Consent forms

- Interview Guide

- Interview file folder:

- Note paper

- Address and Directions

- Extension cord

- Recorder case

- Recorder with batteries (charged)

- Stand

- Power cord

- Ear buds

- Timer

- SD card (empty)

- Back up recorder

Recording:

- Settings: Moniter 'off'

- Start back up recorder

- Record light on; Check space on disk

- Check volume with ear buds

- Mid-interview monitor check

- $\quad$ Save at end

Structure of Interview:

- Pre-interview Questionnaire

- Consent form

- Definition of IPV

- Background - early experience

- Feminist/non-feminist/profeminist

- Pro gender equality/believe we are there already/women have more advantages

- Understanding of IPV - changes over time

$\circ$ Women engage in retaliation or self-defence?

- Best approach to services for men?

- Commitments

- Scenario - 3 questions: what happens next, what should happen, what would you put in notes.

- Internal debates - model, complexities and contested meanings

- Class/race/sexual orientation/gender identity

- How to end

- Hopes and fears

- Role of compassion

- How often have you had this conversation?

- Benefits and/or downsides

- Attend events?

- Other contacts?

- Next steps in this project - transcript, focus group, report 


\section{APPENDIX D: FOCUS GROUP DATA COLLECTION TOOLS \\ Carleton \\ Canada's Capital University}

\section{Focus Group Participant Consent Form}

Title of the study: Feminist Commitments and Conundrums: Mapping the field of work to reduce and prevent intimate partner violence

Researcher: Deborah E. Conners, PhD Candidate

613-257-8483; deborah_conners@carleton.ca

Thesis supervisors: Dr. Jacqueline Kennelly, Dept. of Sociology and Anthropology, Carleton University Phone: 613-520-2600 ext. 8103

Email: jacqueline_kennelly@carleton.ca

Dr. Diana Majury, Department of Legal Studies, Carleton University

Phone: 613-520-2600 ext.8863 Email: Diana.Majury@carleton.ca

Ethics Clearance: $\quad$ Ethics clearance for the collection of data: June 13, 2013

Ethics clearance expires: May 312014

Sept 20, 2013

Dear focus group participant,

The information below outlines the responsibilities and rights of participants in my PhD research project. The intention of my research is to examine the field of work on the reduction and prevention of intimate partner violence. As part of this project, I will be (i) interviewing 32 to 40 service providers and activists and (ii) doing one or several focus groups with existing networks which focus on the topic. I am interested in hearing about the work you and others are doing, about how you approach your work, and about what concerns you might have regarding the further reduction and prevention of intimate partner violence. I will be using concepts from the discipline of sociology to analyze my research data. My goal is to can help us to better understand how work on this issue has evolved and to provide support for the further development of progressive social policy regarding intimate partner violence.

Your participation will take the form of an hour-long focus group. The focus group will inquire into your understanding of the work being done to reduce intimate partner violence. As part of the focus group, you will be asked to complete a brief questionnaire to collect demographic information. You will also be asked to record your understanding of the issues being discussed. Flip chart notes taken by the facilitator-researcher and your individual notes 
will form the record of the focus group. This record will become part of the data for the research project.

It is also my intention to host several focus group sessions later in the project to report the early findings to participants and others in the community and to receive feedback on these findings. You will be invited to participate in one of these sessions. (Participation in this focus group session does not require you to participate in the feedback sessions.) You will also have the opportunity to access the dissertation once complete and/or follow up articles that I publish based on this research. Risks of participation in this focus group include possible emotional or psychological effects, or professional impacts, of discussing the topic in a session with your peers. As a benefit of participation, the project could provide you an opportunity to step back from your day to day work to think about the larger context of the work you do to reduce and prevent intimate partner violence.

You are under no obligation to participate and may refuse to respond to specific questions. I will maintain confidentiality and anonymity regarding the research participants, the name of participating groups and the name of the network. Focus group participants will be asked to maintain confidentiality regarding the content of the focus group. However, as the participants of the focus group are known to each other, I want to identify that your participation in the project will be known to some should they read my dissertation.

The interview data will be used in my PhD dissertation and may be used in future studies including a post-doctoral research project on this topic. The data (digital recordings and transcripts of the interviews and focus group) will be kept in a secure cabinet in a secure office, for up to 10 years, at which point it will be destroyed. Only the researcher and the research supervisor will have access to the data.

\section{Acceptance:}

I, agree to participate in the above research study conducted by Deborah E. Conners of the Department of Sociology and Anthropology at Carleton University. This research is being conducted under the supervision of Dr. Jacqueline Kennelly and Dr. Diana Majury.

If I have any questions about the study, I may contact the researcher or her supervisors.

If I have any questions regarding the ethical conduct of this study, I may contact the Chair of the Carleton University Research Ethics Board. The chair's name and contact information is as follows:

Professor Andy Adler, Chair, Research Ethics Board

Carleton University Research Office, Carleton University

1125 Colonel By Drive, Ottawa, Ontario K1S 5B6

Tel: 613-520-2517 E-mail: ethics@carleton.ca

There are two copies of the consent form, one of which is mine to keep.

Date: 


\section{AGENDA FOR FOCUS GROUP}

Guide for Focus Group with Existing Network, September 20, 2013 Deborah Conners

\begin{tabular}{|c|c|}
\hline & 1. Signing consent form \\
\hline 10:0 & $\begin{array}{l}\text { 2. Introduction to project } \\
\text { a. Project genesis and outline } \\
\text { b. Questionnaire - to get your individual response; these form the } \\
\text { data for the study along with the flipchart notes. }\end{array}$ \\
\hline & 3. IPV as a term - others used? \\
\hline $5 \quad 10: 0$ & $\begin{array}{l}\text { 4. Group warm-up question - how did intimate partner violence first come } \\
\text { to your attention as a social issue? (popcorn style }-5 \text { or six responses) } \\
\text { a. Lead from warm up question into identification of early } \\
\text { understanding of IPV }\end{array}$ \\
\hline $5 \quad 10: 1$ & $\begin{array}{l}\text { 5. Has your understanding of IPV changed over the years? How? Current } \\
\text { understanding? }\end{array}$ \\
\hline $10: 3$ & 6. Identification of commitments participants bring to their work \\
\hline 5 & $\begin{array}{l}\text { 7. Discussions of issues they believe are facing the network and feminist } \\
\text { VAW work on this issue. }\end{array}$ \\
\hline $10: 5$ & $\begin{array}{l}\text { 8. What would be required to end intimate partner violence? } \\
\text { (Brainstorm) }\end{array}$ \\
\hline 5 & 9. Collection of consent forms and questionnaire \\
\hline $11: 0$ & $\begin{array}{l}\text { 10. Close } \\
\text { a. Further opportunities for participation - feedback focus } \\
\text { groups } \\
\text { b. Thank you! }\end{array}$ \\
\hline
\end{tabular}




\title{
RESEARCH PARTICIPANT FOCUS GROUP PARTICIPANT QUESTIONNAIRE
}

\author{
Commitments and Conundrums: \\ Mapping the Field of Work to Reduce and Prevent Intimate Partner Violence \\ (IPV) \\ Deborah Conners, PhD Candidate, Carleton University, Ottawa Ontario
}

13. How many hours each week do you spend (on average) working on the reduction and prevention of intimate partner violence (IPV)? Less than 5 hours; between 5 and 20 hours; over 20

14. How many years have you been working on this issue?

15. Do you do paid work on this issue with/for an organization? yes; no

16. Is the organization you work for a member of the networking group meeting today? yes; no

17. What languages do you (personally) provide services in?

18. Does the organization you work for identify as a feminist organization? yes; no

19. Do you identify as a feminist? yes; no

a. Any ways that you qualify yourself further in relation to feminism?

(e.g. second wave/third wave, pro-feminist, womanist, radical)

I would also like to collect some demographic information. Please know that you do not have to answer any question which you do not wish to answer.

20. What is your age:

$18-24$

25-29,

30-39,

40-49,

50-59, $60+$

21. How would you describe your ethnic identity?

22. Are there any issues that you deal with relating to personal disability?

23. How would you describe your sexual orientation and gender identity?

24. What is your education/training background regarding intimate partner violence?

Continued on reverse side... 
Please use this page to note any comments you would like to contribute to the research. I have asked some specific questions here. You may choose to answer none, some, or all of these, and/or provide other comments.

What term do you use for intimate partner violence (IPV)?

Has / how has your understanding of IPV changed over time?

What are three commitments you bring to your work?

1.

2.

3.

What issues or dilemmas do you see facing the networking group meeting today?

Other comments? 


\title{
APPENDIX E: EARLY FINDINGS FEEDBACK DATA COLLECTION TOOLS
}

\author{
Carleton \\ U N I V E R I T Y \\ Canada's Capital University
}

Workshop Participant Consent Form

Title of the study: Commitments and Conundrums: Mapping the field of work to reduce and prevent intimate partner violence

Researcher: Deborah E. Conners, PhD Candidate

613-257-8483; deborah conners@carleton.ca

Thesis supervisors: Dr. Jacqueline Kennelly, Dept. of Sociology and Anthropology, Carleton University Phone: 613-520-2600 ext. 8103

Email: jacqueline_kennelly@carleton.ca

Dr. Diana Majury, Department of Legal Studies, Carleton University

Phone: 613-520-2600 ext. 8863 Email: Diana.Majury@carleton.ca

Ethics Clearance: $\quad$ Ethics clearance for the collection of data: June 13, 2013

Ethics clearance expires: May 312014

April 2, 2014

Dear workshop participant,

The information below outlines the responsibilities and rights of participants in my $\mathrm{PhD}$ research project. The intention of my research is to examine the field of work on the reduction and prevention of intimate partner violence. As part of this project, I have interviewed 32 service providers and activists and facilitated several focus groups. In the interviews and focus groups I heard about the work being done in the field and about concerns people in the field have regarding the further reduction and prevention of intimate partner violence. I am now organizing a workshop to solicit feedback on the early findings of the project. I will be using concepts from the discipline of sociology to analyze my research data. My goal is to can help us to better understand how work on this issue has evolved and to provide support for the further development of progressive social policy regarding intimate partner violence.

Your participation will take the form of attendance at a two to three hour long workshop. The workshop will inquire into your response to the early findings of the research. As part of the workshop, you will be asked to complete a brief questionnaire to collect demographic information. You will also be asked to record your understanding of the issues being discussed. Flip chart notes taken by the workshop facilitator or the researcher in addition to your individual questionnaire form will provide the record of the workshop. This record will become part of the 
data for the research project. You will have the opportunity to access the dissertation once complete and/or any follow up articles that I publish based on this research.

Risks of participation in this workshop include possible emotional or psychological effects, or professional impacts, of discussing the topic in a session with your peers. As a benefit of participation, the project could provide you an opportunity to step back from your day to day work to think about the larger context of the work you do to reduce and prevent intimate partner violence.

You are under no obligation to participate and may refuse to respond to specific questions. I will maintain confidentiality and anonymity regarding the research participants and the names of participating groups or organizations. Workshop participants will be asked to maintain confidentiality regarding the content of the workshop. However, you need to be aware that your participation in the project will be known to others who attend. The dissertation and any other published articles or books will maintain anonymity. However others may know who said what as it is referenced the report because they were present at the workshop.

The interview, focus group and workshop data will be used in my PhD dissertation and may be used in future studies including a post-doctoral research project on this topic. The data (digital recordings and transcripts of the interviews, and notes from the focus groups and workshops) will be kept in a secure cabinet in a secure office, for up to 10 years, at which point it will be destroyed. Only the researcher and the research supervisor will have access to the data.

\title{
Acceptance:
}

I, agree to participate in the above research study conducted by Deborah E. Conners of the Department of Sociology and Anthropology at Carleton University. This research is being conducted under the supervision of Dr. Jacqueline Kennelly and Dr. Diana Majury.

If I have any questions about the study, I may contact the researcher or her supervisors.

If I have any questions regarding the ethical conduct of this study, I may contact the Chair of the Carleton University Research Ethics Board. The chair's name and contact information is as follows:

\author{
Professor Andy Adler, Chair \\ Research Ethics Board \\ Carleton University Research Office \\ Carleton University \\ 1125 Colonel By Drive \\ Ottawa, Ontario K1S 5B6
}

Tel: 613-520-2517 E-mail: ethics@carleton.ca

There are two copies of the consent form, one of which is mine to keep.
Participant's signature: (Signature)
Date: (Date) 


\section{Workshop Agenda}

\begin{tabular}{|c|c|c|}
\hline Time & Agenda/Facilitation Notes & Prep/Set up \\
\hline $12: 15$ & $\begin{array}{l}\text { Set up and Gathering } \\
\text { G coffee \& food [Deb] } \\
\text { G } \text { Consent/demographics forms to participants }\end{array}$ & $\begin{array}{l}\text { Welcome flip with } \\
\text { Goals [CP] }\end{array}$ \\
\hline $\begin{array}{r} \\
(30 \\
\min )\end{array}$ & $\begin{array}{l}\text { 1. Opening } \\
\text { a. Welcome, thank you and who I am (Deb, } 5 \\
\text { min.) } \\
\text { b. Pass to Facilitator } \\
\text { c. Goal of Meeting and Agenda: } \\
\text { i. Share themes from early research } \\
\text { ii. Gather your views on the implications } \\
\text { d. Introductions (as people wish) } \\
\text { e. Logistics (washrooms, no break, consent } \\
\text { forms) }\end{array}$ & \\
\hline $\begin{array}{r}(30 \\
\min )\end{array}$ & $\begin{array}{l}\text { 2. Presentation of Findings } \\
\text { a. Project Genesis } \\
\text { b. Language } \\
\text { c. This is what I heard } \\
\text { - How we define "The Problem" } \\
\text { - How we see "Action to Address the } \\
\text { Problem" }\end{array}$ & $\begin{array}{l}\text { Presentation } \\
\text { handout? [Deb] } \\
\text { List of responses for } \\
\text { the two areas (cause } \\
\text { of violence and } \\
\text { what to do about it) } \\
\text { [Deb] }\end{array}$ \\
\hline $\begin{array}{r}(45 \\
\min )\end{array}$ & $\begin{array}{l}\text { 3. Discussion: } \\
\text { a. Presentation of the Questions: } \\
\text { - What are your thoughts on what you've } \\
\text { heard? } \\
\text { - What are the implications of the } \\
\text { divergence of opinion? } \\
\text { b. Think ( } 3 \text { min.) } \\
\text { c. Share - go-around then discussion flip- } \\
\text { charting main points ( } 25 \text { min }) \\
\text { d. Continuum* (15 min) }\end{array}$ & $\begin{array}{l}\text { Participant sheet } \\
\text { [CP] (see next page) } \\
\text { *Continuum } \\
\text { statement: } \\
\text { "Convergence is } \\
\text { essential for } \\
\text { effective feminist } \\
\text { action on Intimate } \\
\text { Partner Violence." }\end{array}$ \\
\hline $\begin{array}{r}(15 \\
\min )\end{array}$ & $\begin{array}{l}\text { 4. Closing } \\
\begin{array}{l}\text { a. Next Steps } \\
\text { - workshop notes } \\
\text { - for Deb's research } \\
\text { b. Closing round/Collect sheets } \\
\text { c. Thank you! }\end{array}\end{array}$ & \\
\hline $3 \mathrm{pm}$ & Workshop over & \\
\hline
\end{tabular}




\section{Research Workshop Participant Questionnaire}

\section{Commitments and Conundrums:}

\section{Mapping the Field of Work to Reduce and Prevent Intimate Partner Violence (IPV) \\ Deborah Conners, PhD Candidate, Carleton University, Ottawa Ontario}

1. How many hours each week do you spend (on average) working on the reduction and prevention of intimate partner violence (IPV)? 20 (best guess) None; 1 to 5 hours; between 5 and 20 hours; over

2. How many years have you been working on this issue?

3. Do you work on this issue in private practice? yes; (best guess) no

4. Do you do paid work on this issue with/for an organization? yes; no

5. Do you volunteer on this issue with/for an organization? yes; no

6. What genders does your organization/private practice serve?

7. What languages does your organization/private practice provide services in?

8. If you work for an organization, does it identify as a feminist organization? _.yes; __ no

9. Do you identify as a feminist? yes; no; Only if I get to define it

a. What is feminism to you?

I would also like to collect some demographic information. Please know that you do not have to answer any question which you do not wish to answer.

10. What is your age: $18-24$ 25-29, 30-39, 40-49, $50-59$ $60+$

11. How would you describe your ethnic identity?

12. Do you have a disability?

13. How would you describe your sexual orientation? (e.g. straight, gay, queer, other)

14. How would you describe your gender identity? (e.g. female, male, trans, other)

15. What is your (general) education/training background regarding intimate partner violence?

project.

\section{Please check this box if you have participated in a previous activity of this}


Workshop Participant Reaction: (Kindly hand this in at the end of the session)

1. What are your thoughts or feelings on what you've heard?

2. What are the implications of the research?

Please use back of sheet if you need more space ... 